\title{
Characterization of DuPont 1900 Series Resistors Applied to DuPont 5704 Dielectric on Alumina Substrates
}

Federal Manufacturing \& Technologies

Gregg E. Barner

KCP-613-5890

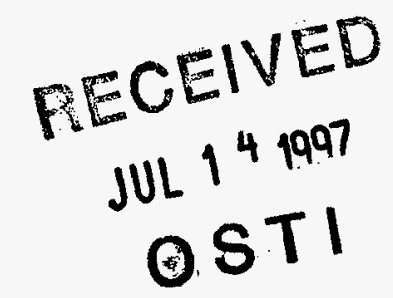

Published June 1997

Topical Report

DISTRIBUTION OF THIS DOCUMENT IS UNLIMTED

Approved for public release; distribution is unlimited.
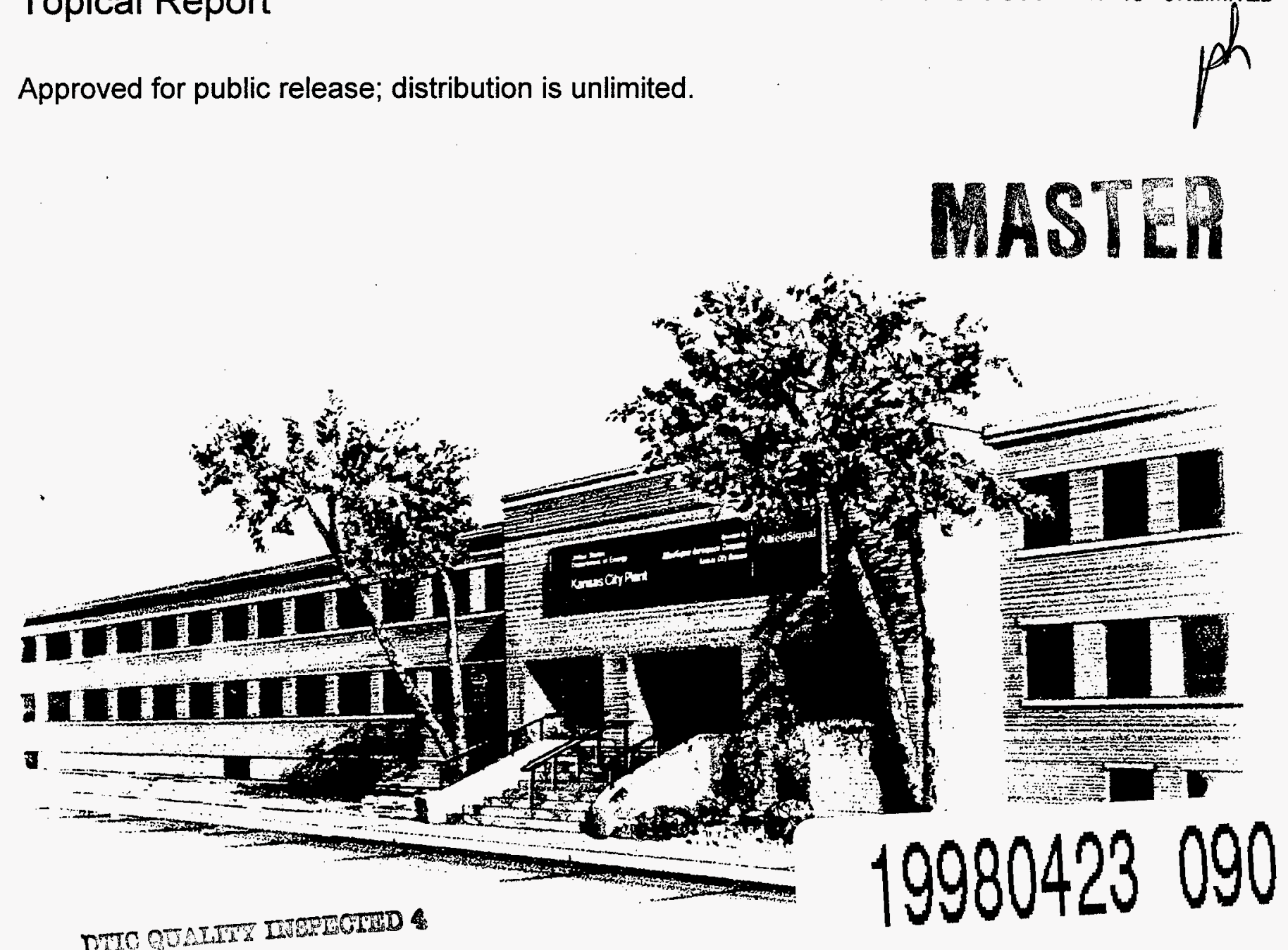


\section{DISCLAIMER}

This report was prepared as an account of work sponsored by an agency of the United States Government. Neither the United States Government nor any agency thereof, nor any of their employees, makes any warranty, express or implied, or assumes any legal liability or responsibility for the accuracy, completeness, or usefulness of any information, apparatus, product, or process disclosed, or represents that its use would not infringe privately owned rights. The views and opinions of authors expressed herein do not necessarily state or reflect those of the United States Government or any agency thereof.

All data prepared, analyzed and presented has been developed in a specific context of work and was prepared for internal evaluation and use pursuant to that work authorized under the referenced contract. Reference herein to any specific commercial product, process or service by trade name, trademark, manufacturer, or otherwise, does not necessarily constitute or imply its endorsement, recommendation, or favoring by the United States Government, any agency thereof or AlliedSignal Inc.

Printed in the United States of America.

This report has been reproduced from the best available copy.

Available to DOE and DOE contractors from the Office of Scientific and Technical Information, P. O. Box 62, Oak Ridge, Tennessee 37831; prices available from (615) 576-8401, FTS 626-8401.

Available to the public from the National Technical Information Service, U. S. Department of Commerce, 5285 Port Royal Rd., Springfield, Virginia 22161.

A prime contractor with the United States Department of Energy under Contract Number DE-ACO4-76-DP00613.
AlliedSignal Inc. Federal Manufacturing \& Technologies P. O. Box 419159 Kansas City, Missouri 64141-6159 
KCP-613-5890

Distribution Category UC-706

Approved for public release; distribution is unlimited.

\section{CHARACTERIZATION OF DUPONT 1900 SERIES RESISTORS APPLIED TO DUPONT 5704 DIELECTRIC ON ALUMINA SUBSTRATES}

Gregg E. Barner

Published June 1997

Topical Report

Gregg E. Barner, Project Leader

Project Team:

Sam. W. Bandler

John E. Guffey 


\section{CONTENTS}

Section

Page

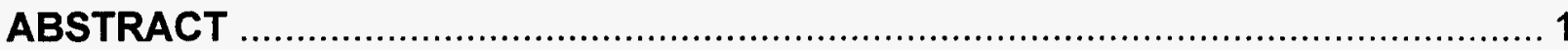

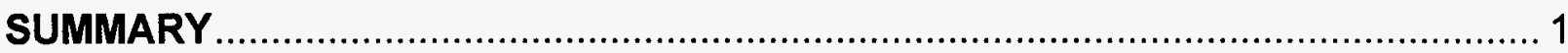

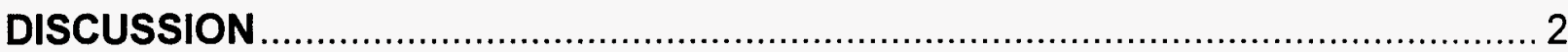

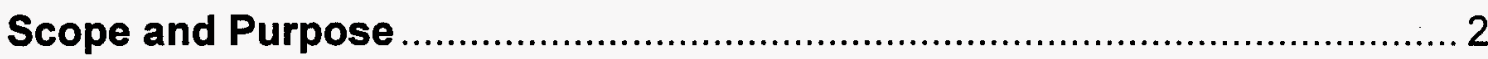

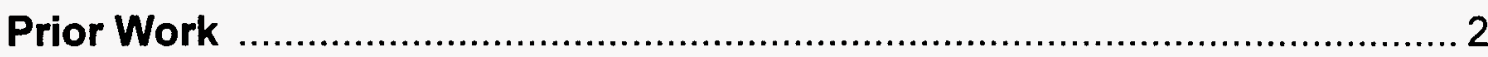

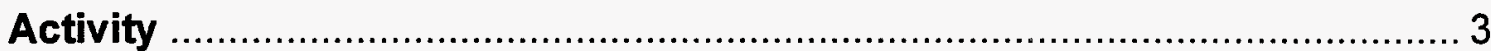

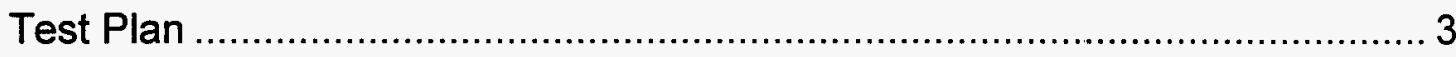

Test Sample Configuration and Fabrication ..................................... 4

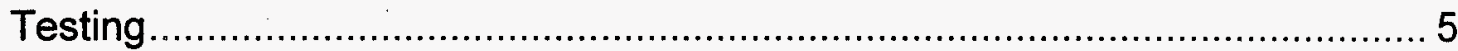

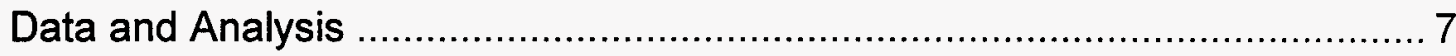

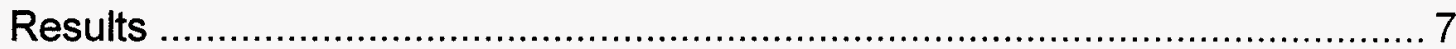

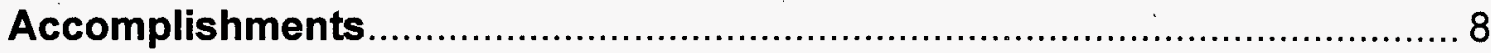

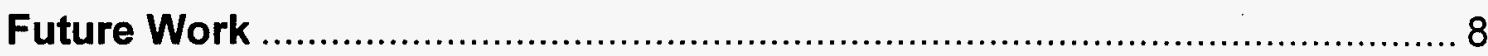

APPENDIX A. Characterization of Printing, Drying, and Firing of DuPont 1900 Series Resistors on Two layers of DuPont 5704 Dielectric

APPENDIX B. Characterization of Laser Trimming of DuPont 1900

Series Resistors on Two layers of DuPont 5704 Dielectric 58 


\section{ILLUSTRATIONS}

Figure

Page

$1 \quad$ Resistor Printing Methodologies .....................................................................

$2 \quad$ Two Square Resistor Test Pattern ............................................................. 4

$3 \quad$ Resistor Sintering Time/Temperature Profiles.............................................. 6

\section{TABLE}

Number

Page

1 Sintering Profiles for DuPont 1900 Series Resistors 


\section{ABSTRACT}

Existing thick film hybrid microcircuit (HMC) production utilizing integral thick film resistors requires that thick film resistors be deposited via screen printing directly on the base alumina substrate material. This requirement, when coupled with circuits of moderate to high density and associated layer buildup prior to resistor application, results in printing on surfaces with significant topography surrounding the resistor, compared to required as-printed resistor thicknesses. Due to the technological requirement to print resistors after most other thick film processing has been completed, resistor printing is seldom performed on a flat surface. The surface topography of the substrate surrounding the resistor area prohibits the printing process from maintaining a relatively uniform printed resistor thickness across the substrate. Although resistors are, in most cases, adjusted to final electrical values by physically modifying the length-towidth ratio through laser trimming, the resistors must be within certain resistance ranges. This variation in thickness translates into potential scrap product through extreme variation in as-fired resistor electrical values and/or product incapable of being laser trimmed due to excessive resistor thickness. The development of a thick film resistor application process compatible with existing conductor and dielectric materials and enabling more planarization of the print surface was needed to enhance production yields on products of moderate complexity.

\section{SUMMARY}

Development of Characterization Methodology. In an effort to establish a planarized surface for thick film resistor application on HMCs, an evaluation was performed to establish design and manufacturing parameters for integral thick film resistors utilizing DuPont 1900 series resistor compositions printed on DuPont 5704 dielectric material on $96 \%$ alumina ceramic. These materials were selected based on DuPont's recommendation for compatibility with existing production technology at AlliedSignal Federal Manufacturing \& Technologies (FM\&T). This evaluation was performed on two layers of dielectrics for six resistivity compositions: 10 ohms/square (DuPont 1911), 100 ohms/square (DuPont 1921), 1K ohms/square (DuPont 1931), 10K ohms/square (DuPont 1939), 100K ohms/square (DuPont 1949), and $1 \mathrm{M}$ ohms/square (DuPont 1959). The characterization effort focused on two main areas: (1) application (screen printing) and sintering (firing) and (2) final resistor electrical adjustment (laser trimming). 
Test Procedures. The test samples were subjected to a series of environmental and electrical tests which included the following: as-fired resistance, trimmed resistance, isolation resistance, 24 hour drift, temperature shock, temperature cycle, 1000 hour aging, and temperature coefficient of resistance (TCR) determination.

Test Results. Based on the testing that was done, the test results indicated that integral thick film resistors printed on dielectric, using otherwise existing thick film technology, perform comparably to thick film resistors printed directly on alumina.

\section{DISCUSSION}

\section{SCOPE AND PURPOSE}

The purpose of this project was to evaluate and characterize thick film resistor materials suitable for application via screen printing on dielectric materials used in existing thick film production at FM\&T. This capability is needed to facilitate the manufacture of moderate to high density hybrid microcircuits containing integral thick film resistors that are not candidates for low temperature cofired ceramic (LTCC) technology. The advantage of printing the resistor materials on dielectric - versus the currently used process of printing directly on the ceramic substrate - is the reduced effect of surface topography on print thickness, resulting in less resistor thickness variation. The reduced variation in as-printed thickness should result in less scrap product caused by the effects of excessive variability of resistor electrical properties and thickness on subsequent manufacturing processes. The ultimate result is improved producibility of moderate to high density thick film microelectronic products. Refer to Figure 1 for a visual comparison of the two resistor printing methodologies.

\section{PRIOR WORK}

Thick film technology was refined to meet the requirements of RF applications and multilayer circuits utilizing thick film resistors (specifically DuPont 1400 series resistor compositions) printed on the base ceramic substrate. Additionally, in support of the development of low temperature cofired ceramic technology (LTCC) at FM\&T, DuPont 1931 and 1949 resistor compositions have been used in the fabrication of trimmed resistors on DuPont 851 LTCC and DuPont 951 LTCC. All six DuPont 1900 Series resistor compositions have been printed on DuPont 951 LTCC. All six DuPont 2000 series resistor compositions have been printed on DuPont 951 LTCC. 

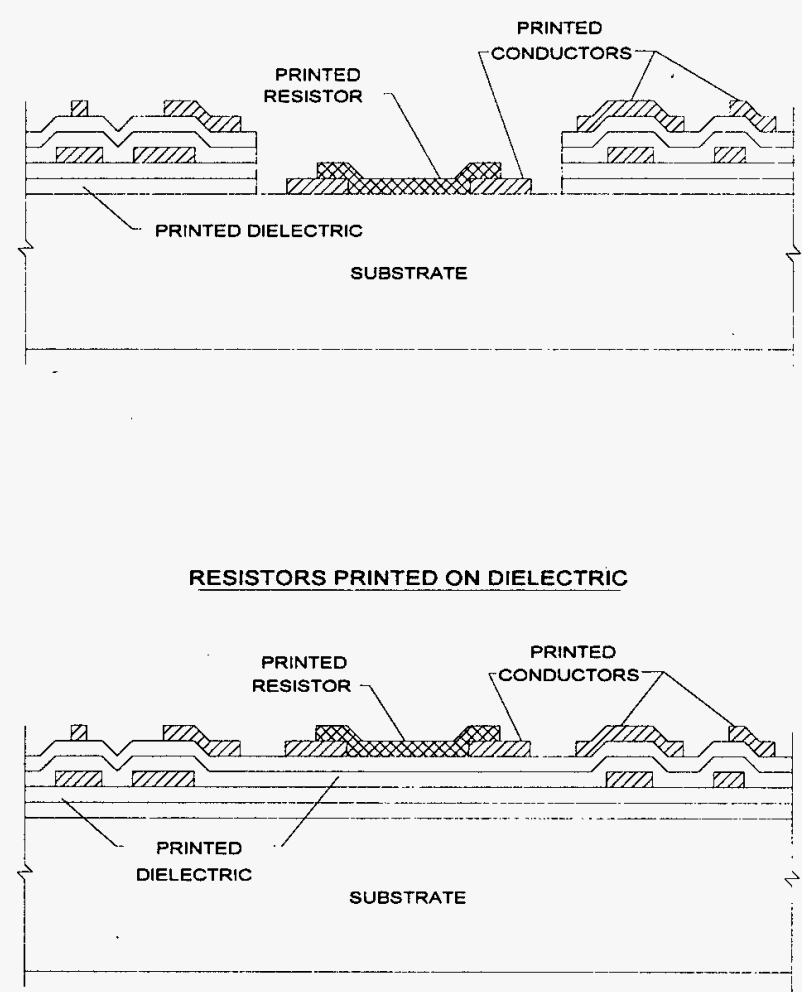

Figure 1. Resistor Printing Methodologies

The electrical properties and associated environmental tests used to evaluate these resistors included:

Untrimmed resistor stability (24 hour resistance change)

Post laser trim stability (24 hour resistance change)

Post temperature cycle resistance change $\left(-125\right.$ to $\left.+150^{\circ} \mathrm{C}\right)$

Temperature shock resistance change (ambient to $+300^{\circ} \mathrm{C}$ )

Resistance change at $150^{\circ} \mathrm{C}(200,600$, and 1000 hours $)$

Hot TCR $\left(+25\right.$ to $\left.+125^{\circ} \mathrm{C}\right)$

Cold TCR $\left(-55\right.$ to $\left.+25^{\circ} \mathrm{C}\right)$

\section{ACTIVITY}

\section{Test Plan}

A plan was developed to characterize the materials and manufacturing processes used in printing integral thick film resistors on dielectric materials and to ensure similar performance from existing production technology. 
The plan utilized a test sample design that has been used at FM\&T in the evaluation of other resistor systems and that provides a method of data comparison between resistor systems.

Prior to determining the electrical performance of the screen-printed resistors on different dielectric thicknesses $(2,6$, and 10 dielectric prints with corresponding dielectric thicknesses of $0.0015,0.0045$ and 0.0075 inch), the manufacturing parameters for printing, sintering, and laser trimming of the materials were determined using test samples with double-printed dielectric.

Although processes were centered around DuPont recommendations where applicable, sensitivity to processing parameter variation was evaluated for resistor geometry, resistor orientation, print thickness, firing temperature, and laser trimming parameters.

\section{Test Sample Configuration and Fabrication}

Each test sample contained 12 resistors each with a two-to-one length to width aspect ratio. The test sample shown in Figure 2 provided resistors of $0.025,0050$, and 0.100 inch widths oriented with the resistor lengths parallel and perpendicular to the direction of squeegee travel to simulate actual production.

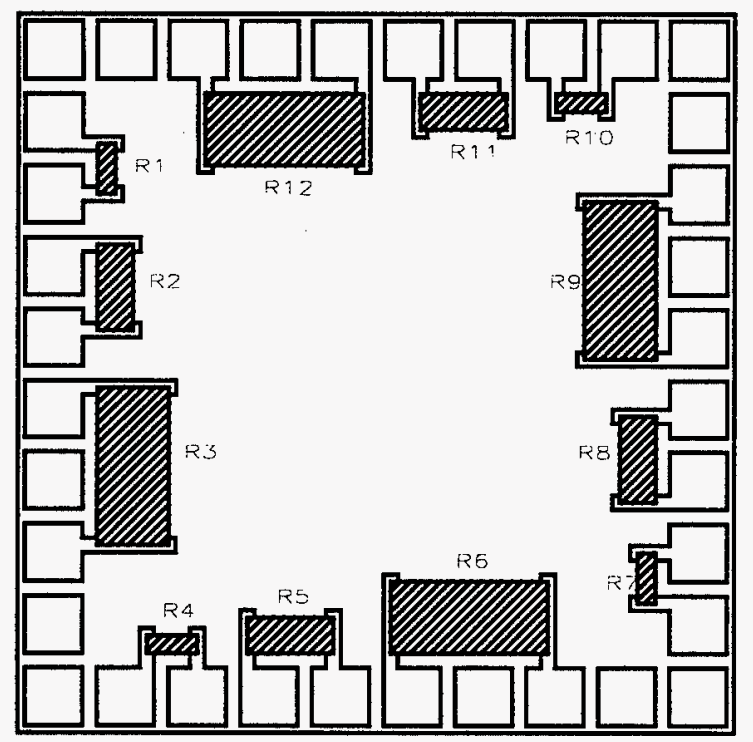

Figure 2. Two Square Resistor Test Pattern

The initial evaluation consisted of printing 72 test samples for each resistor composition, encapsulation, and firing combination, generating a total of 288 resistors for each geometry. Test samples were printed to the dried target thickness range recommended by DuPont which is 25 microns, the same as for the DuPont 1400 series compositions. Test samples were prepared both with and without glass encapsulation for comparison of laser trim parameter determination. Sintering was performed using the time/temperature profiles listed in Table 1. 
Table 1. Sintering Profiles for DuPont 1900 Series Resistors

\begin{tabular}{|c|c|l|}
\hline Time $(\mathrm{min})$ & Peak Temperature $\left({ }^{\circ} \mathrm{C}\right)$ & Profile Description \\
\hline 60 & 850 & Current production \\
\hline 30 & 850 & DuPont recommendation \\
\hline 30 & 825 & Process sensitivity evaluation \\
\hline 30 & 875 & Process sensitivity evaluation \\
\hline
\end{tabular}

The 60 minute profile maintained approximate ascent and descent rates of $50^{\circ} \mathrm{C}$ per minute, and the 30 minute profiles maintained ascent and descent rates of approximately $100^{\circ} \mathrm{C}$ per minute as illustrated in Figure 3 . The test sample matrix for the initial material evaluation is shown in Table 1.

\section{Testing}

Initial electrical testing of as-fired resistors was performed after the test samples had been printed and fired and again after encapsulation to determine the encapsulation effects.

In order to eliminate the effects of print thickness and print width variations on fired sheet resistivity determinations, the untrimmed resistance measurements are normalized to account for these variations. This calculation is used to determine typical as-fired sheet resistivities for each resistor composition and, subsequently, the resistor nominal design values incorporated into product definitions. The following equation is used for this determination:

$$
R_{\text {Nomalized }}=\frac{\left(\frac{\bar{R}_{M}}{2}\right) \times \bar{T}_{D}}{T_{R}} \times \frac{\bar{W}_{F}}{W_{R}}
$$

where

$\bar{R}_{M} \quad=\quad$ The Average As-Measured Resistance

$\bar{T}_{D} \quad=\quad$ Average Dried Thickness

$T_{R} \quad=\quad$ Reference Dried Thickness (25 microns)

$\overline{W_{F}} \quad=\quad$ Average Fired Width

$W_{R}=$ Reference Fired Width $(0.025,0.050$, or 0.100 inch $)$ 


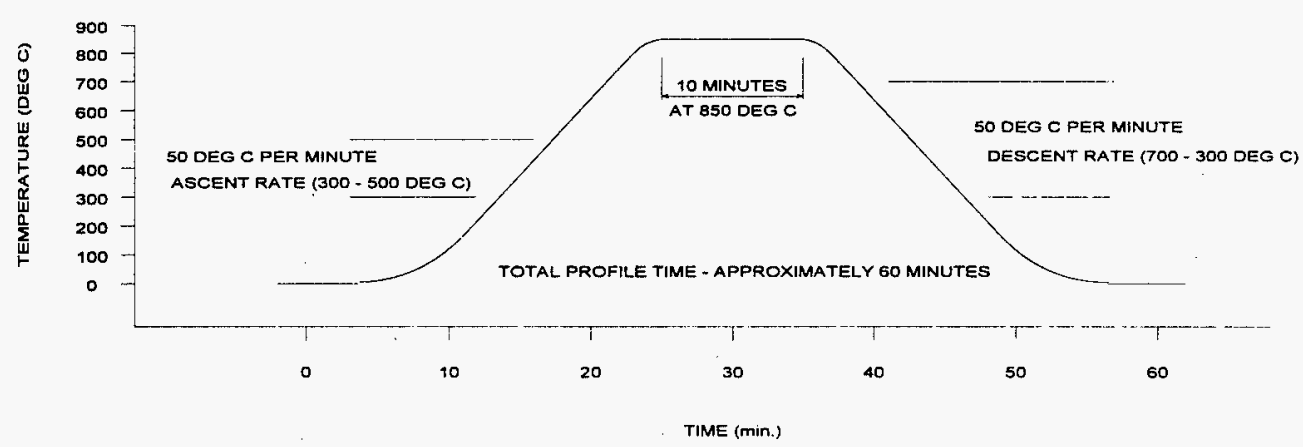

30 MINUTE 850 DEG C THICK FILM SINTERING PROFILE

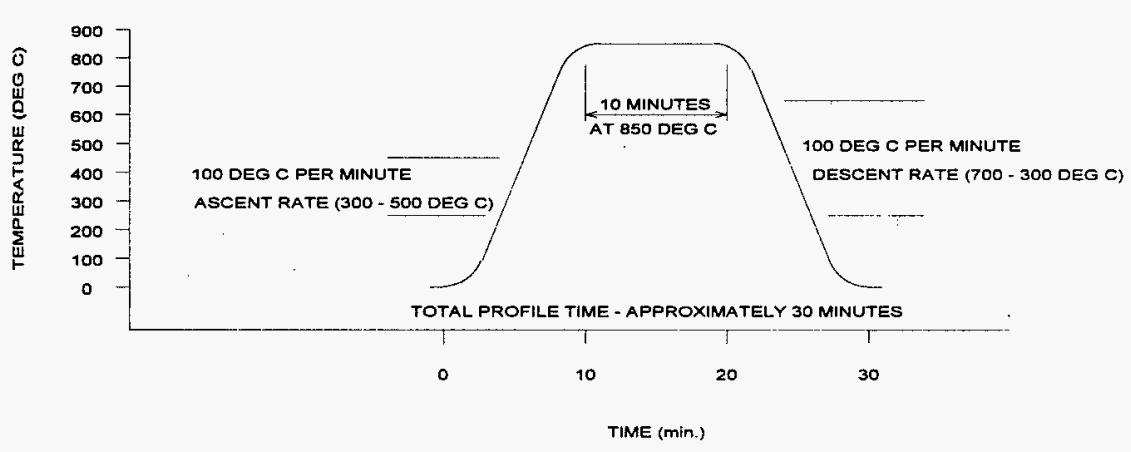

Figure 3. Resistor Sintering Time/Temperature Profiles

Additionally both trimmed and untrimmed test samples were subjected to tests to determine the optimum laser trim parameters and the effects of optimized laser trimming on future resistor performance. These tests were as follows:

- Isolation resistance.

- 24 hour short term drift.

- Temperature shock (solder pot shock test): $25^{\circ} \mathrm{C}$ to $268^{\circ} \mathrm{C}, 268^{\circ} \mathrm{C}$ for 15 seconds, and back to $25^{\circ} \mathrm{C}$.

- Temperature cycle: $-50^{\circ} \mathrm{C}$ to $125^{\circ} \mathrm{C}$ with approximately 5 seconds ramp time, ten cycles, 15 minutes minimum at each temperature extreme.

- Temperature coefficient of resistance (TCR) measured and calculated at $-55^{\circ} \mathrm{C}$, $25^{\circ} \mathrm{C}$, and $125^{\circ} \mathrm{C}$.

- 1000 hour aging test at $150^{\circ} \mathrm{C}$, ambient humidity.

Resistance was measured after each test, and the change in resistance was calculated. 


\section{Data and Analysis}

The evaluation data established the following recommendations and observations regarding material characteristics, design criteria, and manufacturing parameters for the six DuPont 1900 series resistor compositions:

1. DuPont $\mathbf{1 9 0 0}$ series thick film resistors printed on two layers of DuPont $\mathbf{5 7 0 4}$ dielectric should be designed to $70 \%$ of trimmed nominal value.

2. The minimum resistor dimension should be 0.050 inch.

3. DuPont 1911 (10 ohm/square) paste should not be used because of paste cracking after firing, which leads to poor resistor stability.

4. Target print thicknesses for each of the six pastes ranged from 41 to 46 microns to yield the DuPont recommended dried thickness of 25 microns, resulting in optimum as-fired resistivities and maximum post-trim resistor stability.

5. Firing of DuPont 1900 series resistors should be performed using a 30 minute $850^{\circ} \mathrm{C}$ profile in which average as-fired resistivities for all six DuPont 1900 series pastes ranged from $29 \%$ above nominal to $30 \%$ below nominal, which is a range similar to DuPont 1400 series resistors (23\% above nominal to $23 \%$ below nominal) used on existing thick film production designs.

6. Resistors should be encapsulated (overglazed) with DuPont 9137 encapsulant to maximize stability and minimize changes in TCR due to laser trimming.

Resistivities for all six pastes were unaffected by encapsulation.

7. Resistivities were virtually unaffected by resistor orientation but were dependent on resistor geometry.

8. Overall print lot capability ( $+/-3$ sigma) was $+/-30 \%$ from average fired values for all pastes.

9. Preliminary estimates for encapsulated samples indicate that resistor tolerances as tight as $1 \%$ are possible with $100 \%$ yield for resistors made with DuPont 1921 through 1959 pastes. Since this is preliminary, it is recommended initially that tolerances should not be tighter than $2 \%$.

\section{Results}

The test samples demonstrated that a capability for printing thick film resistors on dielectric can be incorporated into existing FM\&T thick film production, thereby providing enhanced producibility for moderate to high density microelectronic products. 


\section{ACCOMPLISHMENTS}

In an effort to provide improved producibility of moderate to high density thick film microelectronic products utilizing integral thick film resistors, a capability was developed to apply thick film resistors directly on dielectric, thereby minimizing variations in thickness caused by the effects of surface topography.

\section{FUTURE WORK}

Future work to be done to maintain the state-of-the-art capability could include the evaluation of the DuPont 1900 series resistor compositions on additional dielectric layers.

Future work to be done to enhance the state-of-the-art capability at FM\&T will include the evaluation of the DuPont 2000 series resistor compositions for use with existing thick film processes and materials. The intent will be to minimize the number of different thick film resistor technologies required to support a variety of thick film and low temperature cofired ceramic (LTCC) product types.

Future work to be done to develop additional capabilities will include evaluating the compatibility of DuPont 2000 series resistors with different thick film processes and materials not in use at FM\&T. 


\section{APPENDIX A}

Characterization of Printing, Drying, and Firing of DuPont 1900 Series Resistors on Two Layers of DuPont 5704 Dielectric

By Gregg E. Barner

August 1996 


\section{TABLE OF CONTENTS}

SUMMARY

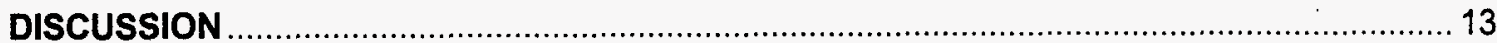

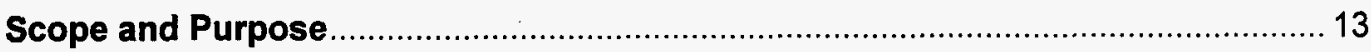

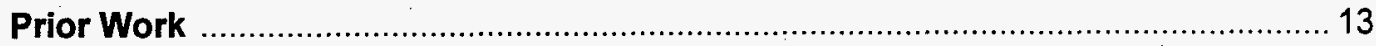

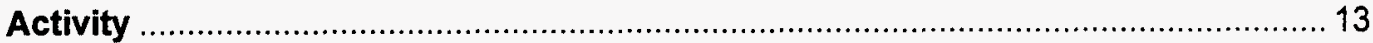

Test Sample Configuration and Fabrication .......................................................... 13

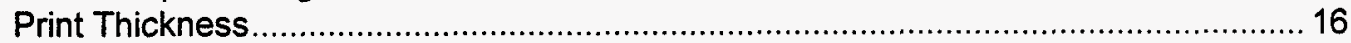

Untrimmed Resistance Measurements ................................................................... 16

Normalized Sheet Resistance and Design Considerations........................................ 16

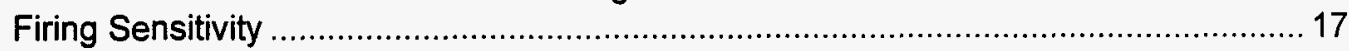

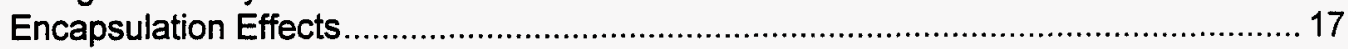

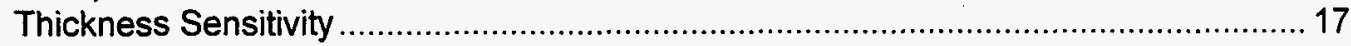

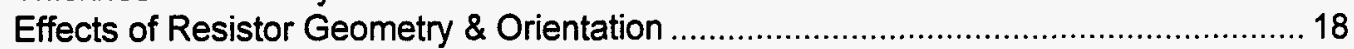

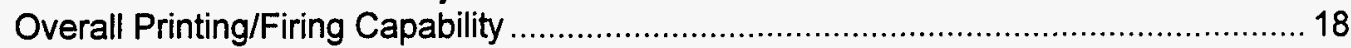

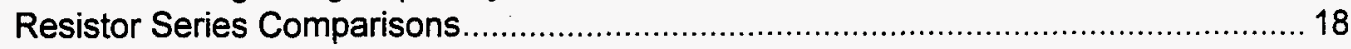

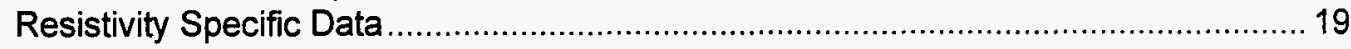

ACCOMPLISHMENTS

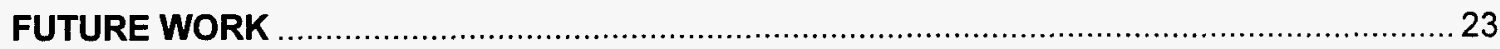

APPENDIX 1

Summary Data for DuPont 1900 Series

Firing Sensitivity for DuPont 1900 Series Resistors ............................................ 25

Sensitivity to Overglaze for DuPont 1900 Series Resistors .................................... 26

Thickness Sensitivity for DuPont 1900 Series Resistors ........................................ 27

Thickness Relationship for DuPont 1900 Series Resistors .................................. 27

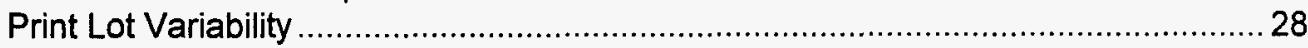

Geometry/Orientation Affects ......................................................................... 30

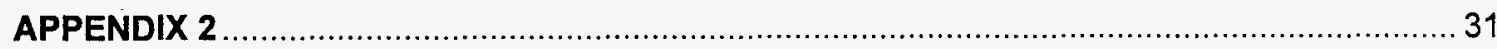

Comparative Data for DuPont 1400/1900/2000 Series

Untrimmed Resistances for DuPont 1400/1900/2000 Series Resistors .................... 32

Untrimmed Resistances for DuPont 1400/1900 Series Resistors .............................. 32

Substrate Comparison for DuPont 1900 Series Resistors ..................................... 33

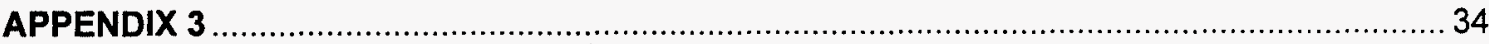

Data for DuPont 1911 - 10 Ohm Resistor

Untrimmed Resistances (Percent from Nominal) ................................................ 35

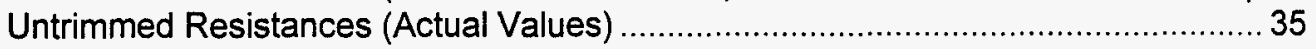

Normalized Resistances (Percent from Nominal) ............................................... 36

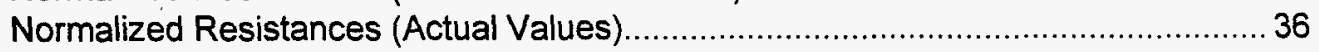




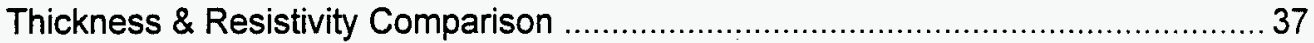

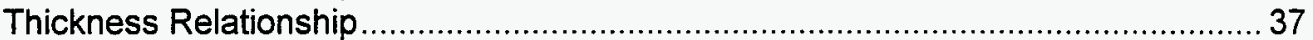

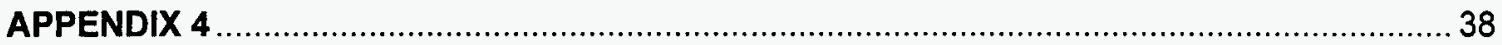

Data for DuPont 1921 - 100 Ohm Resistor

Untrimmed Resistances (Percent from Nominal) .............................................. 39

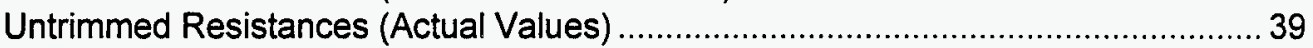

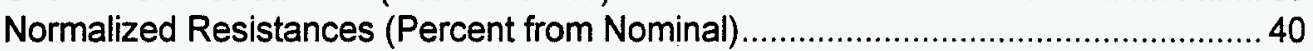

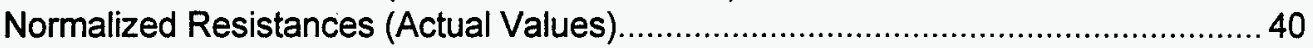

Thickness \& Resistivity Comparison .................................................................. 41

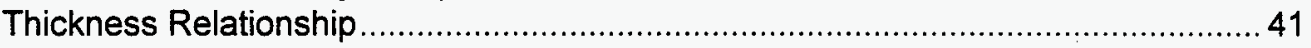

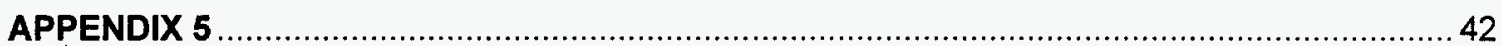

Data for DuPont 1931 - 1K Ohm Resistor

Untrimmed Resistances (Percent from Nominal) ................................................... 43

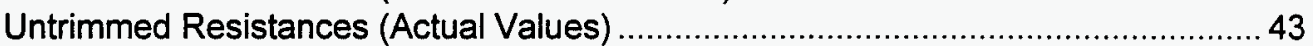

Normalized Resistances (Percent from Nominal) ............................................ 44

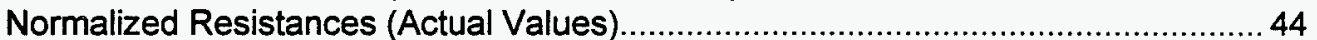

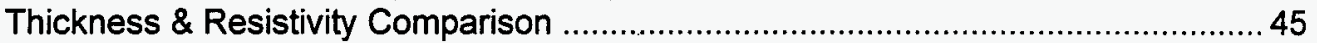

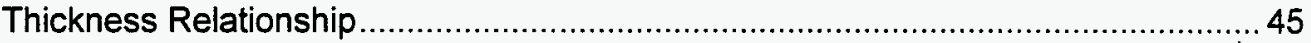

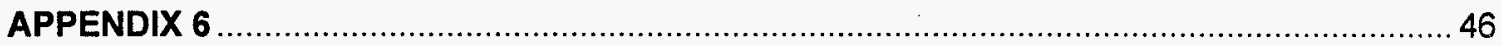

Data for DuPont 1939 - 10K Ohm Resistor

Untrimmed Resistances (Percent from Nominal) ...............................................4 47

Untrimmed Resistances (Actual Values) ...............................................................4 47

Normalized Resistances (Percent from Nominal) .............................................48 48

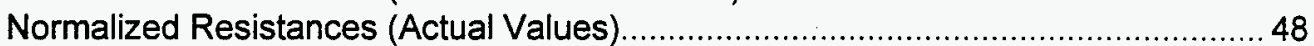

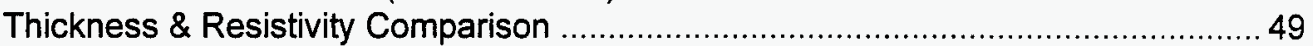

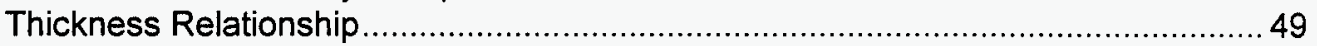

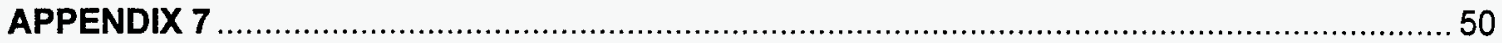

Data for DuPont 1949 - 100K Ohm Resistor

Untrimmed Resistances (Percent from Nominal) ..............................................5 51

Untrimmed Resistances (Actual Values) .......................................................... 51

Normalized Resistances (Percent from Nominal) .................................................. 52

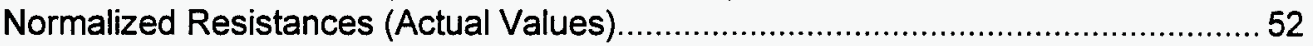

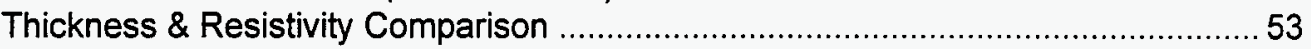

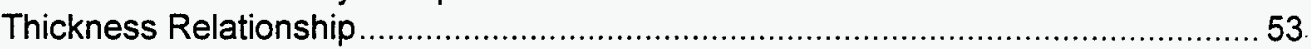

APPENDIX 8

Data for DuPont 1959 -1Meg Ohm Resistor

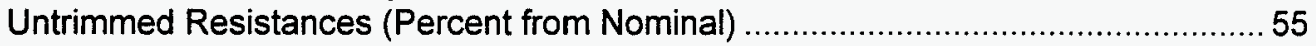

Untrimmed Resistances (Actual Values) ........................................................... 55

Normalized Resistances (Percent from Nominal) ...............................................56

Normalized Resistances (Actual Values) ............................................................ 56

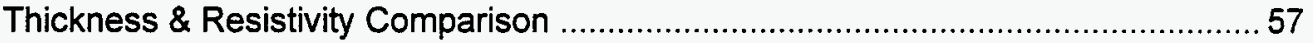

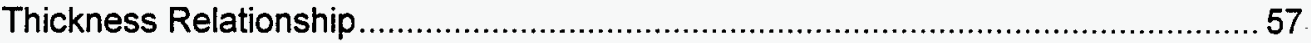




\section{SUMMARY}

An evaluation was performed to establish design and manufacturing parameters for integral thick film resistors utilizing DuPont 1900 Series Resistor Compositions printed on DuPont 5704 Dielectric material. This evaluation was performed for (6) resistivity compositions $(10,100,1 \mathrm{~K}, 10 \mathrm{~K}, 100 \mathrm{~K}$ and $1 \mathrm{Meg}$ Ohm per square) in conjunction with the evaluation of laser trimming DuPont 1900 Series Resistors printed on DuPont 5704 Dielectric material. Both evaluations support an effort to develop a production capability to utilize integral thick film resistors on thick film hybrid microcircuit products.

Test samples were fabricated using a 2 square test pattern configuration consisting of resistors with length to width aspect ratios of $2: 1$ and minimum dimensions of $.025^{\prime \prime}, .050 "$, and .100". The test pattern configuration is illustrated in Figure 1. The test samples were printed on (2) layers of DuPont 5704 Dielectric both with and without encapsulation. The test samples were fired using 850 (nominal), 825 , and 875 degree $C$ - 30 minute, and 850 degree C - 60 minute firing profiles.

The evaluation established the following material characteristics, design criteria, and manufacturing parameters for the (6) DuPont 1900 Series Resistor compositions:

1. Target print thicknesses for each of the six pastes ranged from 41 to 46 microns to yield the DuPont recommended dried thickness of 25 microns resulting in optimum as-fired resistivities and maximum post-trim resistor stability.

2. DuPont 1900 Series thick film resistors printed on (2) layers of DuPont 5704 dielectric should be designed to $70 \%$ of trimmed nominal value.

3. Average resistivities for all (6) DuPont 1900 Series pastes ranged from $29 \%$ above nominal to $30 \%$ below nominal which is a similar range to DuPont 1400 Series resistors ( $23 \%$ above nominal to $23 \%$ below nominal) used on existing thick film production designs.

4. Resistivities for all (6) pastes were unaffected by encapsulation (overglaze).

5. Resistivities were virtually unaffected by resistor orientation, however were more dependent on resistor geometry.

6. Overall print lot capability $(+/-3$ sigma) was $+/-30 \%$ from average fired values for all pastes. 


\section{DISCUSSION}

\section{SCOPE AND PURPOSE}

The objective of this printing and firing evaluation was to determine the following characteristics for all (6) DuPont 1900 Series Resistor Compositions printed on 2 layers of DuPont 5704 Dielectric material on alumina substrates in an effort to develop a production fabrication capability utilizing integral thick film resistors printed on dielectric:

1. Target print thicknesses consistent with manufacturer's recommendations and compatible with subsequent resistor firing and trimming processes.

2. Resistor physical design requirements compatible with manufacturing processes.

3. Sensitivity of resistance to variations in manufacturing processes including firing, encapsulation (overglaze) and print thickness.

4. Effects of geometry variations on untrimmed resistance.

\section{PRIOR WORK}

Thick film technology was refined to meet the requirements of RF applications and multilayer circuits utilizing thick film resistors (specifically DuPont 1400 Series Resistor Compositions) printed on the base $96 \%$ aluminum oxide substrate. Additionally, another project is currently examining the DuPont 2000 Series Resistor Compositions for printing on DuPont 951 Low Temperature Cofired Ceramic.

\section{ACTIVITY}

\section{Test Sample Configuration and Fabrication}

The evaluation consisted of printing test samples using a two square resistor test pattern with each resistor having a length to width ratio of two. The test pattern shown in Figure 1 provided resistors of .025 inch, .050 inch, and .100 inch widths oriented with the resistor lengths parallel and perpendicular to the direction of squeegee travel to simulate actual production. The two square test patterns provide resistors which have nominal untrimmed resistances of twice the nominal 
as-fired sheet resistance. Each test pattern contained two resistors of each width in each orientation. Test patterns were printed on substrates containing nine test patterns each. The test sample substrates were comprised of .025 inch thick $96 \%$ alumina with 2 layers of DuPont 5704 fired to a final thickness of 35 40 microns.

Test samples for each resistor composition were prepared as follows:
With Encapsulation
825 Degree C Fire
850 Degree C Fire
875 Degree C Fire

Without Encapsulation

825 Degree C Fire

850 Degree C Fire

875 Degree C Fire

The complete sample size for each resistor composition, encapsulation, and firing combination was eight substrates (72 test samples) generating a total of 288 resistors for each geometry.

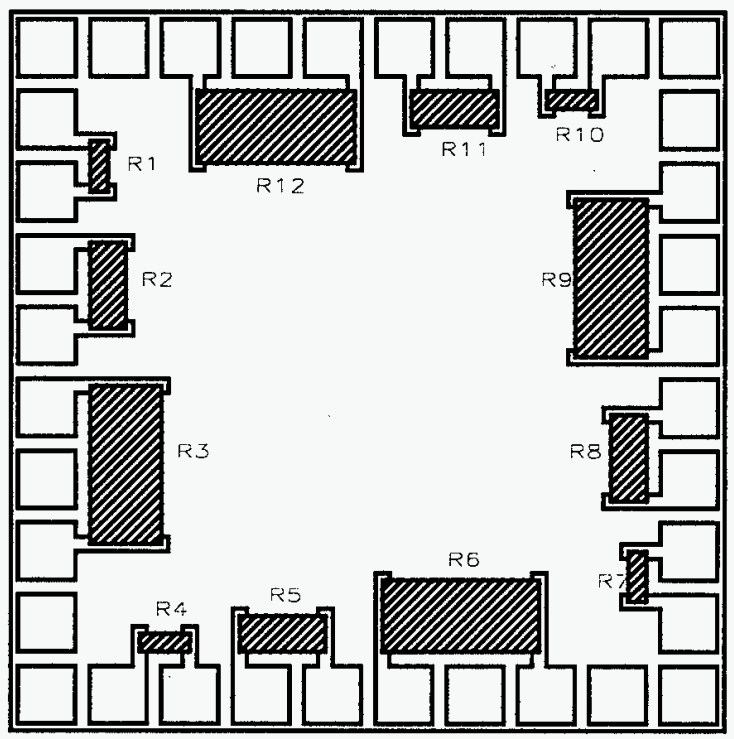

Figure 1 Two Square Resistor Test Pattern

The test samples were printed to the dried target thickness range recommended by DuPont of 23 to 27 microns which is the same for DuPont 1400 Series Compositions. Test samples were prepared both with and without glass encapsulation for comparison of laser trim parameter determination. 


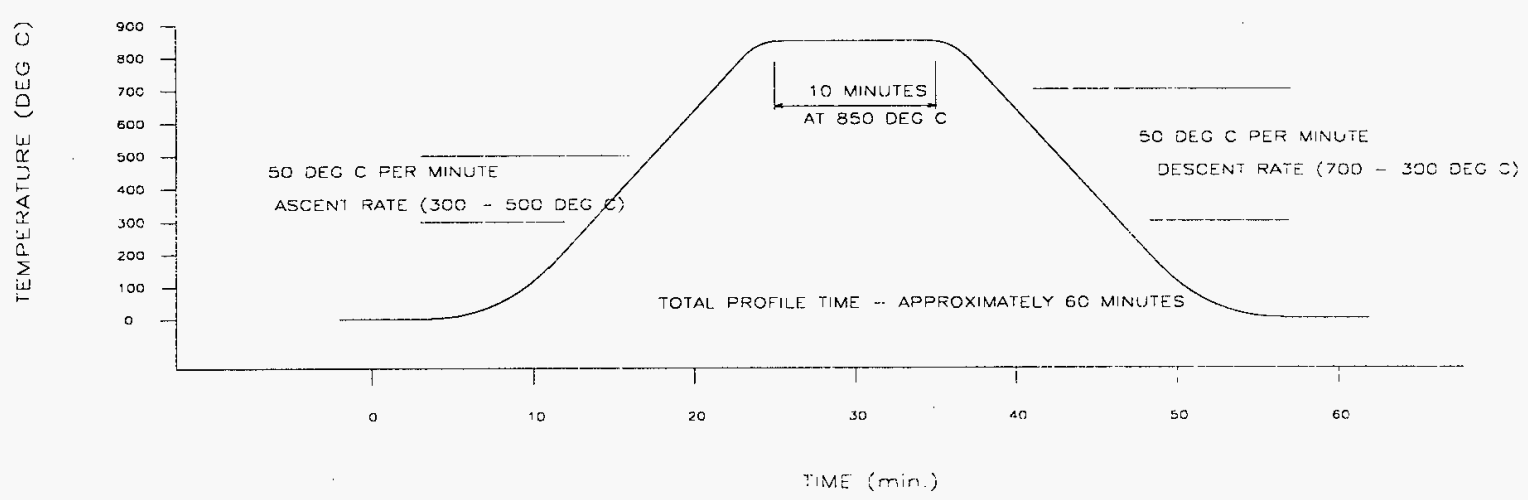

30 MINUTE 850 DEG C THICK FILM SINTERING PFOFILE

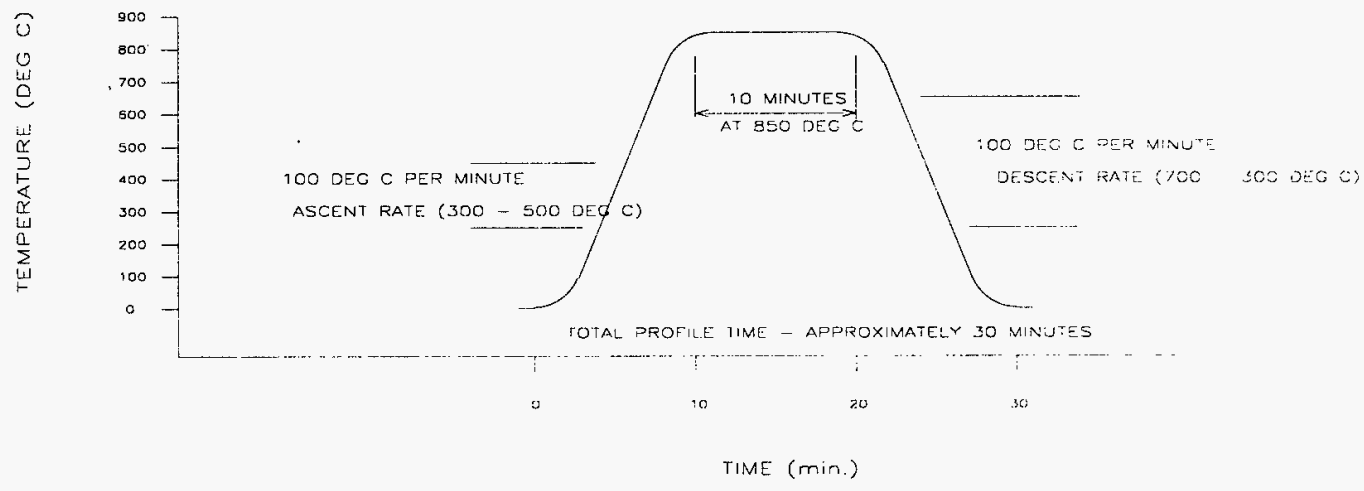

Figure 2 Resistor Sintering Time/Temperature Profiles

Sintering (firing) was performed using a 30 minute, 850 degree $C$, time and temperature profile compared to a 60 minute, 850 degree $C$, time and temperature profile currently used in thick film production utilizing DuPont 1400 Series resistors. Both profiles provide a peak temperature of 850 degrees $C$ with a time at peak temperature of 10 minutes. The 30 minute and 60 minute profiles maintain approximate ascent and descent rates of 100 and 50 deg. $C$ per minute, respectively as illustrated in Figure 2. Sensitivity of the resistor compositions to firing process variations was further evaluated using 825 degree $\mathrm{C}$ and 875 degree $\mathrm{C}, 30$ minute profiles. 


\section{Print Thickness}

The manufacturer's recommended target dried thickness for DuPont 1900 Series Resistors is 23 to 27 microns. The evaluation established target wet printed thicknesses needed to obtain a dried thickness of 23 to 27 microns. Figures 1-5 and 1-6 illustrate the comparison between wet (as-printed), dried, and fired thickness and resistivity for each paste composition.

\section{Untrimmed Resistance Measurements}

As part of the overall evaluation of the sensitivity of DuPont 1900 Series Resistor Compositions to variations in manufacturing processes, such as firing, encapsulation, thickness, and geometry, electrical resistance measurements were made on as-fired (untrimmed) resistors. The untrimmed resistance data is shown for each resistor composition in the appropriate appendix both as a percent from nominal and actual resistance.

\section{Normalized Sheet Resistance and Design Considerations}

In order to eliminate the effects of print thickness and print width variations on fired sheet resistivity determinations, the untrimmed resistance measurements are normalized to account for these variations. This calculation is used to determine typical as-fired sheet resistivities for each resistor composition and subsequently the resistor nominal design values incorporated into product definitions. The following equation is used for this determination:

$$
R_{\text {Nomalized }}=\frac{\left(\frac{\bar{R}_{M}}{2}\right) \times \bar{T}_{D}}{T_{R}} \times \frac{\bar{W}_{F}}{W_{R}}
$$

$\bar{R}_{M} \quad=\quad$ The Average As-Measured Resistance

$\bar{T}_{D} \quad=\quad$ Average Dried Thickness

$T_{R} \quad=\quad$ Reference Dried Thickness (25 microns)

$\overline{W_{F}} \quad=\quad$ Average Fired Width

$W_{R}=$ Reference Fired Width $(.025, .050$, or .100 inch $)$ 
The normalized resistance data is shown for each resistor composition in the appropriate appendix both as a percent from nominal and actual resistance.

\section{Firing Sensitivity}

Figure 1-1 illustrates the untrimmed sheet resistance as a percent of the nominal sheet resistance for each resistivity and firing profile combination. This data indicates DuPont 1900 Series Resistors printed to a dried target thickness of 2327 microns, range from 29 percent below nominal to 29 percent above nominal when fired using a 30 minute, 850 degree $C$ profile. These values shift by typically $10-20$ percent when fired using 825 or 875 degree $C$ profiles depending on the specific resistor composition.

Figure 1-2 illustrates the normalized sheet resistivity as a percent of the nominal sheet resistance for each resistivity and firing profile. This data indicates DuPont 1900 Series Resistors normalized to a dried target thickness of 25 microns, range from 10 percent above nominal to 30 percent below nominal when fired using a 30 minute, 850 degree $C$ profile. These values shift by up to 20 percent when fired using 825 or 875 degree $C$ profiles.

\section{Encapsulation Effects}

Virtually no difference in resistivities was observed between encapsulated and unencapsulated resistors for all six resistor compositions. Figure 1-4 shows sensitivity to overglaze for untrimmed resistance and Figure 1-5 for normalized resistance. Trim parameters yielding acceptable visual and electrical results were significantly reduced with encapsulated samples.

\section{Thickness Sensitivity}

Figure 1-5 illustrates variations in untrimmed resistance as a percent from nominal for various dried thicknesses. The relationship shows typically that thickness is inversely proportional to resistance for all resistor compositions. Figure 1-6 shows the relationship between wet, dried, and fired thicknesses for each resistor composition. The dried thickness target range of 18 to 20 microns was maintained by printing the wet thickness within the range of 32 to 38 microns for each resistor composition. 


\section{Effects of Resistor Geometry and Orientation}

Figure 1-11 illustrates untrimmed resistance as a percent from nominal for each resistor geometry and orientation combination. The geometries tested were .025 inch, .050 inch, and .100 inch minimum resistor dimensions (resistor width) and the orientation refers to the direction of the resistor length compared to the direction of the squeegee travel. The chart shows for each paste composition the effect of resistor orientation was negligible with all geometries exhibiting a spread of typically less than 10 percent between resistors parallel and perpendicular to the squeegee travel. The inherent lack of surface topography on this substrate material would contribute to this consistency. Resistor geometry, however, can be seen to have more of an effect on resistance with most paste compositions displaying a 10 percent spread between the .025 inch and .050 inch geometries compared to a $20-25$ percent spread between .050 inch and .100 inch resistor geometries. The larger resistor geometries tend to print thinner resulting in higher resistivities.

\section{Overall Printing/Firing Capability}

The within print lot variability of as-fired resistance is shown in Figures 1-7 through $1-10$ for $.025 ., .050$, and .100 inch resistors. The data presented in these figures is a composite of both parallel and perpendicular orientations. The 3 sigma limits were typically $+/-25 \%$ except for the $10 \mathrm{Ohm}$ and $100 \mathrm{Ohm}$ compositions which were $+/-50 \%$.

\section{Resistor Series Comparisons}

Figures 2-1 and 2-2 illustrate relative resistivities (as a percent from nominal) for DuPont 1900 Series Resistor Compositions versus DuPont 1400 and DuPont 2000 Series Resistor Compositions. DuPont 1400 is currently used in thick film production on aluminum oxide substrate material. DuPont 2000 is used in LTCC production at AlliedSignal Federal Manufacturing \& Technologies. DuPont 1900 can be seen to be comparable to the $1400 / 2000$ Series in terms of percent from nominal for untrimmed resistivities. Additionally DuPont 1900 Series Resistor Compositions printed on DuPont 951 LTCC versus 2 layers of DuPont 5704 on alumina yielded fired values typically within $10-15 \%$ of each other. 


\section{Resistivity Specific Data}

10 Ohm - DuPont 1911 (Reference Appendix 3 for data)

1. Average untrimmed resistances were centered $25 \%$ above nominal for 50 mil geometries with a spread of approximately $+/-20 \%$ when fired using the 850 degree C - 30 minute profile. Normalized resistance was centered at nominal with a spread of $5-10 \%$.

2. Composite print lot capabilities (+/- 3 sigma for all geometries) ranged from $15 \%$ to $+85 \%$ from nominal.

3. Firing sensitivities indicated a $10 \%$ upward shift between 850 degree $C-30$ minute \& 850 degree C - 60 minute profiles compared to a $10-15 \%$ downward shift between 850 degree $\mathrm{C}-30$ minute $\& 825$ or 875 degrees $\mathrm{C}$. -30 minute profiles.

4. Encapsulation resulted in no significant change in as-fired resistivity $(+/-1 \%)$.

5. Thickness sensitivity indicated a $+/-20 \%$ shift in resistivities between dried thicknesses of 25 microns and 28 or 22 microns.

6. The target wet print thickness for DuPont 2011 is 41 microns yielding a dried thickness of 25 microns.

7. Resistance sensitivity to substrate material when comparing DuPont 951 LTCC and $\mathrm{AlO} 2$ with 2 dielectric prints indicated a $7 \%$ increase for resistors printed on LTCC substrates.

8. Resistances were effected by resistor geometry as follows; 25 mil resistors were approximately nominal value and $50 \& 100$ mil resistors $15 \% \& 40 \%$ above nominal respectively.

9. Resistances were effected by orientation as follows; resistors parallel to squeegee travel were $10-15 \%$ lower than resistors perpendicular to squeegee travel.

\section{Ohm - DuPont 1921 (Reference Appendix 4 for data)}

1. Average untrimmed resistances were centered $30 \%$ below nominal for 50 mil geometries with a spread of approximately $+/-10 \%$ when fired using the 850 degree C - 30 minute profile. Normalized resistance was centered $20 \%$ below nominal with a spread of $5-10 \%$.

2. Composite print lot capabilities (+/- 3 sigma for all geometries) ranged from 5 to $96 \%$ above nominal.

3. Firing sensitivities indicated no change between $850 \& 825$ degrees $C-30$ minute profiles with a $15-20 \%$ upward shift between 850 degrees $C-30$ minute and 875 degrees $C-30$ minute $\& 850$ degrees $C-60$ minute profiles. 
4. Encapsulation resulted in no significant change in as-fired resistivity $(+/-1 \%)$

5. Thickness sensitivity indicated a $+/-5 \%$ shift in resistivities between dried thicknesses of 25 microns and 22 or 28 microns.

6. The target wet print thickness for DuPont 1921 is 41 microns yielding a dried thickness of 25 microns.

7. Resistance sensitivity to substrate material when comparing DuPont 951 LTCC and $\mathrm{AlO} 2$ with 2 dielectric prints indicated a $40 \%$ increase for resistors printed on LTCC substrates.

8. Resistances were effected by resistor geometry as follows; 25 mil resistors were approximately $5 \%$ below nominal value and $50 \& 100$ mil resistors $10 \%$ $\& 35 \%$ above nominal respectively.

9. Resistances were effected by orientation as follows; resistors parallel to squeegee travel were $5-10 \%$ lower than resistors perpendicular to squeegee travel.

1K Ohm (DuPont 1931) (Reference Appendix 5 for data)

1. Average untrimmed resistances were centered $33 \%$ below nominal for 50 mil geometries with a spread of $5-15 \%$ when fired using the 850 degree $C-30$ minute profile. Normalized resistance was centered $35 \%$ below nominal with a spread of $5-15 \%$.

2. Composite print lot capabilities (+/- 3 sigma for all geometries) ranged from $50 \%$ to $+15 \%$ from nominal.

3. Firing sensitivities indicated a $1 \%$ upward shift between $850 \& 875$ degrees $C$ with a $20 \%$ downward shift between $850 \& 825$ degrees $C$.

4. Encapsulation resulted in no significant change in as-fired resistivity $(+/-2 \%)$.

5. Thickness sensitivity indicated a $+/-5-10 \%$ shift in resistivities between dried thicknesses of 25 microns and 22 or 28 microns.

6. The target wet print thickness for DuPont 1931 is 42 microns yielding 25 microns dried thickness.

7. Resistance sensitivity to substrate material when comparing DuPont 951 LTCC and $\mathrm{AlO} 2$ with 2 dielectric prints indicated a $20 \%$ increase for resistors printed on LTCC substrates.

8. Resistances were effected by resistor geometry as follows; 25 mil resistors were approximately $40 \%$ below nominal value and $50 \& 100$ mil resistors $35 \% \& 15 \%$ below nominal respectively.

9. Resistances were effected by orientation as follows; resistors parallel to squeegee travel were $0-10 \%$ lower than resistors perpendicular to squeegee travel. 
10K Ohm - (DuPont 1939) (Reference Appendix 6 for data)

1. Average untrimmed resistances were centered $15 \%$ above nominal for 50 mil geometries with a spread of approximately $+/-10 \%$ when fired using the 850 degree C - 30 minute profile. Normalized resistance was centered $10 \%$ above nominal with a spread of $10-15 \%$

2. Composite print lot capabilities ( $+/-3$ sigma for all geometries) ranged from nominal to $45 \%$ above nominal ( $+l-20 \%$ from average fired resistance).

3. Firing sensitivities indicated a $15 \%$ upward shift between $850 \& 875$ degrees C with a $10 \%$ downward shift between $850 \& 825$ degrees $C$.

4. Encapsulation resulted in no significant change in as-fired resistivity $(+/-5 \%)$.

5. Thickness sensitivity indicated a $+/-5-10 \%$ shift in resistivities between dried thicknesses of 25 microns and 22 or 28 microns.

6. The target wet print thickness for DuPont 1939 is 42 microns yielding 25 microns dried thickness.

7. Resistance sensitivity to substrate material when comparing DuPont 951 LTCC and AIO2 with 2 dielectric prints indicated a $10 \%$ decrease for resistors printed on LTCC substrates.

8. Resistances were effected by resistor geometry as follows; 25 mil resistors were approximately $20 \%$ below nominal value and $50 \& 100$ mil resistors $30 \% \& 50 \%$ above nominal respectively.

9. Resistances were effected by orientation as follows; resistors parallel to squeegee travel were $0-10 \%$ lower than resistors perpendicular to squeegee travel.

100K Ohm (DuPont 1949) (Reference Appendix 7 for data)

1. Average untrimmed resistances were centered $3 \%$ below nominal for 50 mil geometries with a spread of $5 \%$ when fired using the 850 degree $C-30$ minute profile. Normalized resistance was centered $3 \%$ below nominal with a spread of $5-10 \%$.

2. Composite print lot capabilities (+/- 3 sigma for all geometries) ranged from $20 \%$ to $+20 \%$ from nominal.

3. Firing sensitivities indicated a 35\% upward shift between 850 \& 875 degrees C with a $10 \%$ downward shift between 850 \& 825 degrees C.

4. Encapsulation resulted in no significant change in as-fired resistivity $(+/-2 \%)$.

5. Thickness sensitivity indicated a $+/-2-5 \%$ shift in resistivities between dried thicknesses of 25 microns and 22 or 28 microns.

6. The target wet print thickness for DuPont 1949 is 45 microns yielding 25 microns dried thickness.

7. Resistance sensitivity to substrate material when comparing DuPont 951 LTCC and AIO2 with 2 dielectric prints indicated a $15 \%$ increase for resistors printed on LTCC substrates. 
8. Resistances were effected by resistor geometry as follows; 25 mil resistors were approximately $20 \%$ above nominal value and $50 \& 100$ mil resistors $30 \% \& 45 \%$ above nominal respectively.

9. Resistances were effected by orientation as follows; resistors parallel to squeegee travel were $3-5 \%$ higher than resistors perpendicular to squeegee travel.

1Meg Ohm (DuPont 1959) (Reference Appendix 8 for data)

1. Average untrimmed resistances were centered $25 \%$ below nominal for 50 mil geometries with a spread of $5-10 \%$ when fired using the 850 degree $C-30$ minute profile. Normalized resistance was centered $20 \%$ below nominal with a spread of $10 \%$.

2. Composite print lot capabilities (+/- 3 sigma for all geometries) ranged from $45 \%$ below nominal to nominal.

3. Firing sensitivities indicated a $30 \%$ upward shift between $850 \& 875$ degrees $C$ with a $15 \%$ upward shift between 850 \& 825 degrees $C$.

4. Encapsulation resulted in no significant change in as-fired resistivity $(+/-4 \%)$.

5. Thickness sensitivity indicated a $+/-5-10 \%$ shift in resistivities between dried thicknesses of 25 microns and 22 or 28 microns.

6. The target wet print thickness for DuPont 1959 is 46 microns yielding 25 microns dried thickness.

7. Resistance sensitivity to substrate material when comparing DuPont 951 LTCC and AlO2 with 2 dielectric prints indicated a $20 \%$ increase for resistors printed on LTCC substrates.

8. Resistances were effected by resistor geometry as follows; 25 mil resistors were approximately $10 \%$ below nominal value and $50 \& 100$ mil resistors $5 \%$ $\& 30 \%$ above nominal respectively.

9. Resistances were effected by orientation as follows; resistors parallel to squeegee travel were $0-10 \%$ lower than resistors perpendicular to squeegee travel. 


\section{ACCOMPLISHMENTS}

Target print thicknesses and sintering process parameters were determined for the six DuPont 1900 Series resistor compositions. These target thicknesses and sintering process parameters are consistent with the manufacturer's recommendations and compatible with AlliedSignal manufacturing processes.

Resistor physical design requirements were established for integral thick film resistors in applications utilizing DuPont 1900 Series Resistor Compositions in conjunction with DuPont 5704 Dielectric printed on alumina substrate material.

\section{FUTURE WORK}

Future work to be done to maintain state-of-the-art capability will include the evaluation of the DuPont 2000 Series Resistor Compositions for use with existing thick film processes and materials (specifically the DuPont 5704 Dielectric Composition printed on alumina substrates) at AlliedSignal's Federal Manufacturing And Technologies.

Future work to be done to develop additional capabilities will include evaluating the compatibility of DuPont 2000 Series Resistors with different thick film processes and materials not in use at AlliedSignal Federal Manufacturing \& Technologies 


\section{APPENDIX 1}

SUMMARY DATA FOR DUPONT 1900 RESISTOR SERIES 


\section{UNTRIMMED SHEET RESISTANCE - DUPONT 1900 SERIES}

Firing Sensitivity - 2 Dielectrics (Unglazed)

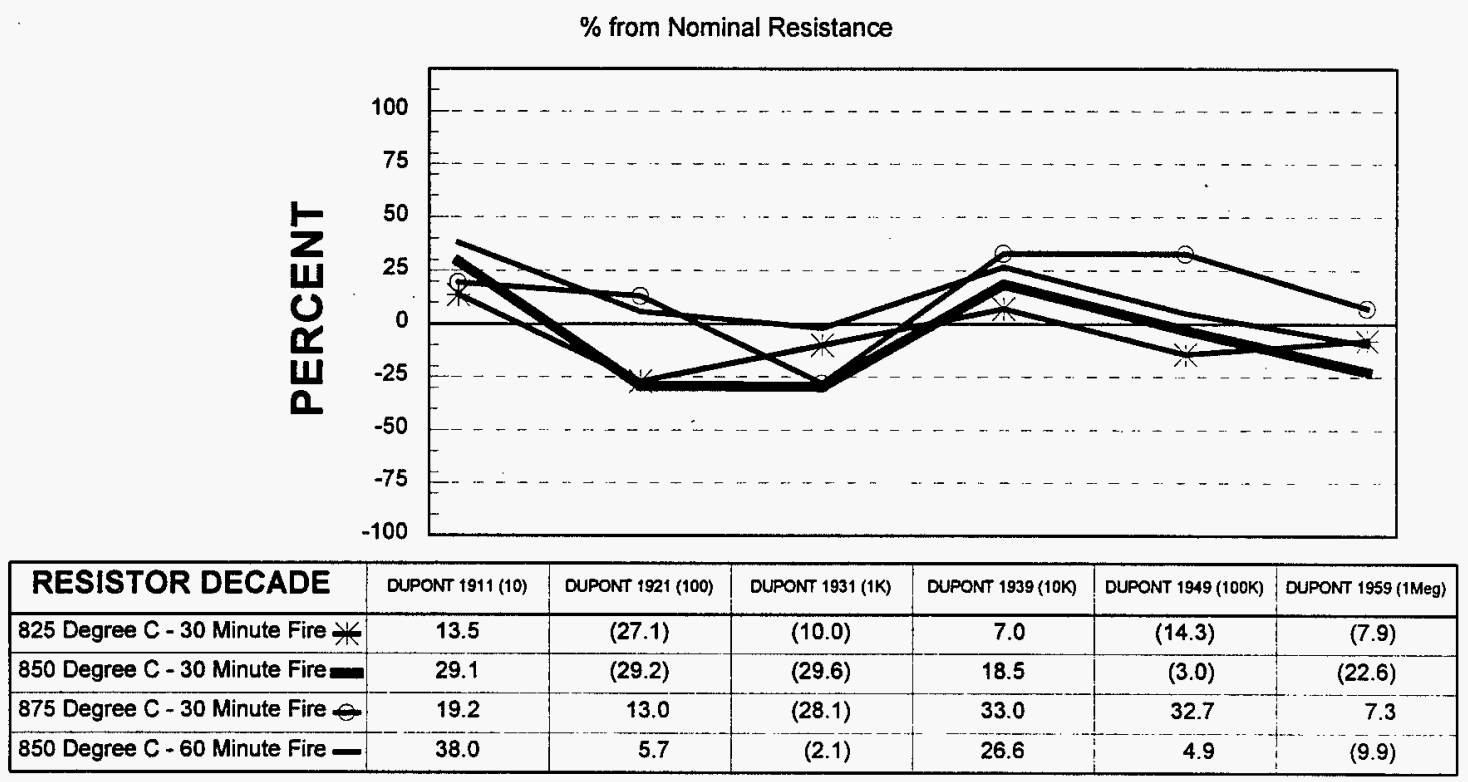

Value in parenthesis is nominal sheet resistance

Data for All Geometry Combinations

Dried Target Thickness $\mathbf{=} 25$ microns

\section{NORMALIZED SHEET RESISTANCE - DUPONT 1900 SERIES}

\section{Firing Sensitivity - 2 Dielectrics (Unglazed)}

$\%$ from Nominal Normalized Sheet Resistance

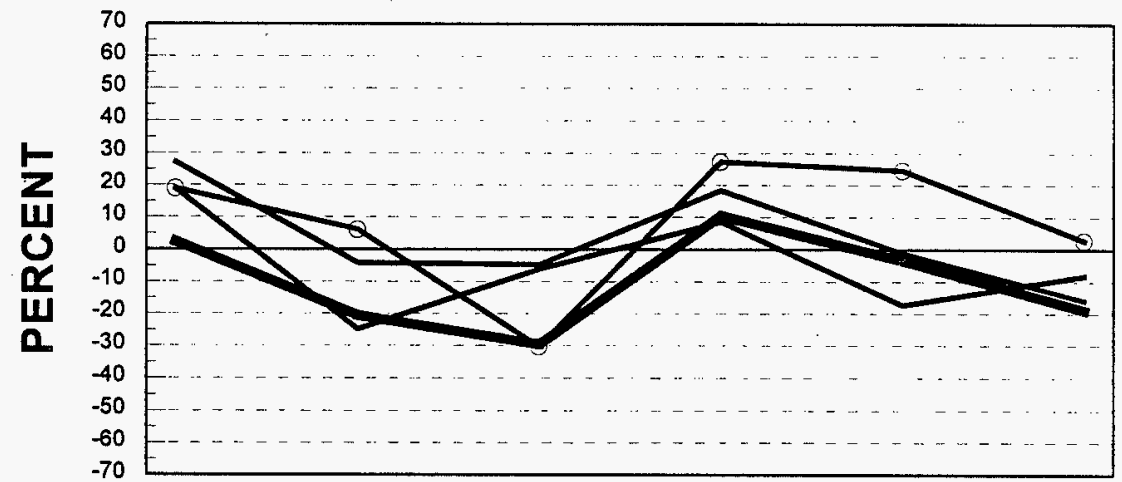

\begin{tabular}{|l|c|c|c|c|c|c|}
\hline RESISTOR DECADE & DUPONT 1911 (10) & DUPONT 1921 (100) & DUPONT 1931 (1K) & DUPONT 1939 (10K) & OUPONT 1949 (100K) & OUPONT 1959 (IMeg) \\
\hline 825 Degree C - 30 Minute Fire - & 18.8 & $(24.9)$ & $(6.1)$ & 8.6 & $(17.4)$ & $(8.2)$ \\
\hline 850 Degree C - 30 Minute Fire & 2.4 & $(20.7)$ & $\frac{(29.7)}{(18)}$ & 10.5 & $(3.5)$ & $(18.9)$ \\
\hline 875 Degree C - 30 Minute Fire - & 18.9 & 6.1 & $(30.3)$ & 27.3 & 24.5 & 2.7 \\
\hline 850 Degree C - 60 Minute Fire - & 27.0 & $(4.3)$ & $(4.8)$ & 18.4 & $(1.1)$ & $(16.0)$ \\
\hline
\end{tabular}

Value in parenthesis is nominal sheet resistance

Data for All Geometry Combinations

Dried Target Thickness $=25$ microns

Figure 1-2 


\section{UNTRIMMED SHEET RESISTANCE - DUPONT 1900 SERIES}

\section{Sensitivity to Overglaze - 2 Dielectrics}

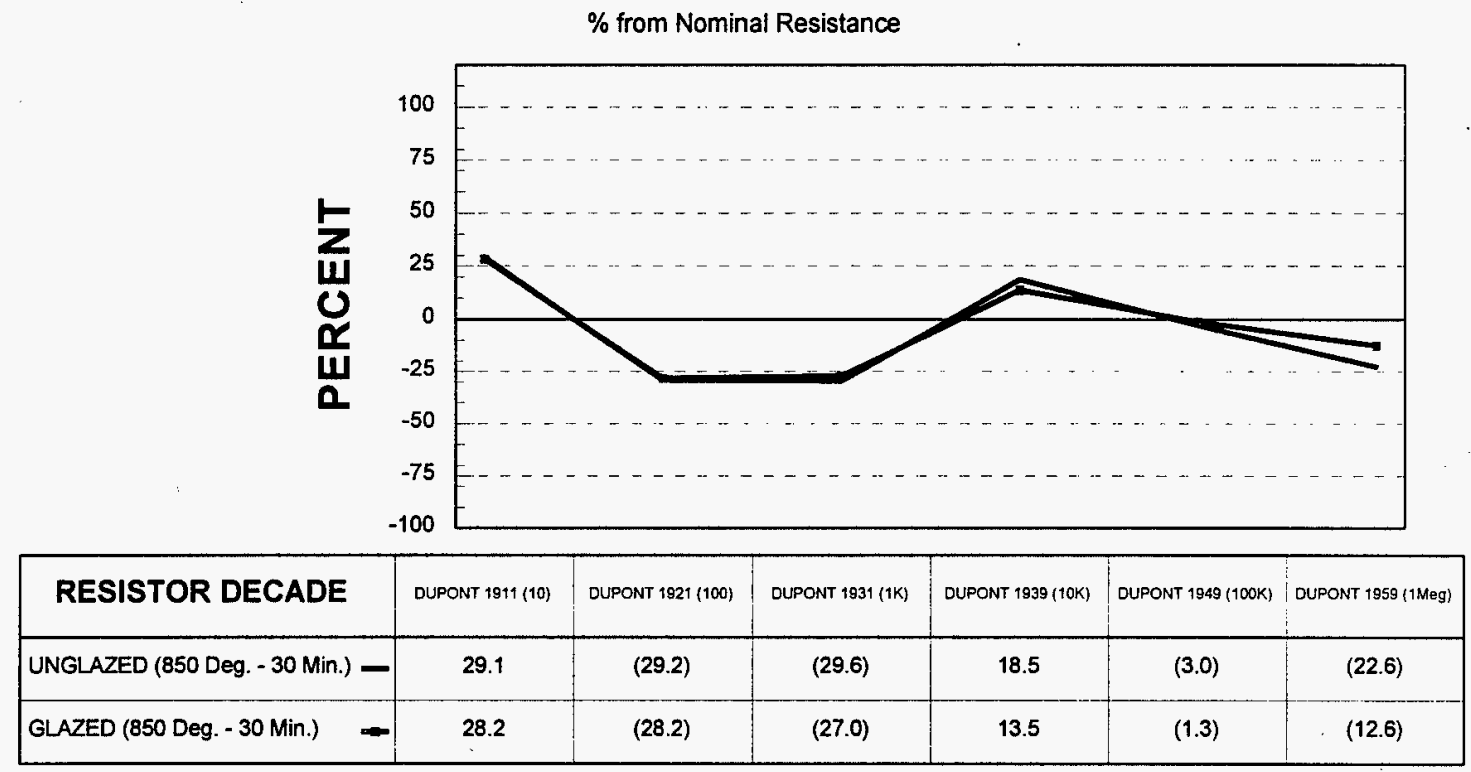

Value in parenthesis is nominal sheet resistance

Data for All Geometry Combinations

Dried Target Thickness $=\mathbf{2 5}$ microns

Figure 1-3

\section{NORMALIZED SHEET RESISTANCE - DUPONT 1900}

\section{Sensitivity to Overglaze - 2 Dielectrics}

$\%$ from Nominal Normalized Sheet Resistance

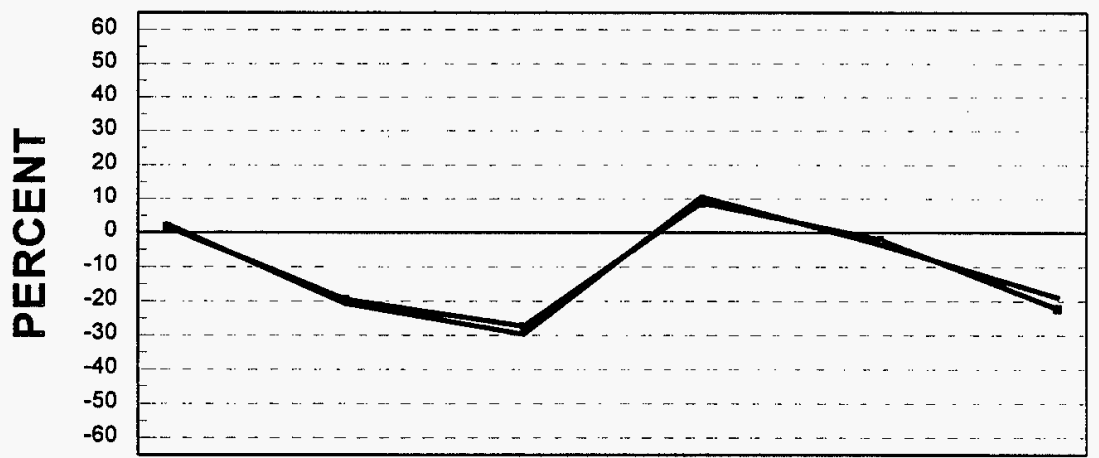

\begin{tabular}{|c|c|c|c|c|c|c|}
\hline RESISTOR DECADE & DUPONT 1911 (10) & DUPONT 1921 (100) & DUPONT 1931 (1K) & DUPONT 1939 (10K) & DUPONT 1949 (100K) & DUPONT 1959 (1Meg) \\
\hline UNGLAZED (850 Deg. - 30 Min.) & 2.4 & $(20.7)$ & $(29.7)$ & 10.5 & $(3.5)$ \\
\hline GLAZED (850 Deg, - 30 Min.) & 1.6 & $(19.5)$ & $(27.4)$ & 8.8 & $(18.9)$ \\
\hline
\end{tabular}

Value in parenthesis is nominal sheet resistance

Data for All Geometry Combinations

Dried Target Thickness $=\mathbf{2 5}$ microns

Figure 1-4 


\section{UNTRIMMED SHEET RESISTANCE - DUPONT 1900 SERIES}

Thickness Sensitivity - 2 Dielectrics (Unglazed)

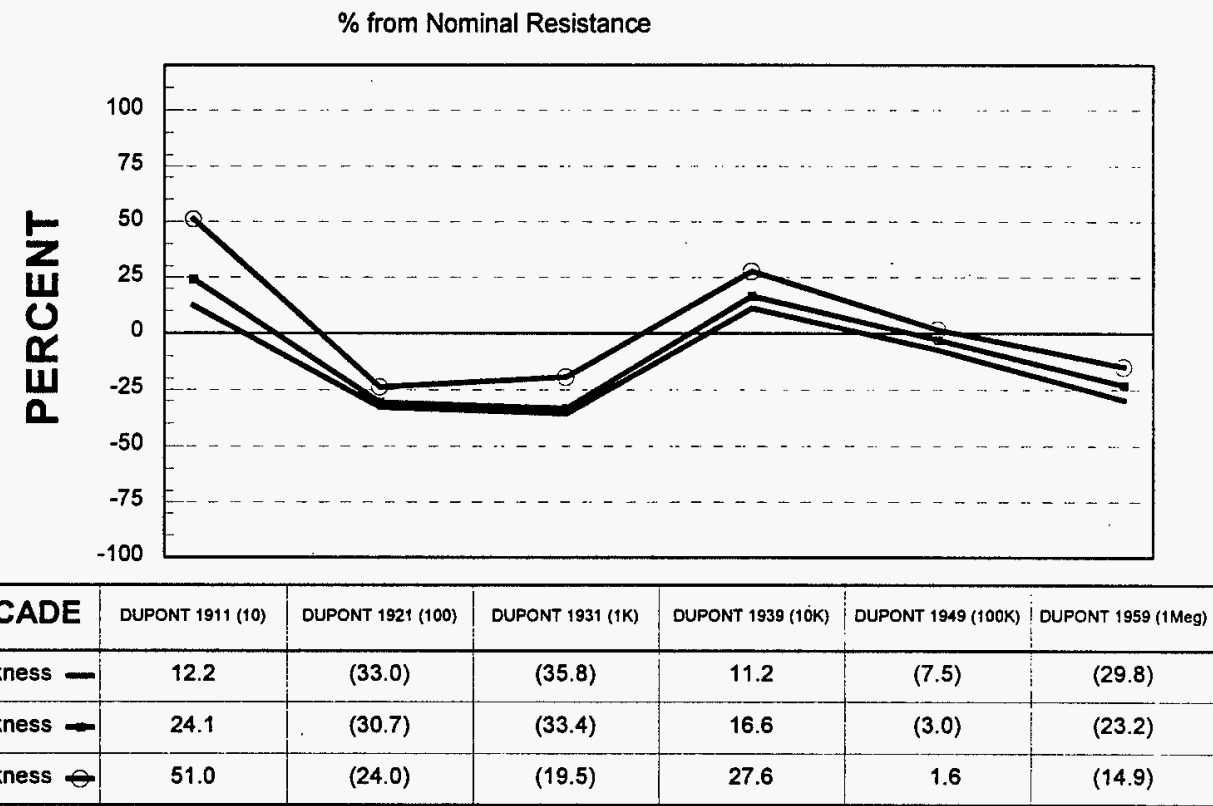

Value in parenthesis is nominal sheet resistance

Data Based on 850 Degree C Fire

Figure 1-5

\section{THICKNESS RELATIONSHIP - DUPONT 1900 SERIES}

Wet, Dried \& Fired Thicknesses

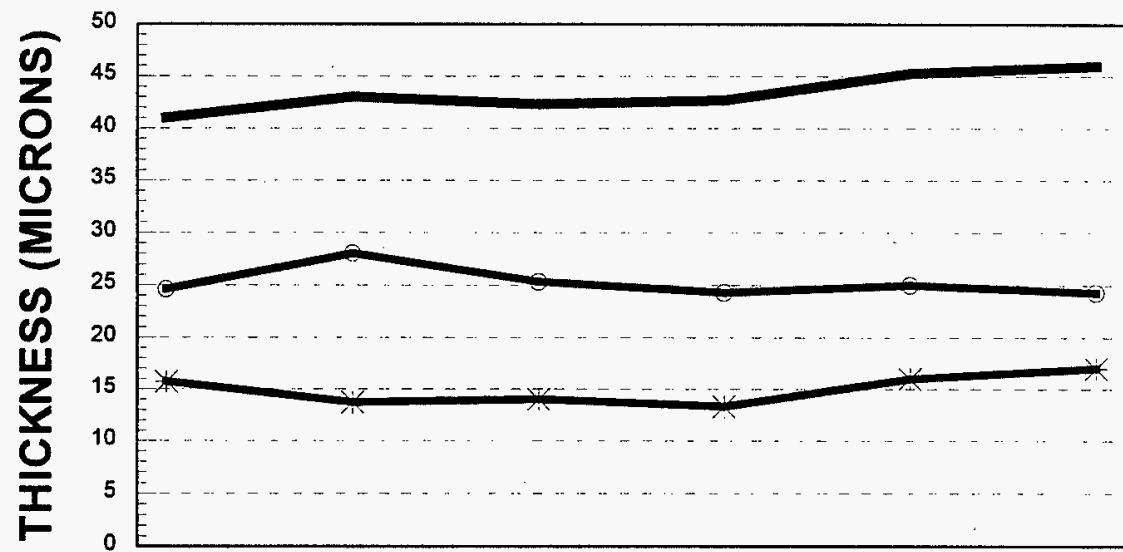

\begin{tabular}{|lc|c|c|c|c|c|c|}
\hline RESISTOR DECADE & DUPONT 1911 (10) & DUPONT 1921 (100) & OUPONT 1931 (1K) & DUPONT 1939 (10K) & DUPONT 1949 (100K) & DUPONT 1959 (1Meg) \\
\hline WET THICKNESS & & 41.0 & 43.0 & 42.3 & 42.7 & 45.3 \\
\hline DRIED THICKNESS & - & 24.6 & 28.0 & 25.3 & 24.3 & 25.0 & 24.3 \\
\hline FIRED THICKNESS & 4 & 15.7 & 13.7 & 14.0 & 13.3 & 16.0 & 17.0 \\
\hline
\end{tabular}

Dried Target Thickness $=25$ microns

Figure 1-6 


\section{UNTRIMMED SHEET RESISTANCE - DUPONT 1900 SERIES}

\section{Print Lot Variability (Unglazed)}

$\%$ from Nominal Resistance

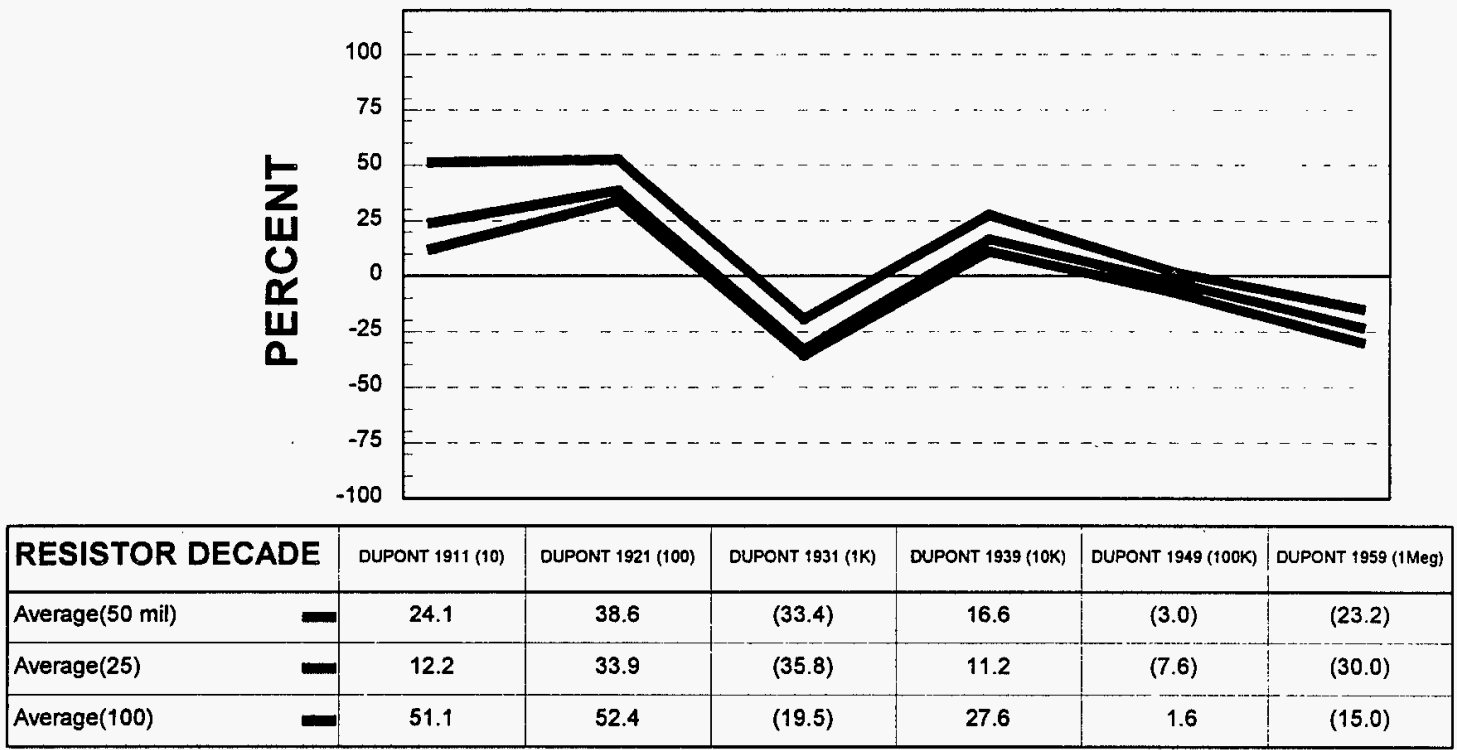

Fired at 850 Degrees C - 30 Minutes

Average Resistances for All Geometries

Figure 1-7

\section{UNTRIMMED SHEET RESISTANCE - DUPONT 1900 SERIES}

Print Lot Variability (Unglazed)

$\%$ from Nominal Resistance

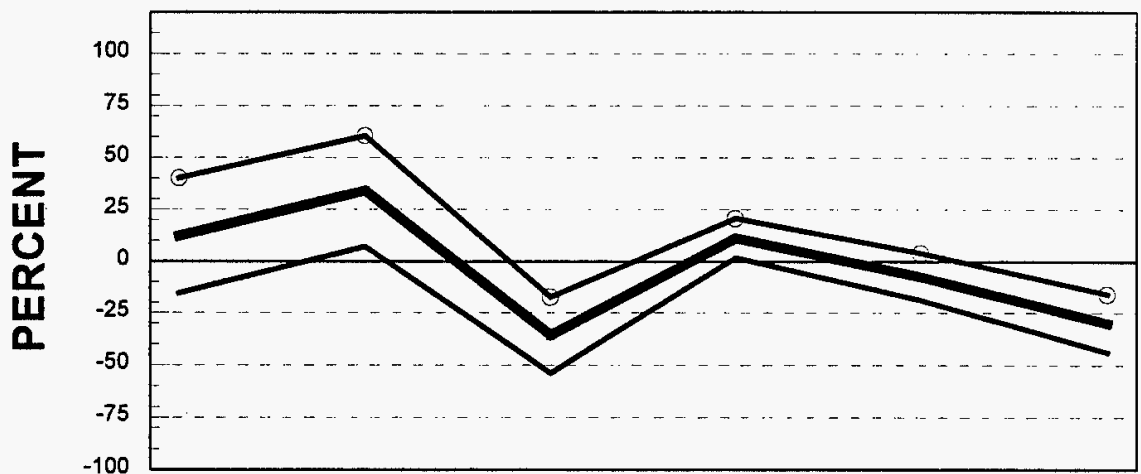

\begin{tabular}{|l|c|c|c|c|c|c|c|}
\hline RESISTOR DECADE & DUPONT 1911 (10) & DUPONT 1921 (100) & DUPONT 1931 (1K) & OUPONT 1939 (10K) & DUPONT 1949 (100K) & DUPONT 1959 (1Meg) \\
\hline -3 Sigma (25) & - & $(15.5)$ & 7.1 & $(54.0)$ & 1.6 & $(18.9)$ & $(44.0)$ \\
\hline Average(25) & - & 12.2 & 33.9 & $(35.8)$ & 11.2 & $(7.6)$ & $(30.0)$ \\
\hline+3 Sigma(25) & - & 40.0 & 60.6 & $(17.4)$ & 20.8 & 3.8 & $(16.0)$ \\
\hline
\end{tabular}

Average +/- 3 Sigma Resistances

Fired at 850 Degrees $\mathrm{C}-30$ Minutes

Based on 25 mil Geometry

Figure 1-8 


\section{UNTRIMMED SHEET RESISTANCE - DUPONT 1900 SERIES}

Print Lot Variability (Unglazed)

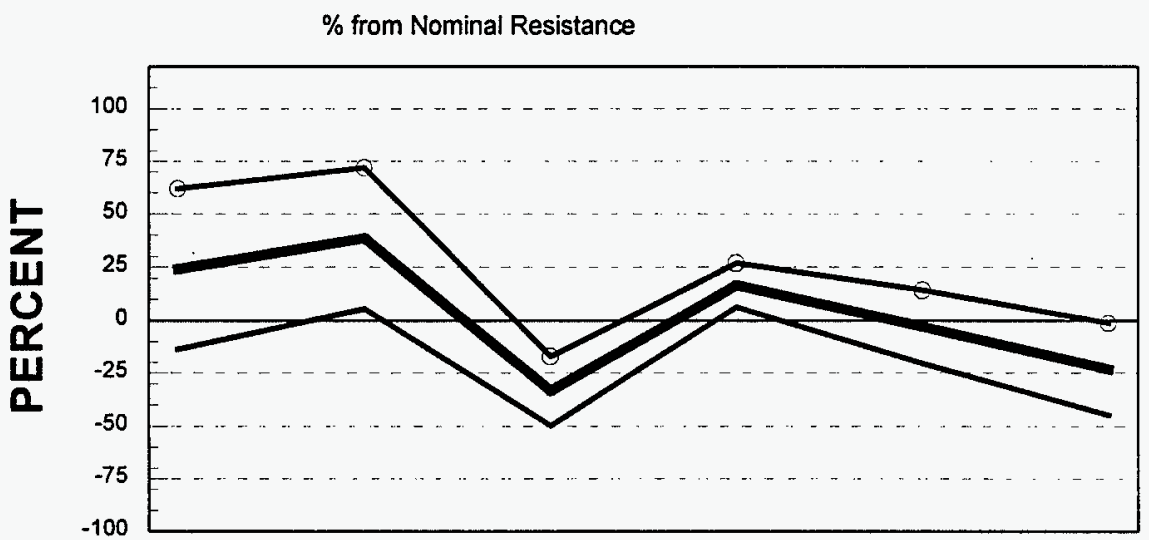

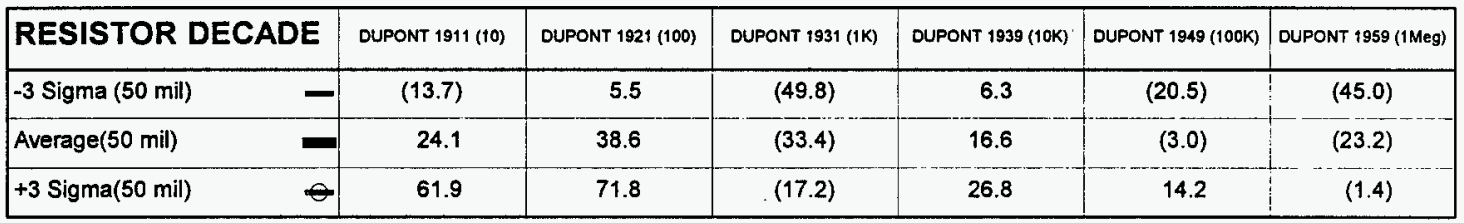

Average +/- 3 Sigma Resistances

Fired at 850 Degrees $C$ - 30 Minutes

Based on 50 mil Geometry

Figure 1-9

\section{UNTRIMMED SHEET RESISTANCE - DUPONT 1900 SERIES}

Print Lot Variability (Unglazed)

$\%$ from Nominal Resistance

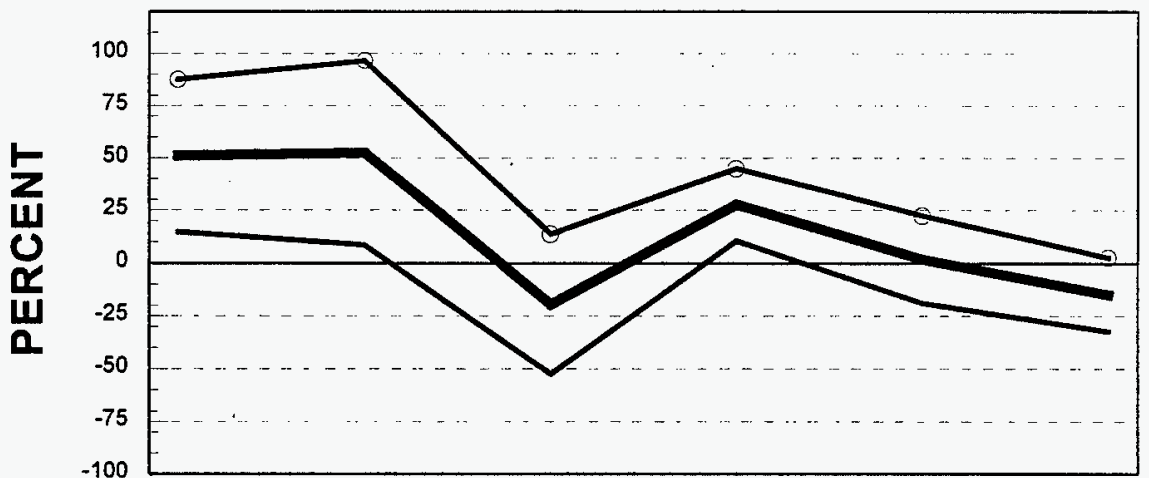

\begin{tabular}{|c|c|c|c|c|c|c|}
\hline RESISTOR DECADE & DUPONT $1911(10)$ & DUPONT $1921(100)$ & DUPONT 1931 (1K) & DUPONT 1939 (10K) & DUPONT 1949 (100K) & DUPONT 1959 (1Meg) \\
\hline -3 Sigma (100) & 14.6 & 8.4 & (52.6) & 10.4 & $(19.0)$ & (32.5) \\
\hline Average $(100)$ & 51.1 & 52.4 & (19.5) & 27.6 & 1.6 & $(15.0)$ \\
\hline +3 Sigma(100) & 87.5 & 96.5 & 13.5 & 44.9 & 22.3 & 2.6 \\
\hline
\end{tabular}

Average +1- 3 Sigma Resistances

Fired at 850 Degrees $C-30$ Minutes

Based on 100 mil Geometry

Figure 1-10 


\section{RESISTOR GEOMETRY \& ORIENTATION AFFECTS}

\section{DUPONT 1900 SERIES}

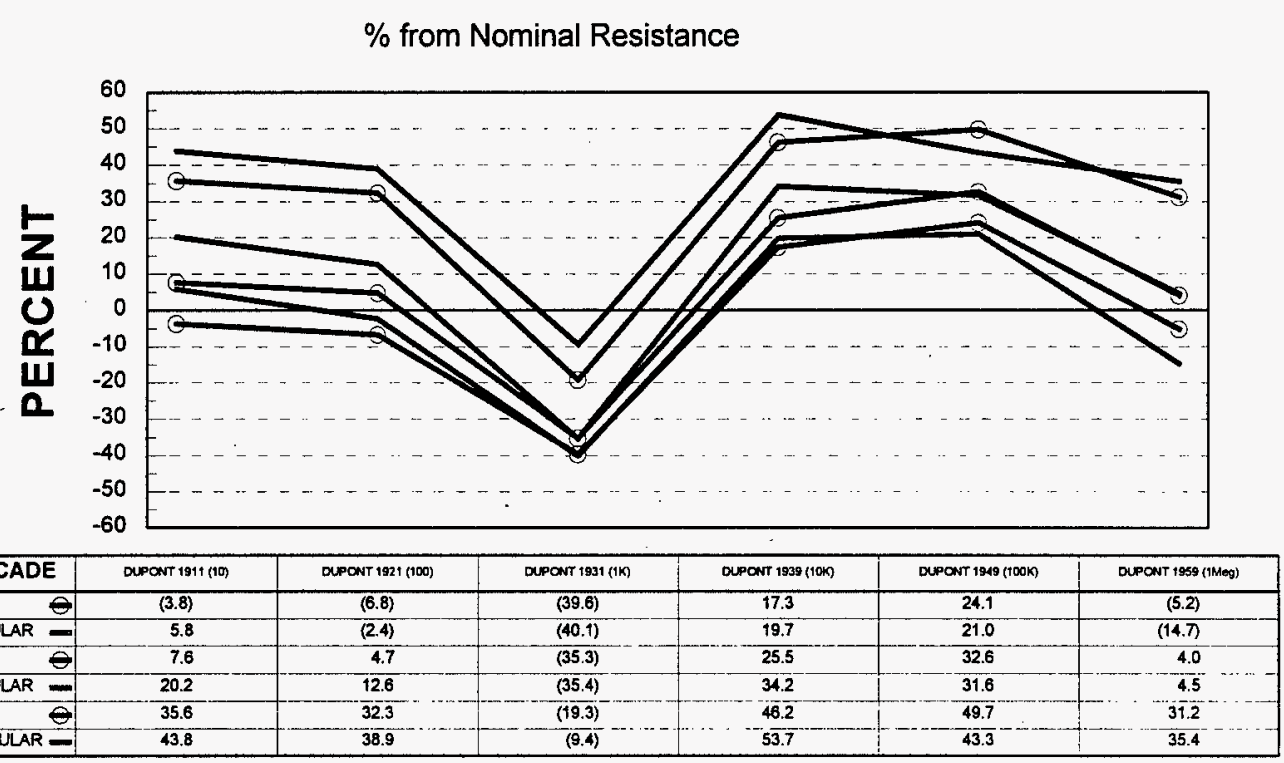

\begin{tabular}{|c|c|c|c|c|c|c|}
\hline RESISTOR DECADE & DUPONT 1911 (10) & DUPONT 1921 (100) & DUPONT 1931 (1K) & DUPOWr 1939 (10kn) & DUPONT 1949 (1000K) & DUPONT IOS9 (IMeg) \\
\hline $25 \mathrm{MIL}$ PARALIEL & (3.8) & $(6.8)$ & $(39.6)$ & 87.3 & 24.1 & $(5.2)$ \\
\hline 25 MIL PERPENDICULAR - & 5.8 & (2.4) & $(40.1)$ & 19.7 & 21.0 & $(14.7)$ \\
\hline 50 MLL PARALLEL & 7.6 & 4.7 & $(35.3)$ & 25.5 & 32.6 & 4.0 \\
\hline 100 ML PARALLEL & 35.6 & 32.3 & $(19.3)$ & 46.2 & 49.7 & 31.2 \\
\hline 100 MIL PERPENDICULAR - & 43.8 & 38.9 & $(9.4)$ & 53.7 & 43.3 & 35.4 \\
\hline
\end{tabular}

Samples were Fired at $850 \mathrm{deg}$. C \& Unglazed

Orientation Refers to Resistor Length Direction

Orientation is Relative to Squeegee Travel

Figure 1-11 


\section{APPENDIX 2}

\section{DUPONT 1400, 1900, \& 2000 RESISTOR SERIES COMPARATIVE DATA}




\section{UNTRIMMED SHEET RESISTANCE}

\section{DUPONT $14001900 \& 2000$ SERIES RESISTORS}

$\%$ from Nominal

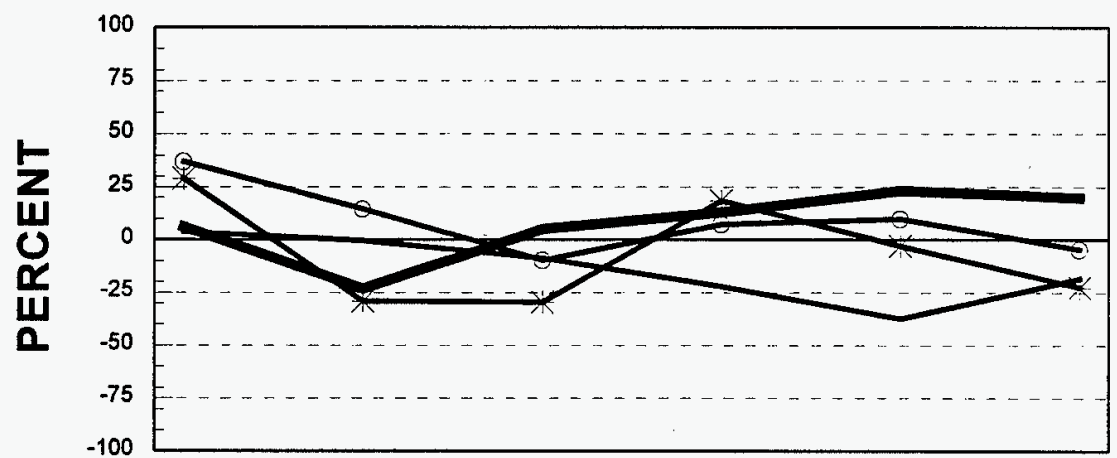

\begin{tabular}{|l|c|c|c|c|c|}
\hline RESISTOR DECADE & $10 \mathrm{OHM}$ & $100 \mathrm{OHM}$ & $1 \mathrm{KOHM}$ & $10 \mathrm{KOHM}$ & $100 \mathrm{KOHM}$ \\
\hline 1400 SERIES (ALO2) $-850 / 60$ & 6.0 & $(23.3)$ & 5.0 & 13.0 & 23.2 \\
\hline 1900 SERIES (2 DIE.) $-850 / 30$ & 29.1 & $(29.2)$ & $(29.6)$ & 18.5 & $(3.0)$ \\
\hline 1900 SERIES (LTCC) $-850 / 30$ & 36.9 & 14.5 & $(9.8)$ & 7.2 & $(22.6)$ \\
\hline 2000 SERIES (LTCC) $-850 / 30-$ & 3.7 & $(0.6)$ & $(8.8)$ & $(22.2)$ & $(37.6)$ \\
\hline
\end{tabular}

Data for Unglazed Samples

Data for All Geometry Combinations

Data Format indicates Substrate \& Firing Profile

Figure 2-1

\section{UNTRIMMED SHEET RESISTANCE}

\section{DUPONT $1400 \& 1900$ SERIES RESISTORS}

$\%$ from Nominal

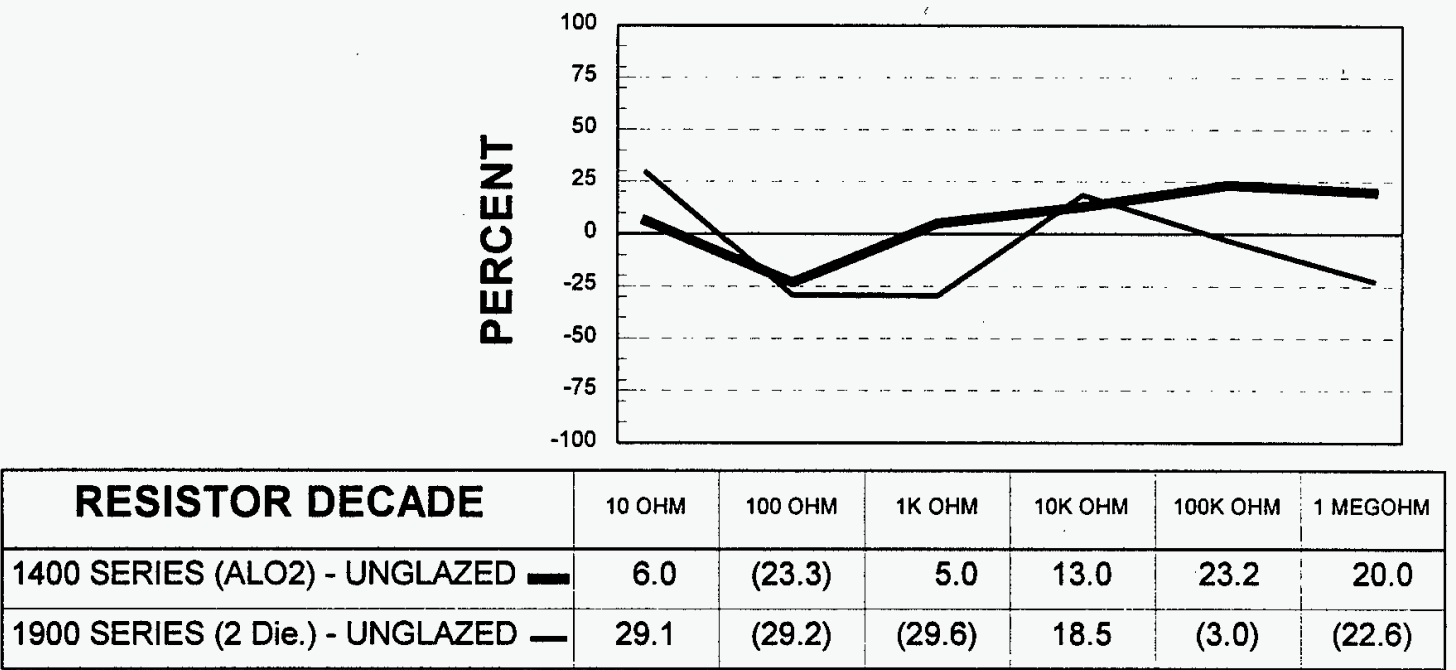

DuPont 1400 Fired @ 850 Deg. C - 60 Minutes

DuPont 1900 Fired @ 850 Deg. C - 30 Minutes

Data for All Geometry Combinations

Figure 2-2 


\section{UNTRIMMED SHEET RESISTANCE - DUPONT 1900 SERIES}

Substrate Comparison - LTCC vs. 2 Layers of Die.

$\%$ from Nominal

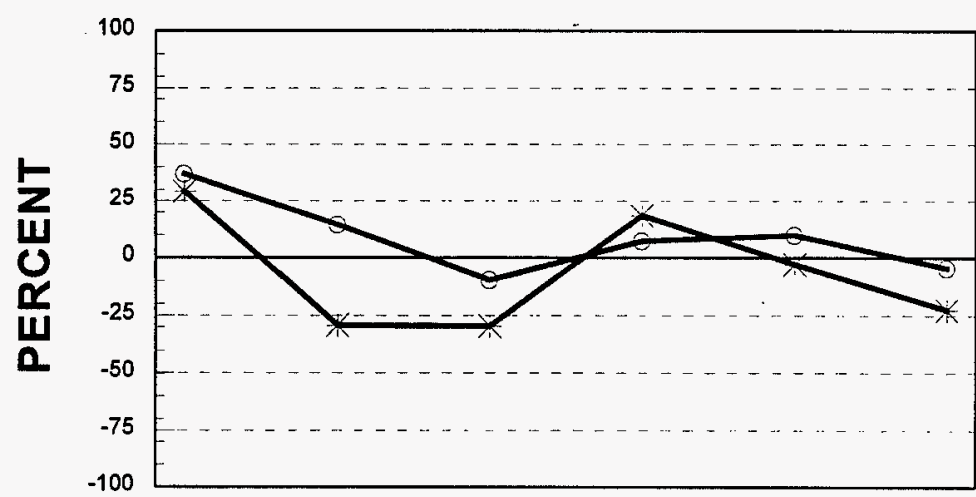

\begin{tabular}{|c|c|c|c|c|c|c|}
\hline RESISTOR DECADE & $10 \mathrm{OHM}$ & $100 \mathrm{OHM}$ & $1 \mathrm{~K} \mathrm{OHM}$ & $10 \mathrm{~K} \mathrm{OHM}$ & $100 \mathrm{OHM}$ & $1 \mathrm{MEGOHM}$ \\
\hline 1900 SERIES (2 DIE.) $-850 / 30 *$ & 29.1 & $(29.2)$ & $(29.6)$ & 18.5 & $(3.0)$ & $(22.6)$ \\
\hline 1900 SERIES (LTCC) $-850 / 30$ & -36.9 & 14.5 & $(9.8)$ & 7.2 & 9.8 & $(4.7)$ \\
\hline
\end{tabular}

Data for Unglazed Samples

Data for All Geometry Combinations

Data Format indicates Substrate \& Firing Profile

Figure 2-3 


\section{APPENDIX 3}

DUPONT 1911 RESISTOR PRINT DATA 


\section{UNTRIMMED RESISTANCE SUMMARY \\ DUPONT 1911 (10 OHMS PER SQUARE)}

Percent from Nominal - 2 Dielectrics
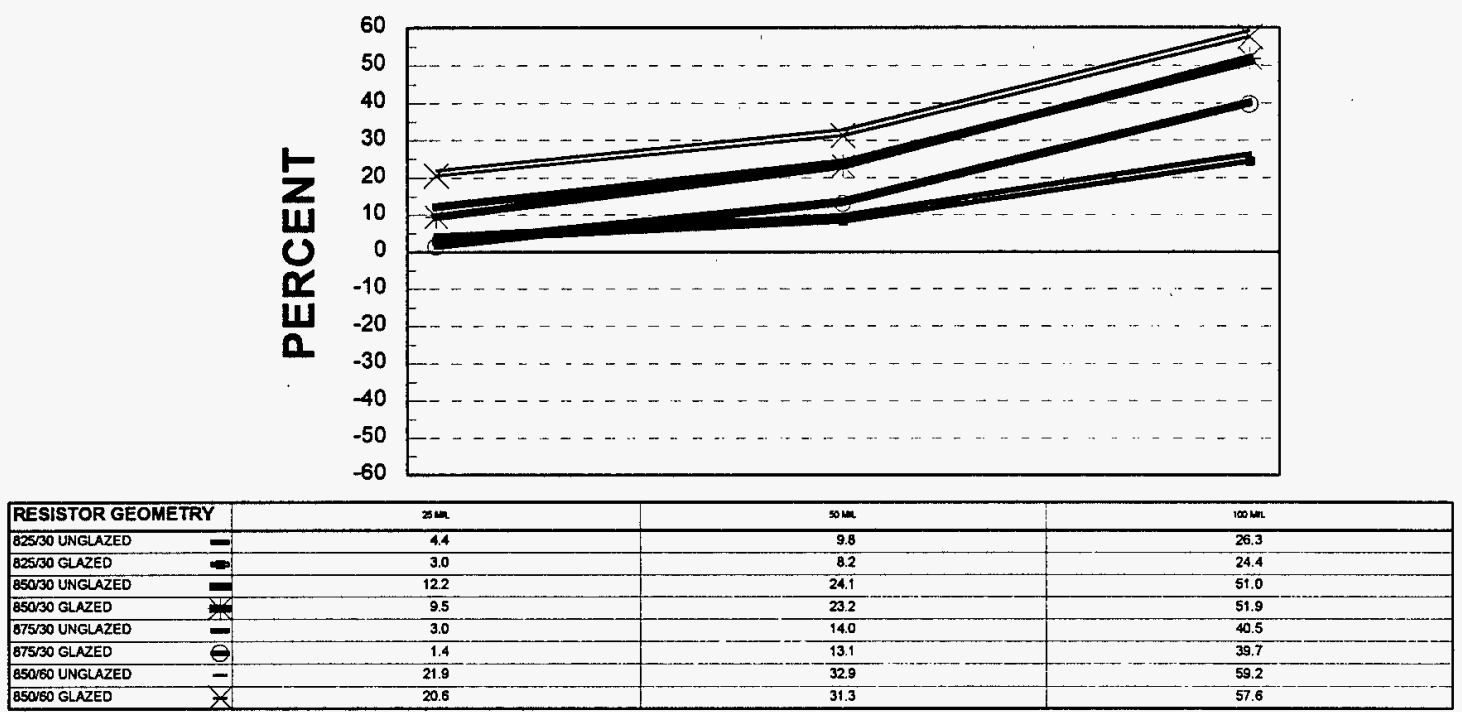

Nominal as-fired resistance is $20 \mathrm{ohms}$.

Target Dried Thickness is $\mathbf{2 5}$ Microns

Figure 3-1

\section{UNTRIMMED RESISTANCE SUMMARY DUPONT 1911 (10 OHMS PER SQUARE)}

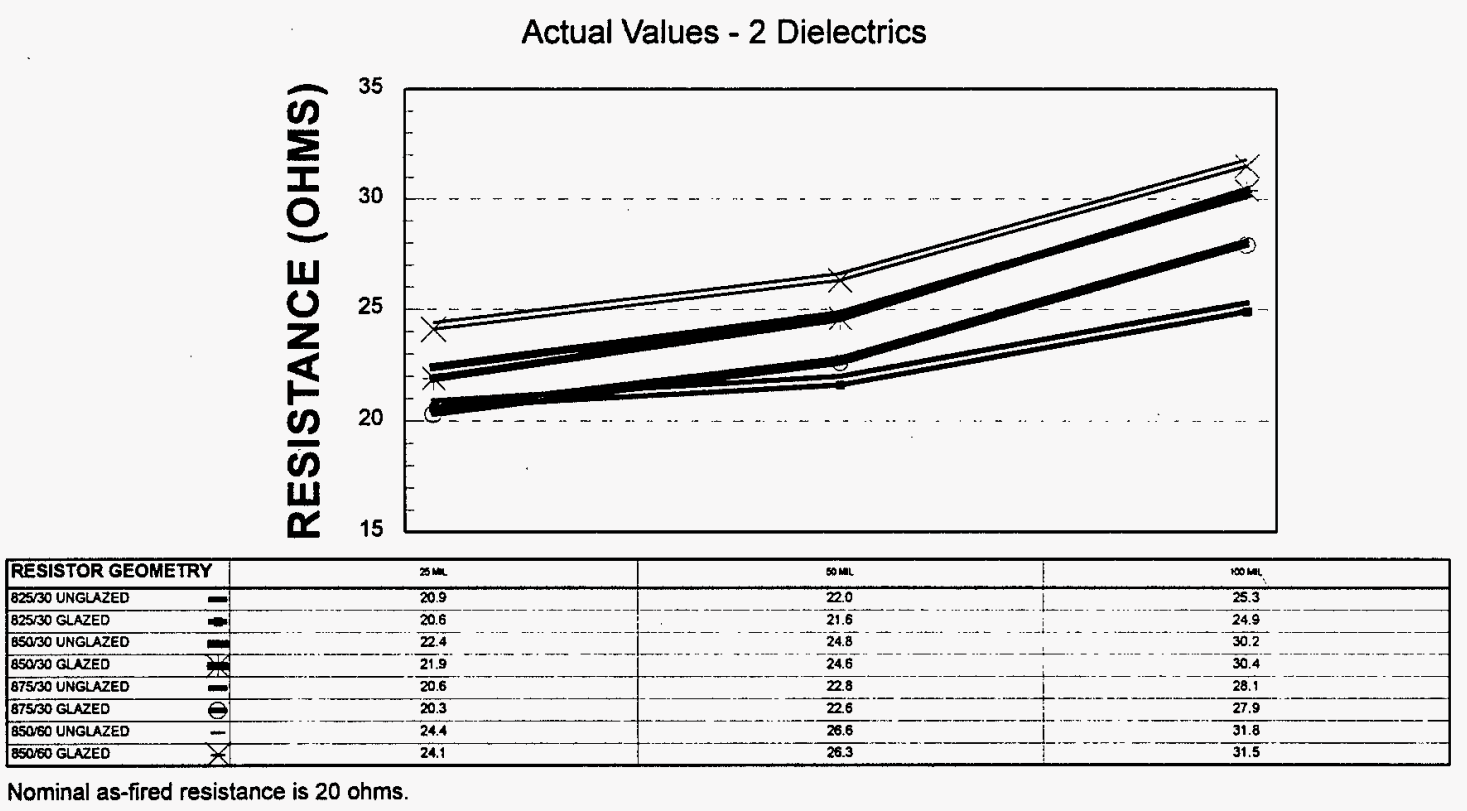

Figure 3-2 


\section{NORMALIZED SHEET RESISTANCE DUPONT 1911 (10 OHMS PER SQUARE)}

Percent from Nominal - 2 Dielectrics

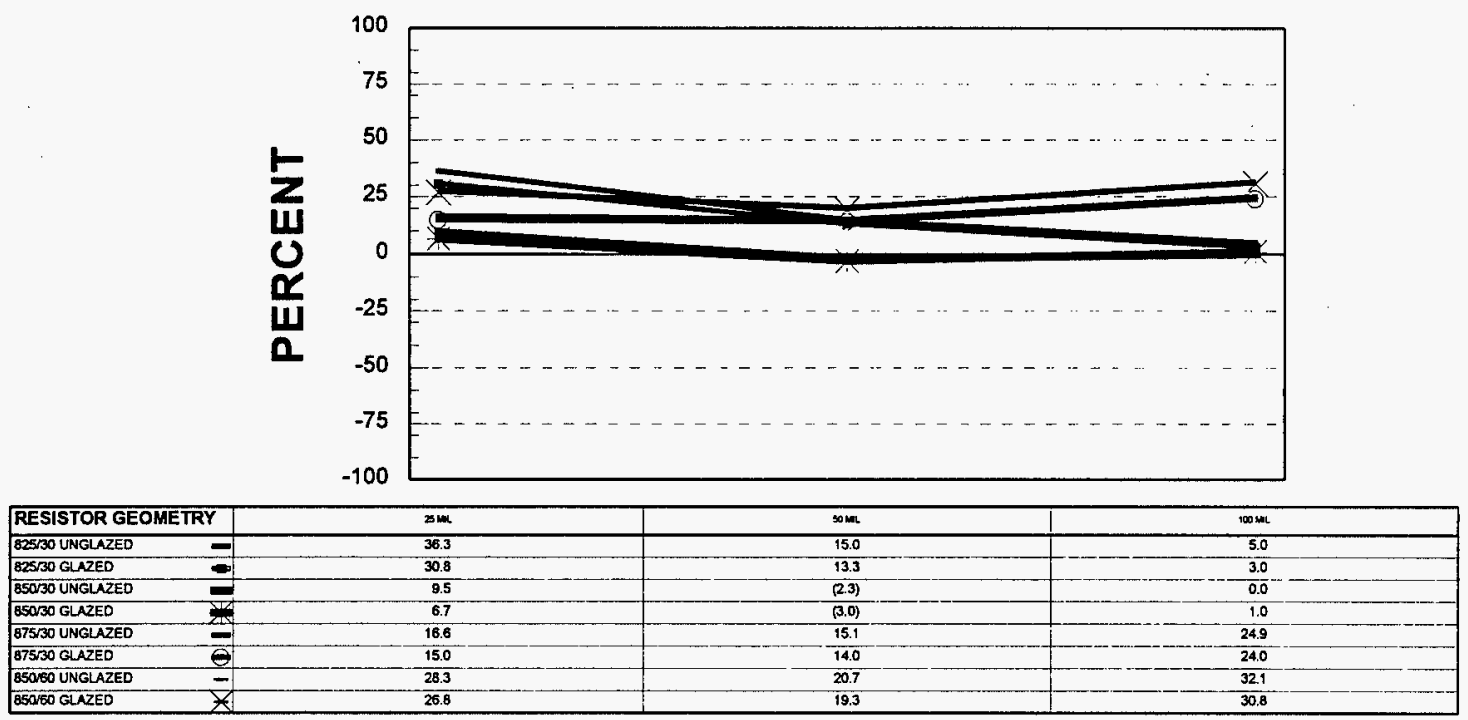

Nominal as-fired resistance is 20 ohms

Target Dried Thickness is 25 Microns

Figure 3-3

\section{NORMALIZED SHEET RESISTANCE}

\section{DUPONT 1911 (10 OHMS PER SQUARE)}

Actual Values - 2 Dielectrics
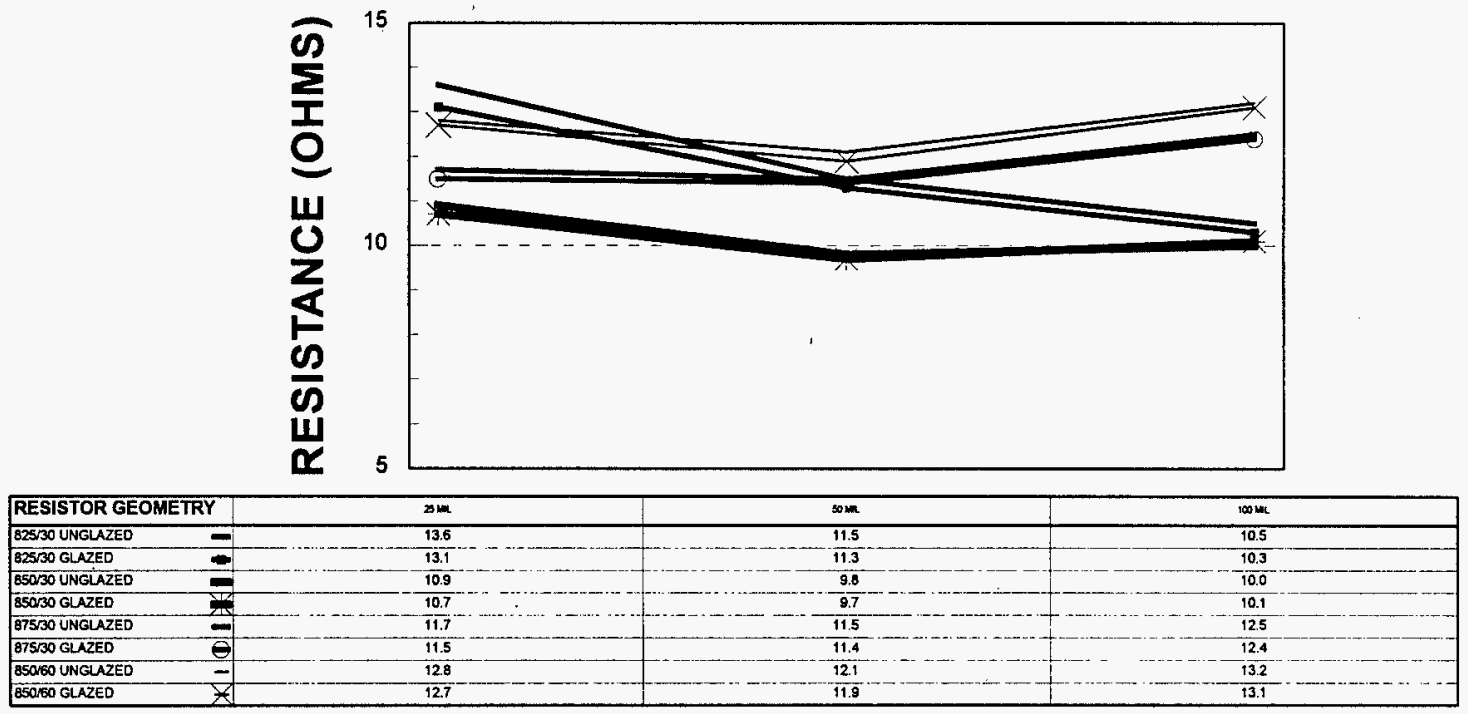

Nominal as-fired resistance is 20 ohms.

Target D́ried Thickness is 25 Microns

Figure 3-4 


\section{THICKNESS \& RESISITIVITY COMPARISON DUPONT 1911 (10 OHMS PER SQUARE)}

Actual Values - 2 Dielectrics
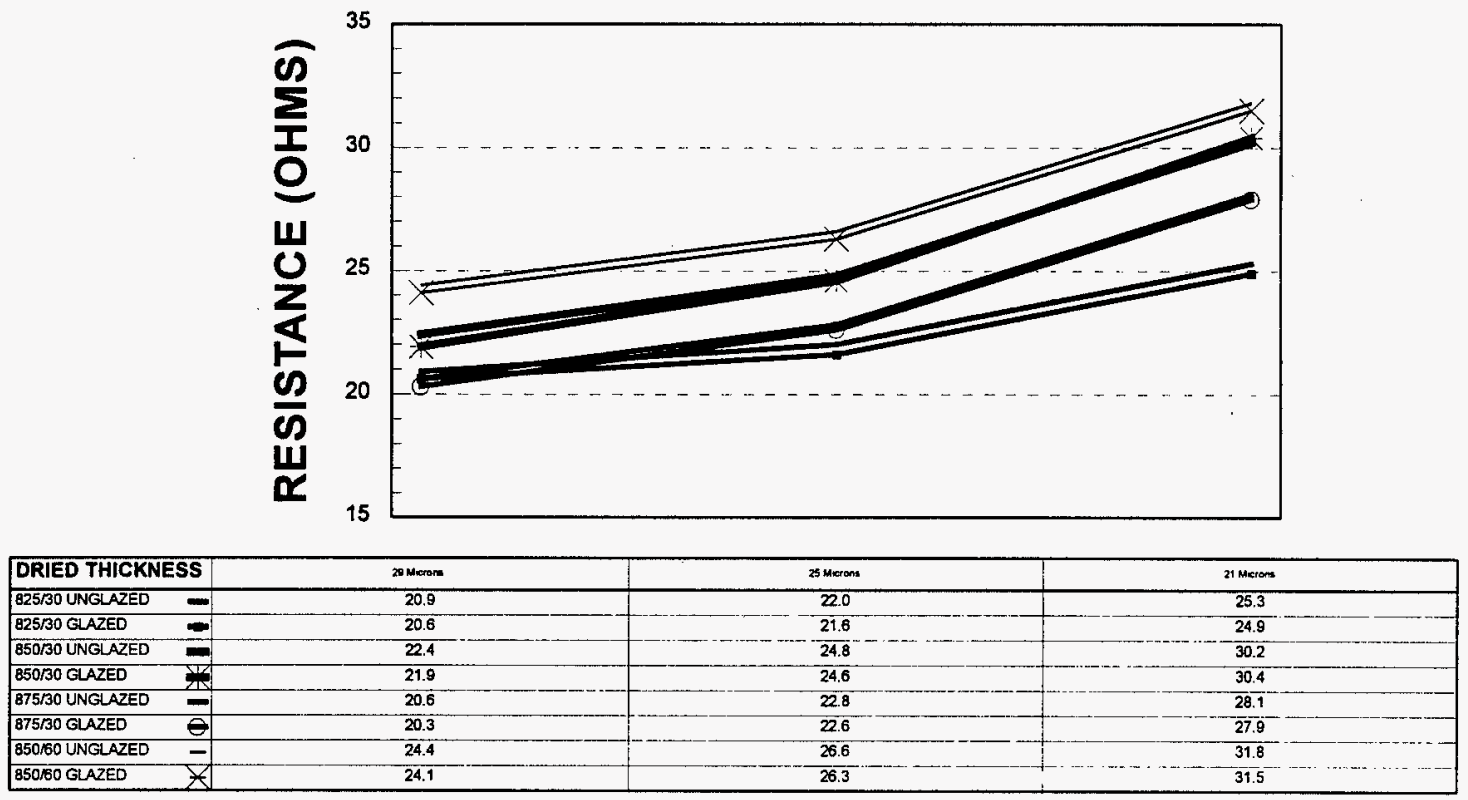

Figure 3-5

\section{THICKNESS RELATIONSHIP}

\section{DUPONT 1911 (10 OHMS PER SQUARE)}

Printed on 2 Dielectrics

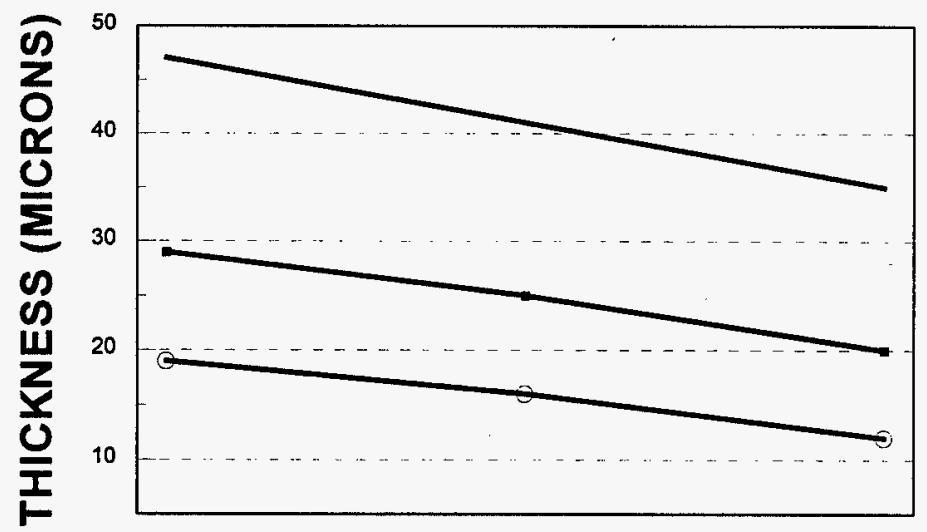

\begin{tabular}{|l|c|c|c|}
\hline GEOMETRY & $25 \mathrm{MIL}$ & $50 \mathrm{MIL}$ & $100 \mathrm{MIL}$ \\
\hline WET THICKNESS - & 47 & 41 & 35 \\
\hline DRIED THICKNESS - & 29 & 25 & 20 \\
\hline FIRED THICKNESS - & 19 & 16 & 12 \\
\hline
\end{tabular}

Figure 3-6 


\section{APPENDIX 4}

\section{DUPONT 1921 RESISTOR PRINT DATA}




\section{UNTRIMMED RESISTANCE SUMMARY DUPONT 1921 (100 OHMS PER SQUARE)}

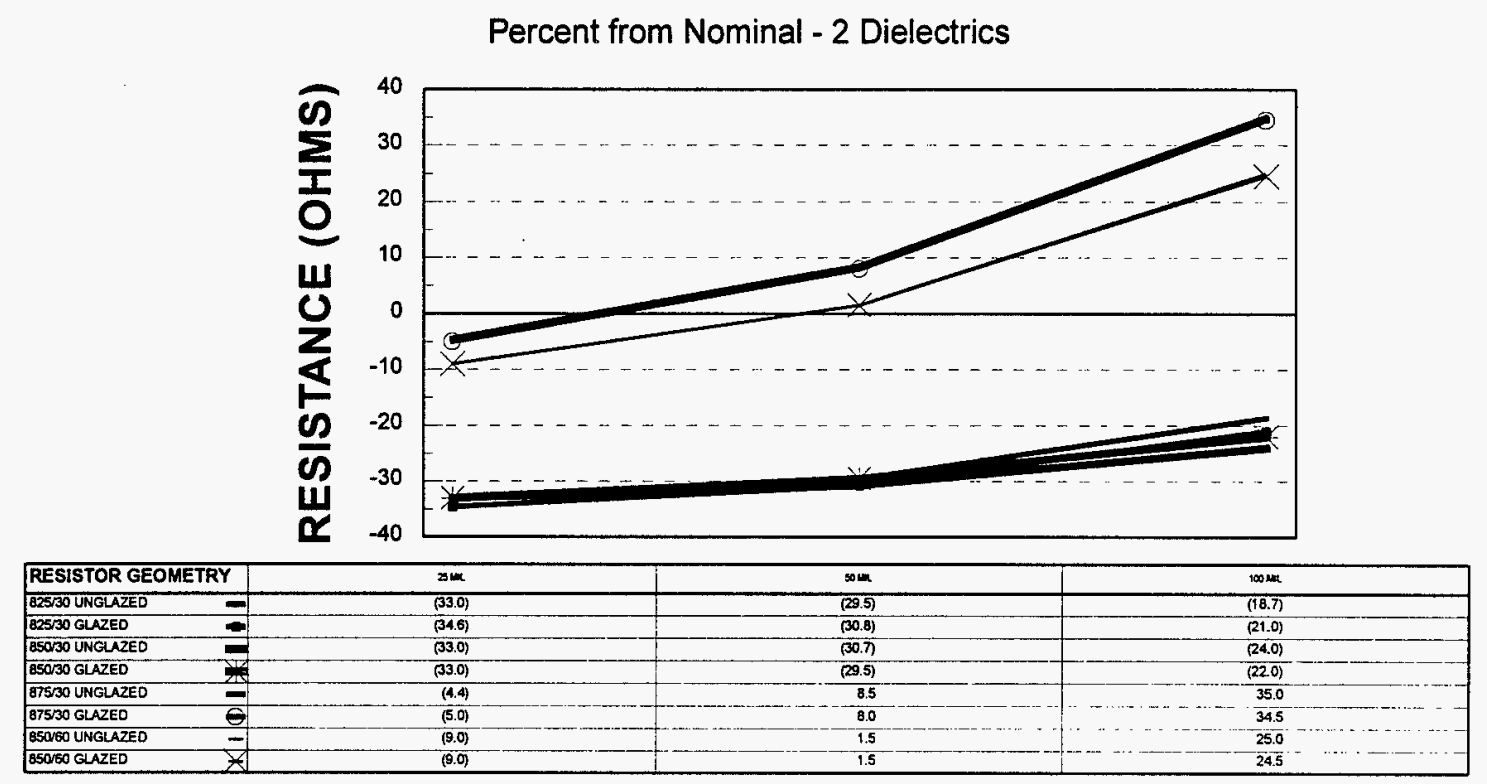

Nominal as-fired resistance is $200 \mathrm{ohms}$.

Target Dried Thickness is $\mathbf{2 5}$ microns

Figure 4-1

\section{UNTRIMMED RESISTANCE SUMMARY \\ DUPONT 1921 (100 OHMS PER SQUARE)}

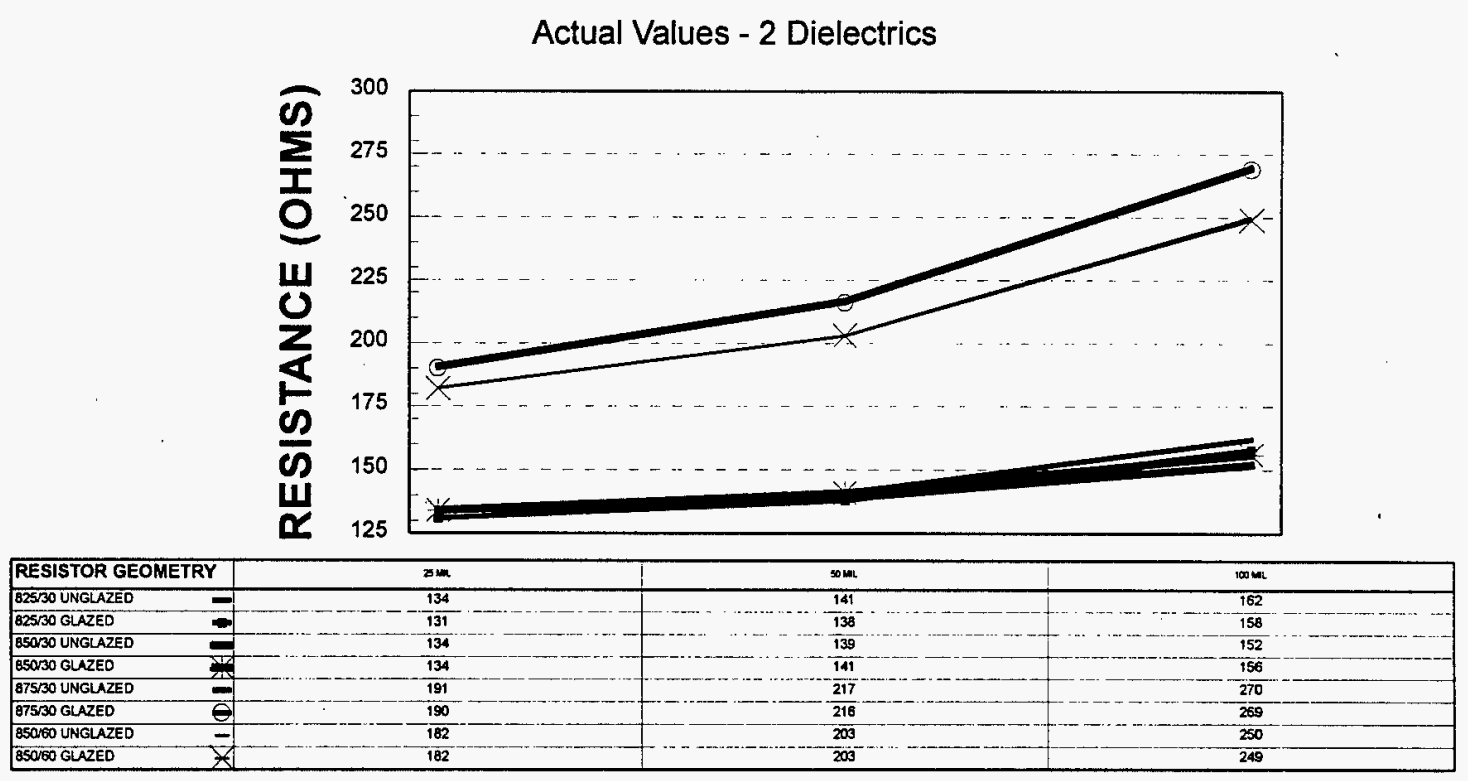

Nominal as-fired resistance is 200 ohms.

Target Dried Thickness is 25 microns

Figure 4-2 


\section{NORMALIZED SHEET RESISTANCE}

\section{DUPONT 1921 (100 OHMS PER SQUARE)}

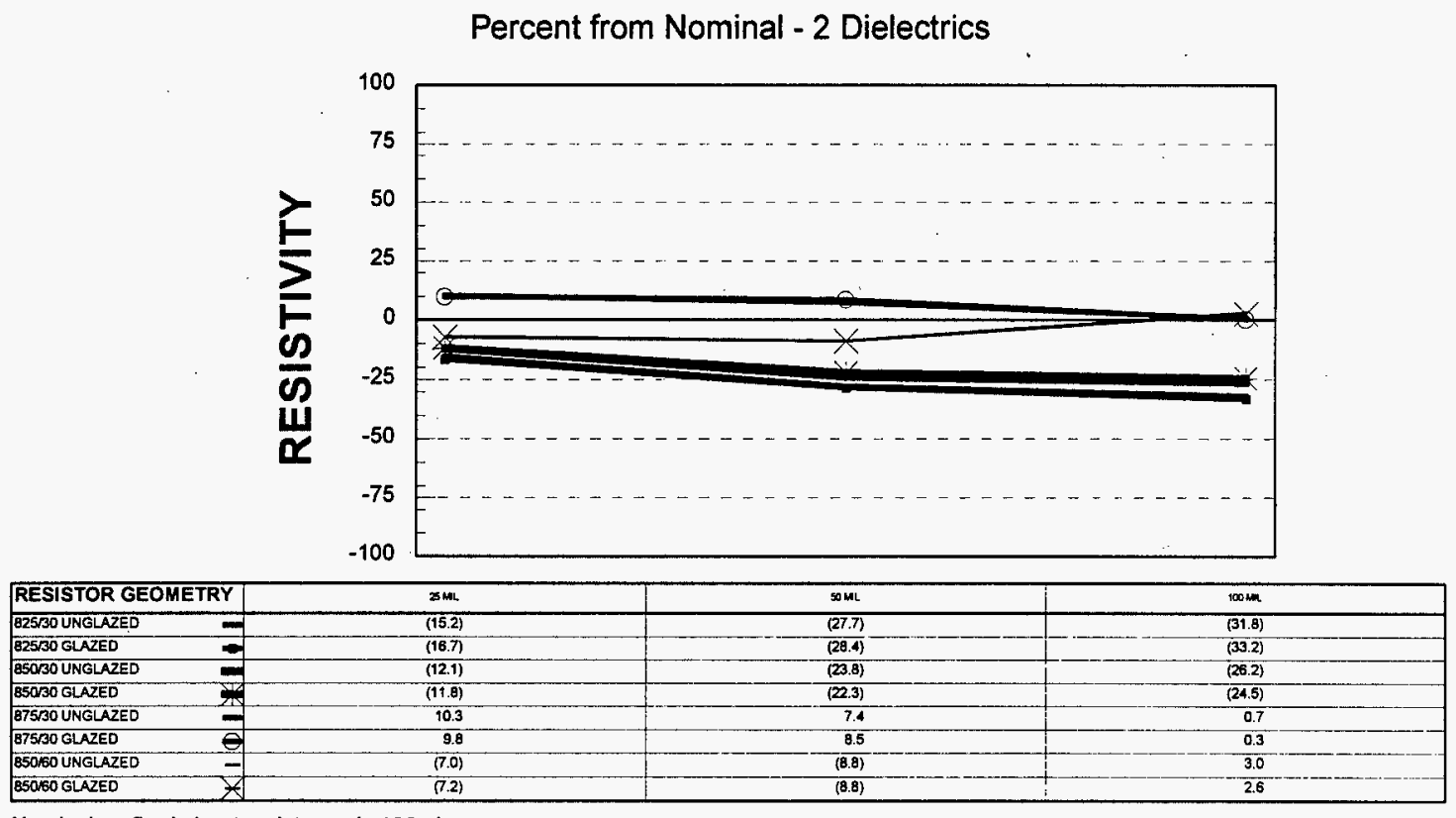

Figure 4-3

\section{NORMALIZED SHEET RESISTANCE}

\section{DUPONT 1921 (100 OHMS PER SQUARE)}

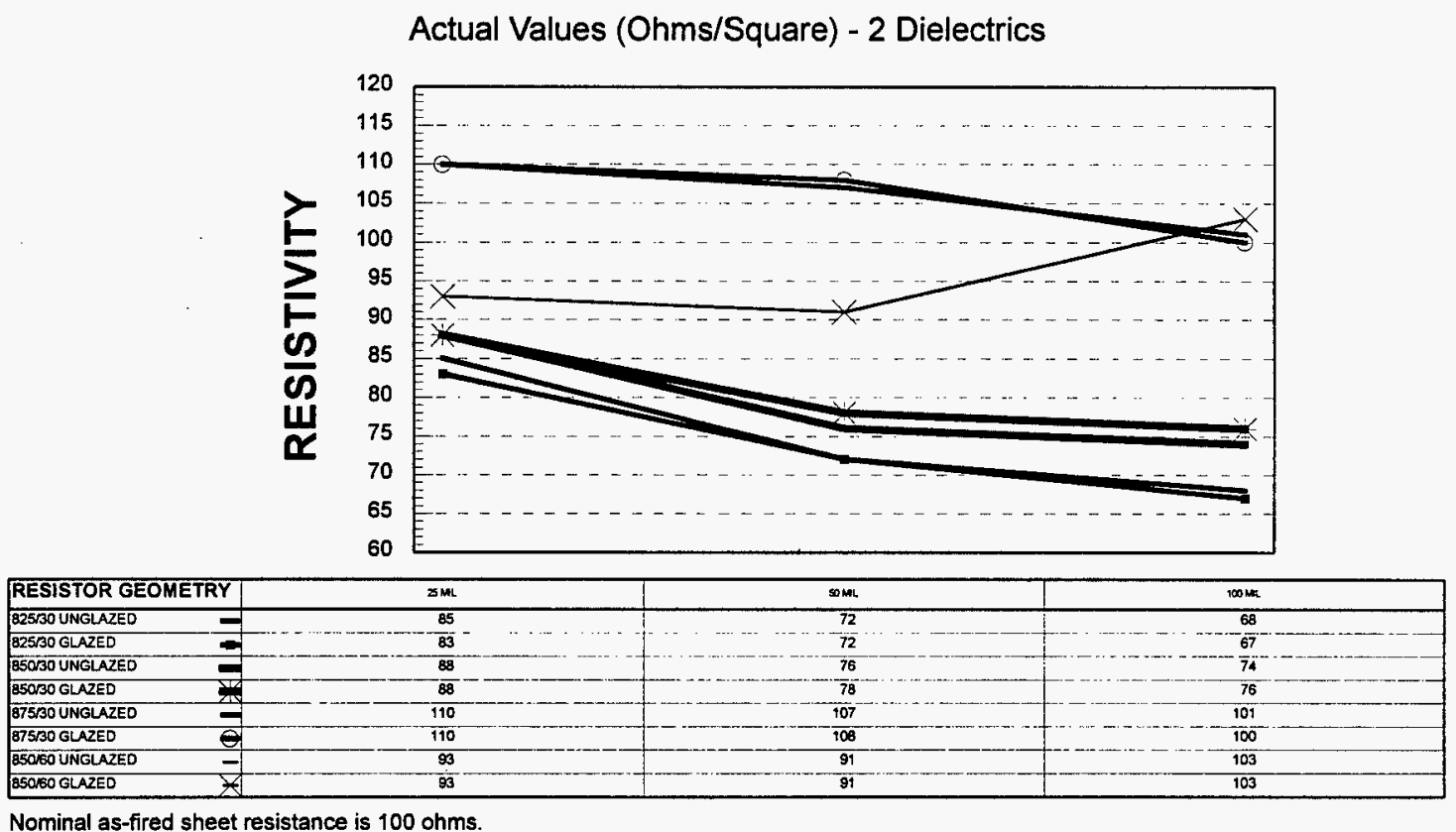

Figure 4-4 


\section{THICKNESS \& RESISITIVITY COMPARISON}

\section{DUPONT 1921 (100 OHMS PER SQUARE)}

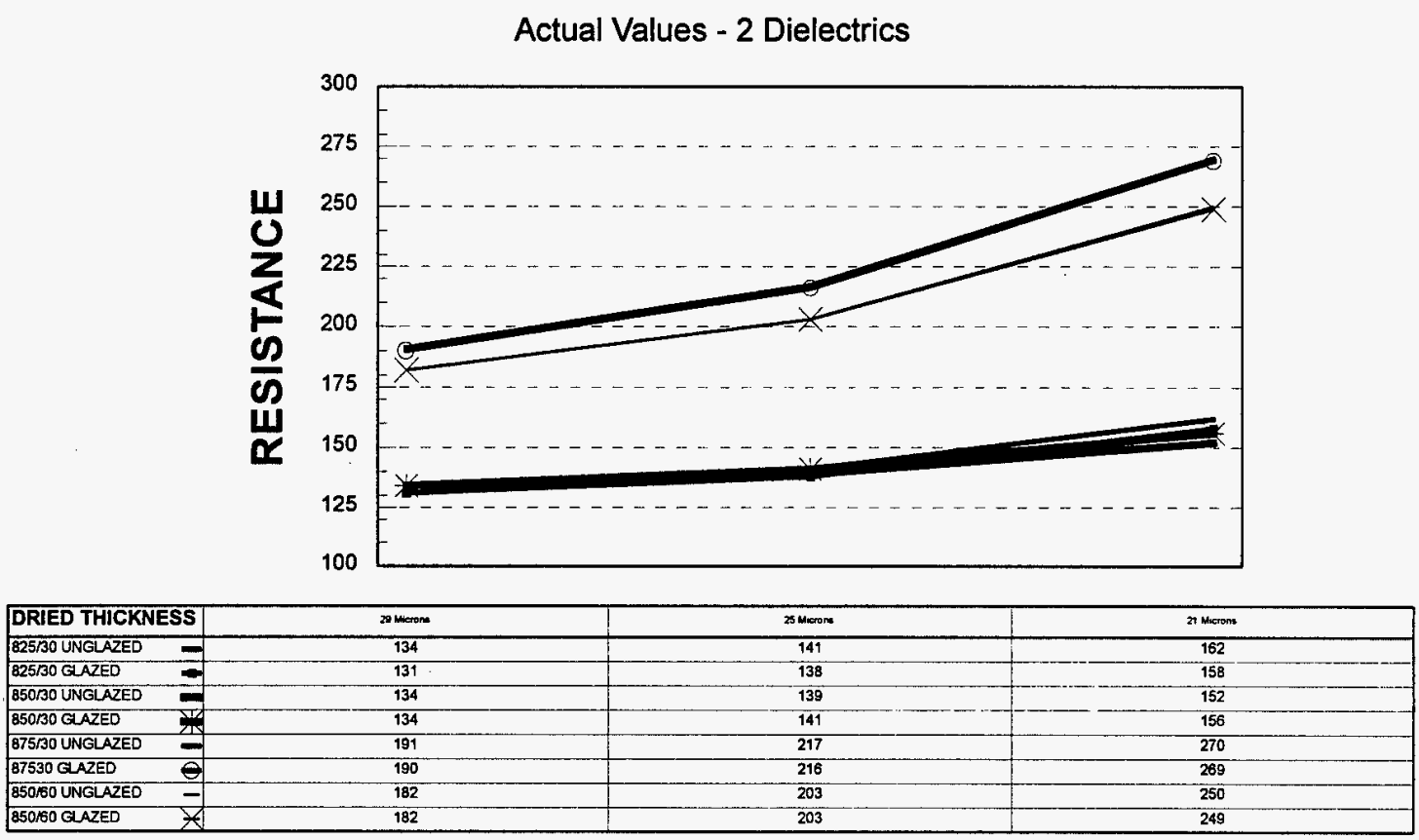

Figure 4-5

\section{THICKNESS RELATIONSHIP}

\section{DUPONT 1921 (100 OHMS PER SQUARE)}

Printed on 2 Dielectrics

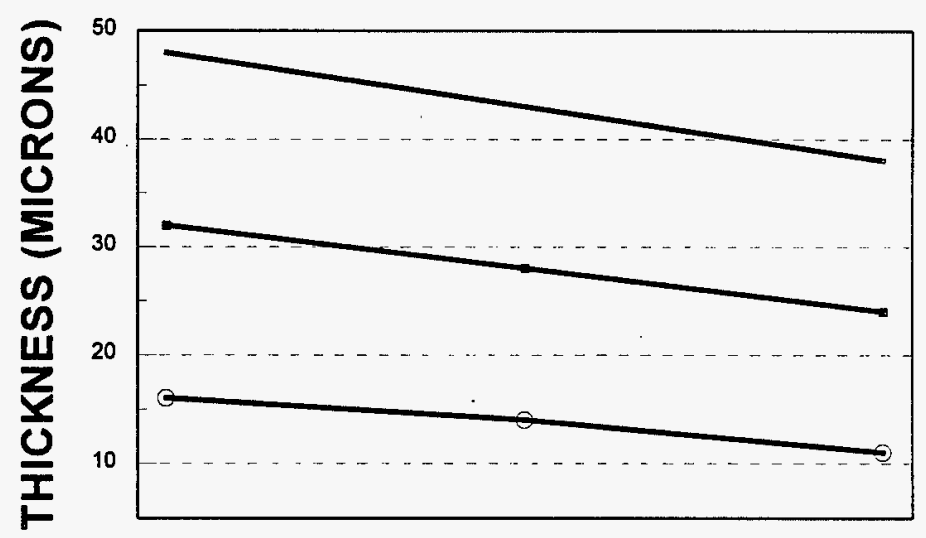

\begin{tabular}{|l|c|c|c|}
\hline \multicolumn{1}{|c|}{ GEOMETRY } & $25 \mathrm{ML}$ & $50 \mathrm{MLL}$ & $100 \mathrm{MIL}$ \\
\hline WET THICKNESS - & 48 & 43 & 38 \\
\hline DRIED THICKNESS - & 32 & 28 & 24 \\
\hline FIRED THICKNESS - & 16 & 14 & 11 \\
\hline
\end{tabular}

Figure 4-6 


\section{APPENDIX 5}

\section{DUPONT 1931 RESISTOR PRINT DATA}




\section{UNTRIMMED RESISTANCE SUMMARY \\ DUPONT 1931 (1K OHM PER SQUARE)}

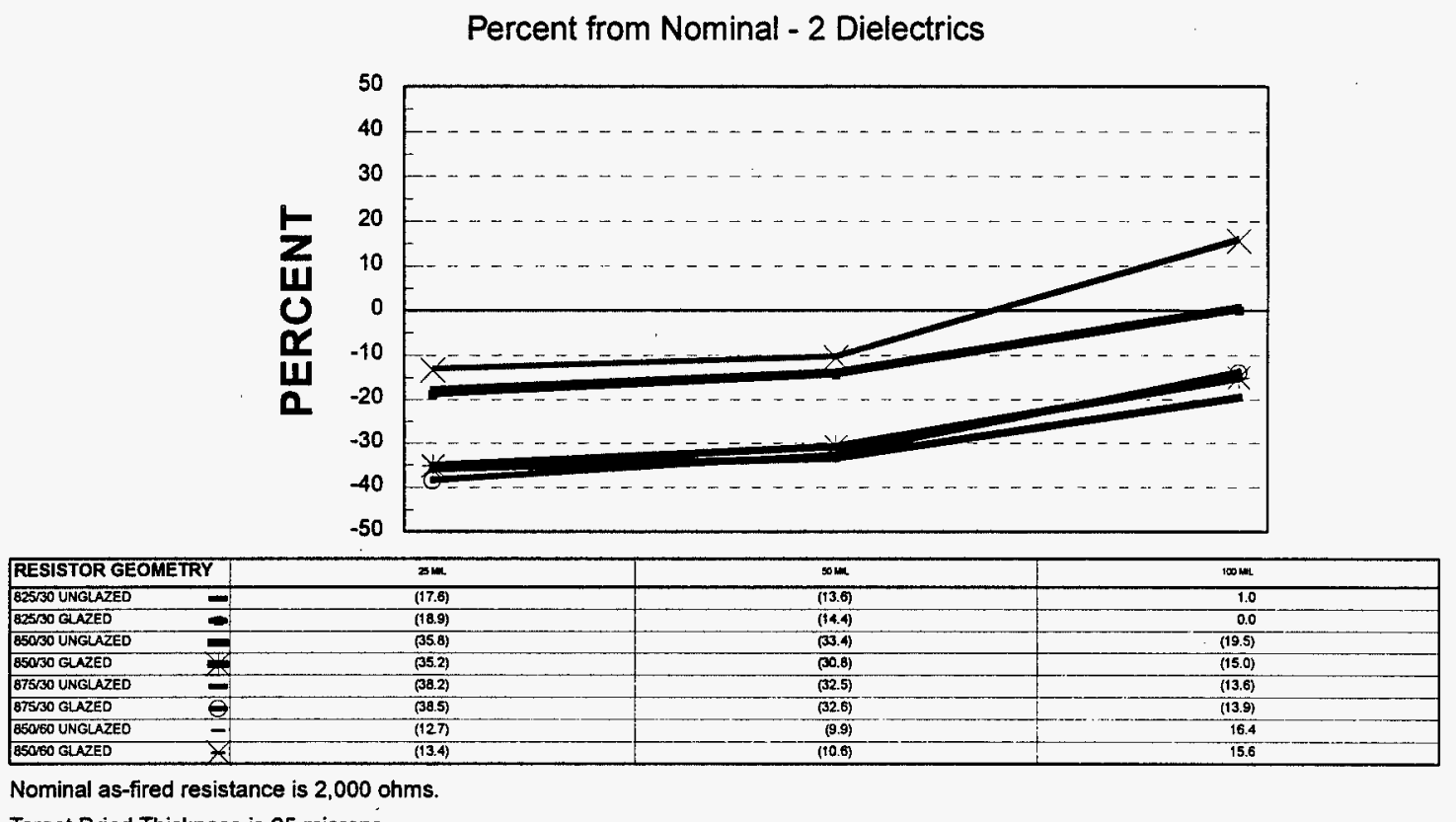

Figure 5-1

\section{UNTRIMMED RESISTANCE SUMMARY \\ DUPONT 1931 (1K OHM PER SQUARE)}

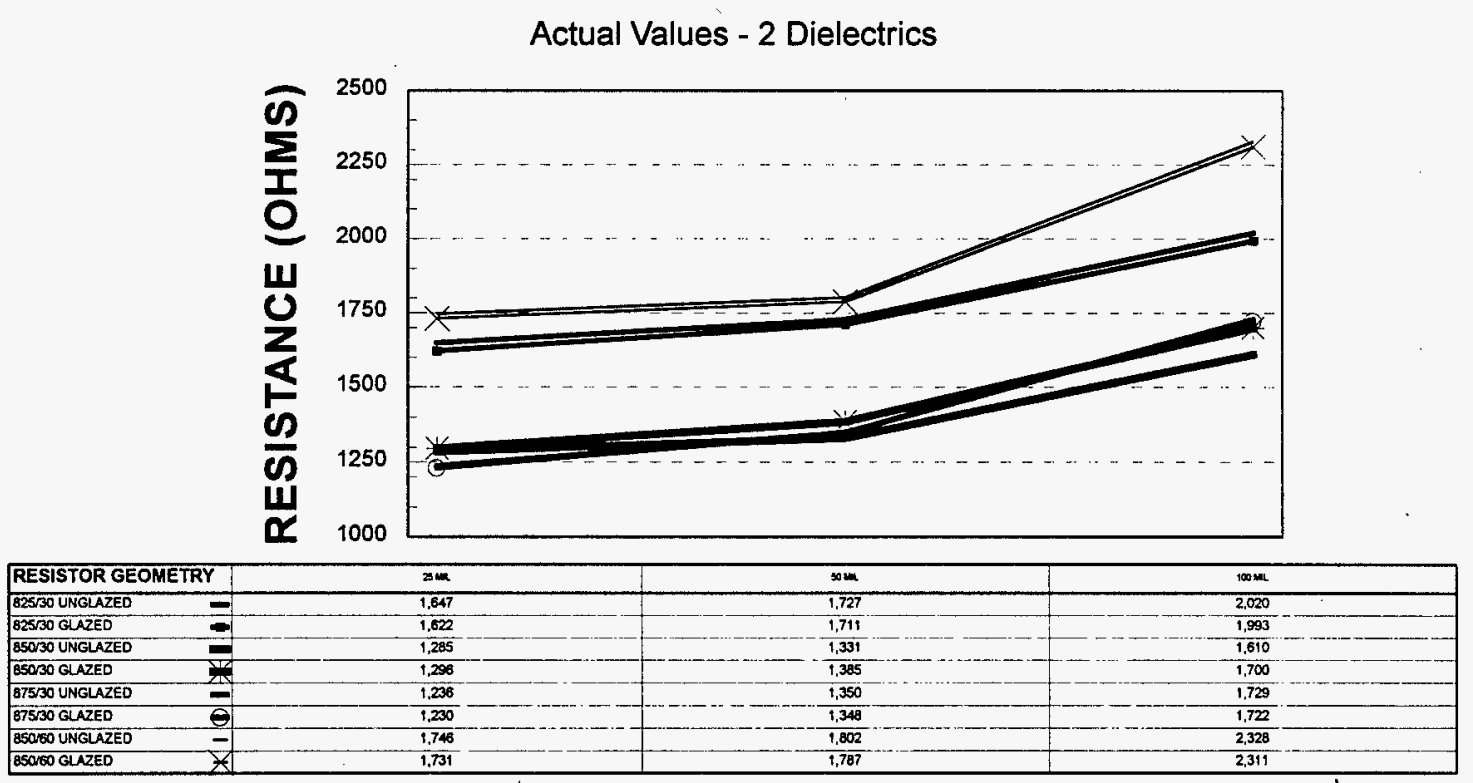

Nominal as-fired resistance is 2,000 ohms.

Target Dried Thickness is 25 microns

Figure 5-2 


\section{NORMALIZED SHEET RESISTANCE \\ DUPONT 1931 (1K OHM PER SQUARE)}

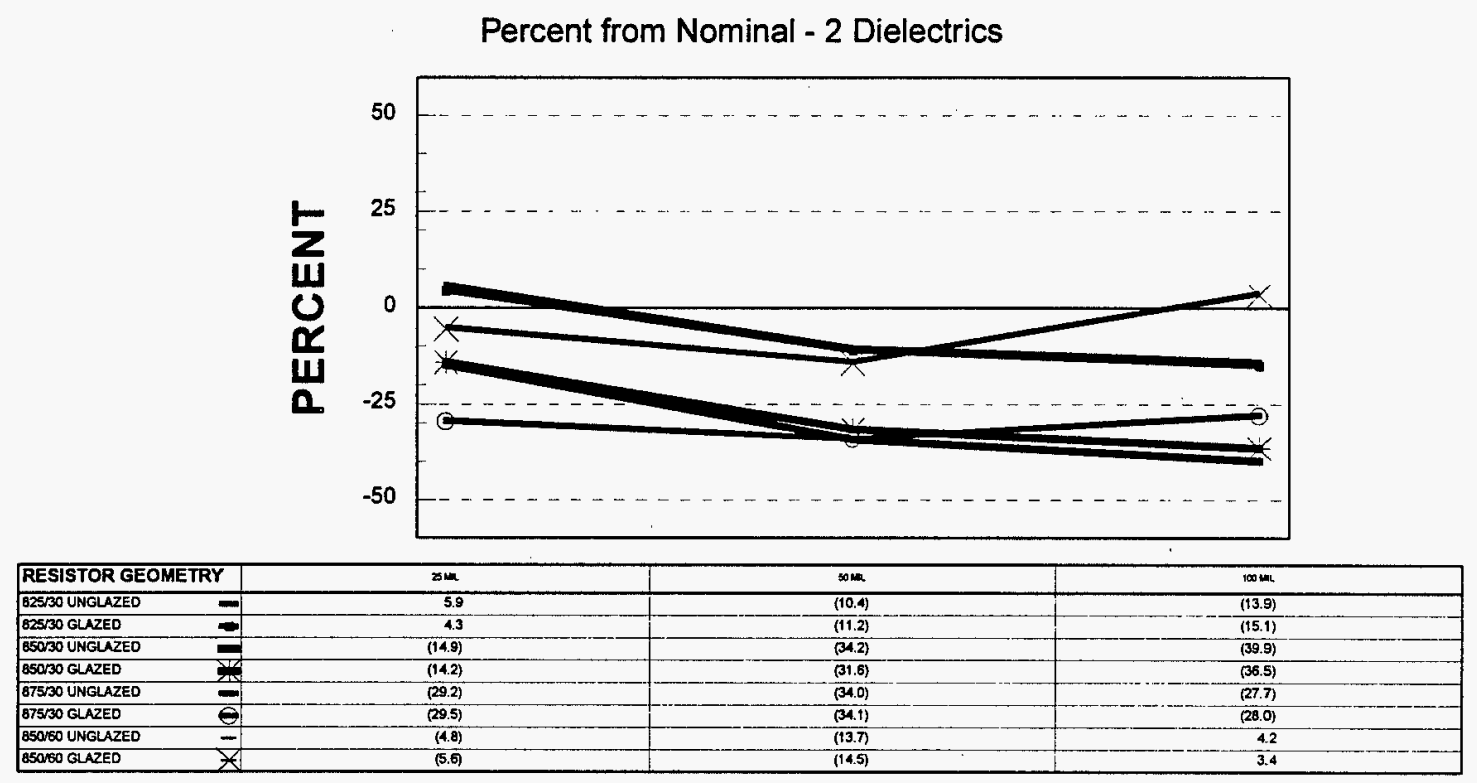

Nominal as-fired resistance is 2,000 ohms.

Target Dried Thickness is 25 microns

Figure 5-3

\section{NORMALIZED SHEET RESISTANCE}

\section{DUPONT 1931 (1K OHM PER SQUARE)}

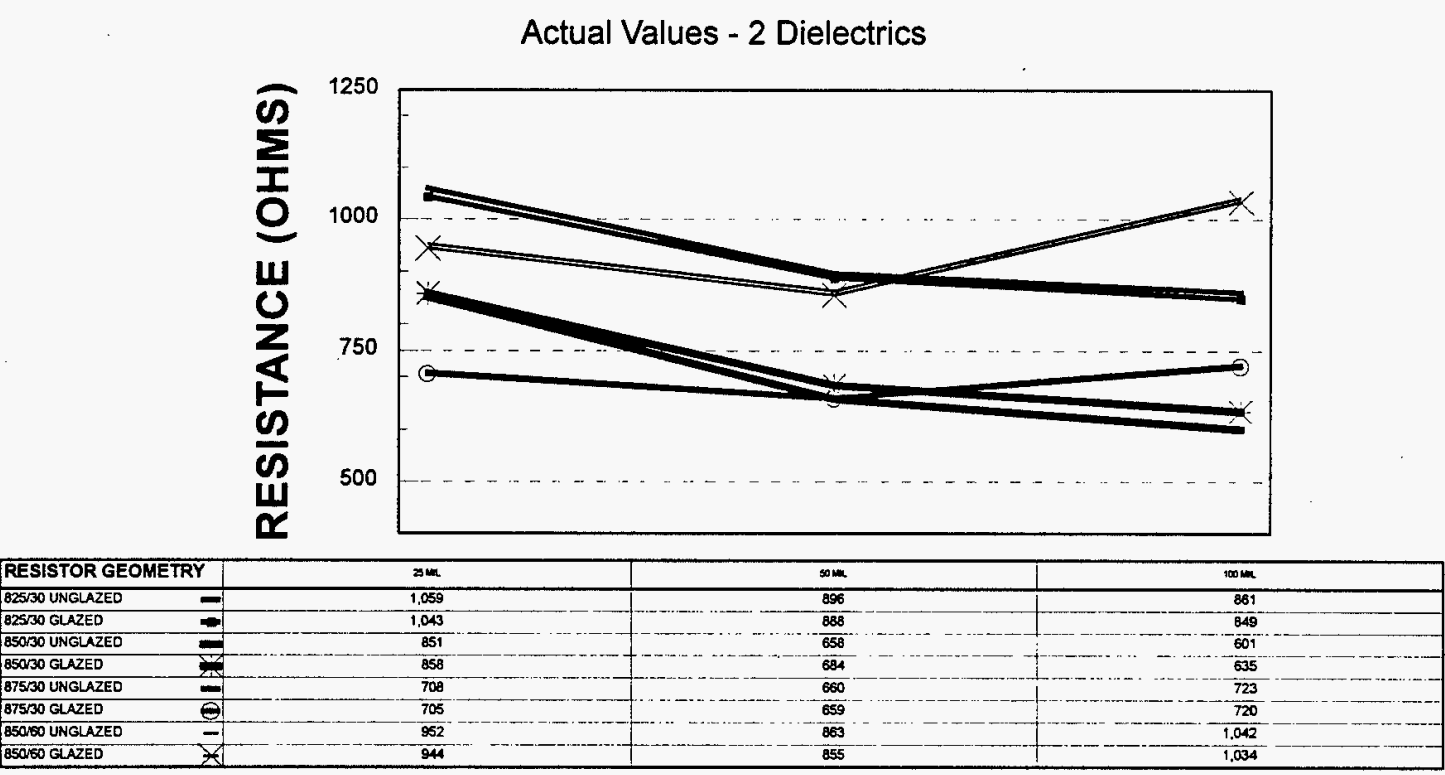

Nominal as-fired resistance is 2,000 ohms.

Target Dried Thickness is 25 microns

Figure 5-4 


\section{THICKNESS \& RESISITIVITY COMPARISON}

\section{DUPONT 1931 (1K OHM PER SQUARE)}

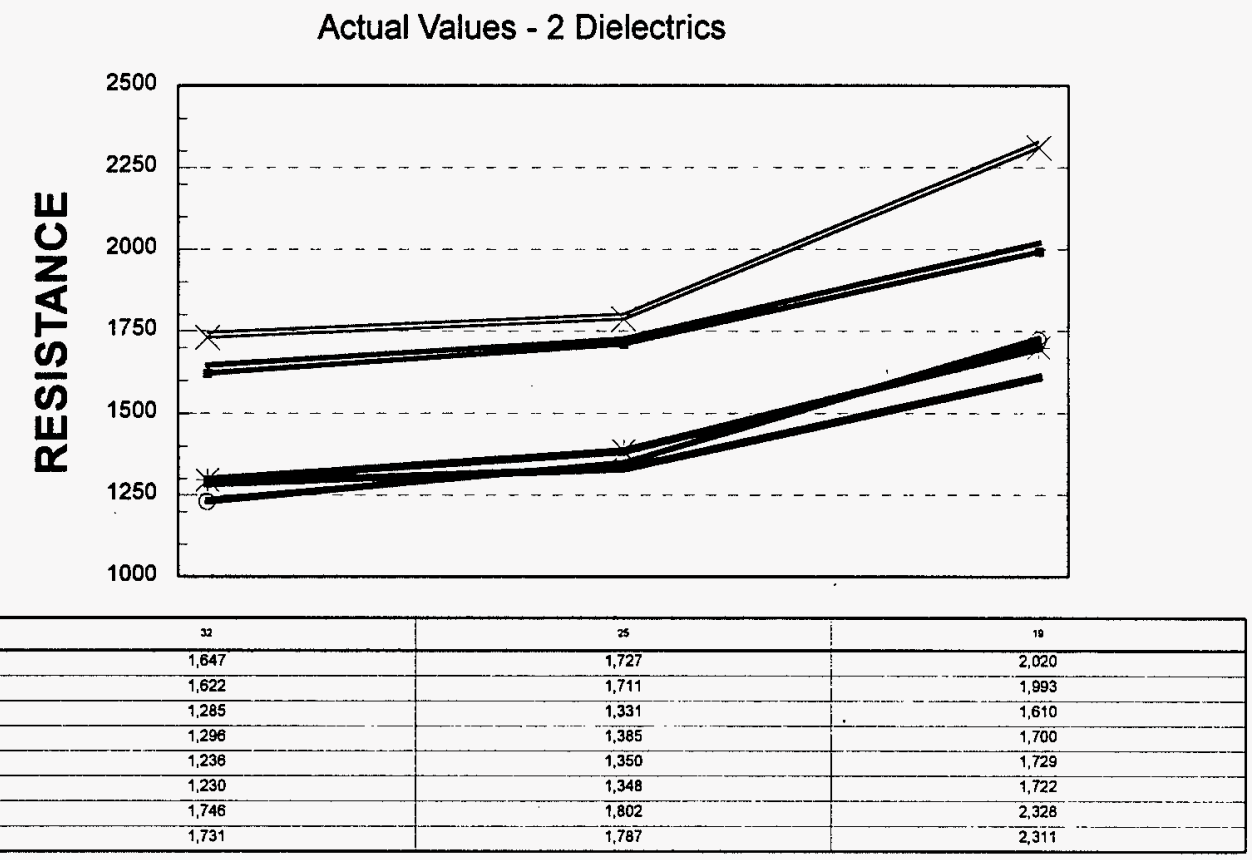

Figure 5-5

\section{THICKNESS RELATIONSHIP}

\section{DUPONT 1931 (1K OHM PER SQUARE)}

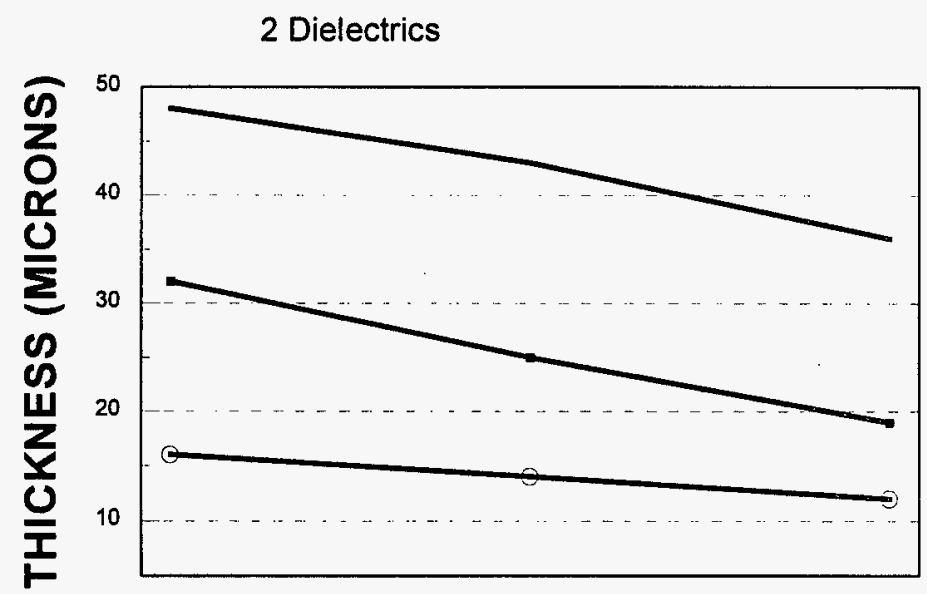

\begin{tabular}{|l|c|c|c|}
\hline \multicolumn{1}{|c|}{ GEOMETRY } & $25 \mathrm{MIL}$ & $50 \mathrm{MIL}$ & $100 \mathrm{MIL}$ \\
\hline WET THICKNESS - & 48 & 43 & 36 \\
\hline DRIED THICKNESS & 32 & 25 & 19 \\
\hline FIRED THICKNESS - & 16 & 14 & 12 \\
\hline
\end{tabular}

Figure 5-6 


\section{APPENDIX 6}

\section{DUPONT 1939 RESISTOR PRINT DATA}




\section{UNTRIMMED RESISTANCE SUMMARY}

\section{DUPONT 1939 (10K OHMS PER SQUARE)}

Percent from Nominal - 2 Dielectrics

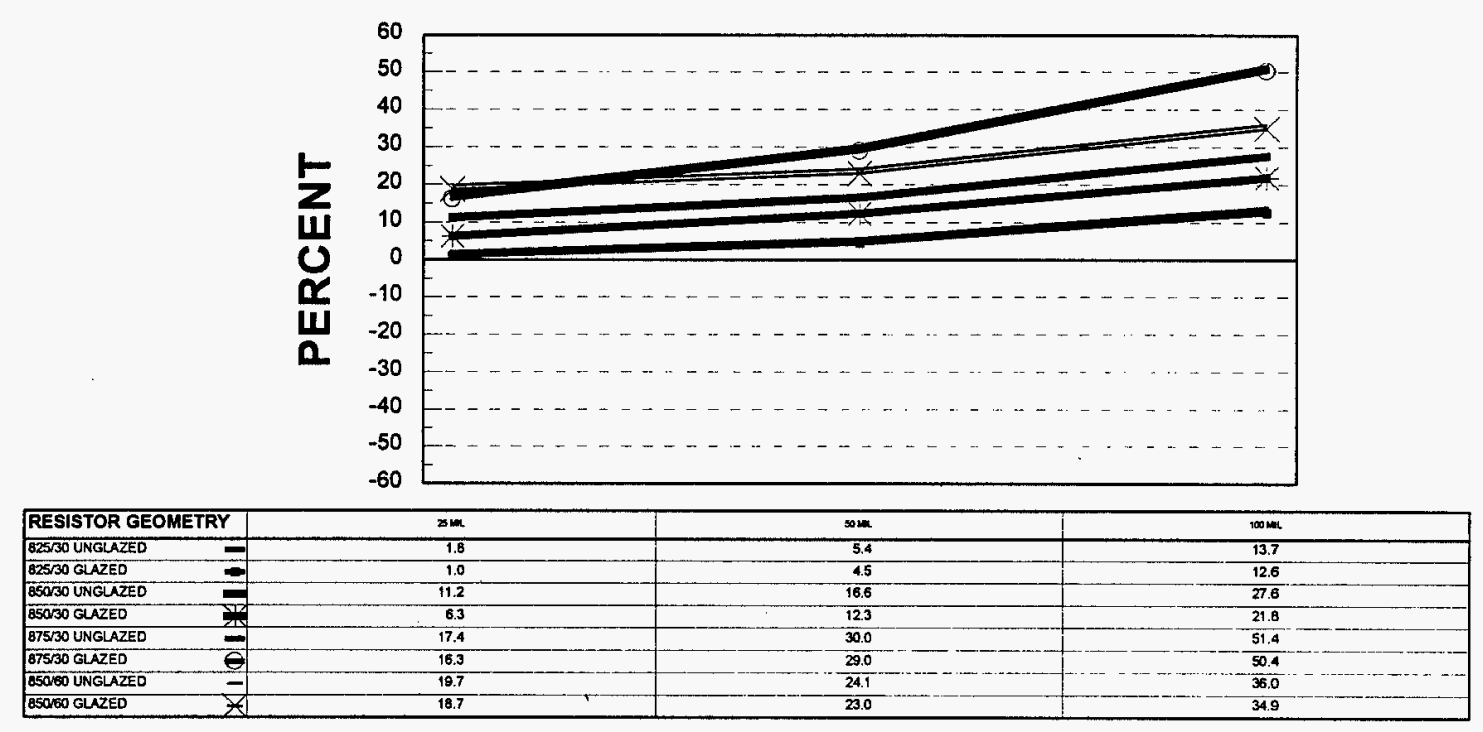

Nominal as-fired resistance is $20,000 \mathrm{ohms}$.

Target Dried Thickness is 25 microns

Figure 6-1

\section{UNTRIMMED RESISTANCE SUMMARY}

\section{DUPONT 1939 (10K OHMS PER SQUARE)}

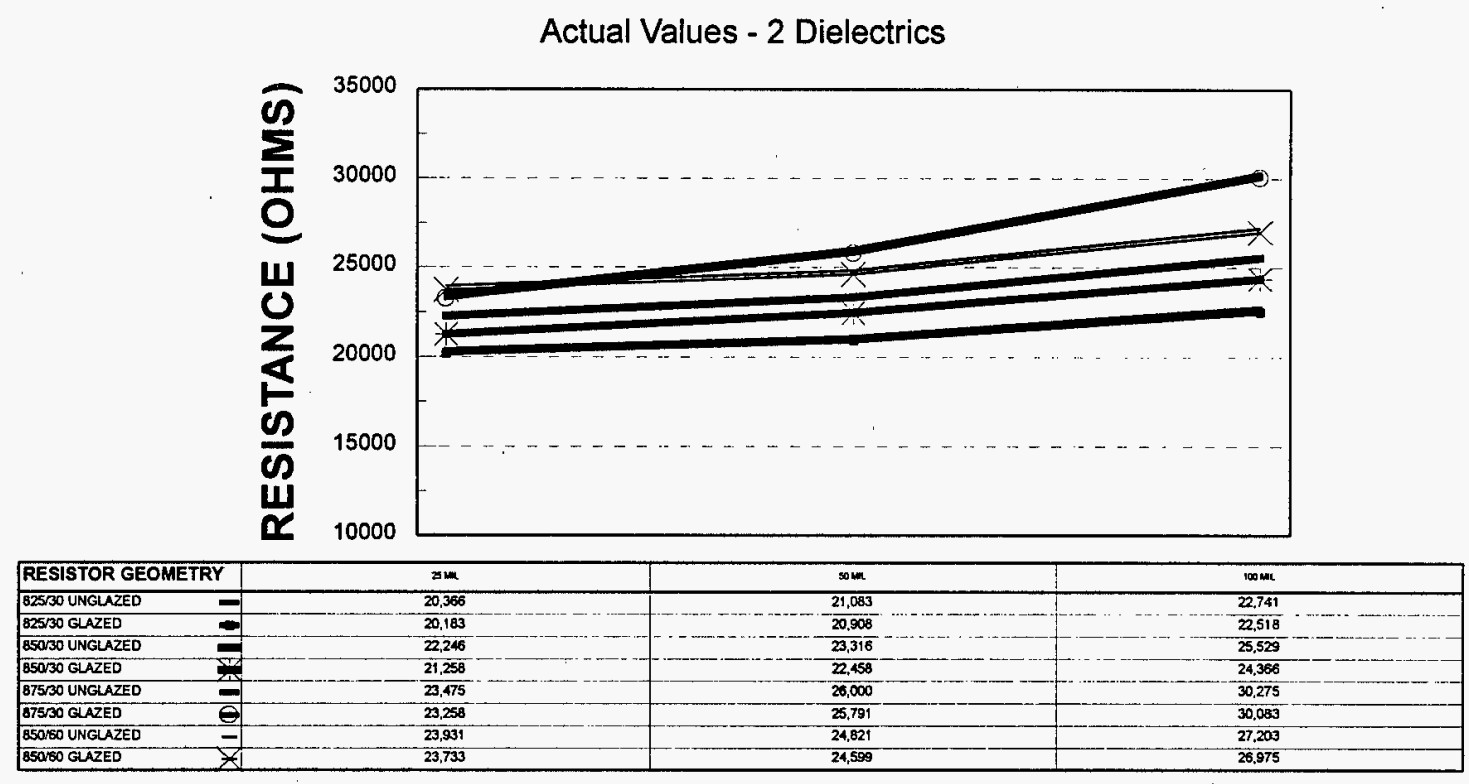

Nominal as-fired resistance is 20,000 ohms.

Target Dried Thickness is 25 microns

Figure 6-2 


\section{NORMALIZED SHEET RESISTANCE \\ DUPONT 1939 (10K OHMS PER SQUARE)}

Percent from Nominal - 2 Dielectrics
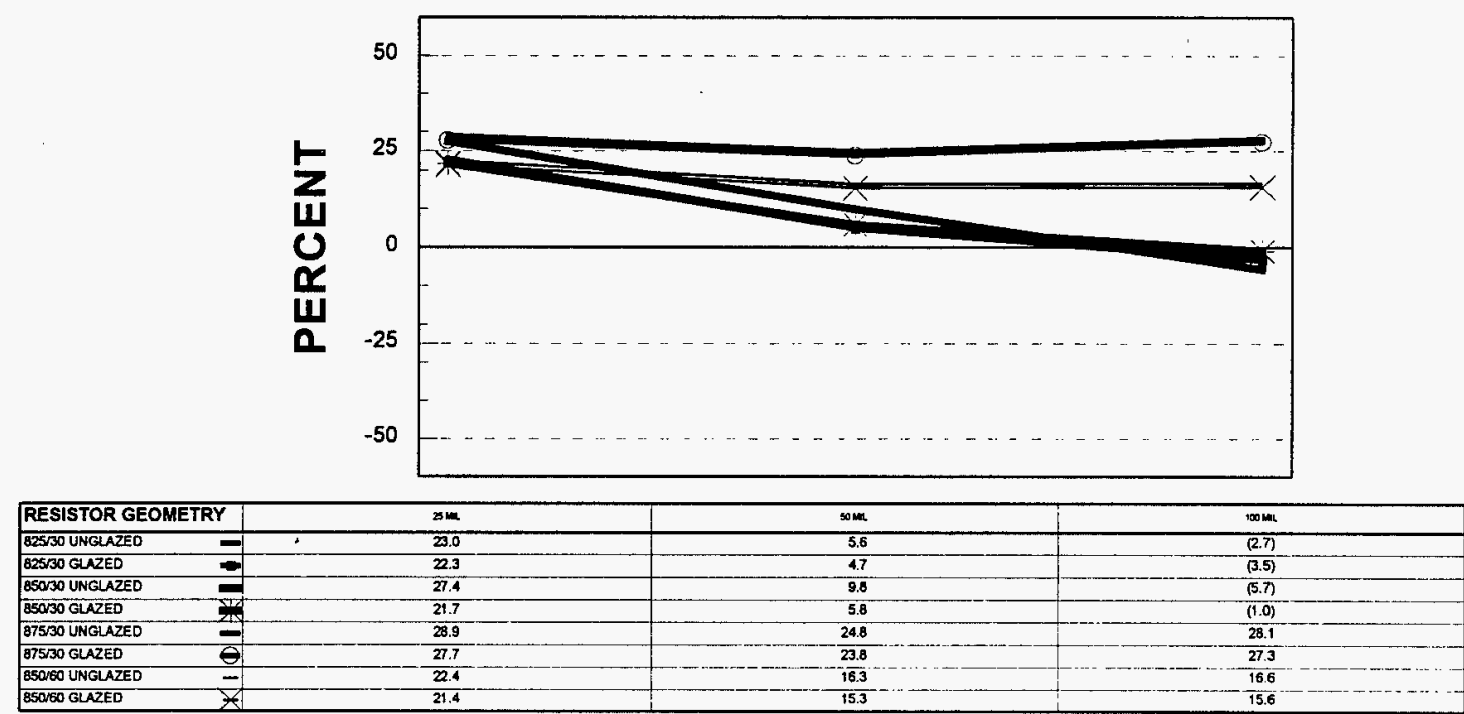

Nominal as-fired resistance is 20,000 ohms.

Target Dried Thickness is $\mathbf{2 5}$ microns

Figure 6-3

\section{NORMALIZED SHEET RESISTANCE \\ DUPONT 1939 (10K OHMS PER SQUARE) - ON LTCC}

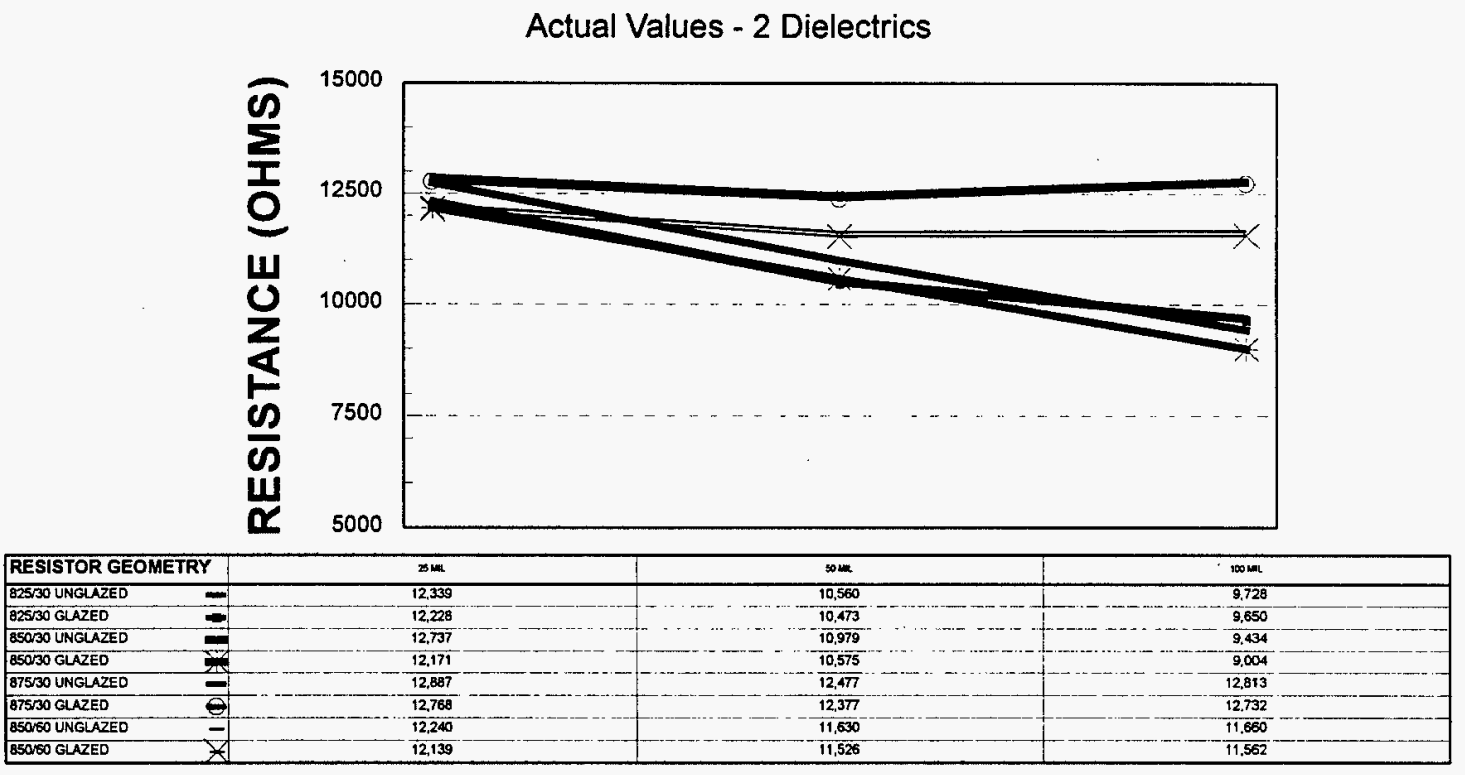

Nominal as-fired resistance is 20,000 ohms.

TargetDried Thickness is 25 microns

Figure 6-4 


\section{THICKNESS \& RESISITIVITY COMPARISON DUPONT 1939 (10K OHMS PER SQUARE)}

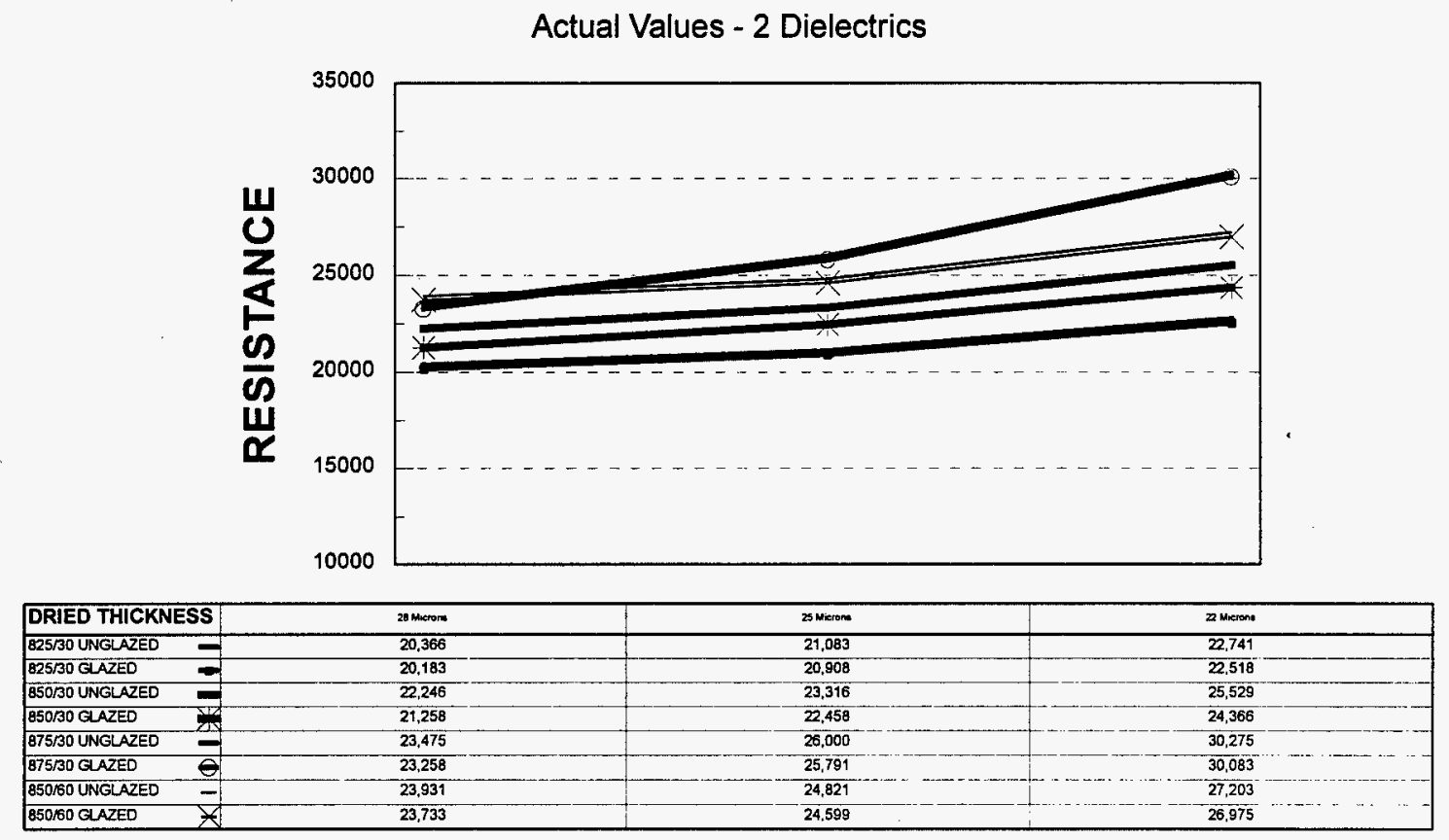

Figure 6-5

\section{THICKNESS RELATIONSHIP \\ DUPONT 1939 (10K OHMS PER SQUARE)}

Printed on 2 Dielectrics

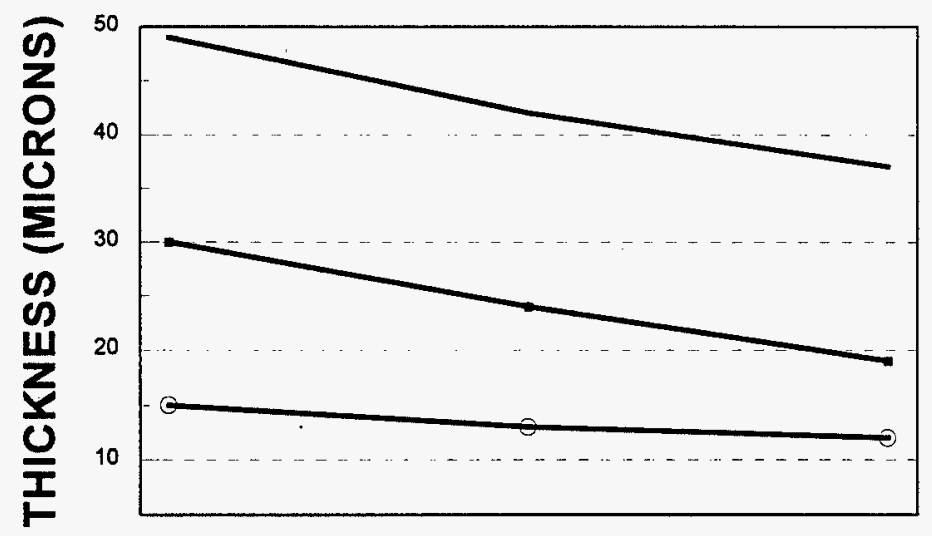

\begin{tabular}{|l|c|c|c|}
\hline \multicolumn{1}{|c|}{ GEOMETRY } & $25 \mathrm{MIL}$ & $50 \mathrm{MLL}$ & $100 \mathrm{MIL}$ \\
\hline WET THICKNESS - & 49 & 42 & 37 \\
\hline DRIED THICKNESS - & 30 & 24 & 19 \\
\hline FIRED THICKNESS - & 15 & 13 & 12 \\
\hline
\end{tabular}

Figure 6-6 


\section{APPENDIX 7}

\section{DUPONT 1949 RESISTOR PRINT DATA}




\section{UNTRIMMED RESISTANCE SUMMARY DUPONT 1949 (100K OHMS PER SQUARE)}

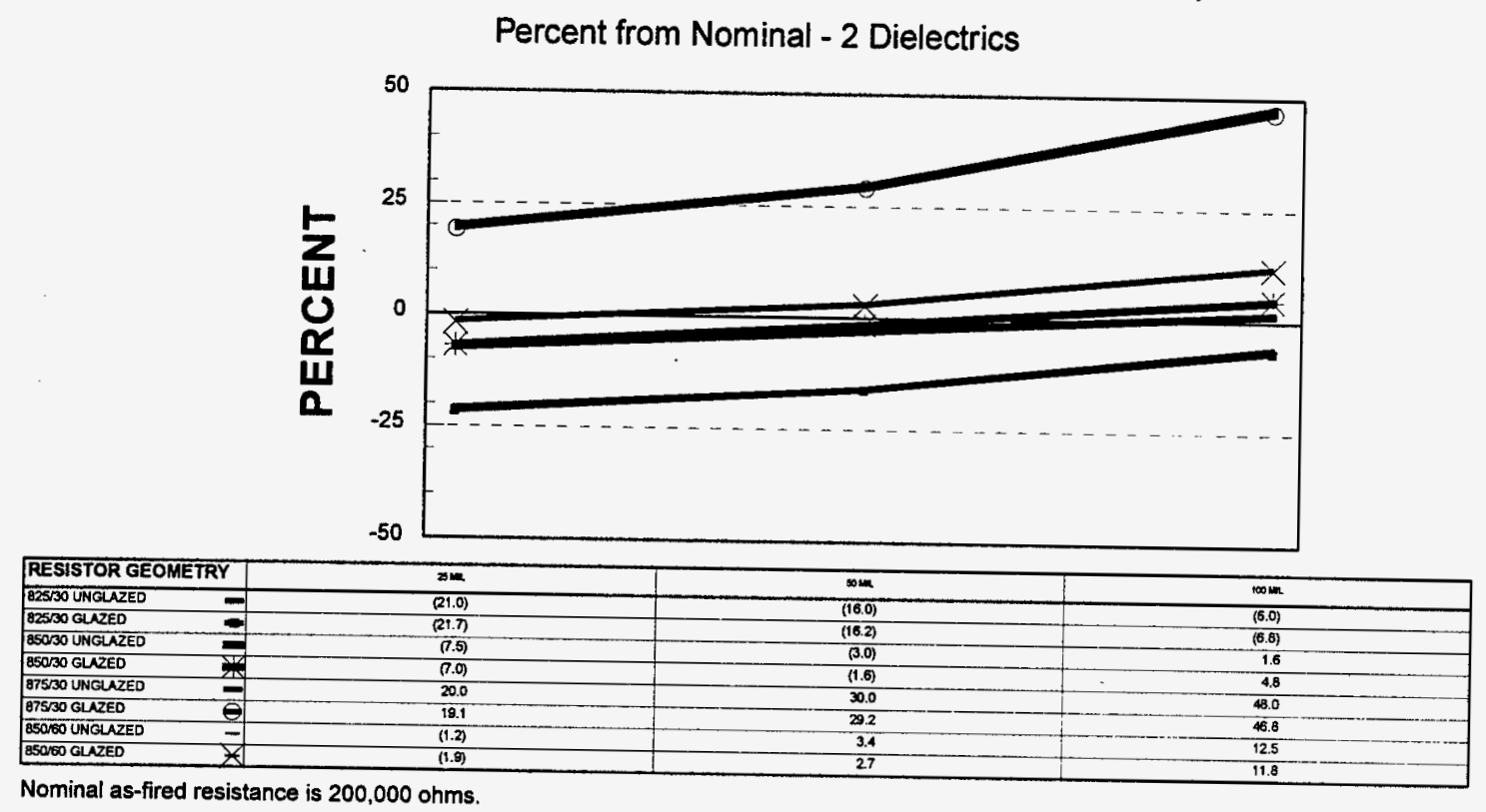

Target Dried Thickness is $\mathbf{2 5}$ microns

Figure 7-1

\section{UNTRIMMED RESISTANCE SUMMARY DUPONT 1949 (100K OHMS PER SQUARE)}

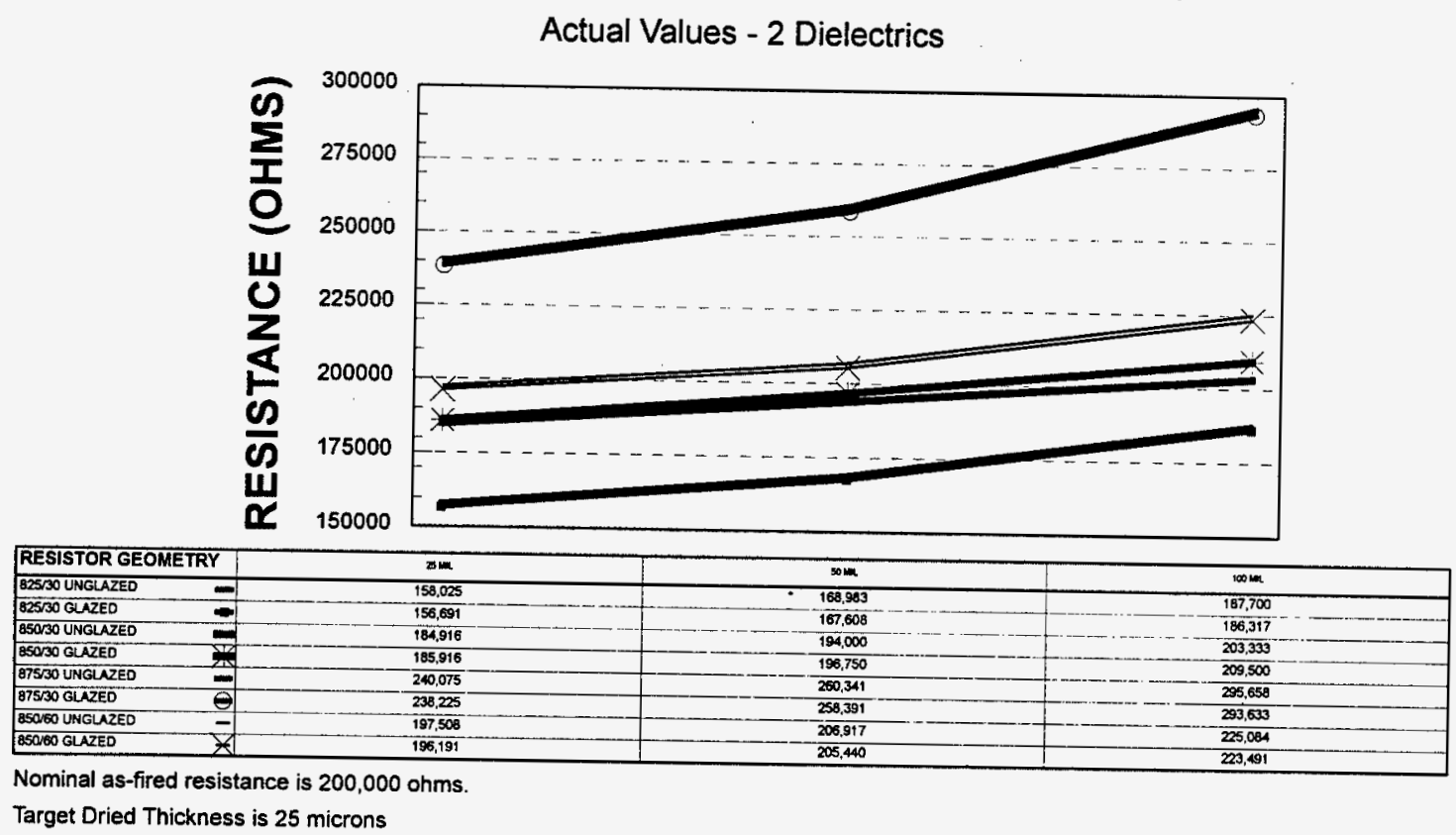

Figure 7-2 


\section{NORMALIZED SHEET RESISTANCE DUPONT 1949 (100K OHMS PER SQUARE)}

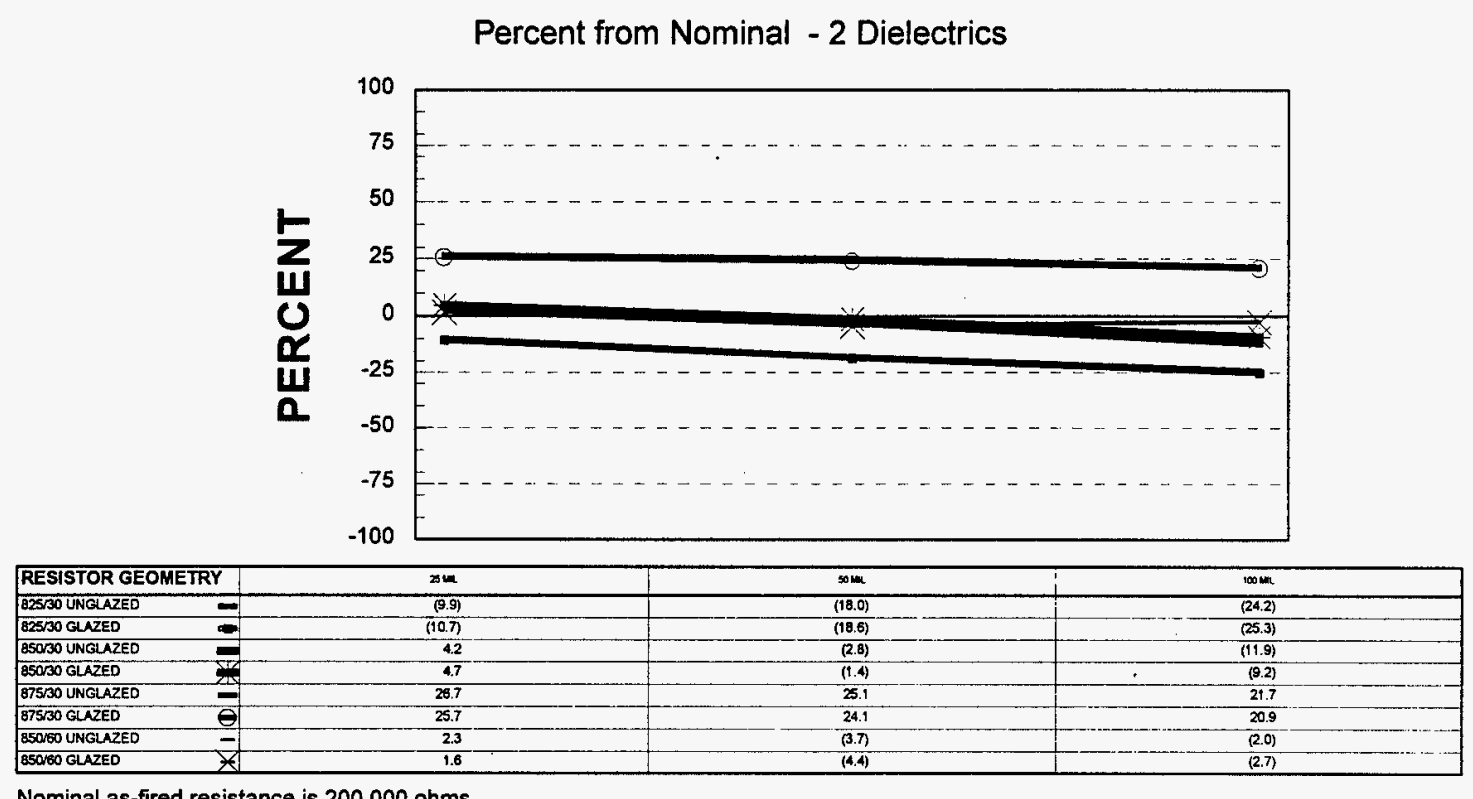

Nominal as-fired resistance is $200,000 \mathrm{ohms}$.

Target Dried Thickness is $\mathbf{2 5}$ microns

Figure 7-3

\section{NORMALIZED SHEET RESISTANCE DUPONT 1949 (100K OHMS PER SQUARE)}

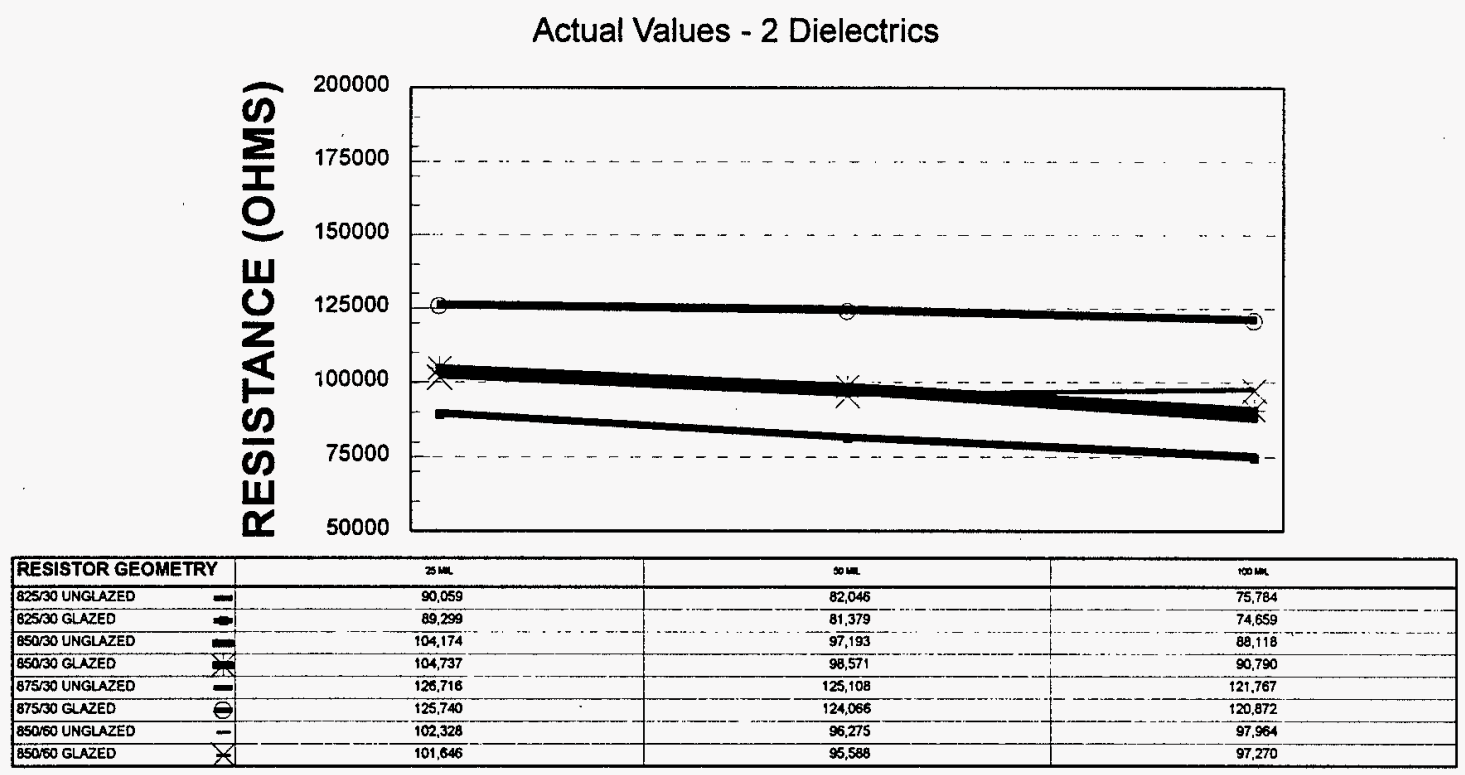

Nominal as-fired resistance is 200,000 ohms.

Target Dried Thickness is $\mathbf{2 5}$ microns

Figure $7-4$ 


\section{THICKNESS \& RESISITIVITY COMPARISON DUPONT 1949 (100K OHMS PER SQUARE)}

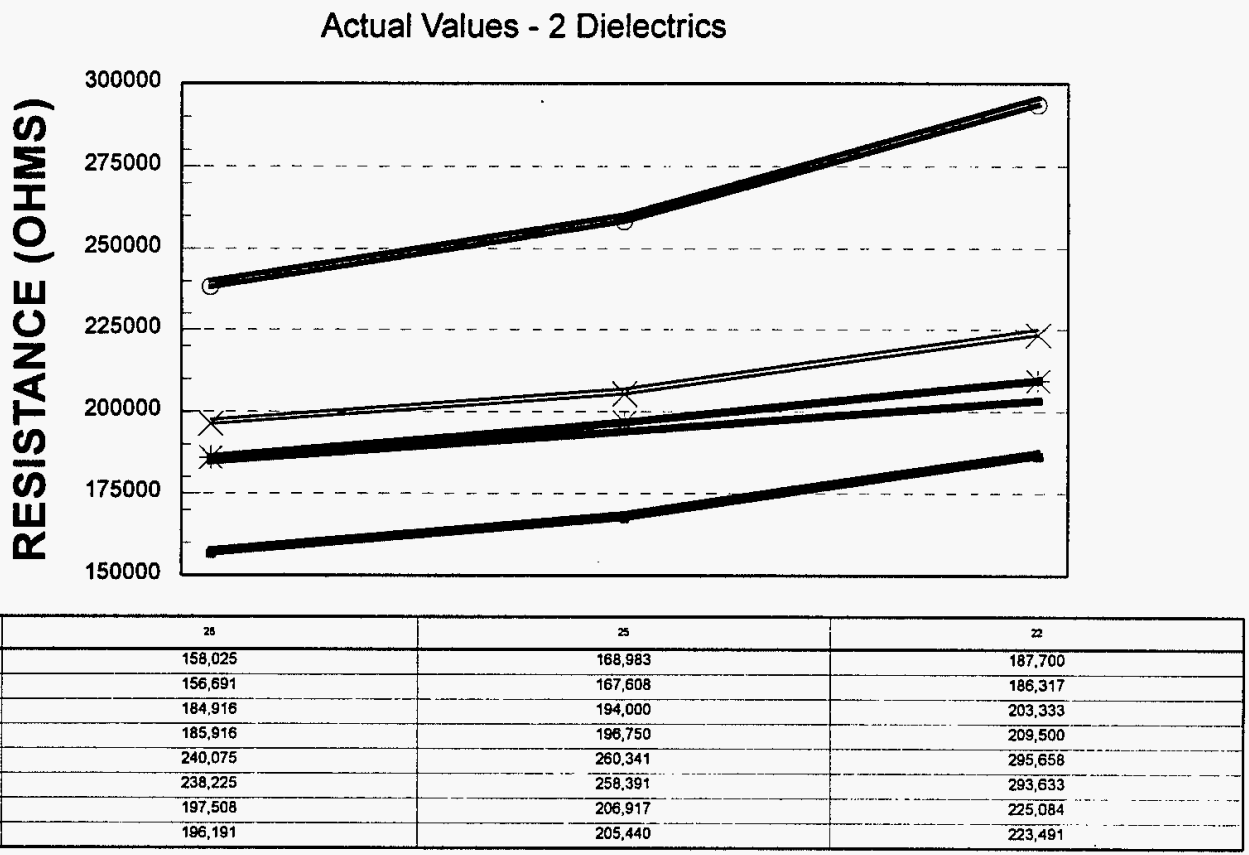

Figure 7-5

\section{THICKNESS RELATIONSHIP}

\section{DUPONT 1949 (100K OHMS PER SQUARE)}

Printed on 2 Dielectrics

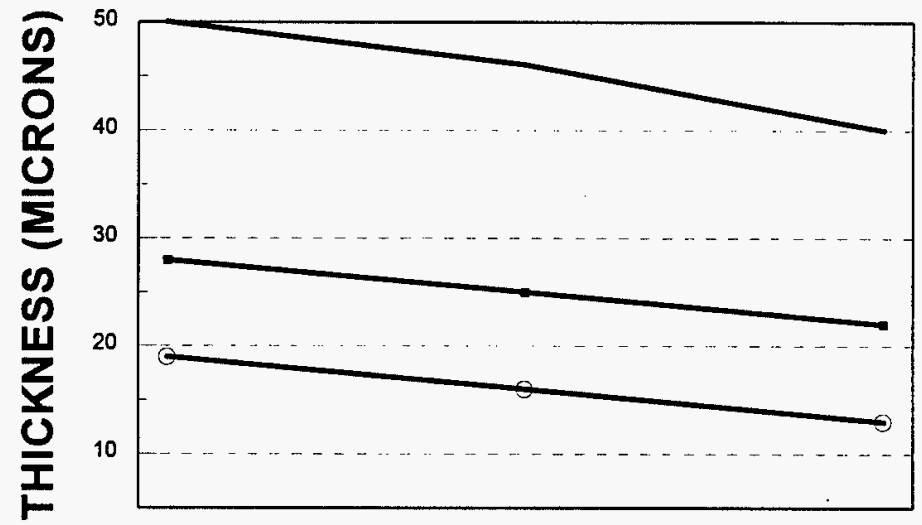

\begin{tabular}{|l|c|c|c|}
\hline \multicolumn{1}{|c|}{ GEOMETRY } & $25 \mathrm{MIL}$ & $50 \mathrm{MIL}$ & $100 \mathrm{MIL}$ \\
\hline WET THICKNESS - & 50 & 46 & 40 \\
\hline DRIED THICKNESS - & 28 & 25 & 22 \\
\hline FIRED THICKNESS - & 19 & 16 & 13 \\
\hline
\end{tabular}

Figure 7-6 


\section{APPENDIX 8}

\section{DUPONT 1959 RESISTOR PRINT DATA}




\section{UNTRIMMED RESISTANCE SUMMARY DUPONT 1959 (1MEG OHM PER SQUARE)}

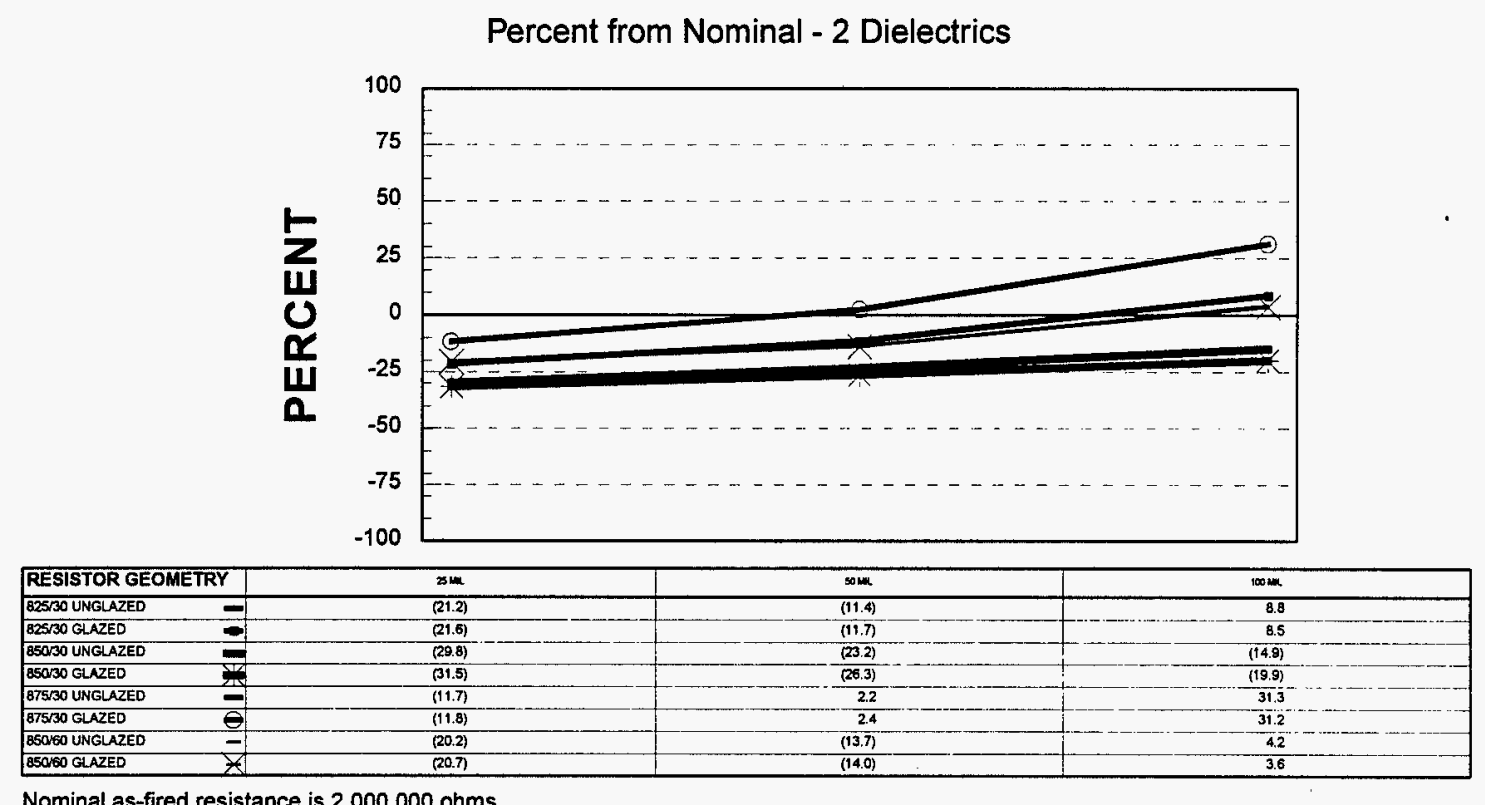

Nominal as-fired resistance is $2,000,000$ ohms.

Target Dried Thickness is 25 microns

Figure 8-1

\section{UNTRIMMED RESISTANCE SUMMARY DUPONT 1959 (1MEG OHM PER SQUARE)}

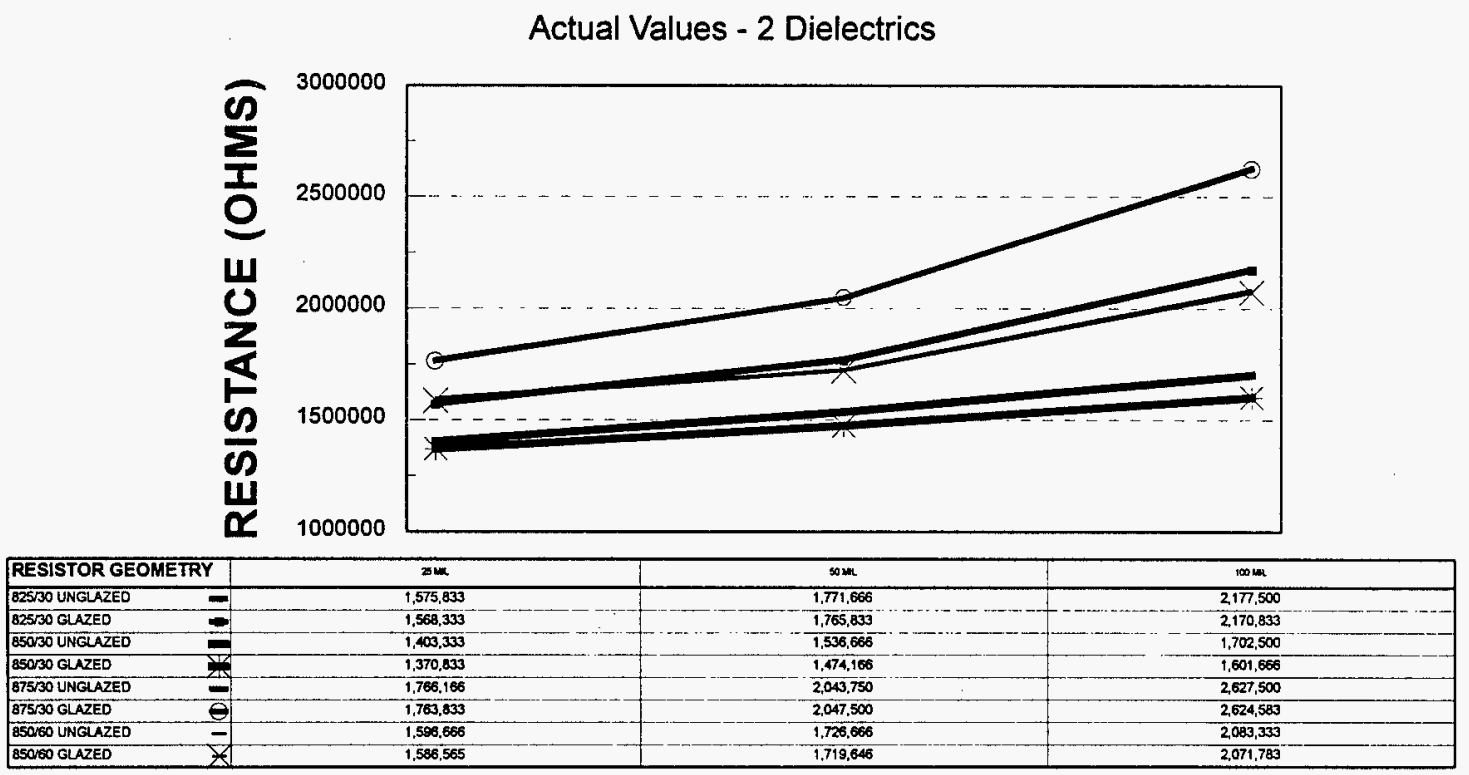

Nominal as-fired resistance is $2,000,000 \mathrm{ohms}$.

Target Dried Thickness is 25 microns

Figure 8-2 


\section{NORMALIZED SHEET RESISTANCE \\ DUPONT 1959 (1MEG OHM PER SQUARE)}

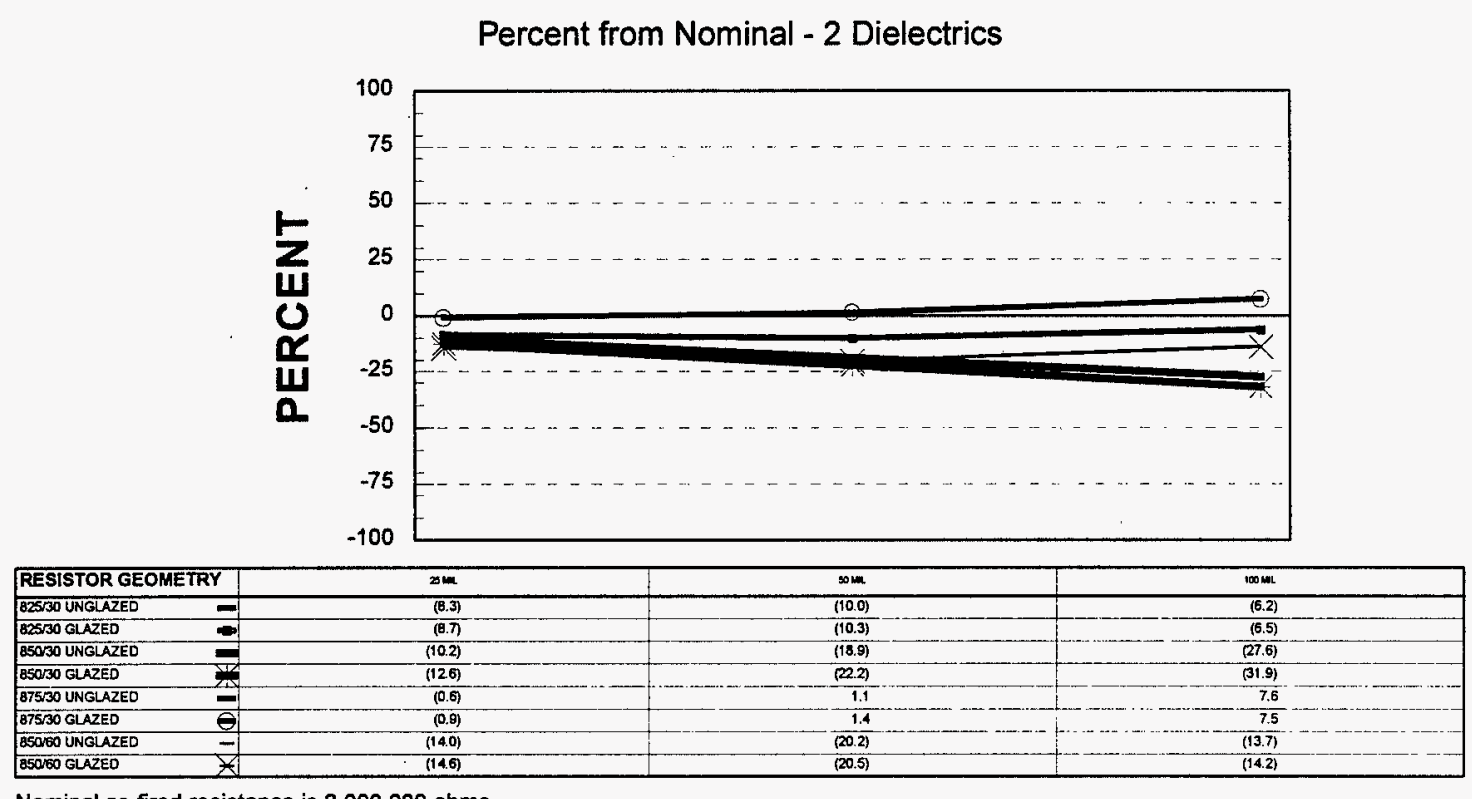

Nominal as-fired resistance is $2,000,000$ ohms.

Target Dried Thickness is $\mathbf{2 5}$ microns

Figure 8-3

\section{NORMALIZED SHEET RESISTANCE \\ DUPONT 1959 (1MEG OHM PER SQUARE)}

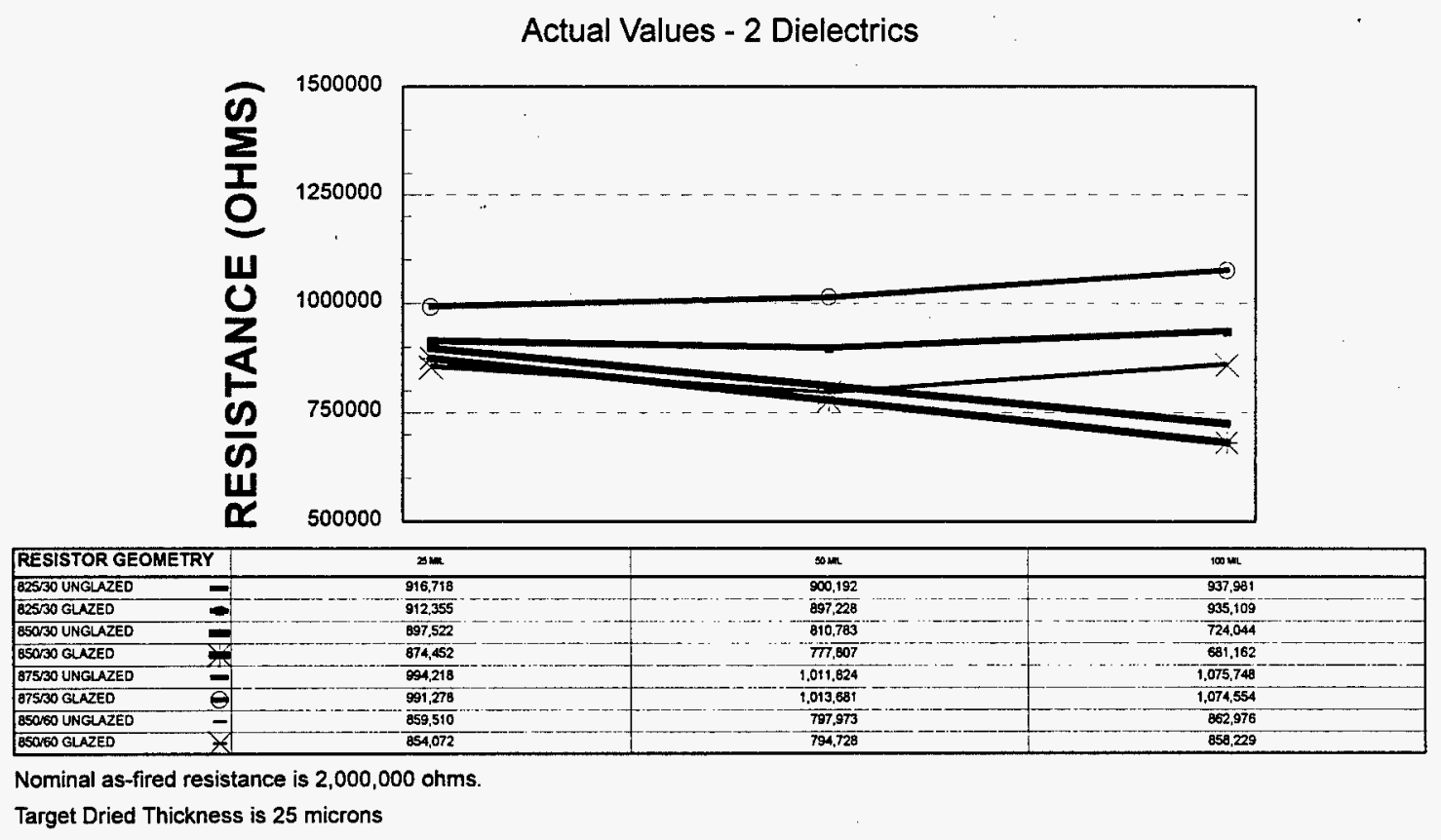

Figure 8-4 


\section{THICKNESS \& RESISITIVITY COMPARISON DUPONT 1959 (1MEG OHM PER SQUARE)}

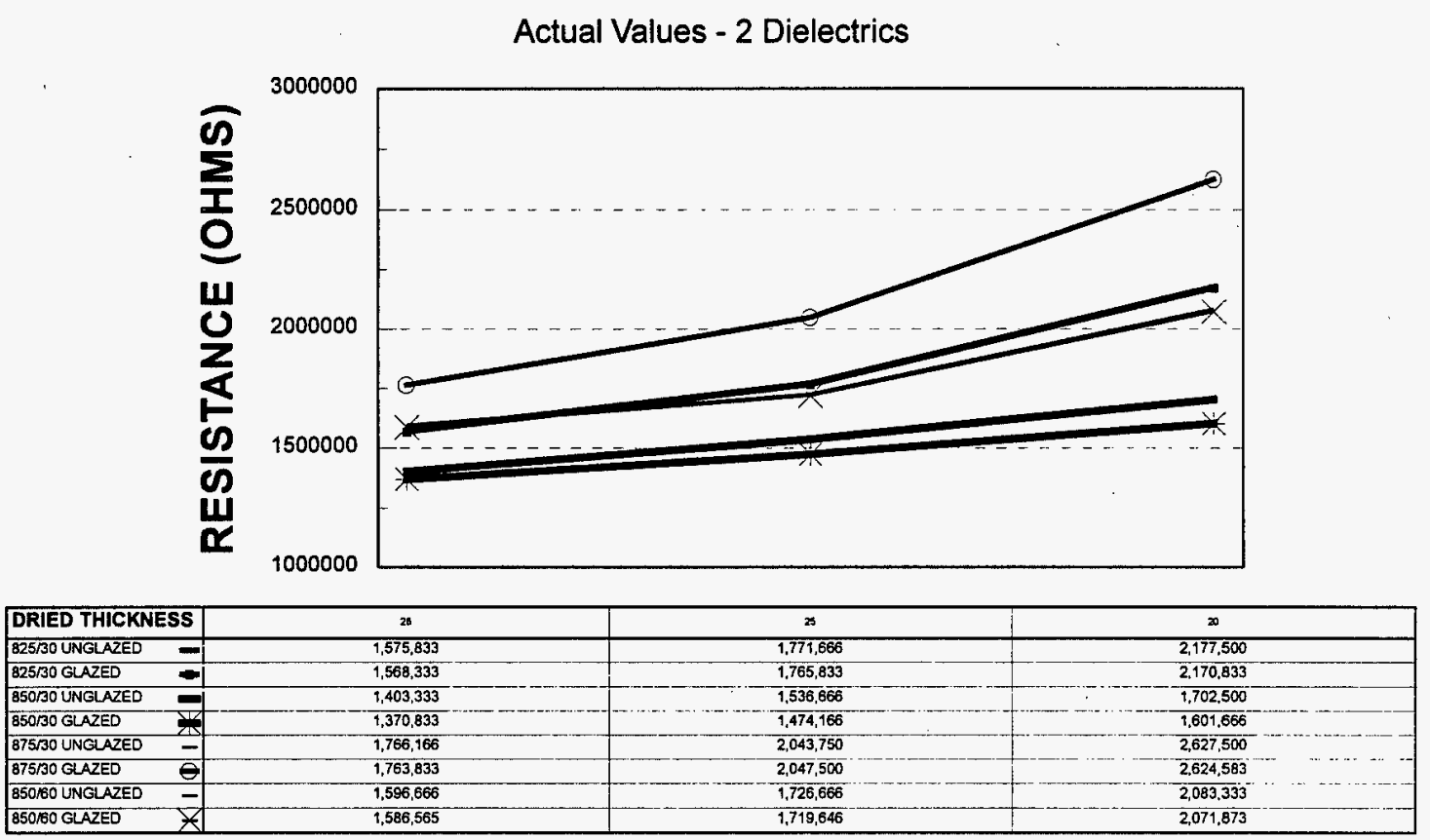

Figure 8-5

\section{THICKNESS RELATIONSHIP}

\section{DUPONT 1959 (1MEG OHM PER SQUARE)}

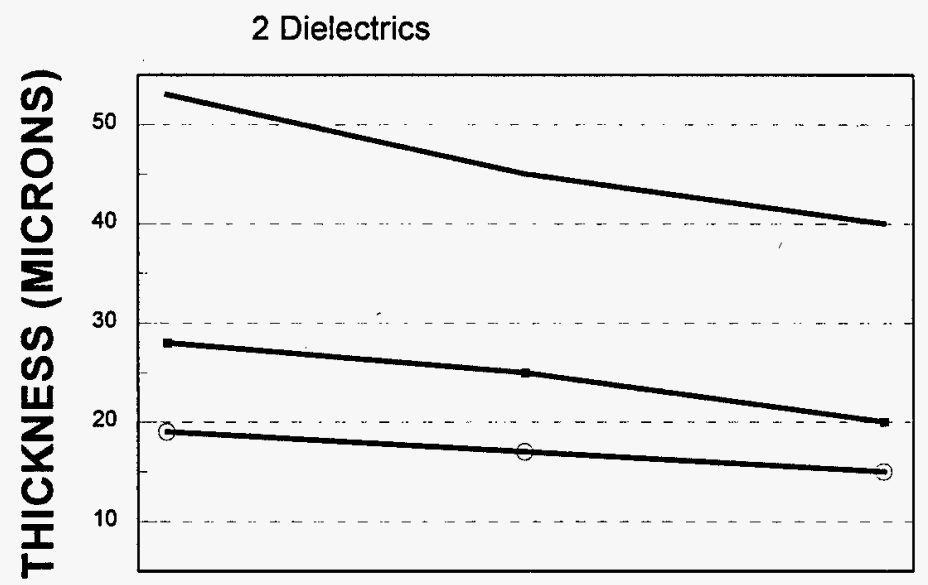

\begin{tabular}{|l|c|c|c|}
\hline \multicolumn{1}{|c|}{ GEOMETRY } & $25 \mathrm{ML}$ & $50 \mathrm{ML}$ & $100 \mathrm{ML}$ \\
\hline WET THICKNESS - & 53 & 45 & 40 \\
\hline DRIED THICKNESS - & 28 & 25 & 20 \\
\hline FIRED THICKNESS & 19 & 17 & 15 \\
\hline
\end{tabular}

Figure 8-6 


\title{
APPENDIX B
}

\section{Characterization of Laser Trimming of DuPont 1900 Series Resistors on Two layers of DuPont 5704 Dielectric}

\author{
By Sam W. Bandler
}

July 1996 


\section{CONTENTS}

SUMMARY

DISCUSSION

Scope and Purpose

64

Prior Work

64

Activity

64

Test Sample Preparation $\quad 64$

Test Descriptions

$\begin{array}{ll}\text { Requirements } & 67\end{array}$

Visual (Viewed at 30X Magnification)

Isolation Resistance $\quad 67$

Application of Requirements $\quad 68$

Observations - 1911 Paste 68

Observations - 1921 Paste $\quad 68$

Observations - 1931 Paste $\quad 69$

Observations - 1939 Paste $\quad 70$

Observation - 1949 Paste 71

Observations - 1959 Paste $\quad 72$

$\begin{array}{ll}\text { ACCOMPLISHMENTS } & 75\end{array}$

$\begin{array}{ll}\text { FUTURE WORK } & 76\end{array}$

$\begin{array}{ll}\text { APPENDIX A } & 77\end{array}$

Test Results For The 1911 Paste $\quad 77$

Pre Trim Distribution $\quad 77$

$\begin{array}{ll}\text { Operating Envelope } & 79\end{array}$

$\begin{array}{ll}\text { APPENDIX B } & 80\end{array}$

Test Results For The 1921 Paste $\quad 80$

Pre Trim Distribution $\quad 80$

Operating Envelope $\quad 82$

Stability For Resistors Trimmed Within The Operating Envelope - Unglazed 83

Stability For Resistors Trimmed Within The Operating Envelope - Glazed $\quad{ }^{\prime} \quad 84$

Stability For Resistors Trimmed At The Operating Point - Unglazed 85

Stability For Resistors Trimmed At The Operating Point - Glazed 86

Analysis Of Resistor Tolerance and Yield Based on Samples Trimmed At The Operating Point Unglazed 
Analysis Of Resistor Tolerance and Yield Based on Samples Trimmed At The Operating Point Glazed

$\begin{array}{ll}\text { APPENDIX C } & 90\end{array}$

Test Results For The 1931 Paste 90

Pre Trim Distribution 90

Operating Envelope $\quad 92$

Stability For Resistors Trimmed Within The Operating Envelope - Unglazed 93

Stability For Resistors Trimmed Within The Operating Envelope - Glazed 94

Stability For Resistors Trimmed At The Operating Point - Unglazed 95

Stability For Resistors Trimmed At The Operating Point - Glazed 96

Analysis Of Resistor Tolerance and Yield Based on Samples Trimmed At The Operating Point Unglazed 98

Analysis Of Resistor Tolerance and Yield Based on Samples Trimmed At The Operating Point Glazed

$\begin{array}{ll}\text { APPENDIX D } & 100\end{array}$

Test Results For The 1939 Paste 100

Pre Trim Distribution $\quad 100$

$\begin{array}{ll}\text { Operating Envelope } & 102\end{array}$

Stability For Resistors Trimmed Within The Operating Envelope - Unglazed 103

Stability For Resistors Trimmed Within The Operating Envelope - Glazed 104

Stability For Resistors Trimmed At The Operating Point - Unglazed 105

Stability For Resistors Trimmed At The Operating Point - Glazed 106

Analysis Of Resistor Tolerance and Yield Based on Samples Trimmed At The Operating Point -

Unglazed 108

Analysis Of Resistor Tolerance and Yield Based on Samples Trimmed At The Operating Point -

Glazed

APPENDIXE $\quad 110$

Test Results For The 1949 Paste $\quad 110$

Pre Trim Distribution $\quad 110$

$\begin{array}{ll}\text { Operating Envelope } & 112\end{array}$

Stability For Resistors Trimmed Within The Operating Envelope - Unglazed 113

Stability For Resistors Trimmed Within The Operating Envelope - Glazed 114

Stability For Resistors Trimmed At The Operating Point - Unglazed 115

Stability For Resistors Trimmed At The Operating Point - Glazed 116

Analysis Of Resistor Tolerance and Yield Based on Samples Trimmed At The Operating Point Unglazed $\quad 118$

Analysis Of Resistor Tolerance and Yield Based on Samples Trimmed At The Operating Point Glazed

$\begin{array}{ll}\text { APPENDIX F } & 120\end{array}$

Test Results For The 1959 Paste $\quad 120$

$\begin{array}{lr}\text { Pre Trim Distribution } & 120\end{array}$

$\begin{array}{ll}\text { Operating Envelope : } & 122\end{array}$

Stability For Resistors Trimmed Within The Operating Envelope - Unglazed 123 
Stability For Resistors Trimmed Within The Operating Envelope - Glazed 124

Stability For Resistors Trimmed At The Operating Point - Unglazed 125

Stability For Resistors Trimmed At The Operating Point - Glazed 126

Analysis Of Resistor Tolerance and Yield Based on Samples Trimmed At The Operating Point -

Unglazed

Analysis Of Resistor Tolerance and Yield Based on Samples Trimmed At The Operating Point -

Unglazed

\section{APPENDIX G}

Miscellaneous Data 


\section{SUMMARY}

Samples were printed, using Du Pont 1911, 1921, 1931, 1939, 1949 and 1959 resistor pastes, on 2 layers of Du Pont 5704 dielectric on $96 \%$ alumina ceramic substrates. The resistivity of the paste is $10 \mathrm{Ohms} / \mathrm{square}, 100 \mathrm{Ohms} / \mathrm{square}$, $1 \mathrm{~K} \mathrm{Ohms} / \mathrm{square}, 10 \mathrm{~K} \mathrm{Ohms} / \mathrm{square}, 100 \mathrm{~K} \mathrm{Ohms} / \mathrm{square}$, and $1 \mathrm{M} \mathrm{Ohms} / \mathrm{square}$, respectively. The samples were divided into four groups and fired at $825^{\circ} \mathrm{C}$ for 30 minutes, $850^{\circ} \mathrm{C}$ for 30 minutes, $850^{\circ} \mathrm{C}$ for 60 minutes, or $875^{\circ} \mathrm{C}$ for 30 minutes. The resistors on half the samples of each paste decade were overcoated with Du Pont 5415D glaze.

Samples were trimmed using various laser settings for beam speed, pulse rate, and power to determine the range of acceptable operation.

Samples were subjected to the following tests:

- Isolation resistance.

- 24 hour short term drift.

- Temperature shock (solder pot shock test): $25^{\circ} \mathrm{C}$ to $268^{\circ} \mathrm{C}, 268^{\circ} \mathrm{C}$ for 15 seconds and back to $25^{\circ} \mathrm{C}$.

- Temperature cycle: $-50^{\circ} \mathrm{C}$ to $125^{\circ} \mathrm{C}$ with approximately 5 seconds ramp time, ten cycles, 15 minutes minimum at each temperature extreme.

- Temperature coefficient of resistance (TCR) measured and calculated at $-55^{\circ} \mathrm{C}, 25^{\circ} \mathrm{C}$, and $125^{\circ} \mathrm{C}$.

- 1000 hour aging test at $150^{\circ} \mathrm{C}$, ambient humidity.

Resistance was measured after each test, and the change in resistance was calculated.

Using visual requirements, isolation resistance, and the results of the above tests, the range for acceptable operation was determined for the 1921 through 1959 pastes. Testing was discontinued on the 1911 paste because the cracks that occurred in the paste after firing were determined to be detrimental to resistor stability.

An operating point for each paste, glazed and unglazed, was selected based on the above results, and additional samples were trimmed at these points. These samples were tested, using the above tests, through the 1000 hour aging test. From this data it was possible to estimate the best possible resistor tolerance and yield.

Based on the results of these tests the following conclusions and recommendations are made:

v 1911 paste should not be used because of paste cracking after firing leading to poor resistor stability.

- The minimum resistor dimension should be 0.050 inches. 
- Resistors should be glaze over-coated to maximize stability and minimize changes in TCR due to laser trimming.

- TCR, for trimmed/glazed samples, was determined to be within the manufacturer's specification of $\pm 100 \mathrm{ppm} l^{\circ} \mathrm{C}$.

- Preliminary estimates, for glazed samples, indicate that resistor tolerances as tight as $\pm 1 \%$ are possible with $100 \%$ yield for resistors made with 1921 through 1959 pastes. Since this is preliminary, it is recommended initially that tolerances should not be tighter than $\pm 2 \%$. 


\section{DISCUSSION}

\section{Scope and Purpose}

The objective of this project was to report on the characterization of laser trimming resistors printed with Du Pont 1900 series resistor pastes on Du Pont 5704 dielectric on $96 \%$ alumina substrates.

\section{Prior Work}

The results of a study of Du Pont 1700 and 1900 series resistor pastes printed on Du Pont 5704 dielectric was conducted by Du Pont. The results were described in a report entitled "Laser Trimming Resistors Over Dielectric". It was published in the October, 1985 issue of Hybrid Circuit Technology."

Du Pont 1700 series resistor pastes have been printed on dielectric at FM\&T.

These resistors were laser trimmed, and the process characterized in 1989.

A related study was conducted on Du Pont 1900 series resistors printed on Du Pont 951 LTCC substrates. The samples were printed and laser trimmed by CTS Corp. and the testing was conducted by FM\&T.

\section{Activity}

\section{Test Sample Preparation}

Du Pont 1911, 1921, 1931, 1939, 1949, and 1959 resistor pastes were used to print resistors on approximately 720 test samples on 2 layers of Du Pont 5704 dielectric on $96 \%$ alumina substrate. The samples were divided into four groups and fired at $825^{\circ} \mathrm{C}$ for 30 minutes $(825 / 30), 850^{\circ} \mathrm{C}$ for 30 minutes $(850 / 30), 850^{\circ}$ $\mathrm{C}$ for 60 minutes $(850 / 60)$, or $875^{\circ} \mathrm{C}$ for 30 minutes $(875 / 30)$. The resistors on half of the samples from each resistor paste decade were over-coated with $\mathrm{Du}$ Pont 5415D glaze 
Each test sample, shown in Figure 1, contains twelve resistors with a length-towidth aspect ratio of $2: 1$. There are three different resistor widths, 0.025 inch (25 mil), 0.050 inch (50 mil) and 0.1 inch (100 mil), on the sample.

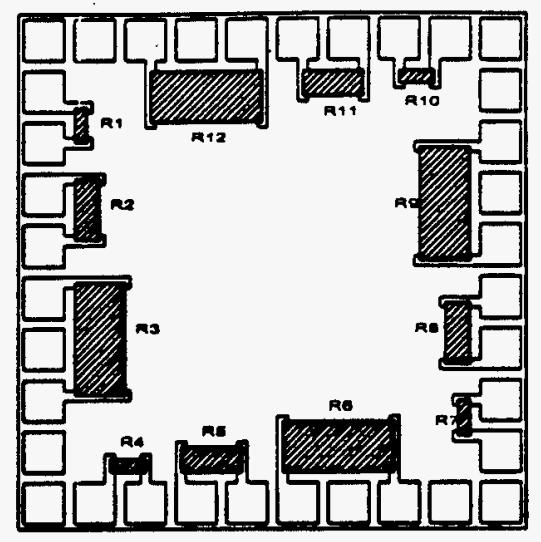

Figure 1

The resistors on all samples were measured to determine the effects of the four firing profiles on initial resistance.

The $850^{\circ} \mathrm{C} / 60$ minute profile, initially the preferred profile, was chosen to develop the laser trimming envelope. The resistors on approximately twenty samples from each paste, both glazed and unglazed, were laser trimmed. They were trimmed using various combinations of pulse rate, beam speed, and power. Two resistors were cut using each combination. The 0.025 inch resistor was cut completely in half, and the 0.05 inch resistor was cut to raise its value 1.4 times its original value. The 0.1 inch resistor was left untrimmed to be used for reference. The trimming was accomplished on a Teradyne model W419 laser trim system.

The acceptable operating range of the laser was determined from these samples for the 1921 through 1959 pastes. The laser trims were evaluated using visual criteria, isolation resistance, and stability as determined by tests described later in this report. An acceptable operating range could not be defined for samples printed with the 1911 paste and trimmed using standard trimming techniques. In addition, it was noted that the resistors were cracked. Resistors printed with 1911 paste in another study were also cracked. It was determined, in this study, that cracks in resistors are detrimental to resistor stability. No further tests were conducted on this paste.

Having established the operating range, an operating point was selected, and an additional 36 samples were trimmed at this point. The samples were selected from those fired using the $850^{\circ} \mathrm{C} / 30$ minute profile. This profile became the preferred profile as the result of initial data from this evaluation and recommendations from Du Pont. The samples were from the 1921 through 1959 
paste decades, both glazed and unglazed. Resistor R4 was cut in half while resistors $R 5, R 7, R 8, R 10, R 11, R 1$ and $R 2$ were trimmed to increase their value approximately 1.4 times. Resistors $R 6, R 9, R 12$, and $R 3$ were left untrimmed to be used for reference. All resistors were tested and evaluated like the first group to determine the tolerance and yield that might be expected.

\section{Test Descriptions}

The samples trimmed for the operating envelope and the samples trimmed at the operating point were subjected to the following tests:

The resistor values on all samples, trimmed and untrimmed, were measured on a Teradyne W419 Laser Trim System within a few seconds of having been laser trimmed. This measurement will hereafter be referred to as $T \varnothing$.

The samples were remeasured again approximately 24 hours later, and the change in resistance was calculated. This was done to determine the ability to repeatably measure them and to obtain some measure of their off-the-shelf stability. In past studies of other resistor pastes, the largest change in resistance typically occurred during the first 24 hours.

Each sample was then subjected to a solder pot shock test. This test involved placing each test sample individually on molten solder heated to approximately $268^{\circ} \mathrm{C}$ for 15 seconds. The sample was removed and placed on a stainless steel table top at approximately $25^{\circ} \mathrm{C}$ and allowed to cool. All of the resistors were remeasured, and the change in resistance, compared to $T \varnothing$, was calculated.

The test samples were then subjected to a temperature cycle test. The test apparatus consisted of two interconnected test chambers. One chamber was set to $-50^{\circ} \mathrm{C}$ while the other was set to $125^{\circ} \mathrm{C}$. A cycle consisted of moving the test samples from one chamber to the other and then back. The approximate transport time was five seconds. The samples were held at each temperature extreme a minimum of 15 minutes. Upon completion of this test, the resistors were again measured, and the change from $T \varnothing$ was calculated.

One sample from each paste decade was removed from the samples trimmed at the operating point. One trimmed and one untrimmed resistor was tested from each sample. These were used to determine the temperature coefficient of resistance (TCR) for the resistors from each paste decade. The TCR test involved measuring the resistors at $25^{\circ} \mathrm{C}$. The samples were then heated to $125^{\circ} \mathrm{C}$ and allowed to stabilize at that temperature for approximately 30 minutes. The resistors were measured at this temperature. The samples were then cooled to $-55^{\circ} \mathrm{C}$ and allowed to stabilize at this temperature for approximately 30 
minutes. The resistors were measured while at this temperature. The following formulas were used:

hot TCR $\left(p p m /^{\circ} \mathrm{C}\right)=\frac{R_{125^{\circ}}-R_{25^{\circ}}}{R_{25^{\circ}}} \times 10,000$

cold TCR $\left(p p m /{ }^{\circ} \mathrm{C}\right)=\frac{\left(R-55^{\circ}\right)-R_{25^{\circ}}}{R_{255^{\circ}}} \times(-12,500)$.

The samples were subjected to the 1000 hour aging test. The samples were placed in an oven heated to $150^{\circ} \mathrm{C}$. At intervals of 200,600 , and 1000 hours the samples were removed from the oven and allowed to cool to room temperature. The resistors were measured, and the change compared to $T \varnothing$ was calculated.

The results of each of the tests are shown in the graphs in the appendices at the end of this report. The results are arranged by paste decade in Appendices $A$ through F. Appendix $G$ contains the TCR data.

\section{Requirements}

There were two main requirements used when considering the ability of a combination of laser parameters to make an acceptable trim. They were visual requirements and isolation resistance.

\section{Visual (Viewed at 30X Magnification)}

- Laser kerf free of obvious debris.

- Laser kerf free of bridges (continuous laser kerf).

- No continuous grooving of the dielectric in the kerf.

- The width of reflowed resistor material on either side of the kerf shall be less than the kerf width.

\section{Isolation Resistance}

Isolation resistance is the value of the resistor that has been cut completely in half. Depending upon the combination of laser parameters selected and the resistor material, the value of the isolation resistance will range from the design value of the resistor to some greater value (typically greater than $32 \mathrm{Meg}$ Ohms).

As the combination of laser parameters is adjusted to cause increasing energy tc be applied to the resistor, the value of the isolation resistance increases from a minimum to some larger value. Increasing laser energy cuts deeper into the 
resistor. At some value of laser energy, the resistor material is removed completely from the laser kerf, and there is a several orders of magnitude increase in resistance. This is the minimum laser energy considered sufficient to trim resistors.

\section{Application of Requirements}

The lower end of the operating envelope is determined by the combination of laser parameters that result in the minimum energy necessary to produce an isolated trim and meet the visual requirements for kerf cleanliness.

The upper end of the operating envelope is determined by the combination of laser parameters that result in the maximum energy that can produce laser trims that meet all the requirements.

\section{Observations - 1911 Paste}

From the data shown in Appendix A the following general observations can be made:

- The 4 firing profiles produced resistors with values above the design value.

- Resistor values did not vary greatly over the 4 profiles.

- Resistor values increased as resistor size increased for each profile.

- The glaze overcoat does not effect post fired resistor values.

- No acceptable operating range was defined using standard trim techniques and visual requirements.

- Resistors, most notably $\mathbf{2 5}$ mil wide, contained numerous cracks that were determined in previous studies to be detrimental to resistor stability.

\section{Observations - 1921 Paste}

From the data shown in Appendix B the following general observations can be made:

- The $825 / 30$ and $850 / 30$ firing profiles produced resistors with values ranging from approximately $-45 \%$ to $+5 \%$ from nominal.

- The $850 / 60$ and $875 / 30$ firing profiles produced resistors with values ranging from $-25 \%$ to $+50 \%$ from nominal.

- Resistor values increased as resistor size increased for each profile.

- The glaze overcoat does not effect post fired resistor values.

- An acceptable operating range was established for glazed and unglazed samples. 
- Laser trimming resistors, glazed or unglazed, reduces their stability.

- The stability of glazed samples trimmed within the envelope ranged from $-.03 \%$ to $+.38 \%$ change in resistance after all tests.

- The stability of unglazed samples trimmed within the envelope ranged from $0 \%$ to $+.14 \%$ change in resistance after all tests.

- An operating point was selected for the glazed samples: a pulse rate of $3 \mathrm{KHz}$ at $550 \mathrm{~mW}$ at .375 ips.

- An operating point was selected for the unglazed samples: a pulse rate of $4 \mathrm{KHz}$ at $450 \mathrm{~mW}$ at .4 ips.

- The $\mathbf{2 5}$ mil wide resistors, both glazed and unglazed, trimmed at the operating point are less stable than the $\mathbf{5 0}$ mil wide resistors.

- Stability for glazed 25 mil resistors ranged from $0 \%$ to $+.39 \%$ change in resistance after all tests.

- Stability for unglazed 25 mil resistors ranged from $0 \%$ to $+.26 \%$ change in resistance after all tests.

- Stability for glazed 50 mil resistors ranged from $0 \%$ to $+.16 \%$ change in resistance after all tests.

- Stability for unglazed 50 mil resistors ranged from $-.05 \%$ to $+.25 \%$ change in resistance after all tests.

- Glaze makes little difference in resistor stability.

- Laser trimming and glaze does not effect TCR.

- TCR is within the manufacturer's specification of $\pm 100 \mathrm{ppm} / \mathrm{C}$.

\section{Observations - 1931 Paste}

From the data shown in Appendix $C$ the following general observations can be made:

- The $825 / 30$ firing profile produced resistors with values ranging from approximately $-29 \%$ to $+48 \%$ from nominal.

- The $850 / 30$ firing profile produced resistors with values ranging from approximately $-45 \%$ to $+5 \%$ from nominal:

- The $850 / 60$ firing profile produced resistors with values ranging from approximately $-29 \%$ to $+47 \%$ from nominal.

- The $875 / 30$ firing profile produced resistors with values ranging from approximately $-55 \%$ to $+5 \%$ from nominal.

- Resistor values increased as resistor size increased for each profile.

- The glaze has little or no effect on post fired resistor values.

- An acceptable operating range was established for glazed and unglazed samples.

- Laser trimming resistors, glazed or unglazed, reduces their stability. 
- The stability of glazed samples trimmed within the envelope ranged from $+.03 \%$ to $+.31 \%$ change in resistance after all tests.

- The stability of unglazed samples trimmed within the envelope ranged from $0 \%$ to $+.12 \%$ change in resistance after all tests.

- An operating point was selected for the glazed samples: a pulse rate of $3 \mathrm{KHz}$ at $550 \mathrm{~mW}$ at .375 ips.

- An operating point was selected for the unglazed samples: a pulse rate of $5 \mathrm{KHz}$ at $475 \mathrm{~mW}$ at .25 ips.

- The 25 mil wide resistors, both glazed and unglazed, trimmed at the operating point are less stable than the $\mathbf{5 0}$ mil wide resistors.

- Stability for glazed 25 mil resistors ranged from $-.05 \%$ to $+.44 \%$ change in resistance after all tests.

- Stability for unglazed 25 mil wide resistors ranged from $-.23 \%$ to $+3.14 \%$ change in resistance after all tests.

- Stability for glazed 50 mil resistors ranged from $-.05 \%$ to $+.16 \%$ change in resistance after all tests.

- Stability for unglazed 50 mil wide resistors ranged from $-.09 \%$ to $+1.01 \%$ change in resistance after all tests.

- Glaze significantly improves trimmed resistor stability.

- Laser trimming and glaze does not effect TCR.

- TCR is within the manufacturer's specification of $\pm 100 \mathrm{ppm} /{ }^{\circ} \mathrm{C}$.

\section{Observations - 1939 Paste}

From the data shown in Appendix $D$ the following general observations can be made:

- The $825 / 30$ and $850 / 30$ firing profiles produced resistors with values mostly above the design value ranging from approximately $-10 \%$ to $+35 \%$ from nominal.

- The $875 / 30$ and $850 / 60$ firing profiles produced resistors with values above the design value ranging from approximately $+10 \%$ to $+65 \%$ from nominal.

- Resistor values increased as resistor size increased for each profile.

- The glaze overcoat does not effect post fired resistor values.

- An acceptable operating range was established for glazed and unglazed samples.

- Laser trimming does not appear to have a large impact on resistor stability.

- The stability of glazed samples trimmed within the envelope ranged from $+.08 \%$ to $+.2 \%$ change in resistance after all tests. 
- The stability of unglazed samples trimmed within the envelope ranged from $+.05 \%$ to $+.11 \%$ change in resistance after all tests.

- An operating point was selected for the glazed samples: a pulse rate of $3 \mathrm{KHz}$, at $550 \mathrm{~mW}$ at .375 ips.

- An operating point was selected for the unglazed samples: a pulse rate of $5 \mathrm{KHz}$ at $475 \mathrm{~mW}$ at .25 ips.

- The 25 mil resistors, both glazed and unglazed, trimmed at the operating point had similar stability.

- Stability for glazed 25 mil resistors ranged from $-.13 \%$ to $+.29 \%$ change in resistance after all tests

- Stability for unglazed 25 mil resistors ranged from $-.06 \%$ to $+.49 \%$ change in resistance after all tests

- Stability for glazed 50 mil resistors ranged from $-.15 \%$ to $+.21 \%$ change in resistance after all tests

- Stability for unglazed 50 mil resistors ranged from $-.12 \%$ to $+.35 \%$ change in resistance after all tests

- Glaze improves laser trimmed resistor stability.

- Laser trimming and glaze does not effect TCR.

- TCR is within the manufacturer's specification of $\pm 100 \mathrm{ppm} /{ }^{\circ} \mathrm{C}$.

\section{Observation - 1949 Paste}

From the data shown in Appendix $E$ the following general observations can be made:

- The 825/30 firing profile produced values, for 25 mil and 50 mil wide resistors, that were less than the nominal design value.

- The values ranged from approximately $-28 \%$ to $-3 \%$ from nominal.

- The $825 / 30$ firing profile produced values, for 100 mil wide resistors, that ranged from approximately $-15 \%$ to $+25 \%$ from nominal.

- The $850 / 30$ firing profile produced resistor values that ranged from approximately $-14 \%$ to $+20 \%$ from nominal.

- The $875 / 30$ firing profile produced values that ranged from $5 \%$ to $85 \%$ from nominal.

- The $850 / 60$ firing profile produced results similar to the $850 / 30$ profile with resistor values that ranged from approximately $-8 \%$ to $+30 \%$.

- Resistor values increased as resistor size increased for each profile.

- The glaze overcoat does not effect post fired resistor values.

- An acceptable operating range was established for unglazed samples.

- An acceptable operating range was defined for the glazed samples, however the envelopes are smaller and area of overlap is much less. 
- Laser trimming resistors, glazed or unglazed, reduces their stability.

- The stability of glazed samples trimmed within the envelope ranged from $+.06 \%$ to $+.31 \%$ change in resistance after all tests.

- The stability of unglazed samples trimmed within the envelope ranged from $-.03 \%$ to $+.27 \%$ change in resistance after all tests.

- An operating point was selected for the glazed samples: a pulse rate of $4 \mathrm{KHz}$ at $625 \mathrm{~mW}$ at .4 ips.

- An operating point was selected for the unglazed samples: a pulse rate of $4 \mathrm{KHz}$ at $450 \mathrm{~mW}$ at .4 ips.

- The $\mathbf{2 5}$ mil wide resistors, both glazed and unglazed, trimmed at the operating point are less stable than the 50 mil wide resistors.

- Stability for glazed 25 mil wide resistors ranged from $-.07 \%$ to $+.74 \%$ change in resistance after all tests.

- Stability for unglazed 25 mil wide resistors ranged from $-.1 \%$ to $+1.28 \%$ change in resistance after all tests.

- Stability for glazed 50 mil wide resistors ranged from $-.07 \%$ to $+.25 \%$ change in resistance after all tests.

- Stability for unglazed 50 mil wide resistors ranged from $-.33 \%$ to $+1.08 \%$ change in resistance after all tests.

- Glaze makes a significant improvement in trimmed resistor stability.

- Trimming unglazed resistors effects TCR

- There is an approximate $30 \mathrm{ppm} /{ }^{\circ} \mathrm{C}$ difference between trimmed and untrimmed.

- There is no difference in TCR between trimmed and untrimmed on glaze samples.

- TCR is within the manufacturer's specification of $\pm 100 \mathrm{ppm} /{ }^{\circ} \mathrm{C}$.

\section{Observations - 1959 Paste}

From the data shown in Appendix $F$ the following general observations can be made:

- The $825 / 30$ firing profile produced resistors with values ranging from above to below the nominal design value.

- The values ranged from approximately $-40 \%$ to $+70 \%$ from nominal.

- The $850 / 30$ firing profile produced resistors with values less than the design nominal ranging from approximately $-40 \%$ to $-5 \%$ from nominal.

- The $875 / 30$ firing profile produced resistors with values similar to the $825 / 30$ profile. They ranged from $-25 \%$ to $+45 \%$ from nominal

- The $850 / 60$ firing profile produced resistors with values similar to the $825 / 30$ profile ranging from approximately $-35 \%$ to $+55 \%$ from nominal. 
- Resistor values increased as resistor size increased for each profile.

- The glaze overcoat does not effect post fired resistor values.

- An acceptable operating range was established for glazed and unglazed samples.

- Laser trimming resistors, glazed or unglazed, reduces their stability.

- The stability of resistors with glaze overcoat is significantly better than those that are unglazed.

- The stability of glazed samples trimmed within the envelope ranged from $+.04 \%$ to $+.29 \%$ change in resistance after all tests.

- The stability of unglazed samples trimmed within the envelope ranged from $-36 \%$ to $+1.87 \%$ change in resistance after all tests.

- An operating point was selected for the glazed samples: a pulse rate of $3 \mathrm{KHz}$ at $550 \mathrm{~mW}$ at .375 ips.

- An operating point was selected for the unglazed samples: a pulse rate of $4 \mathrm{KHz}$ at $450 \mathrm{~mW}$ at .4 ips.

- The stability of untrimmed resistors for this paste decade is less than for the other paste decades.

- The stability for glazed 100 mil wide resistors ranged from $-.24 \%$ to $+.27 \%$ change in resistance after all tests.

- The stability for unglazed 100 mil wide resistors ranged from $-.17 \%$ to $+.3 \%$ change in resistance after all test.

- The $\mathbf{2 5}$ mil wide resistors, both glazed and unglazed, trimmed at the operating point are less stable than the $\mathbf{5 0}$ mil wide resistors.

- Stability for glazed 25 mil resistors ranged from $-.19 \%$ to $+.67 \%$ change in resistance after all tests.

- Stability for unglazed 25 mil wide resistors ranged from $+.28 \%$ to $11.84 \%$ change in resistance after all tests.

- Stability for glazed 50 mil wide resistors ranged from $-.12 \%$ to $+.54 \%$ change in resistance after all tests.

- Stability for unglazed 50 mil wide resistors ranged from $-.12 \%$ to $5.97 \%$ change in resistance after all tests.

- Glaze makes a significant improvement in trimmed resistor stability.

- Trimming unglazed resistors effects TCR

- There is an approximate $100 \mathrm{ppm} /{ }^{\circ} \mathrm{C}$ difference between trimmed and untrimmed.

- There is no difference in TCR between trimmed and untrimmed on glaze samples.

- TCR is within the manufacturer's specification of $\pm 100 \mathrm{ppm} /{ }^{\circ} \mathrm{C}$ on trimmed glaze samples. 
- TCR on trimmed unglazed samples does not meet manufacturer's specifications of $\pm 100 \mathrm{ppm} /{ }^{\circ} \mathrm{C}$ at $-55^{\circ} \mathrm{C}$. 


\section{ACCOMPLISHMENTS}

Data gathered and analyzed during this evaluation have established the following:

- Characterization of the laser trim process using Du Pont 1911, 1921, 1931, 1939, 1949, and 1959 resistor pastes on 2 layers of Du Pont 5704 dielectric printed on $96 \%$ alumina ceramic substrate.

- Characterization of the operating performance of these laser trimmed resistors.

Analysis of the data has allowed the following recommendations to be made:

- 1911 paste should not be used because of paste cracking after firing leading to poor resistor stability.

- The minimum resistor dimension should be 0.050 inches.

- Resistors should be glaze over-coated to maximize stability and minimize changes in TCR due to laser trimming.

- TCR, for trimmed/glazed samples, was determined to be within the manufacturer's specification of $\pm 100 \mathrm{ppm}{ }^{\circ} \mathrm{C}$.

- Preliminary estimates, for glazed samples, indicate that resistor tolerances as tight as $\pm 1 \%$ are possible with $100 \%$ yield for resistors made with 1921 through 1959 pastes. Since this is preliminary, it is recommended initially that tolerances should not be tighter than $\pm 2 \%$. 


\section{FUTURE WORK}

An additional characterization was conducted, in parallel with this effort, on Du Pont 2000 series resistors for use on low temperature cofired ceramic. Resistor performance on this substrate was very good. This resistor series will be evaluated on 2 layers on Du Pont 5704 dielectric on $96 \%$ alumina substrate to determine its potential. Dependent on the results of this evaluation, further evaluations of resistor performance on additional layers of dielectric will be conducted. This will determine the effects of dielectric thickness on resistor performance. 


\section{APPENDIX A}

\section{Test Results For The 1911 Paste}

\section{Pre Trim Distribution}

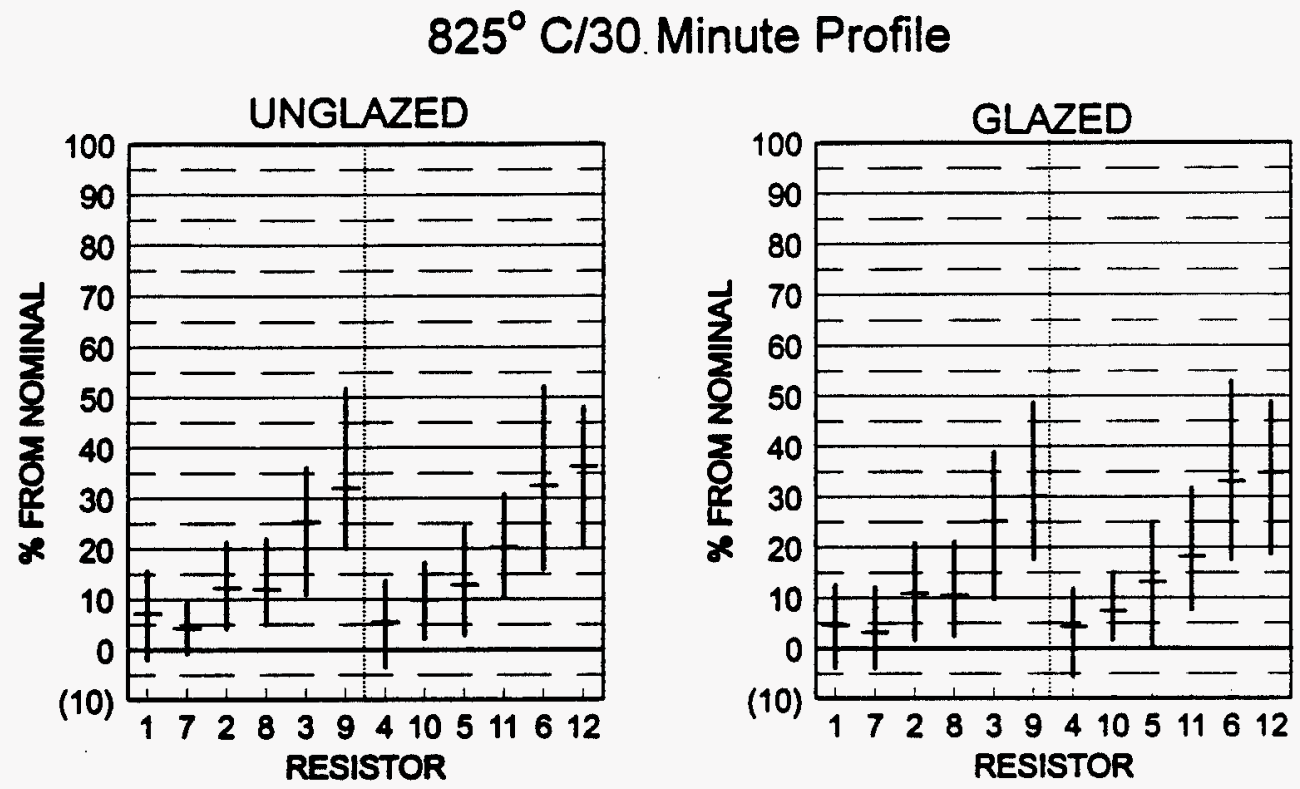

Figure 2
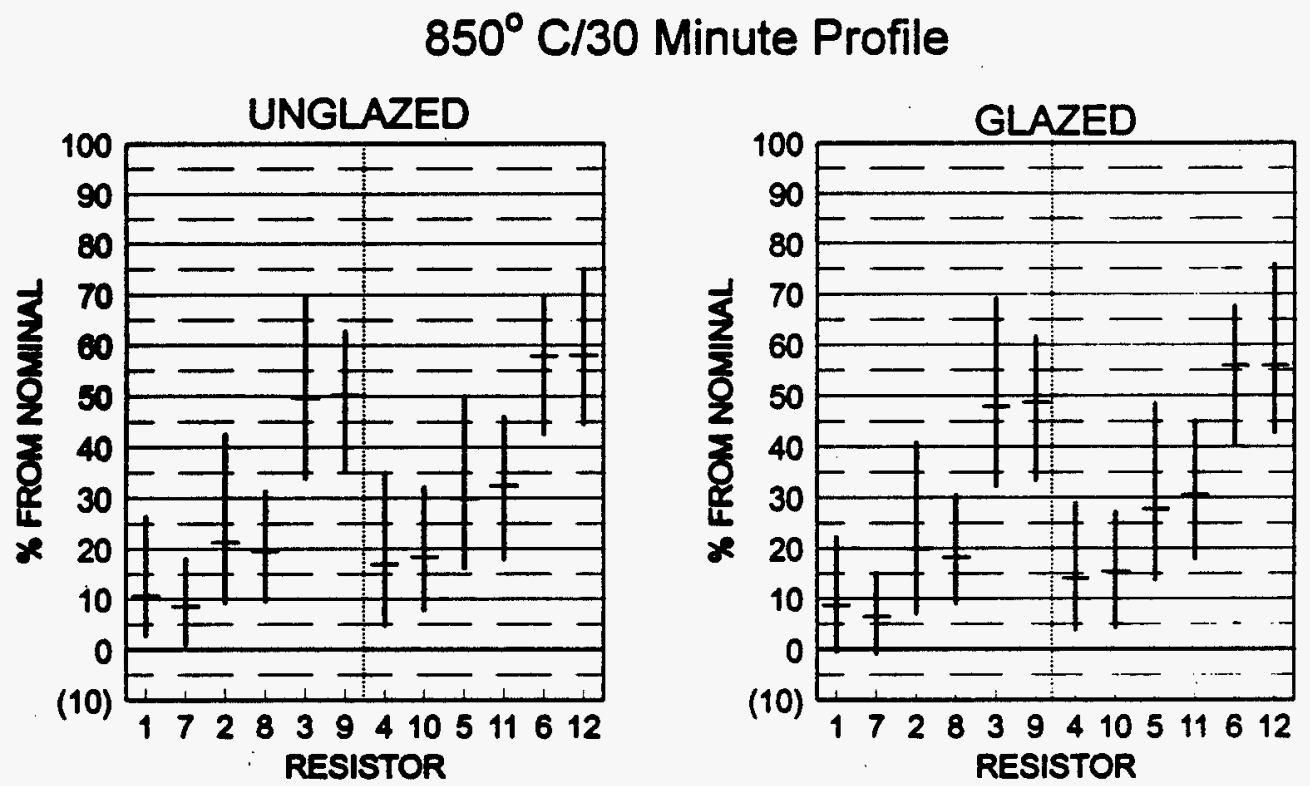

Figure 3 


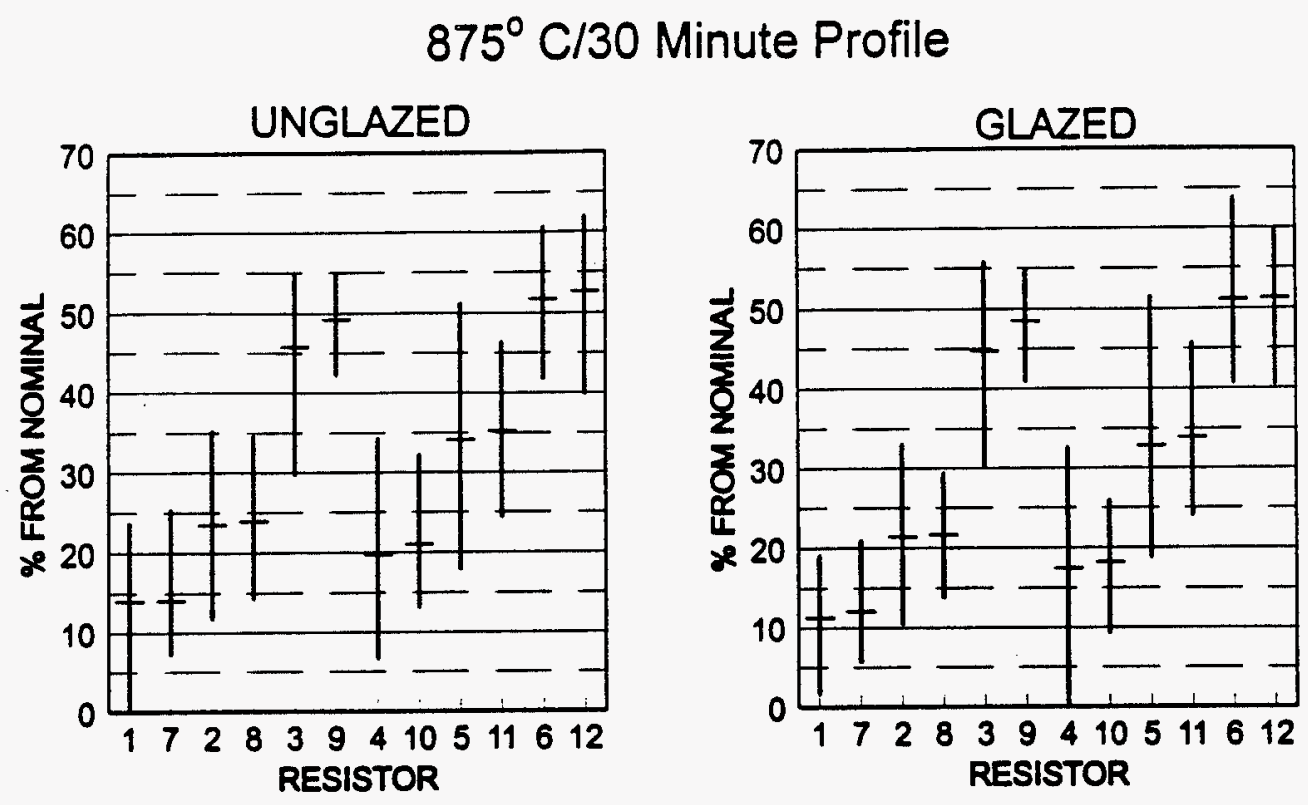

Figure 4
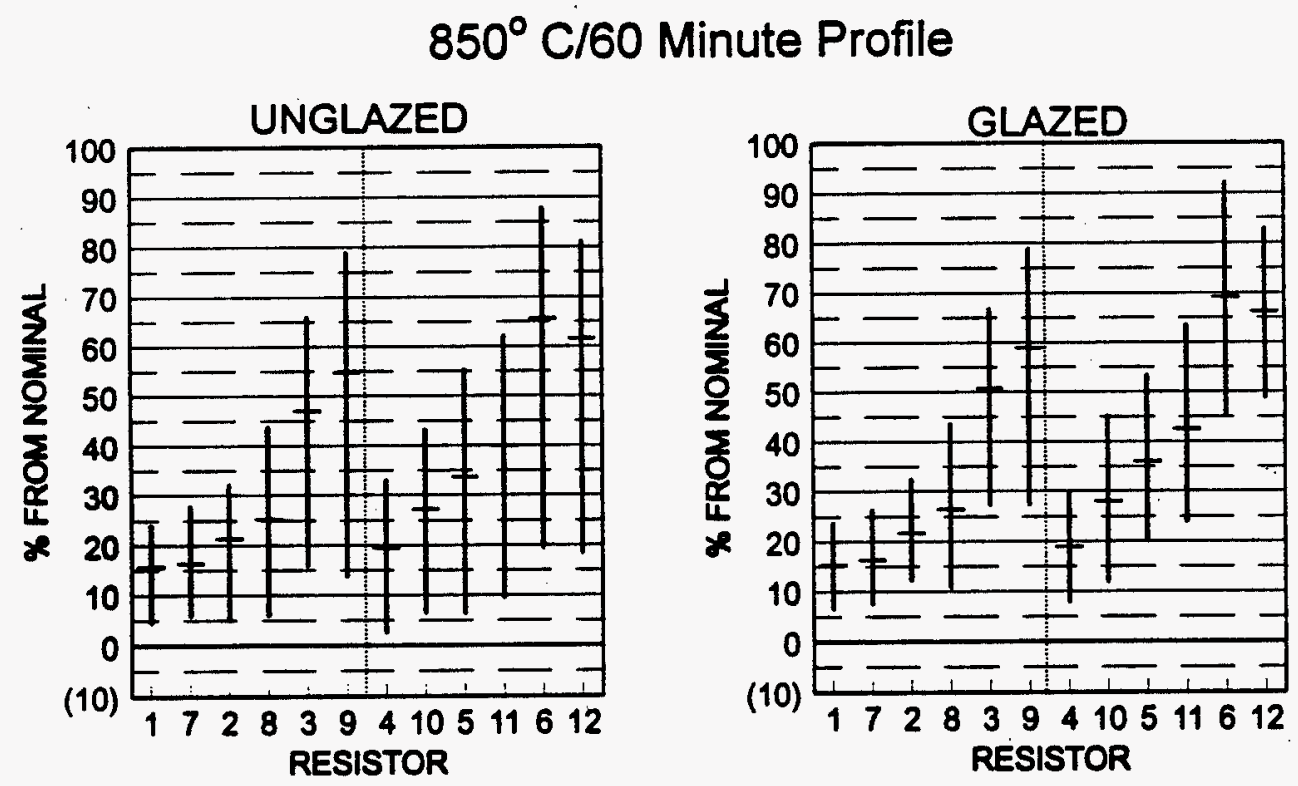

Figure 5 
Operating Envelope

\section{No Glaze on Resistors}

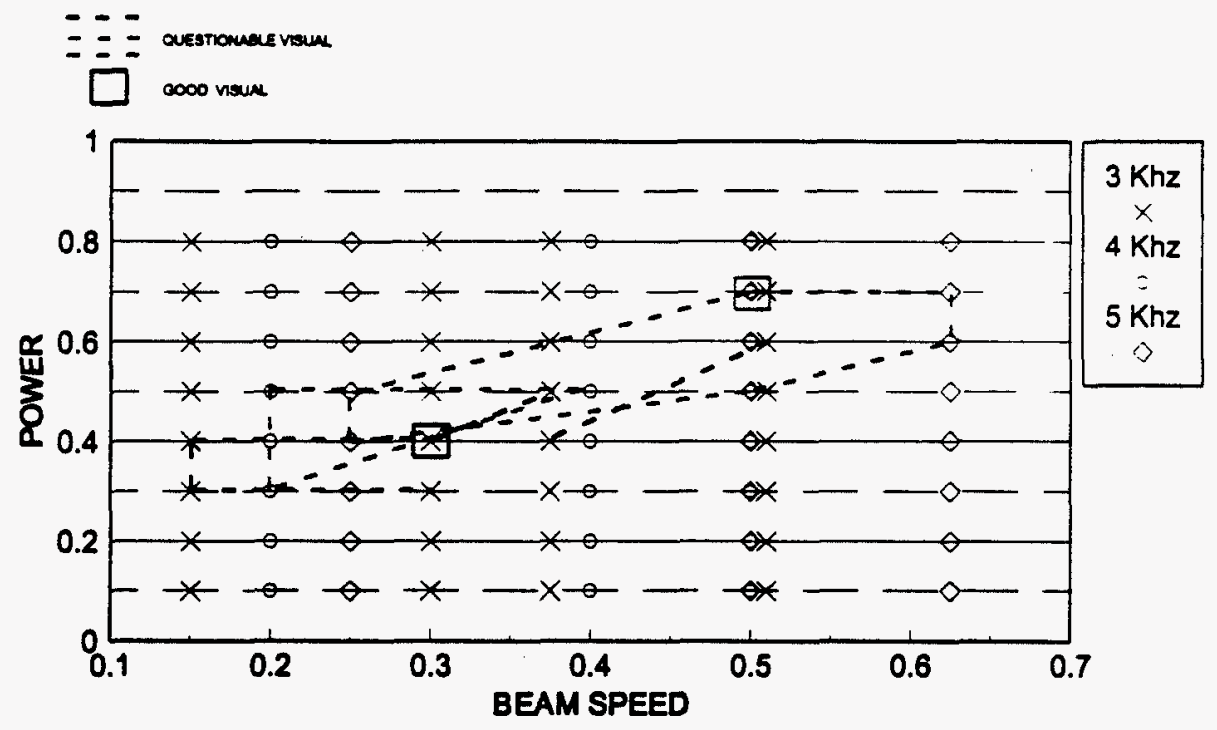

Figure 6

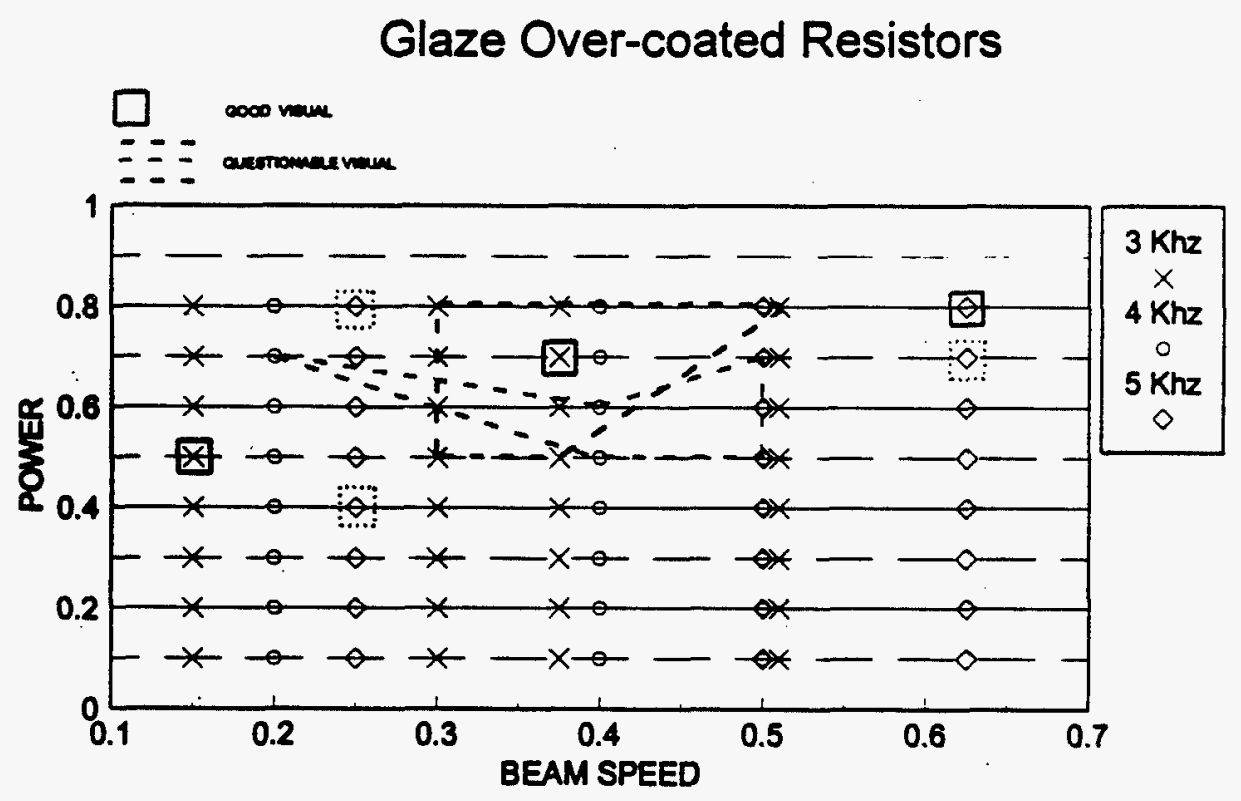

Figure 7 


\section{APPENDIX B}

\section{Test Results For The 1921 Paste}

\section{Pre Trim Distribution}

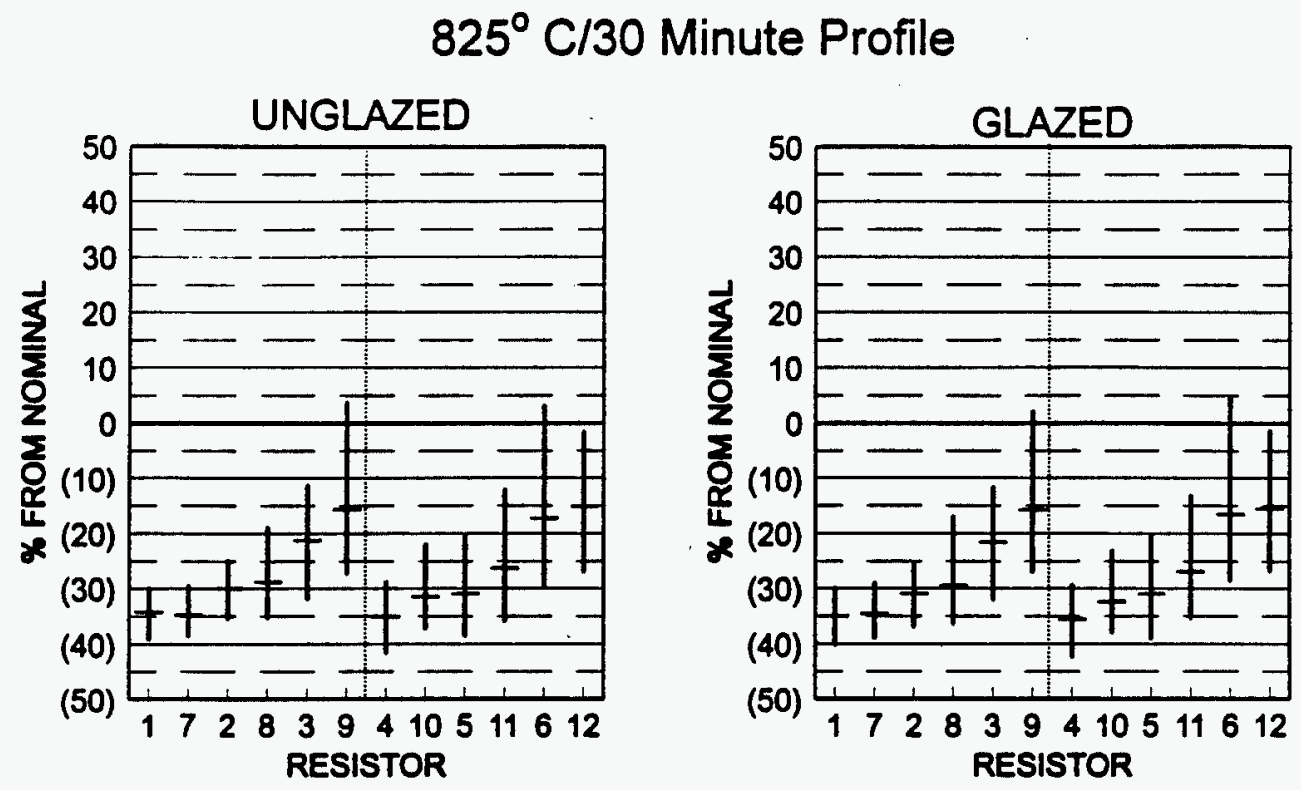

Figure 8
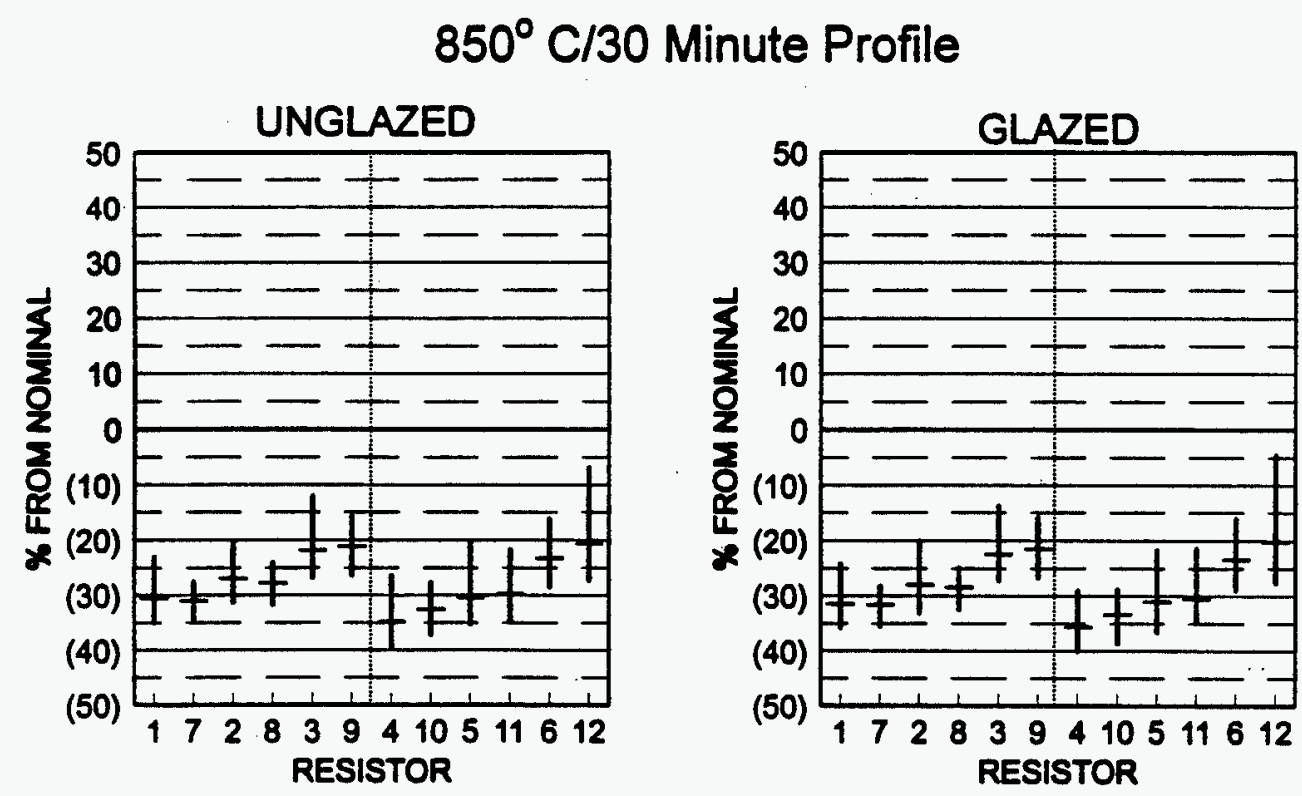

Figure 9 

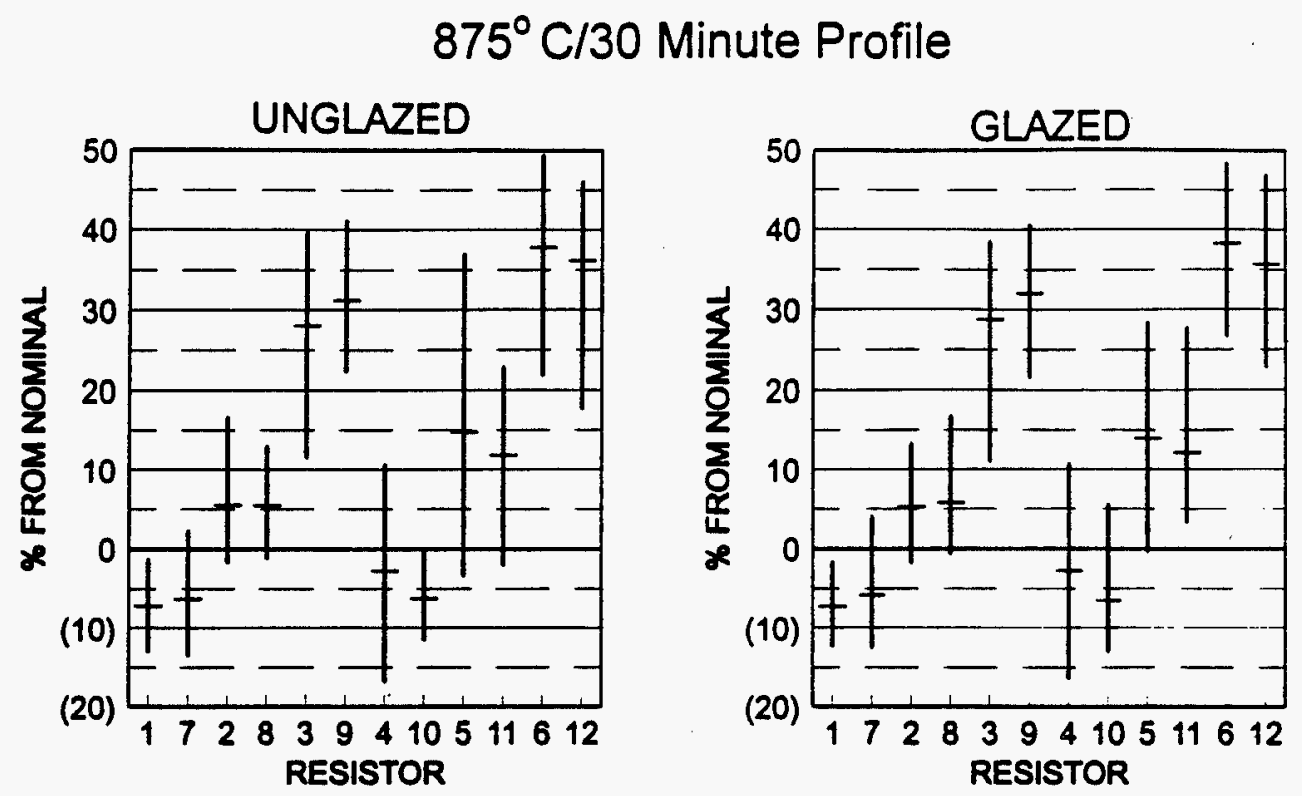

Figure 10
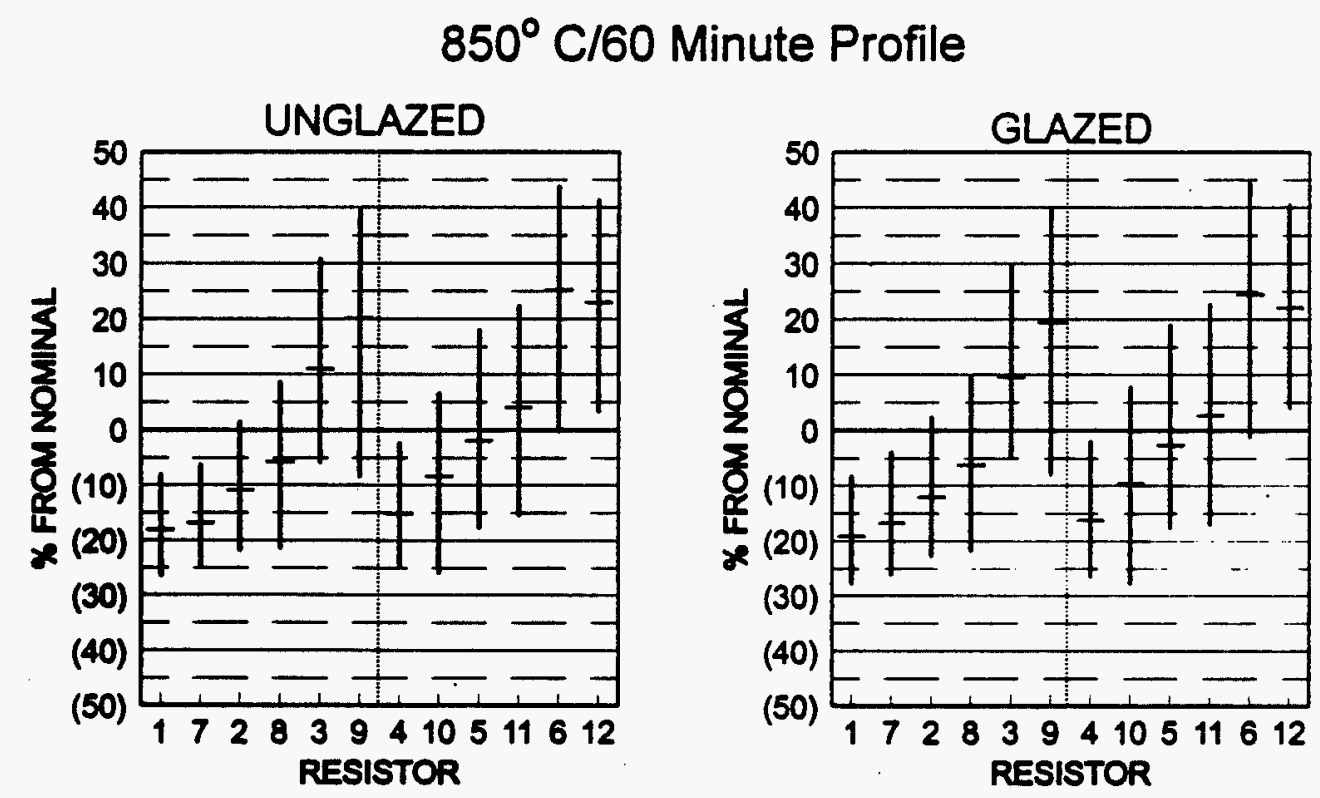

Figure 11 
Operating Envelope

No Glaze on Resistors

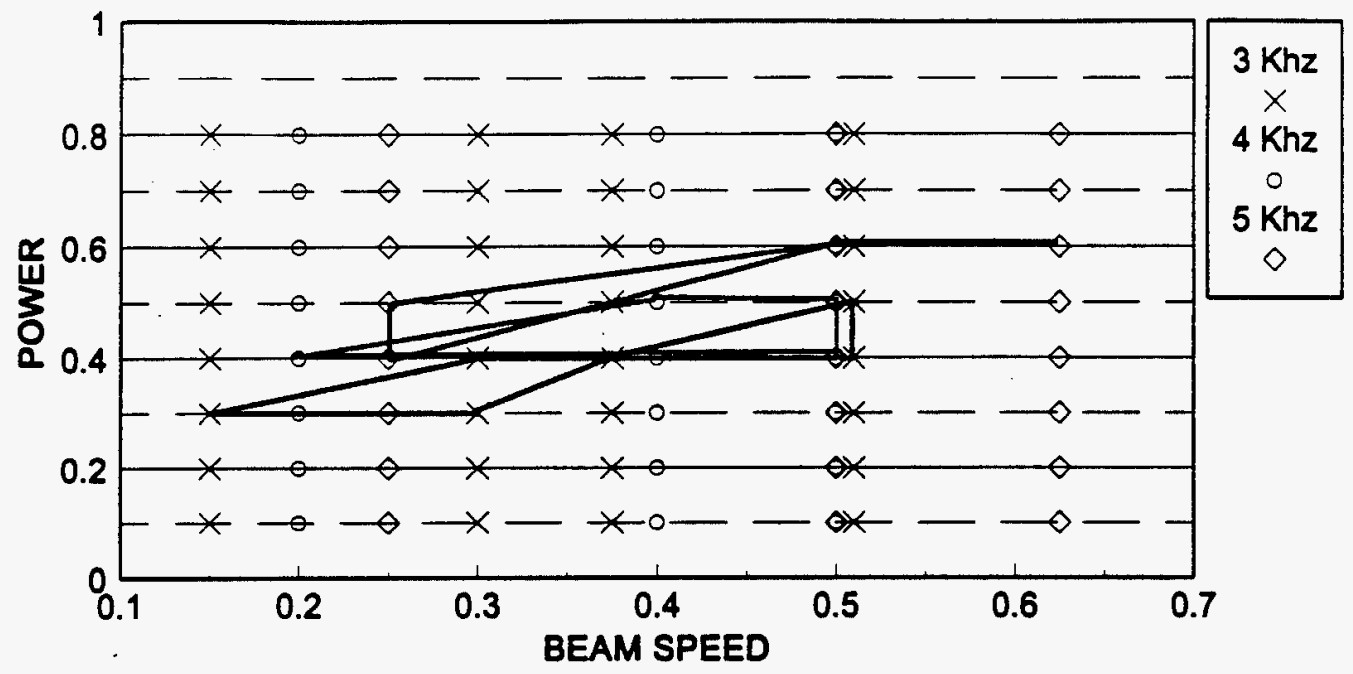

Figure 12

\section{Glaze Over-coated Resistors}

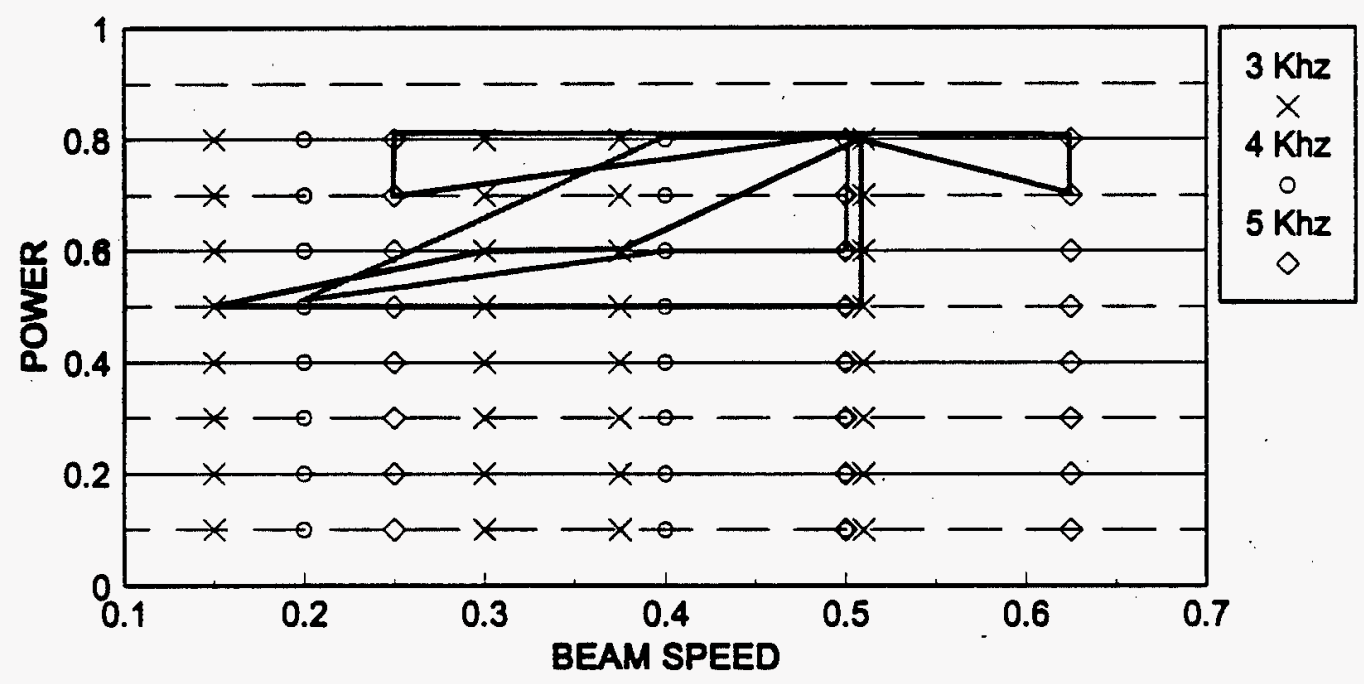

Figure 13 
Stability For Resistors Trimmed Within The Operating Envelope - Unglazed

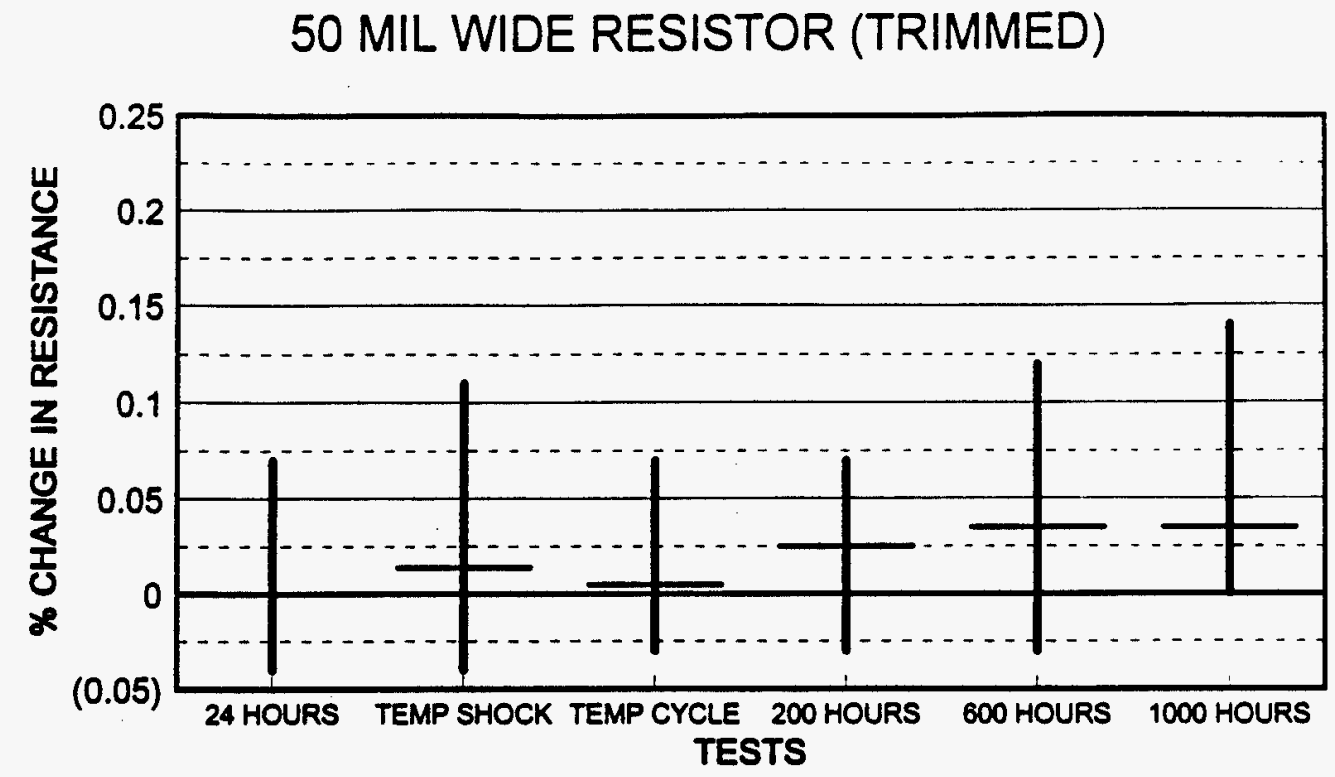

Figure 14

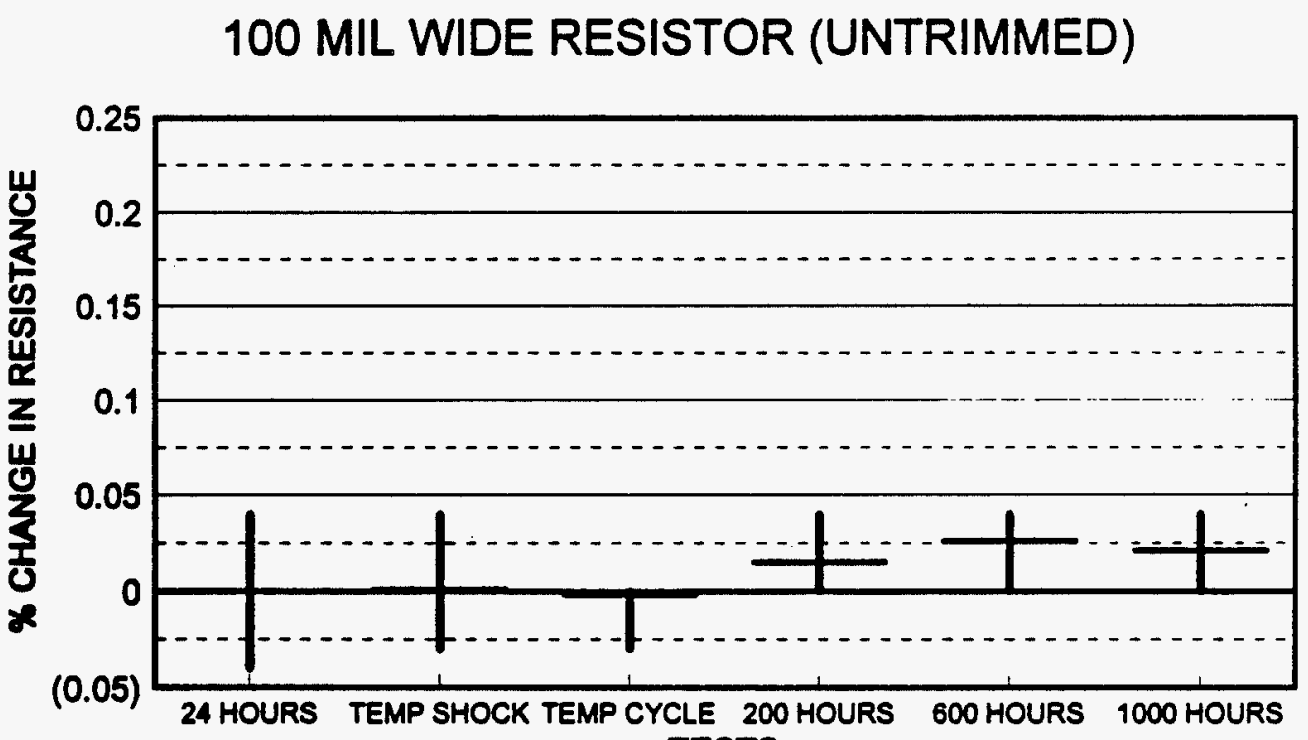

TESTS

Figure 15 
Stability For Resistors Trimmed Within The Operating Envelope - Glazed

50 MIL WIDE RESISTOR (TRIMMED)

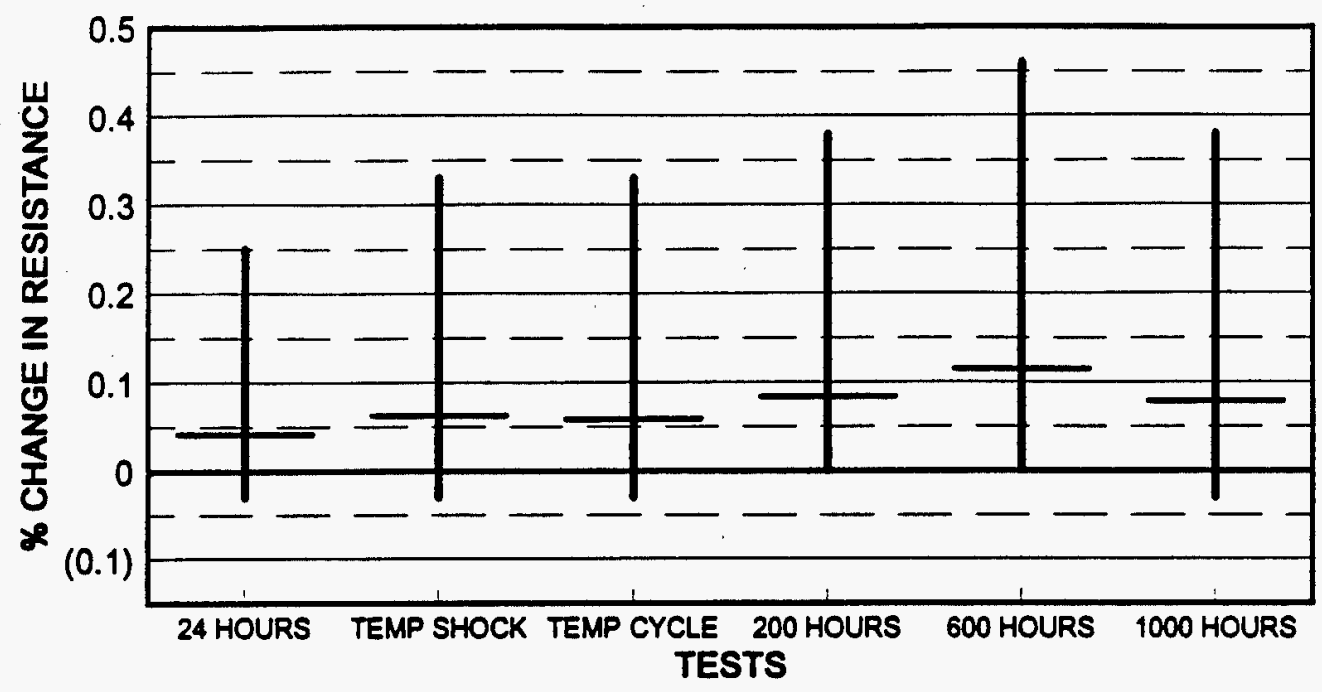

Figure 16

100 MIL WIDE RESISTOR (UNTRIMMED)

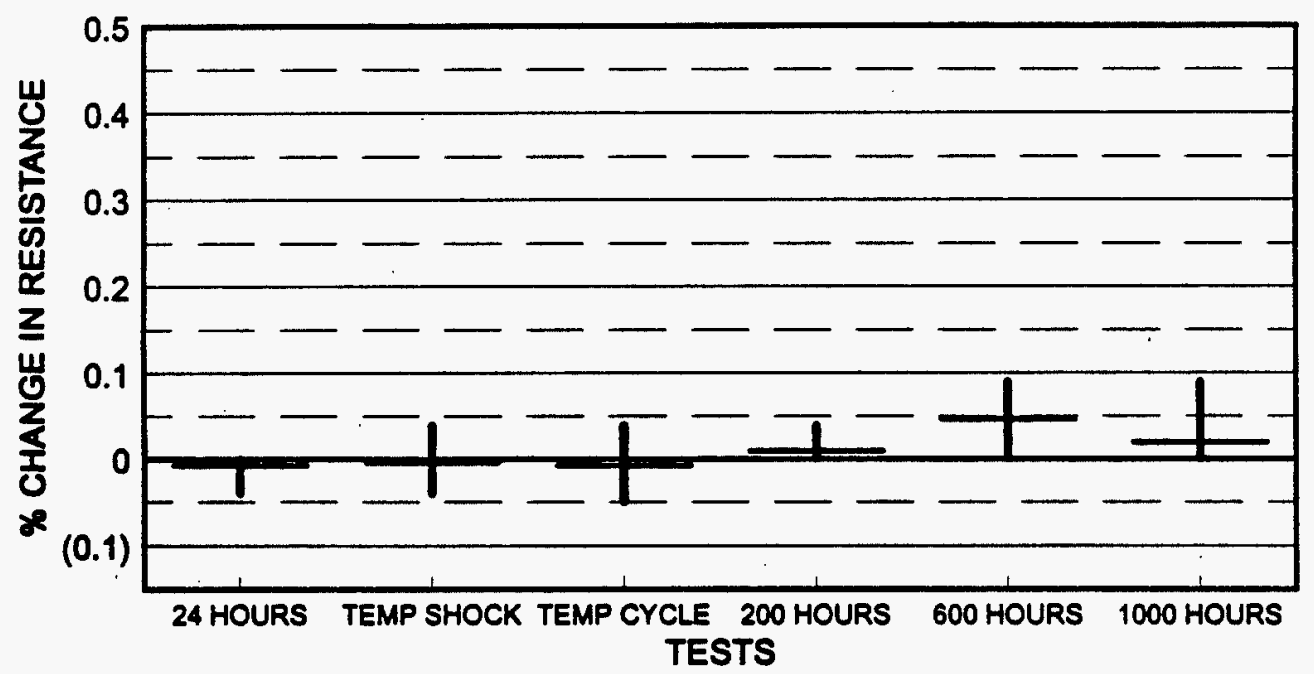

Figure 17 
Stability For Resistors Trimmed At The Operating Point - Unglazed

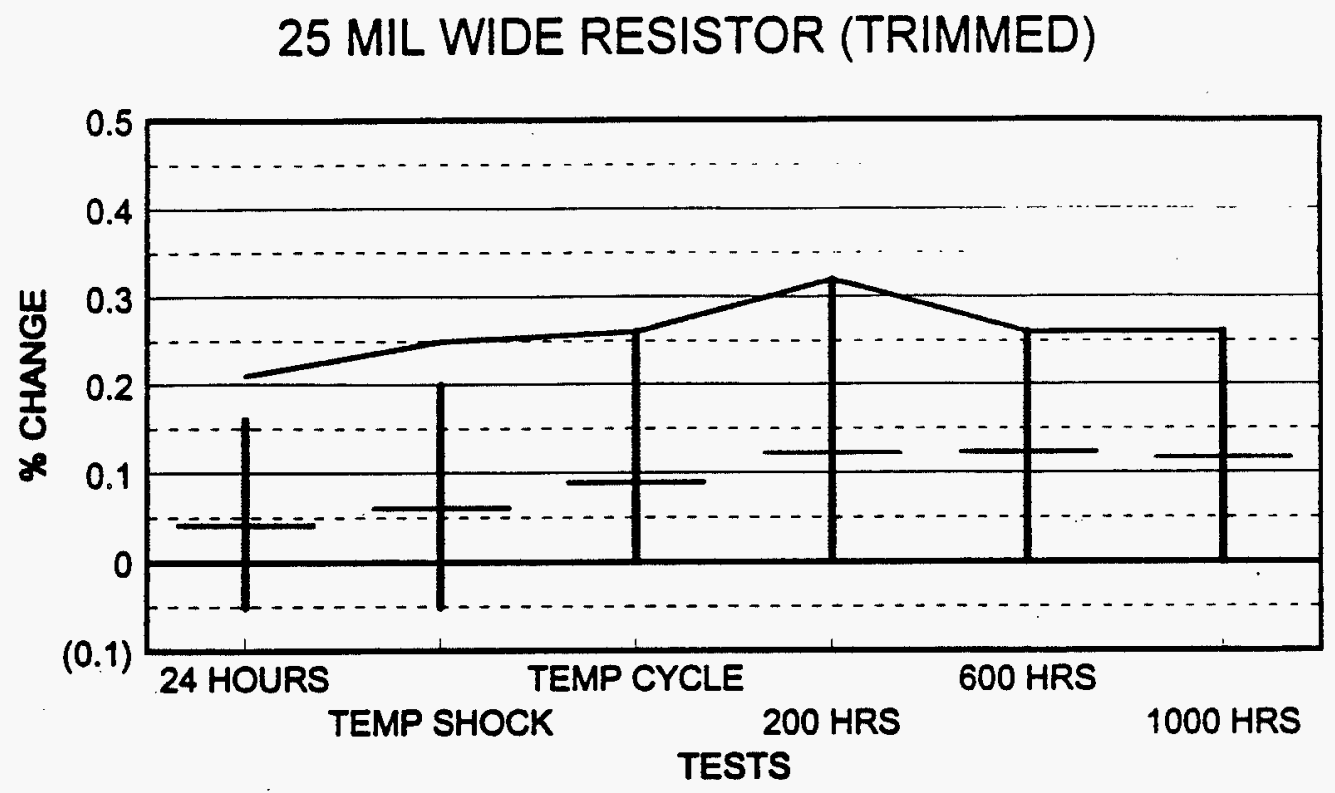

Figure 18

50 MIL WIDE RESISTOR (TRIMMED)

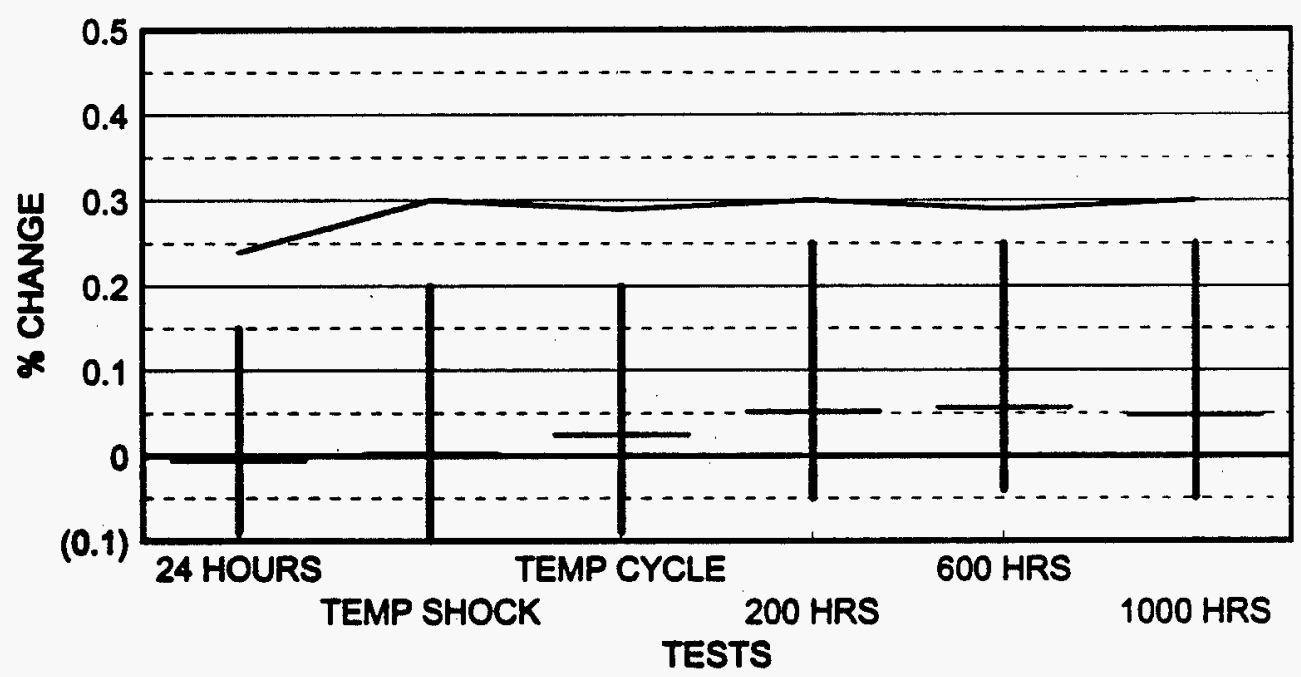

Figure 19 


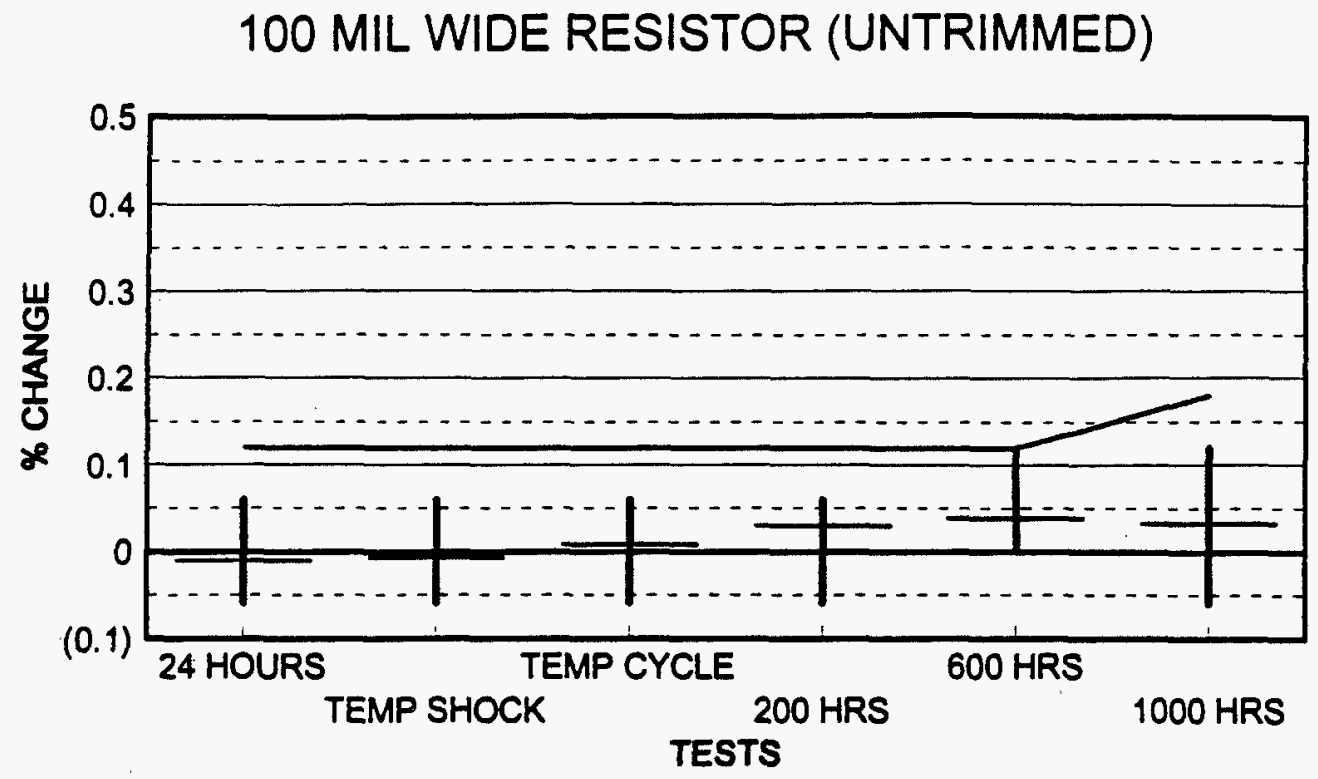

Figure 20

\section{Stability For Resistors Trimmed At The Operating Point - Glazed}

25 MIL WIDE RESISTOR (TRIMMED)

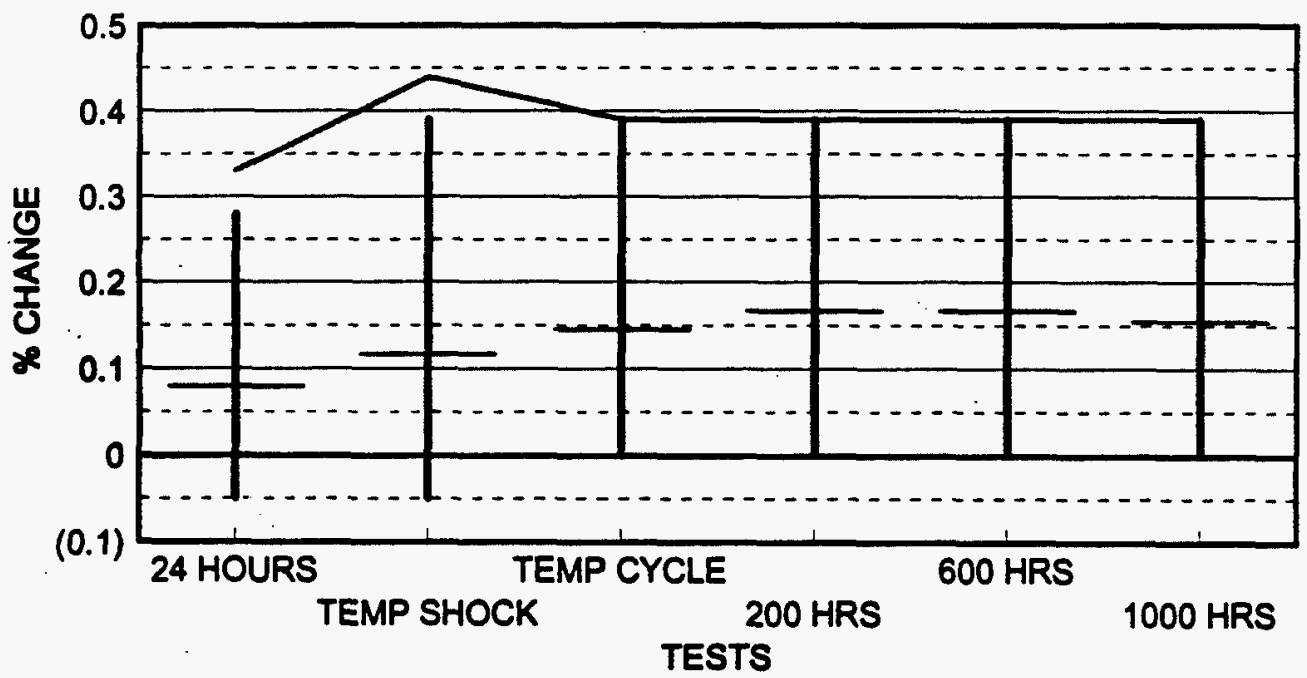

Figure 21 


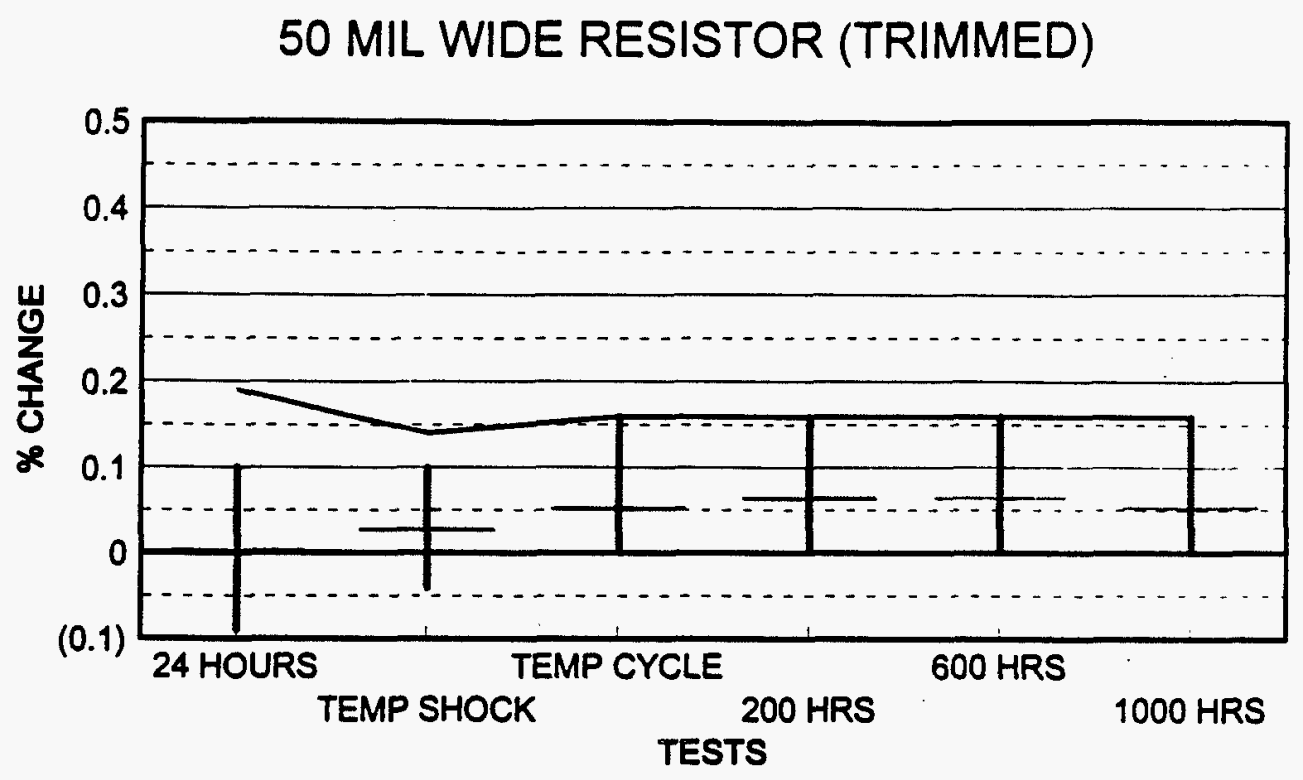

Figure 22

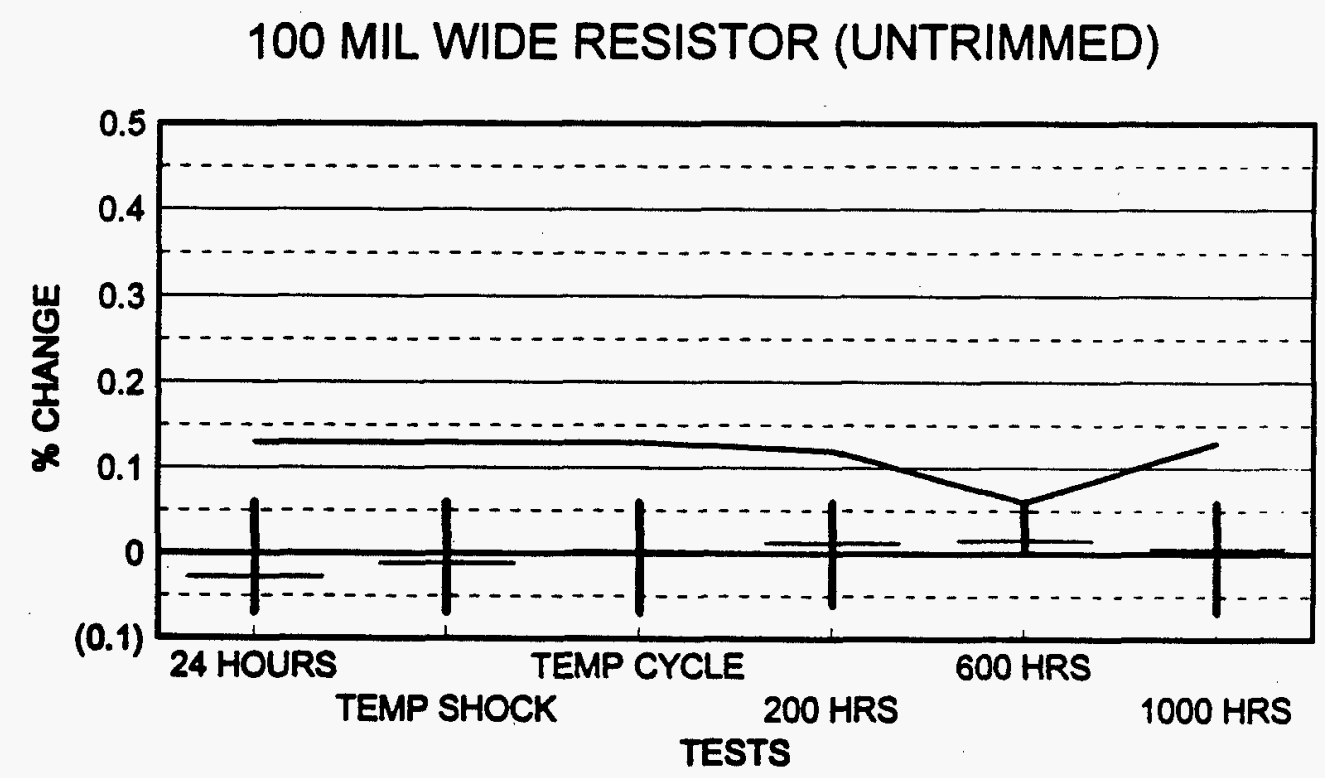

Figure 23 
Analysis Of Resistor Tolerance and Yield Based on Samples Trimmed At The Operating Point - Unglazed

\section{MIL WIDE RESISTOR}

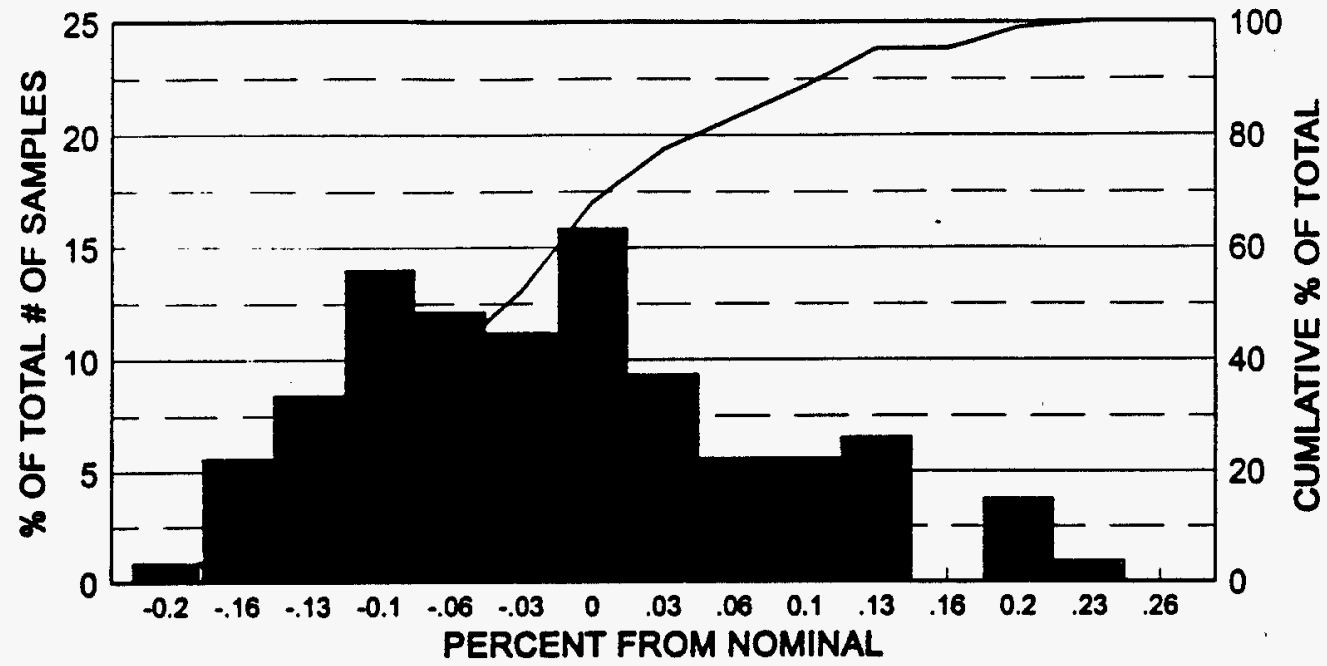

Figure 24

50 MIL WIDE RESISTOR

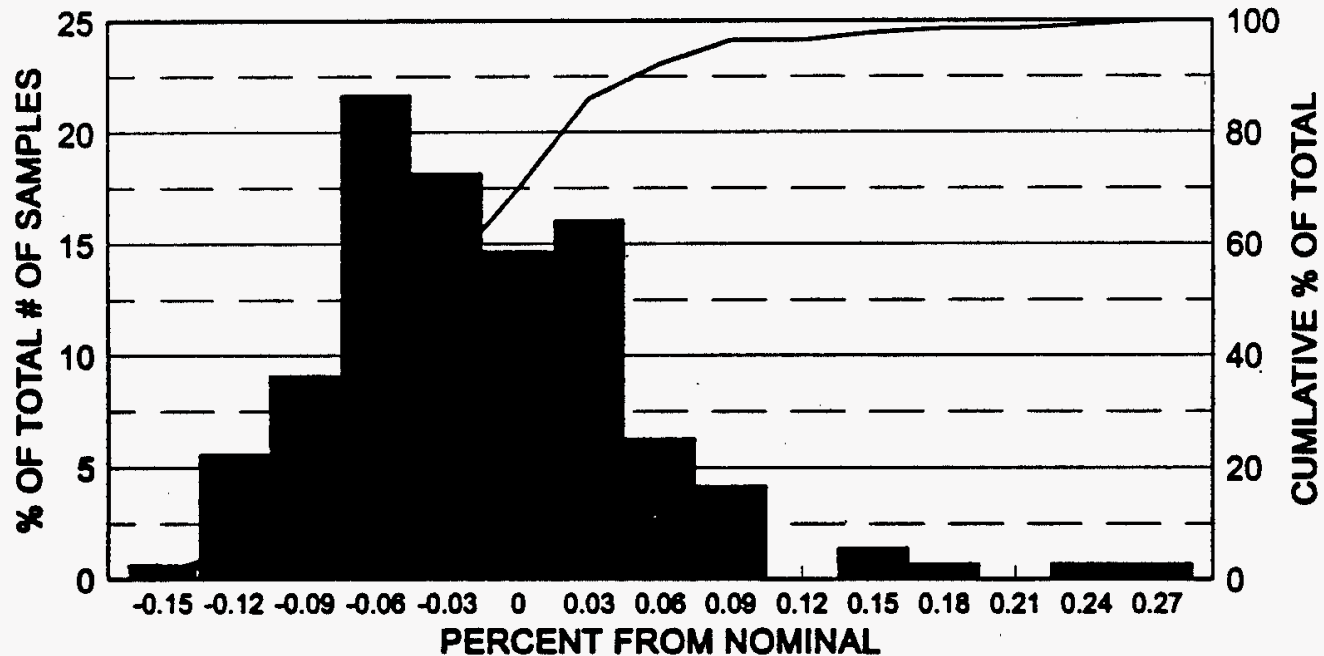

Figure 25 
Analysis Of Resistor Tolerance and Yield Based on Samples Trimmed At The Operating Point - Glazed

\section{MIL WIDE RESISTOR}

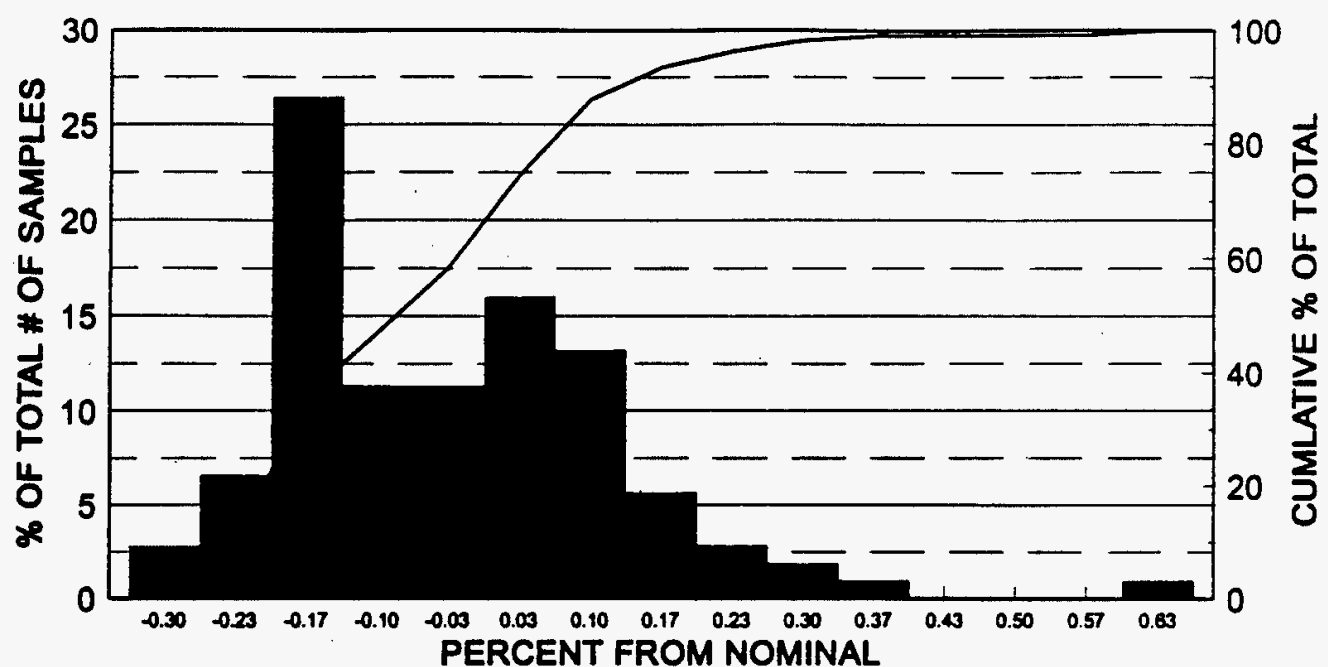

Figure 26

50 MIL WIDE RESISTOR

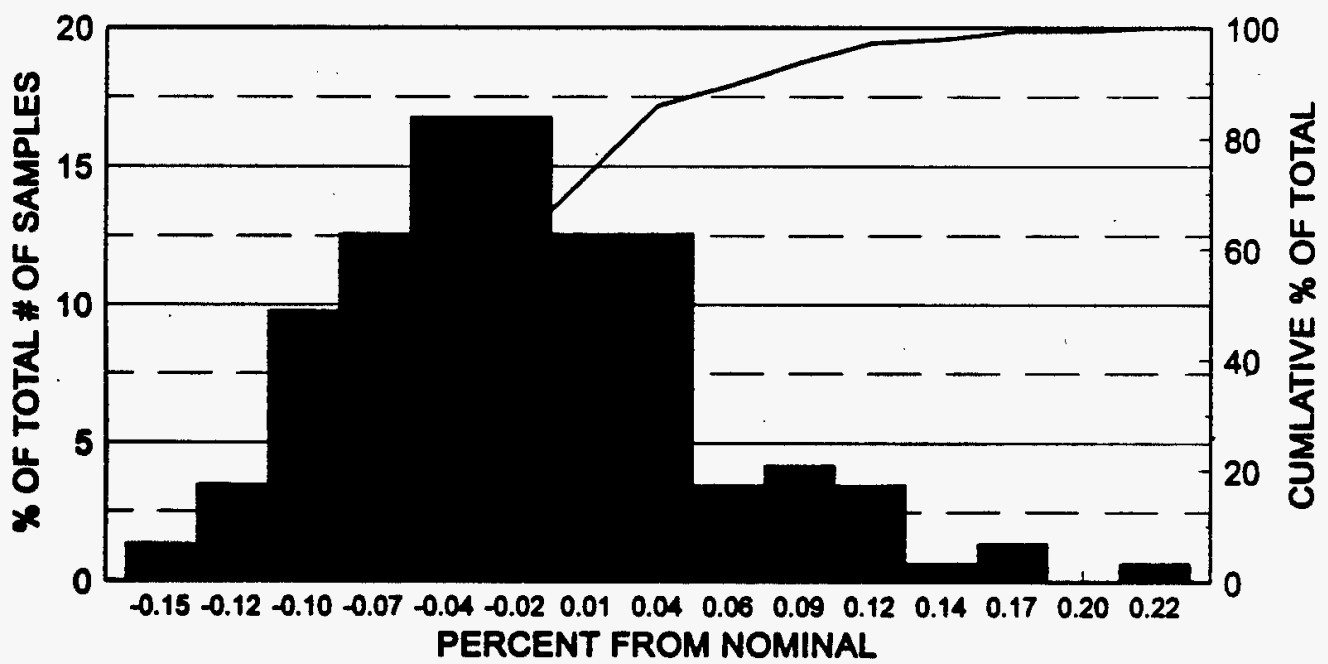

Figure 27 


\section{APPENDIX C}

Test Results For The 1931 Paste

Pre Trim Distribution

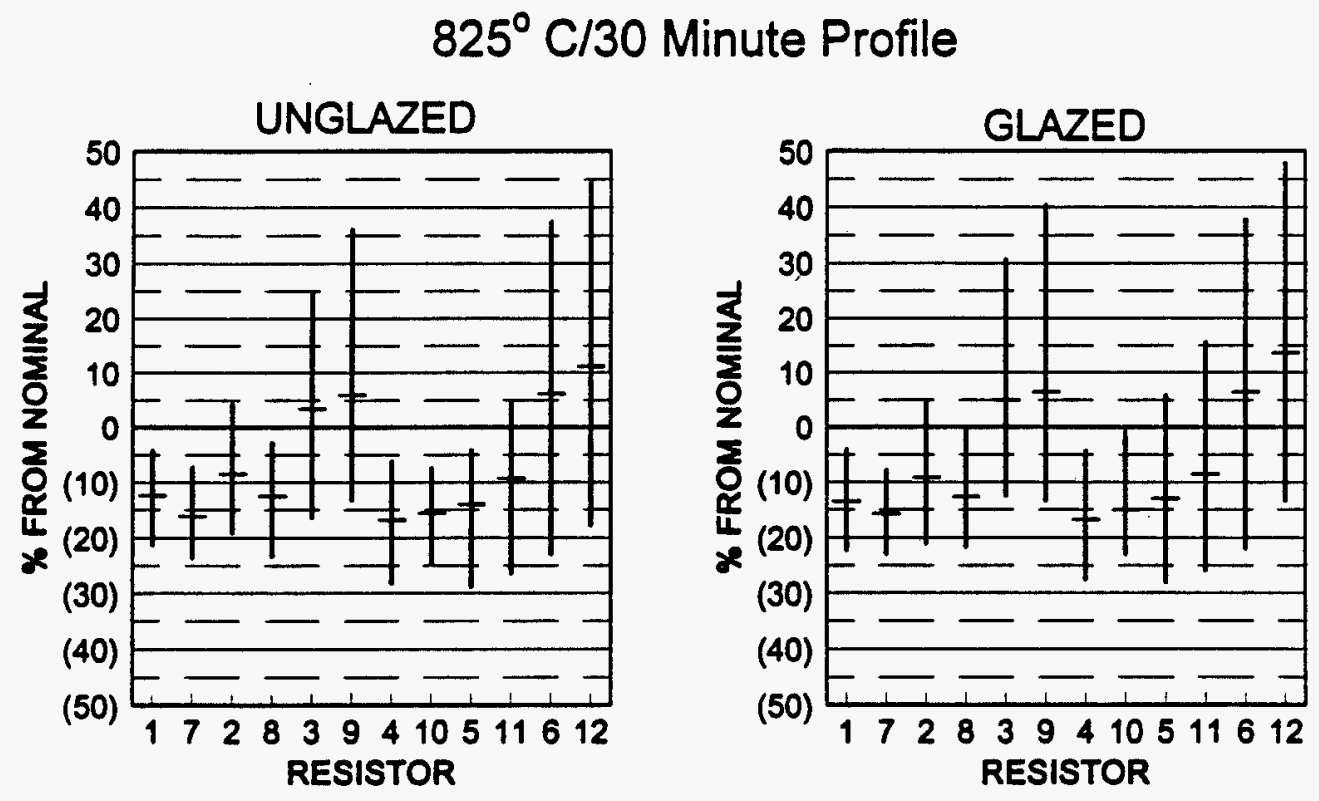

Figure 28
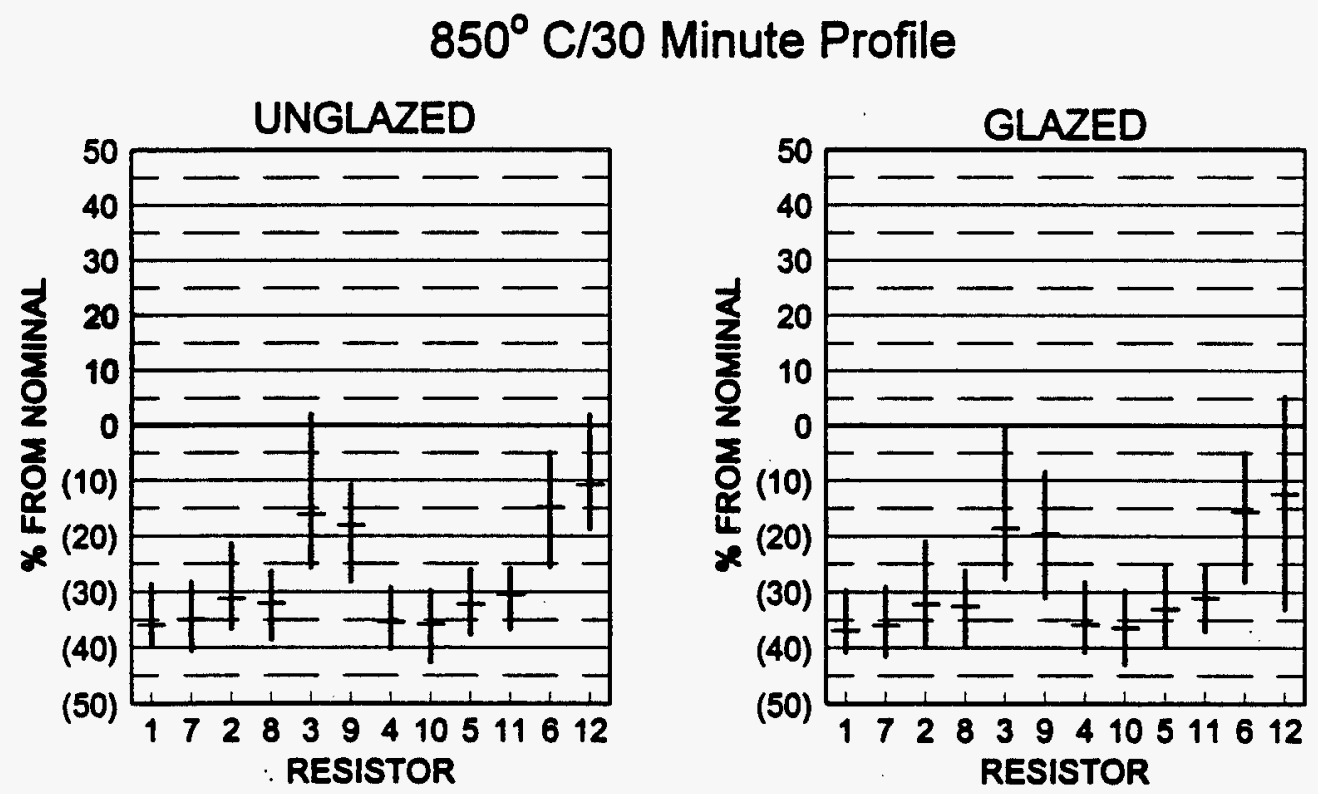

Figure 29 

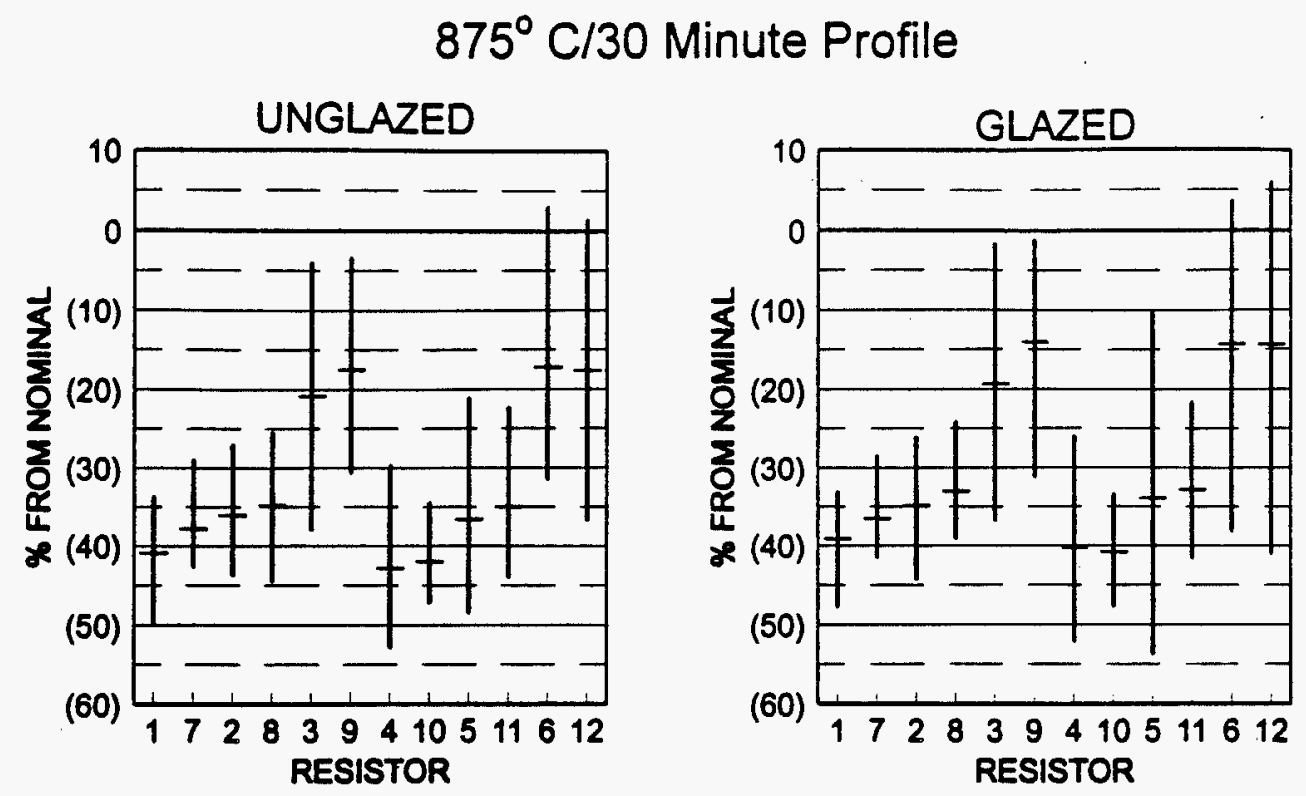

Figure 30

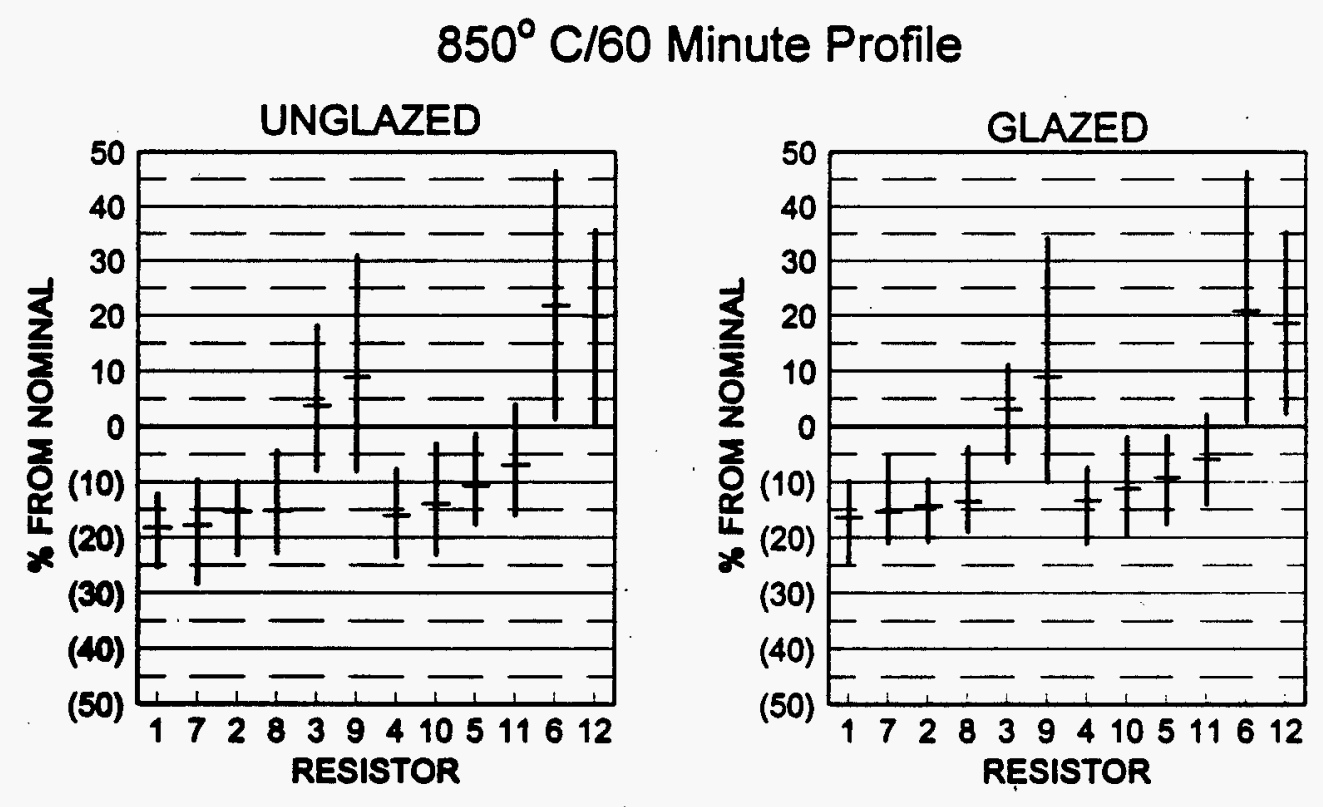

Figure 31 


\section{Operating Envelope}

No Glaze on Resistors

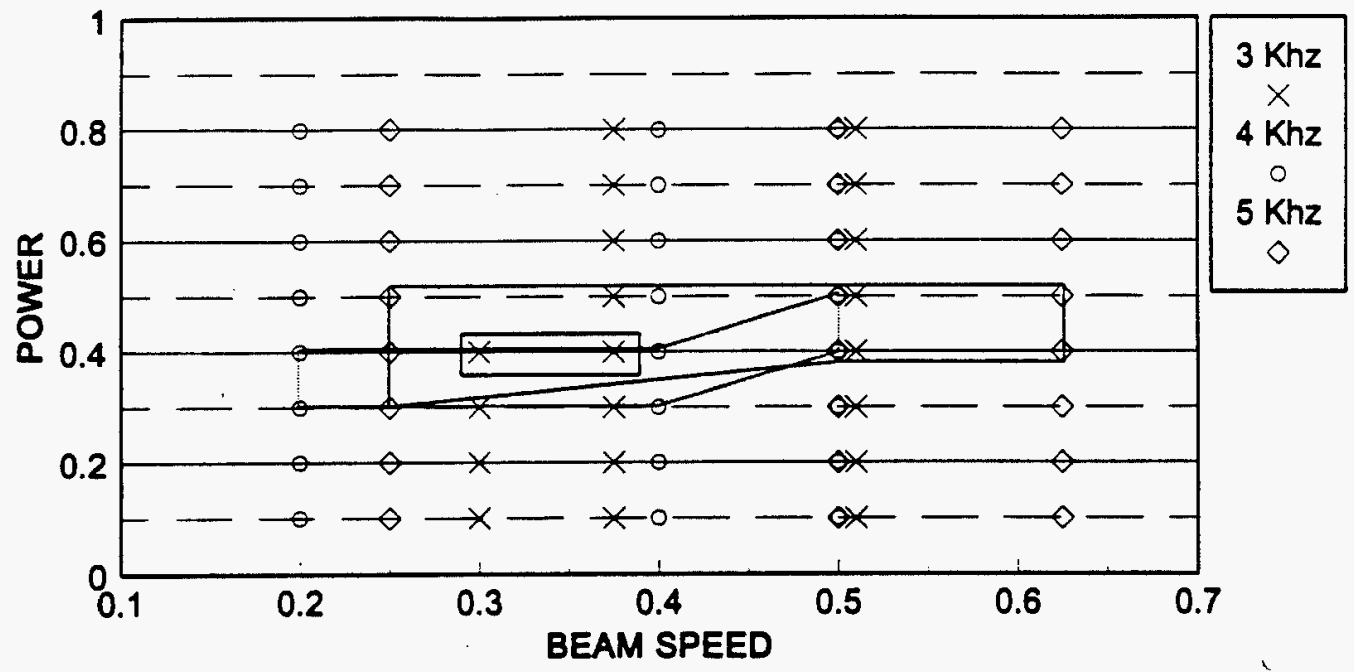

Figure 32

Glaze Over-coated Resistors

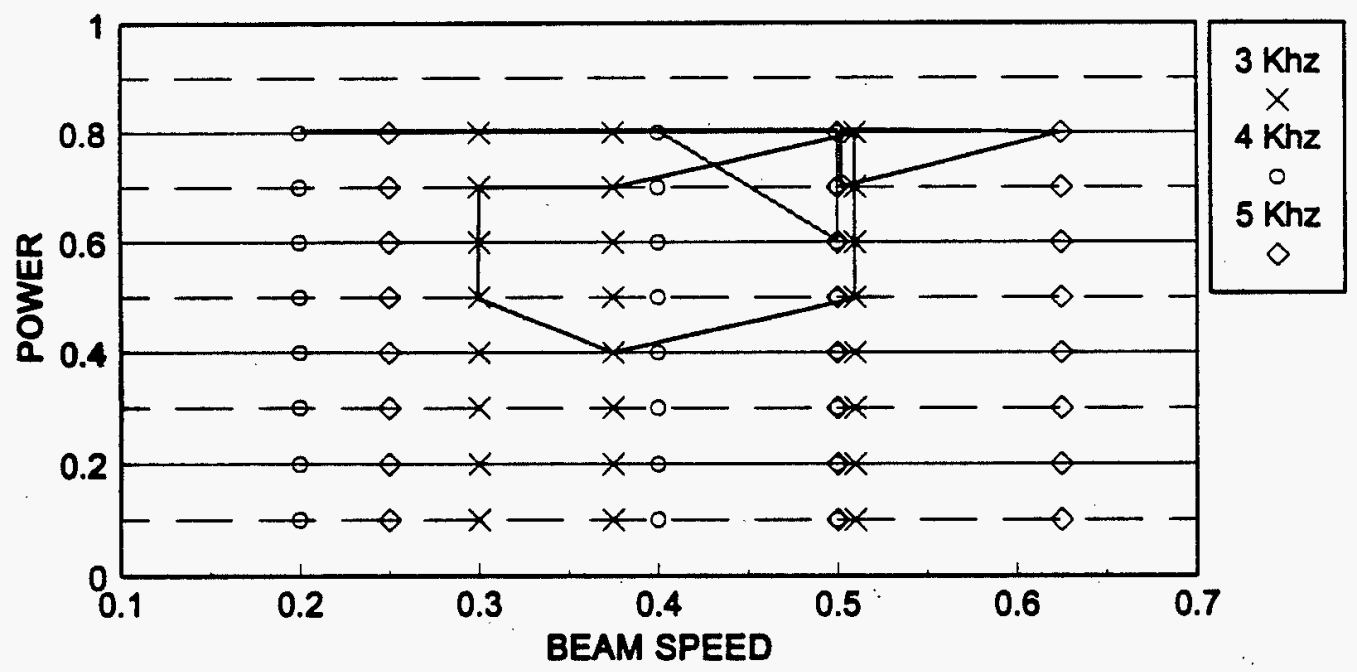

Figure 33 
Stability For Resistors Trimmed Within The Operating Envelope - Unglazed

50 MIL WIDE RESISTOR (TRIMMED)

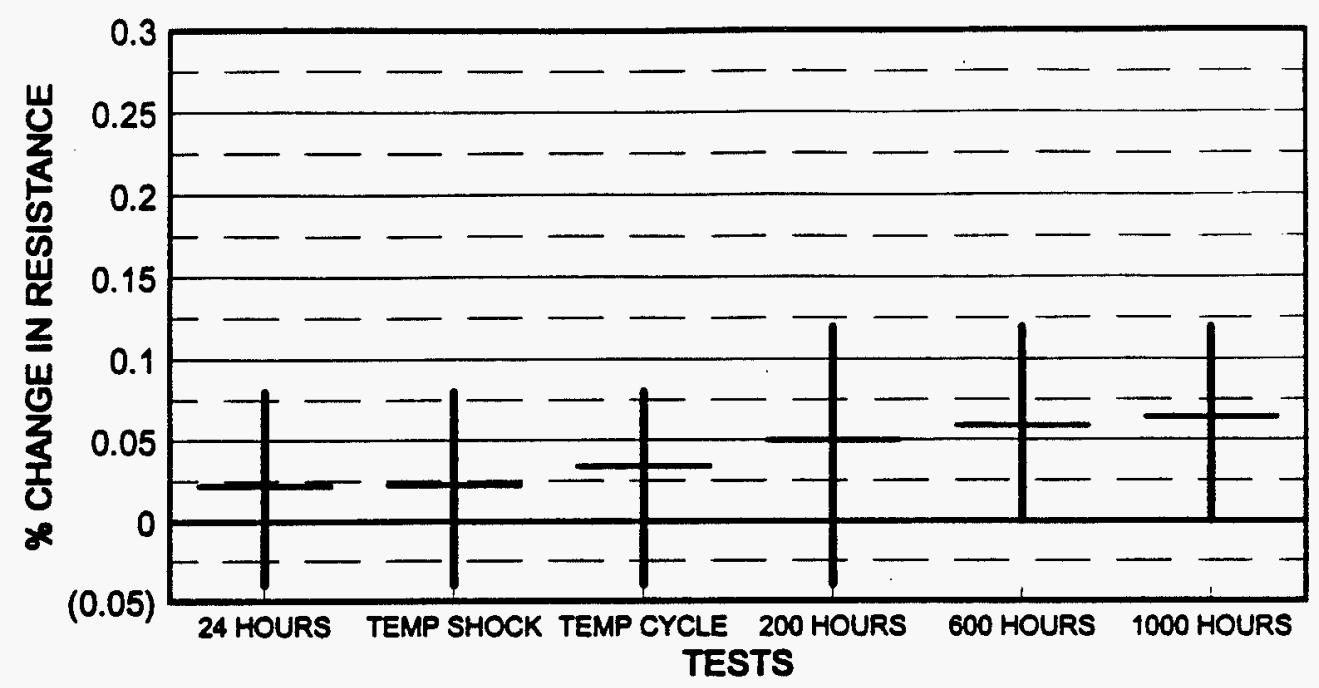

Figure 34

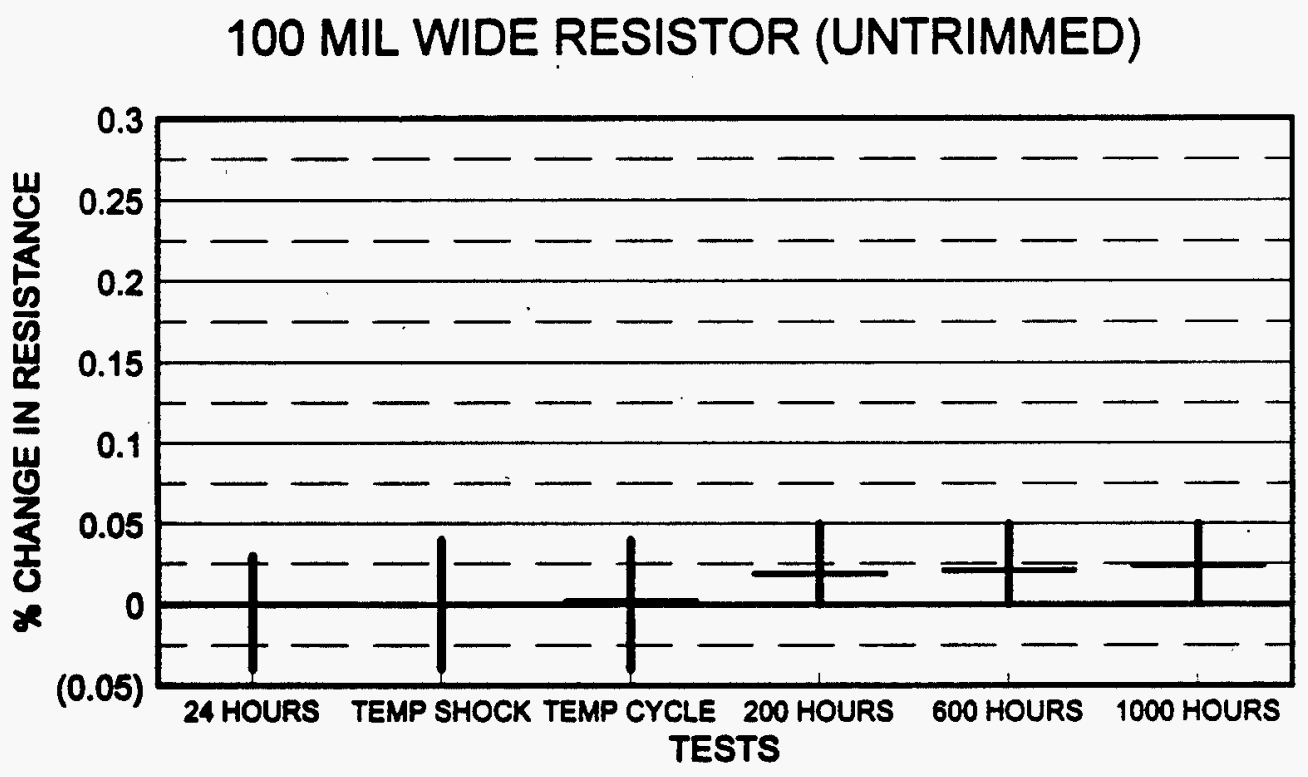

Figure 35 


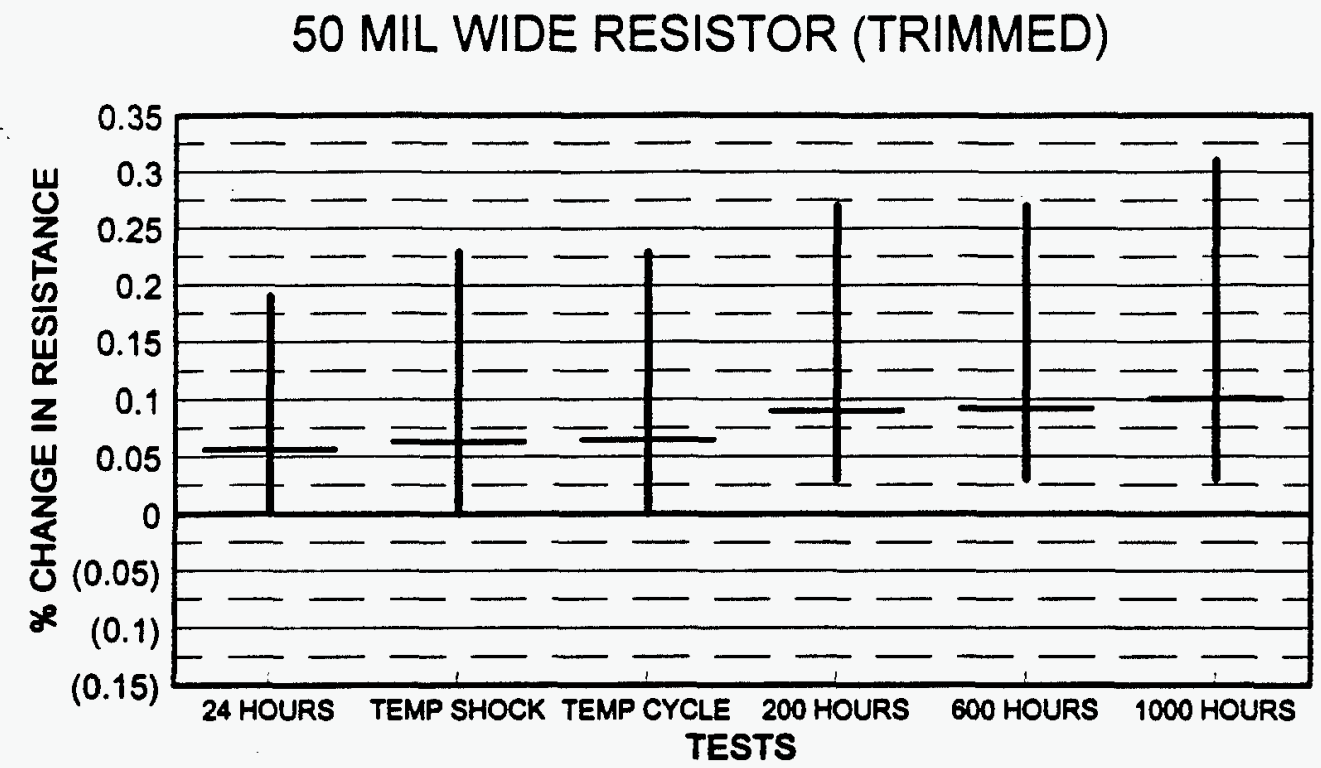

Figure 36

\section{MIL WIDE RESISTOR (UNTRIMMED)}

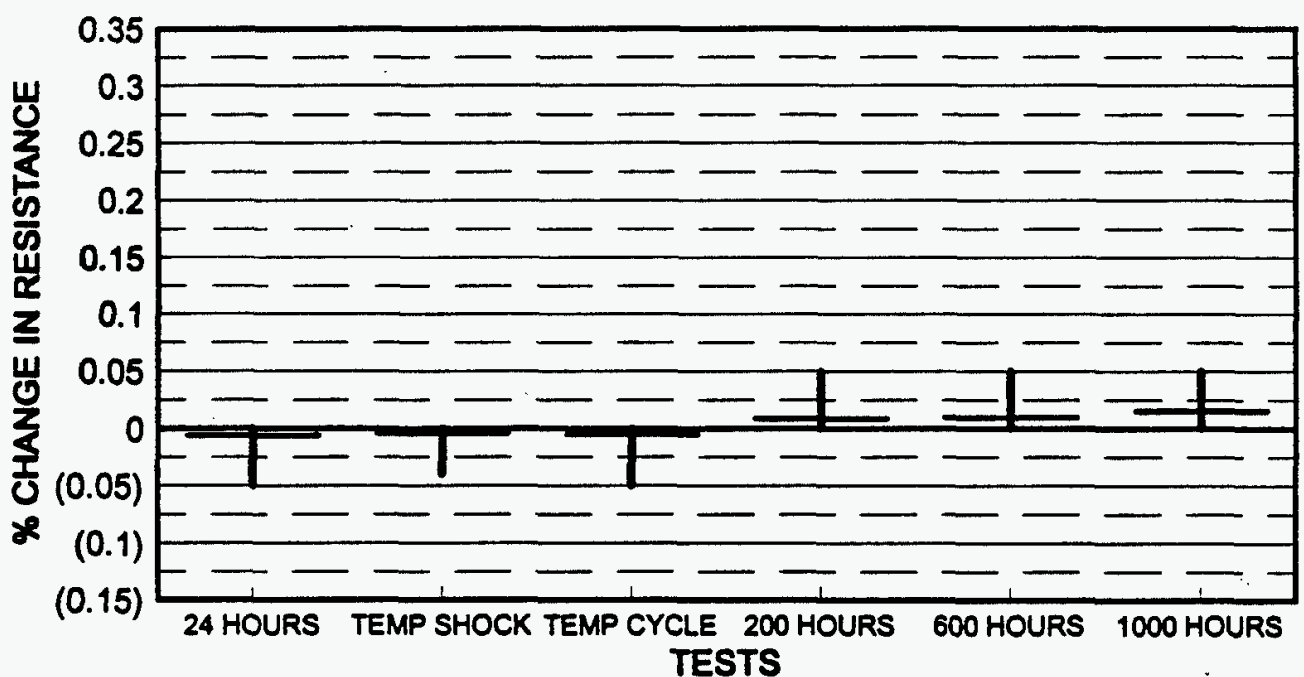

Figure 37 
Stability For Resistors Trimmed At The Operating Point - Unglazed

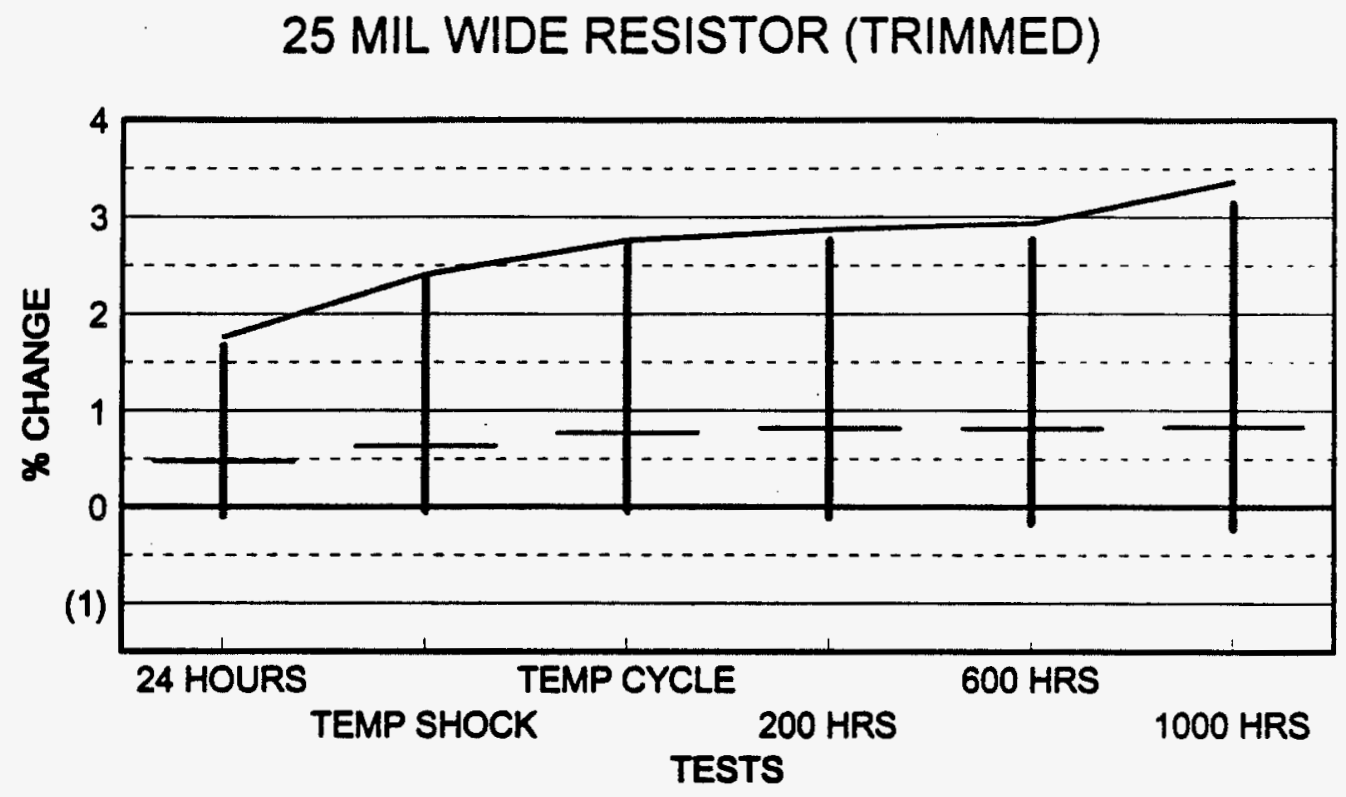

Figure 38

50 MIL WIDE RESISTOR (TRIMMED)

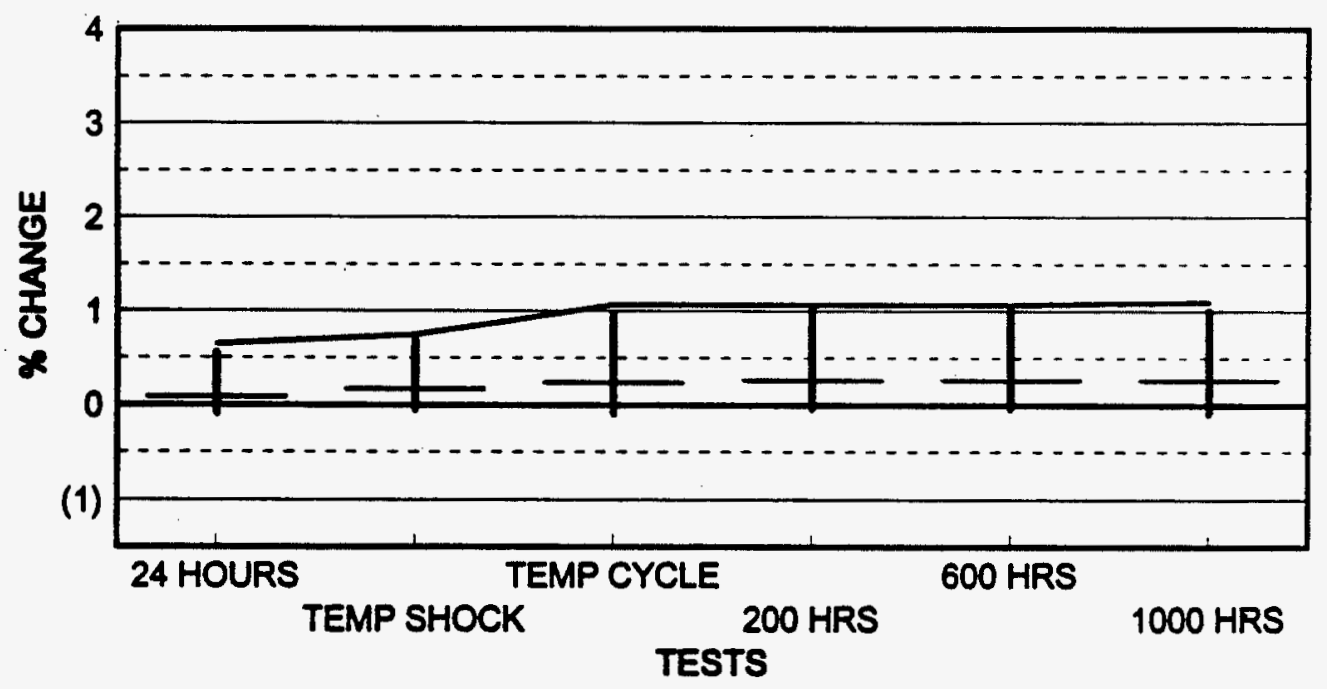

Figure 39 
100 MIL WIDE RESISTOR (UNTRIMMED)

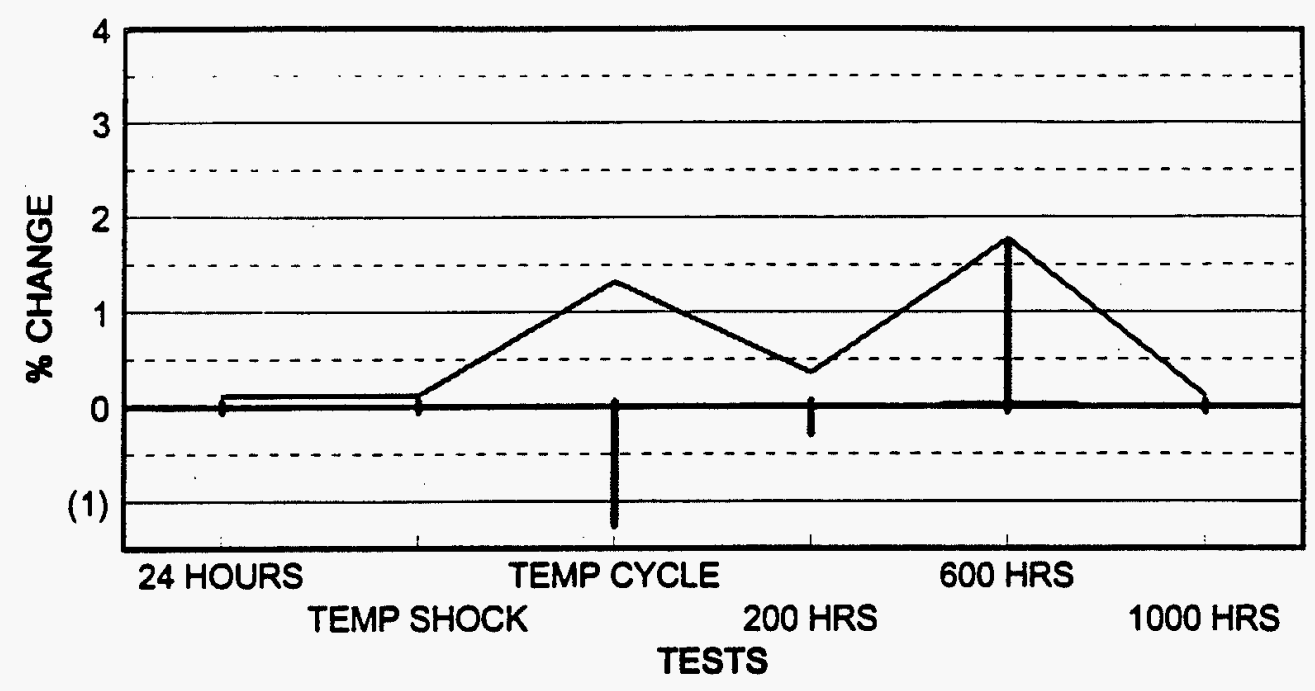

Figure 40

Stability For Resistors Trimmed At The Operating Point - Glazed

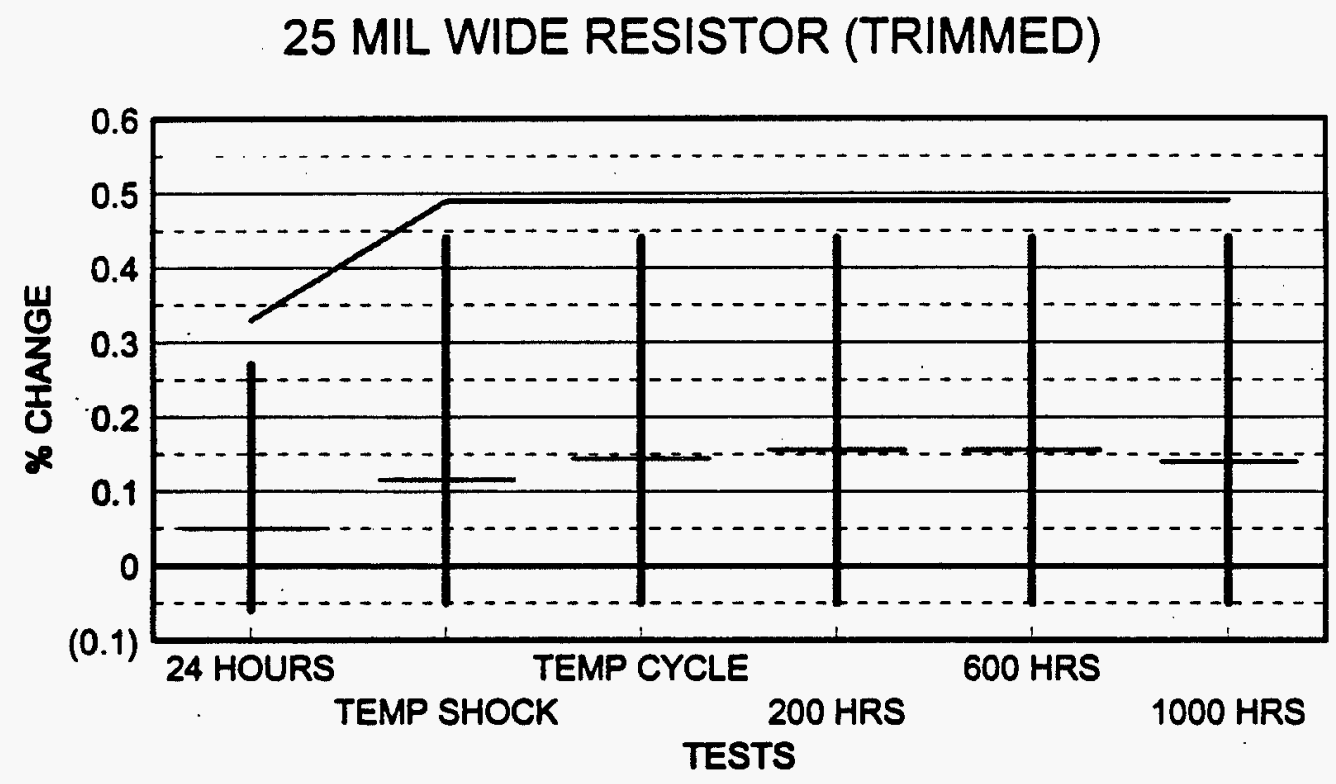

Figure 41 


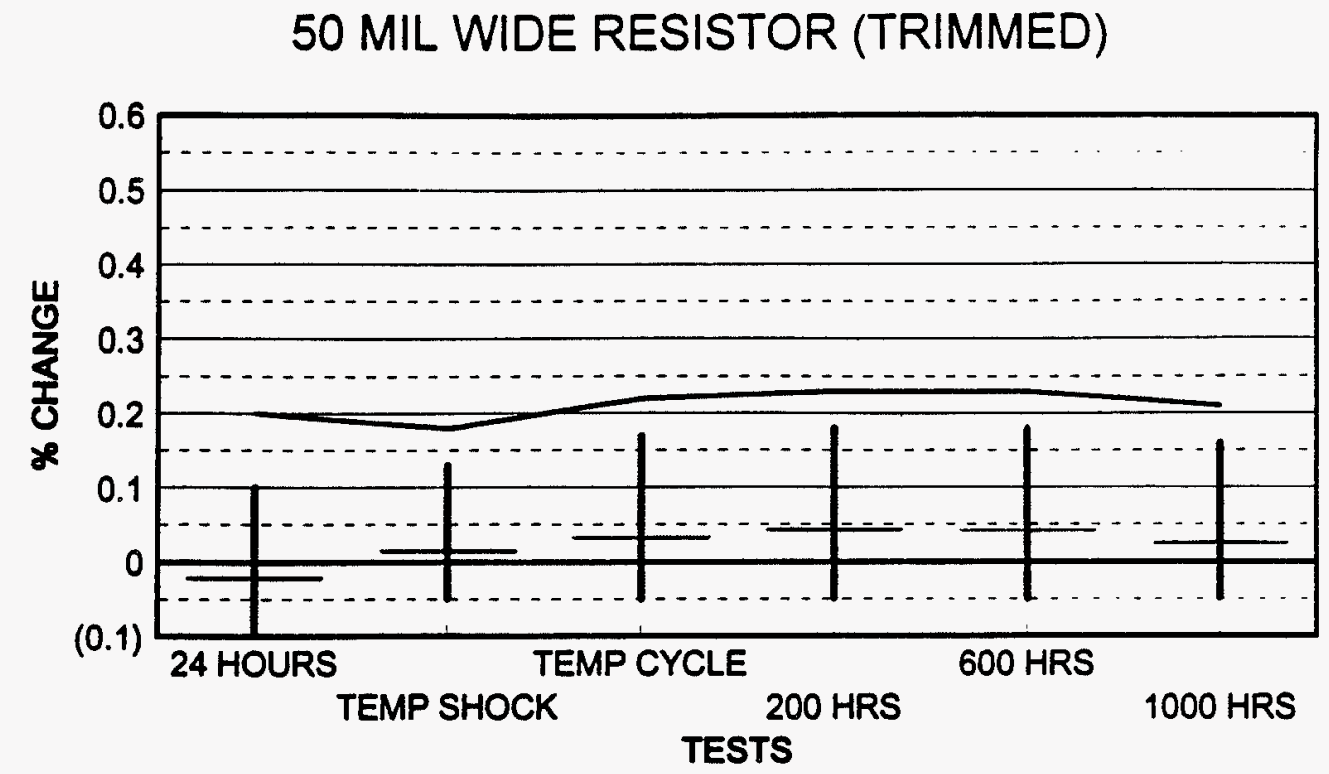

Figure 42

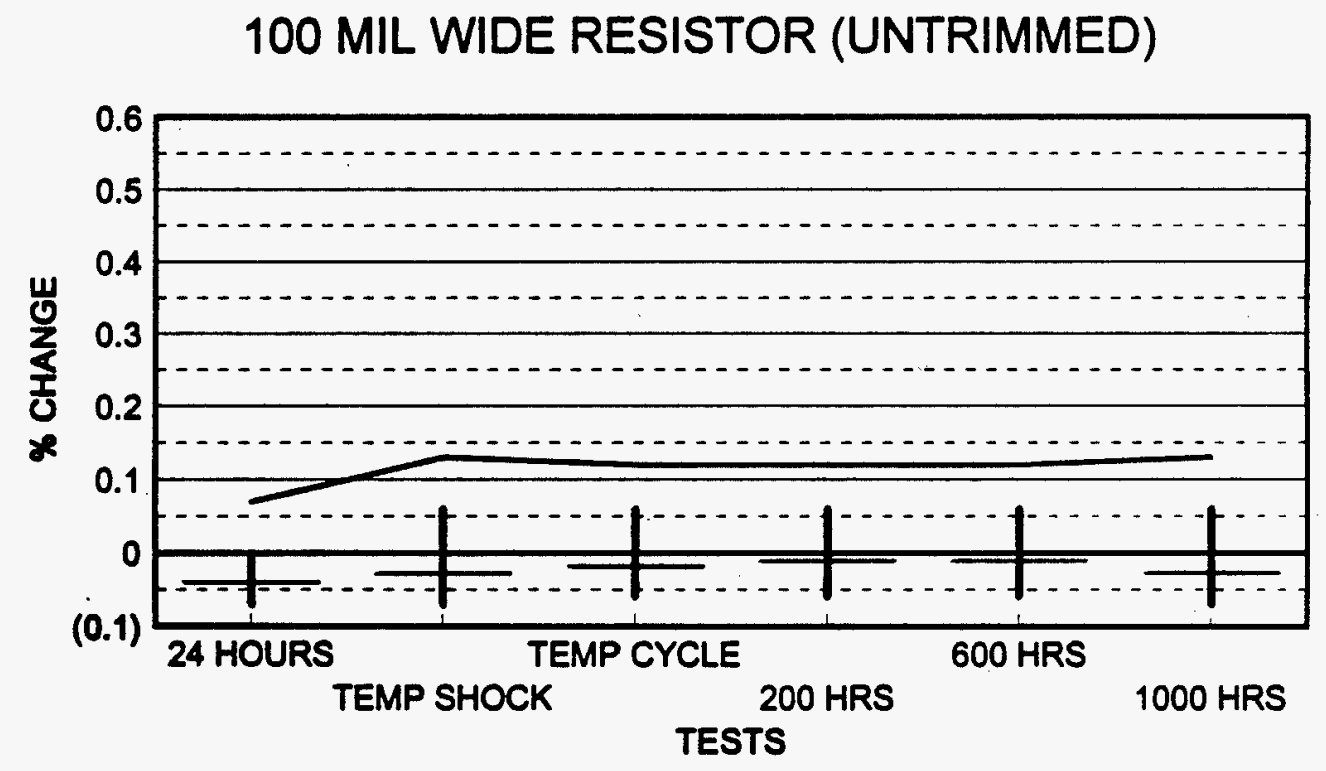

Figure 43 
Analysis Of Resistor Tolerance and Yield Based on Samples Trimmed At The Operating Point - Unglazed

\section{MIL WIDE RESISTOR}

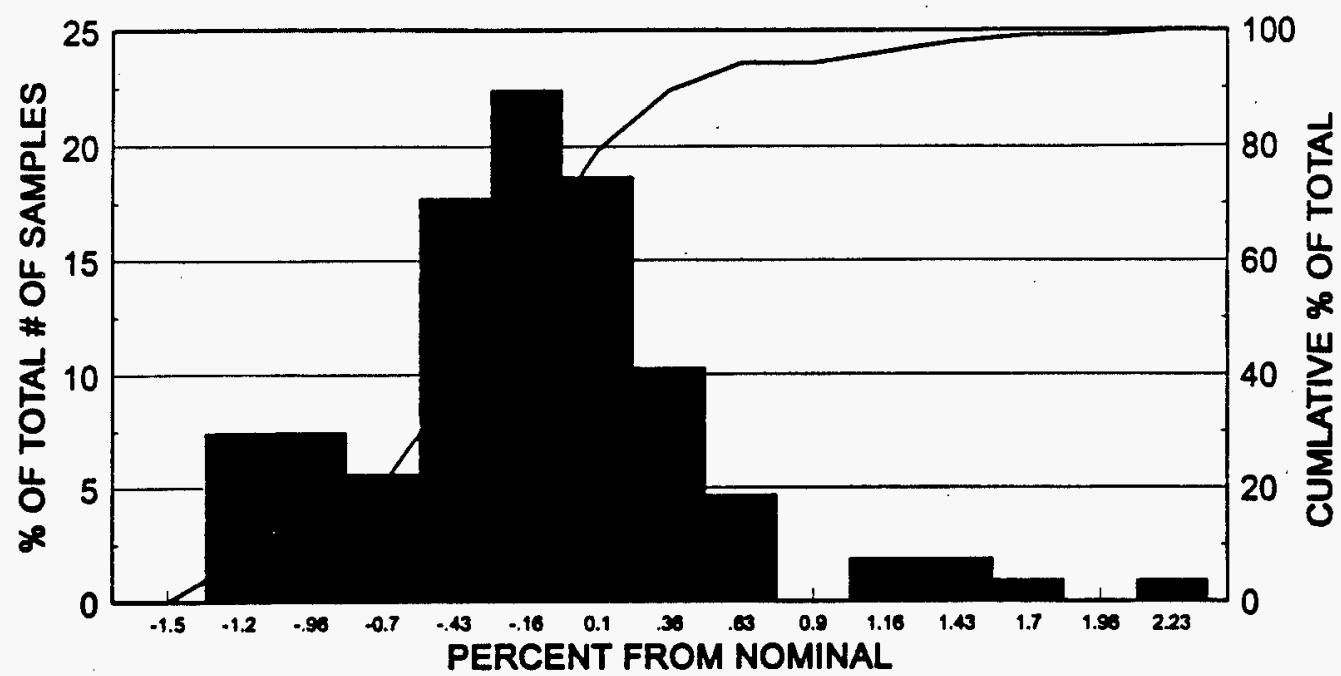

Figure 44

50 MIL WIDE RESISTOR

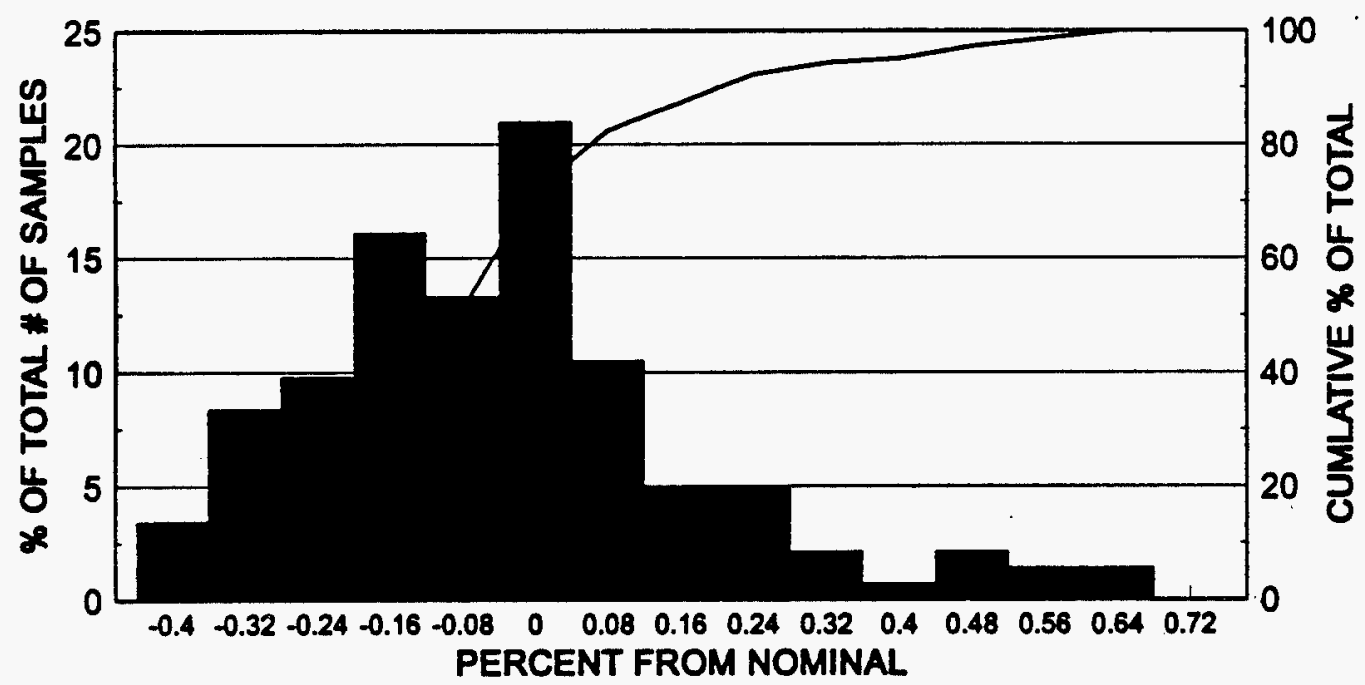

Figure 45 
Analysis Of Resistor Tolerance and Yield Based on Samples Trimmed At The Operating Point - Glazed

25 MIL WIDE RESISTOR

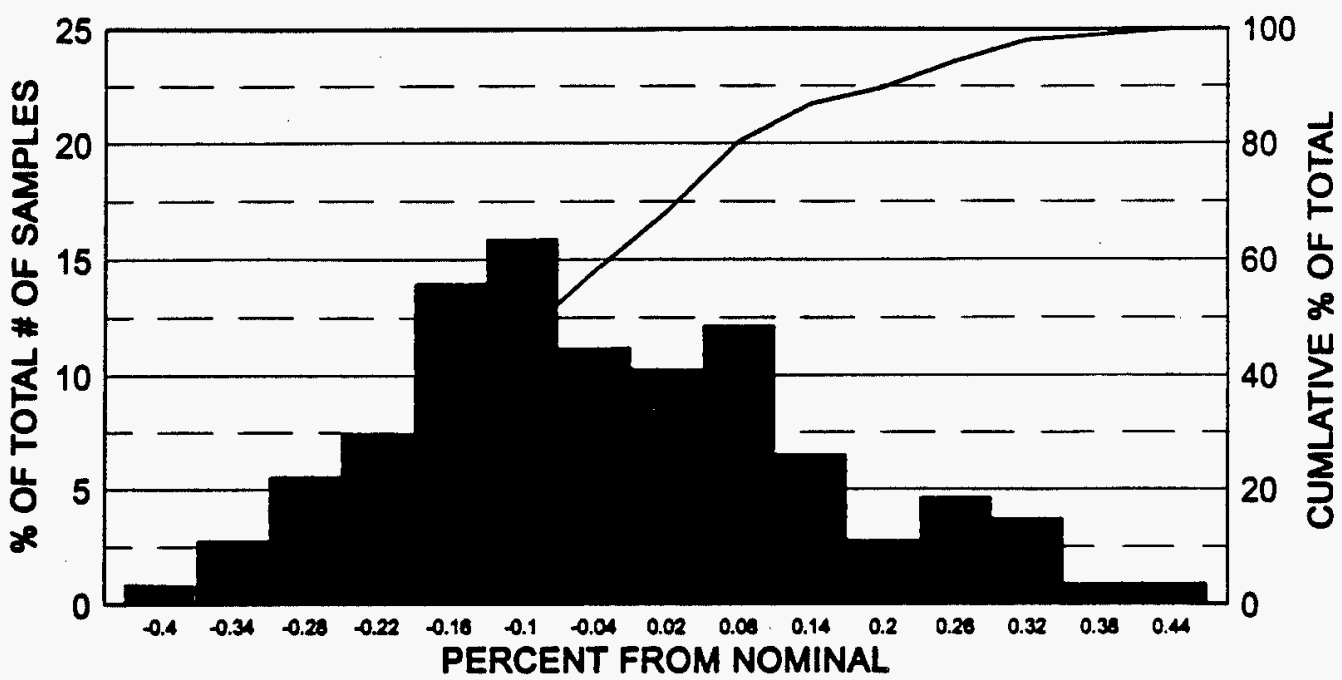

Figure 46

\section{MIL WIDE RESISTOR}

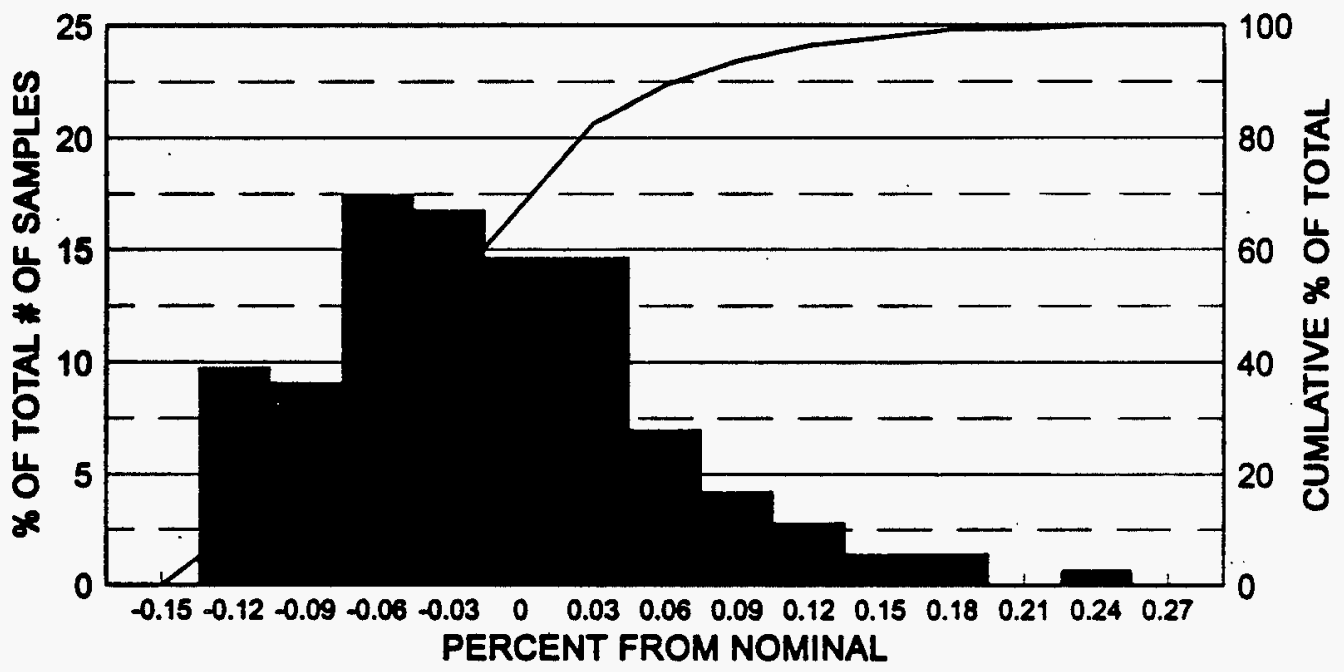

Figure 47 


\section{APPENDIX D}

\section{Test Results For The 1939 Paste}

\section{Pre Trim Distribution}

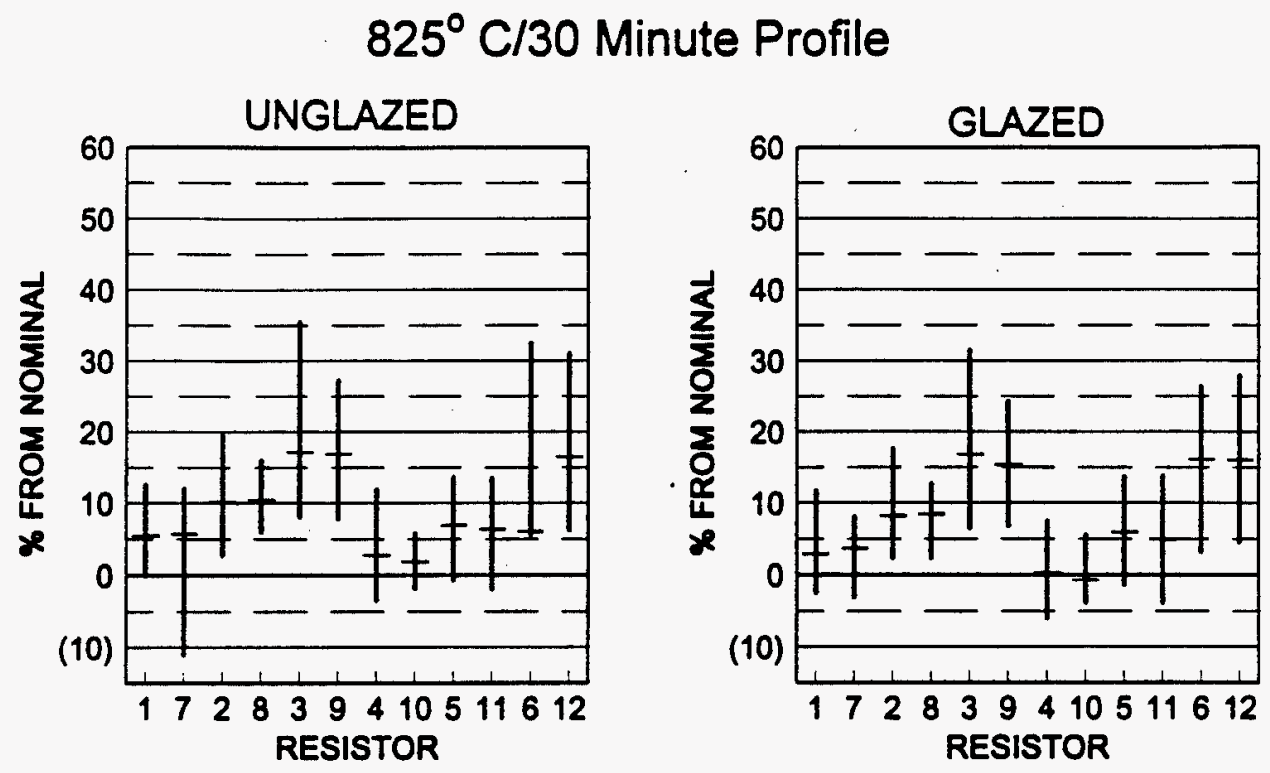

Figure 48
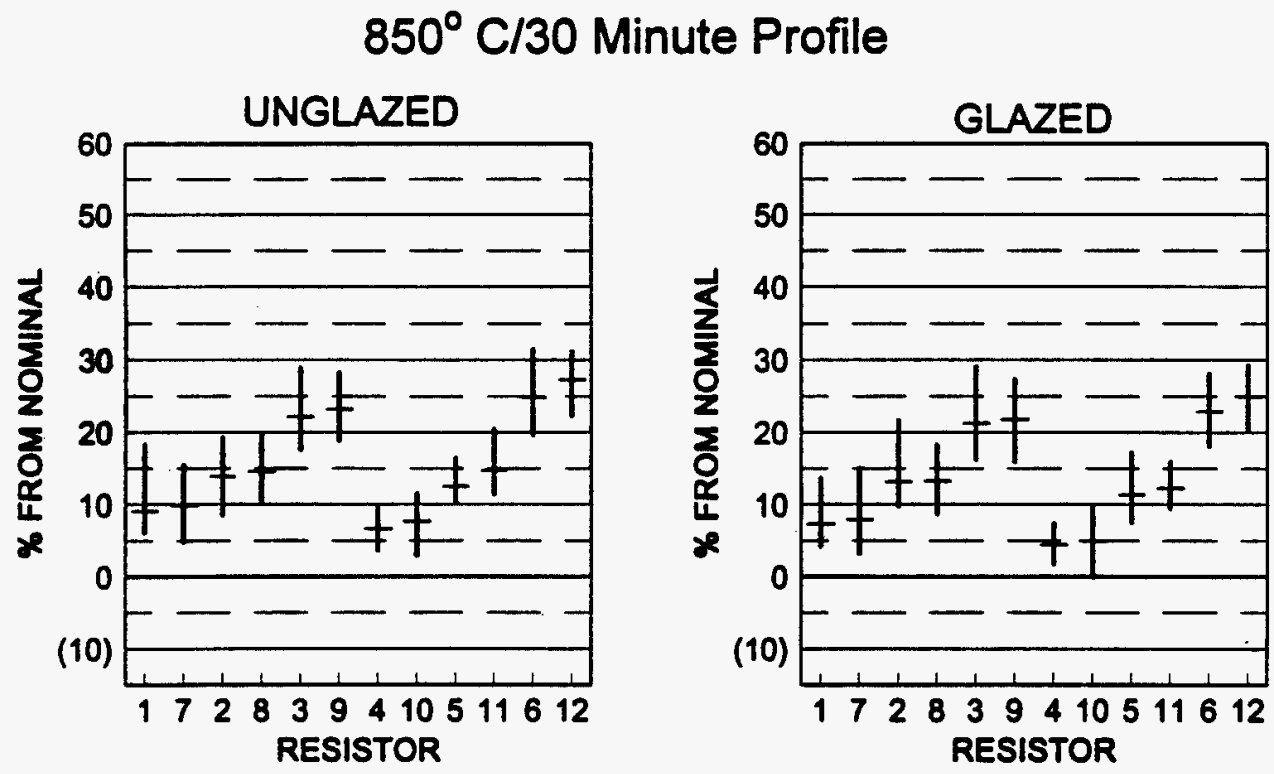

Figure 49 

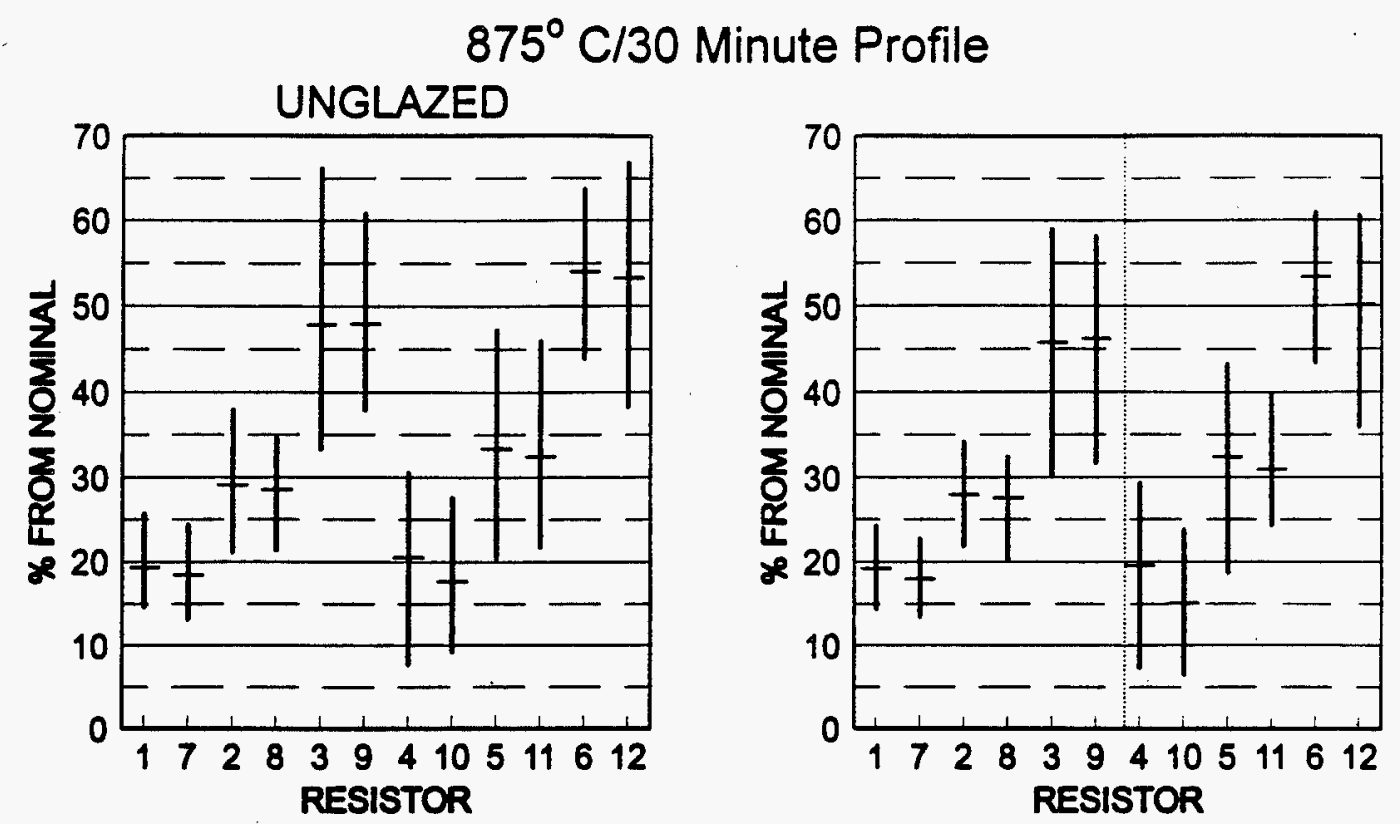

Figure 50
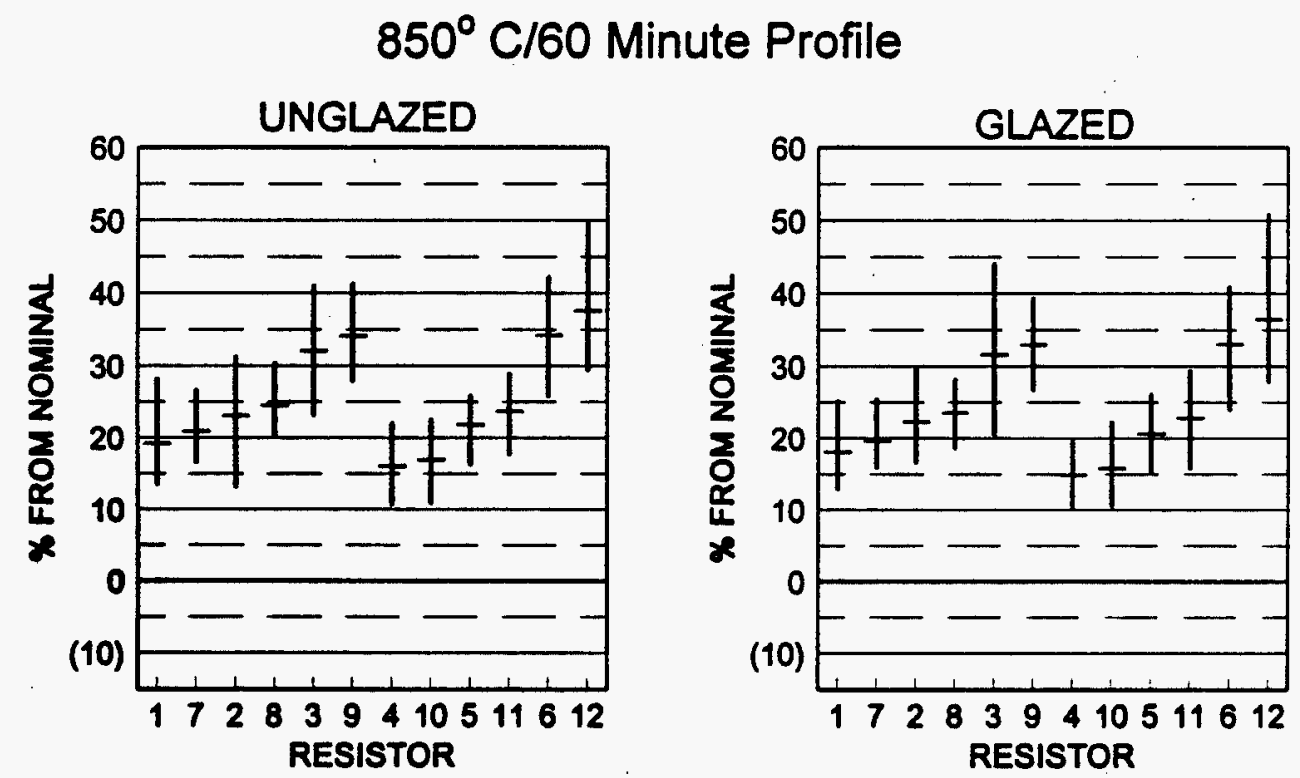

Figure 51 


\section{Operating Envelope}

No Glaze on Resistor

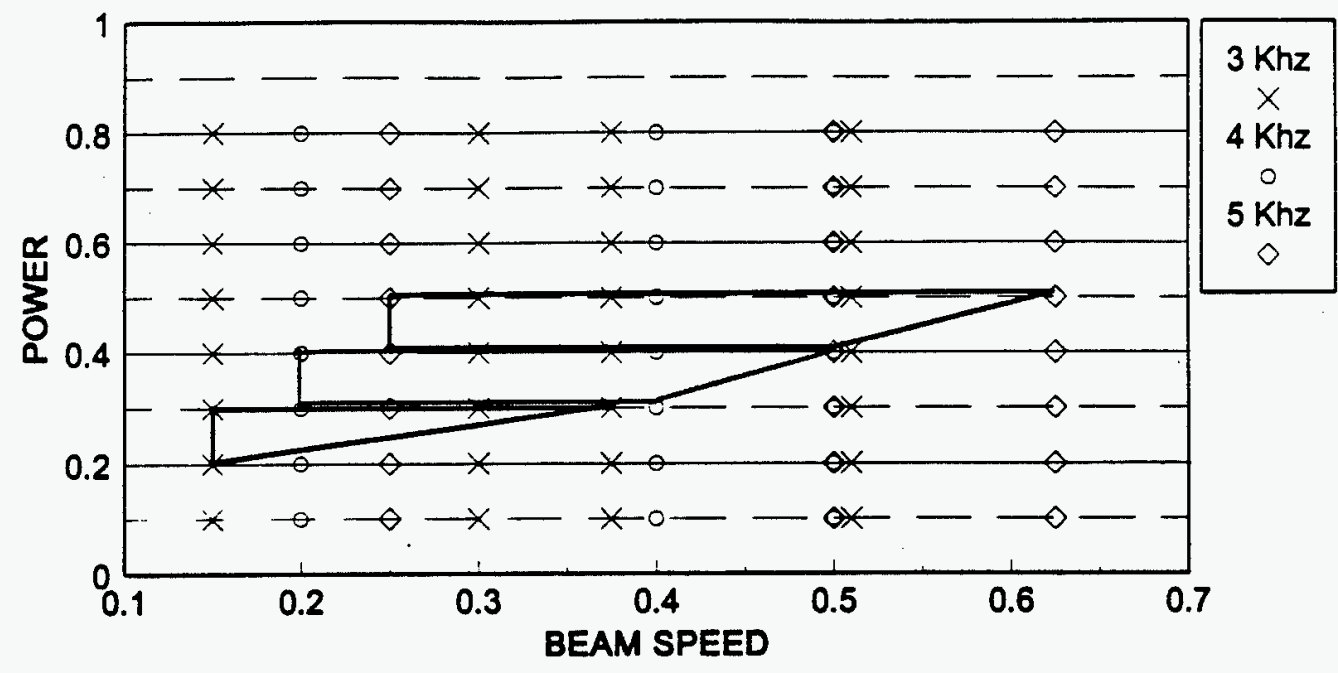

Figure 52

Glaze Over-coated Resistors

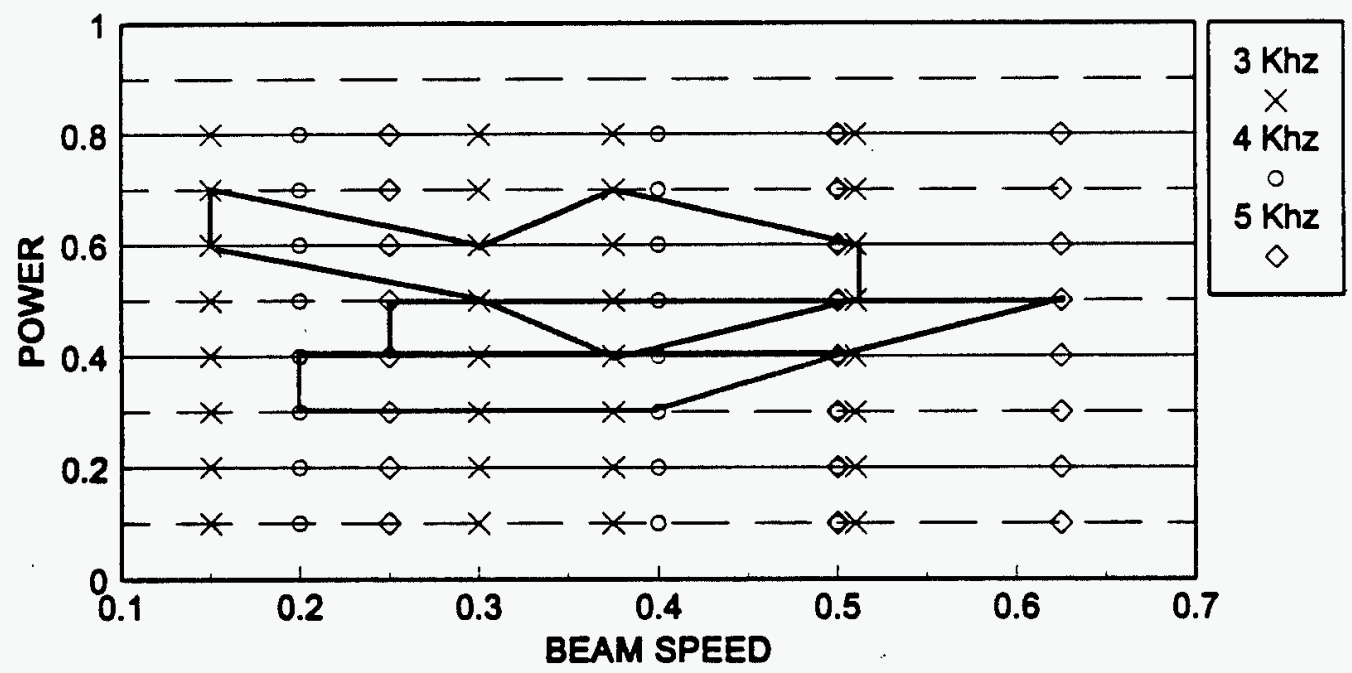

Figure 53 
50 MIL WIDE RESISTOR (TRIMMED)

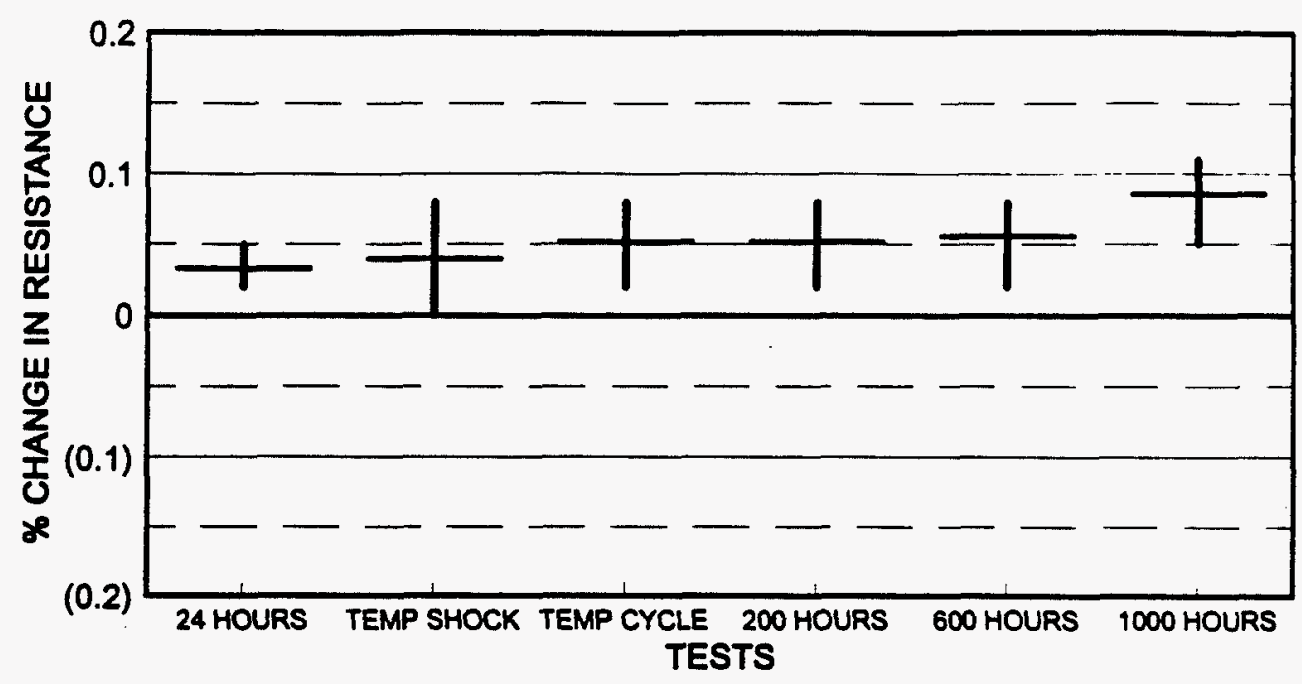

Figure 54

100 MIL WIDE RESISTOR (UNTRIMMED)

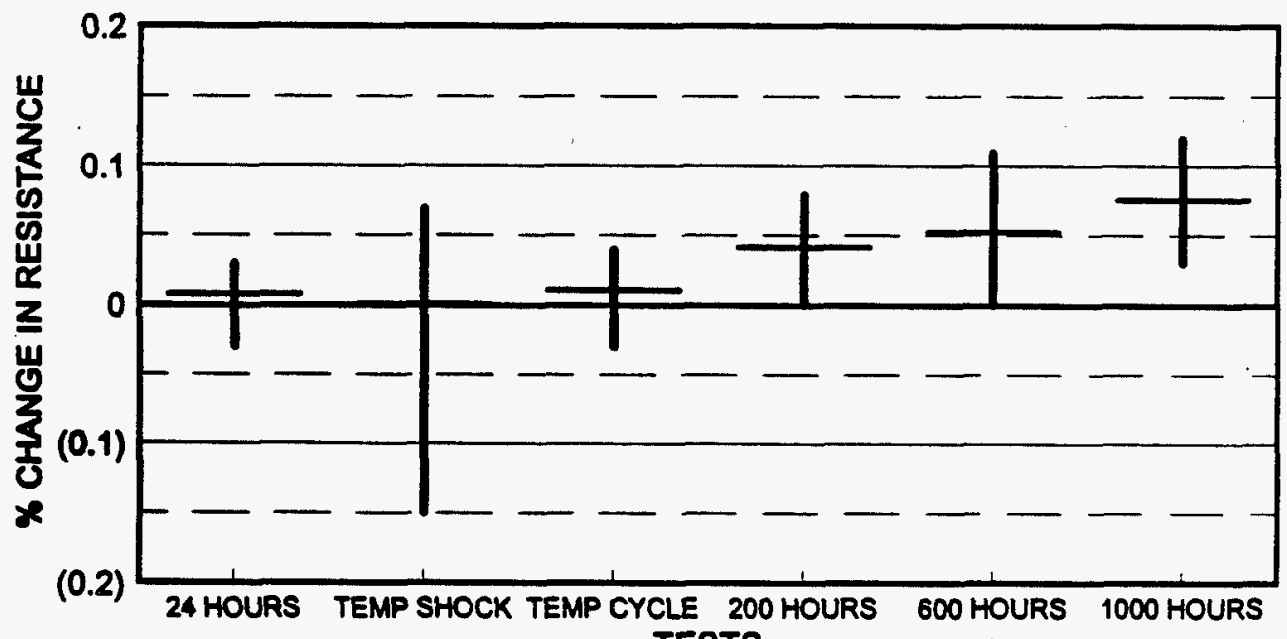

TESTS

Figure 55 
Stability For Resistors Trimmed Within The Operating Envelope - Glazed

50 MIL WIDE RESISTORS (TRIMMED)

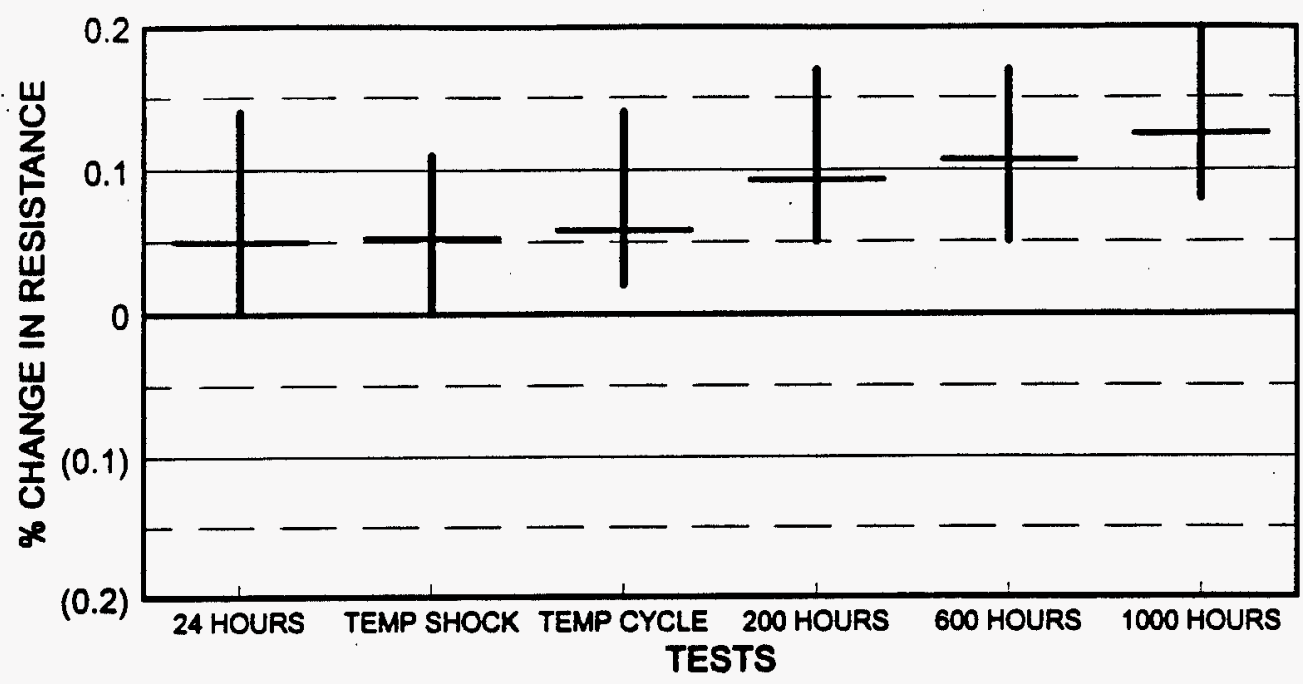

Figure 56

100 MIL WIDE RESISTOR (UNTRIMMED)

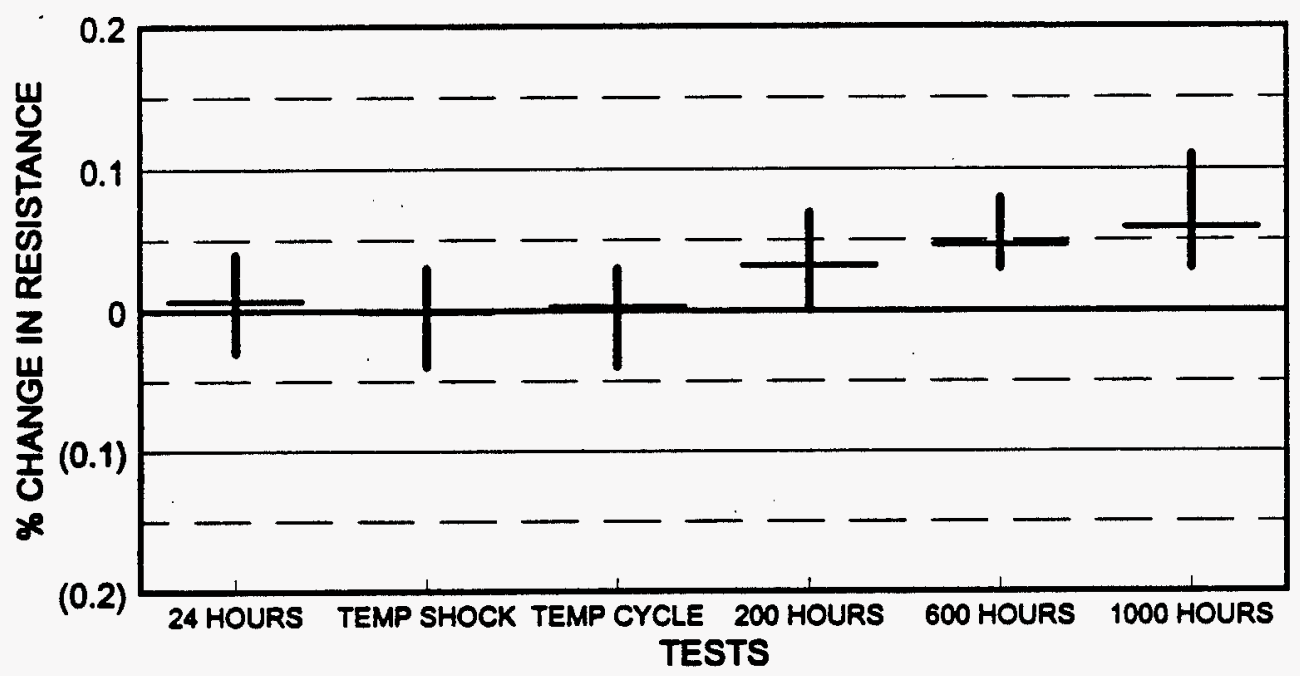

Figure 57 
Stability For Resistor's Trimmed At The Operating Point - Unglazed

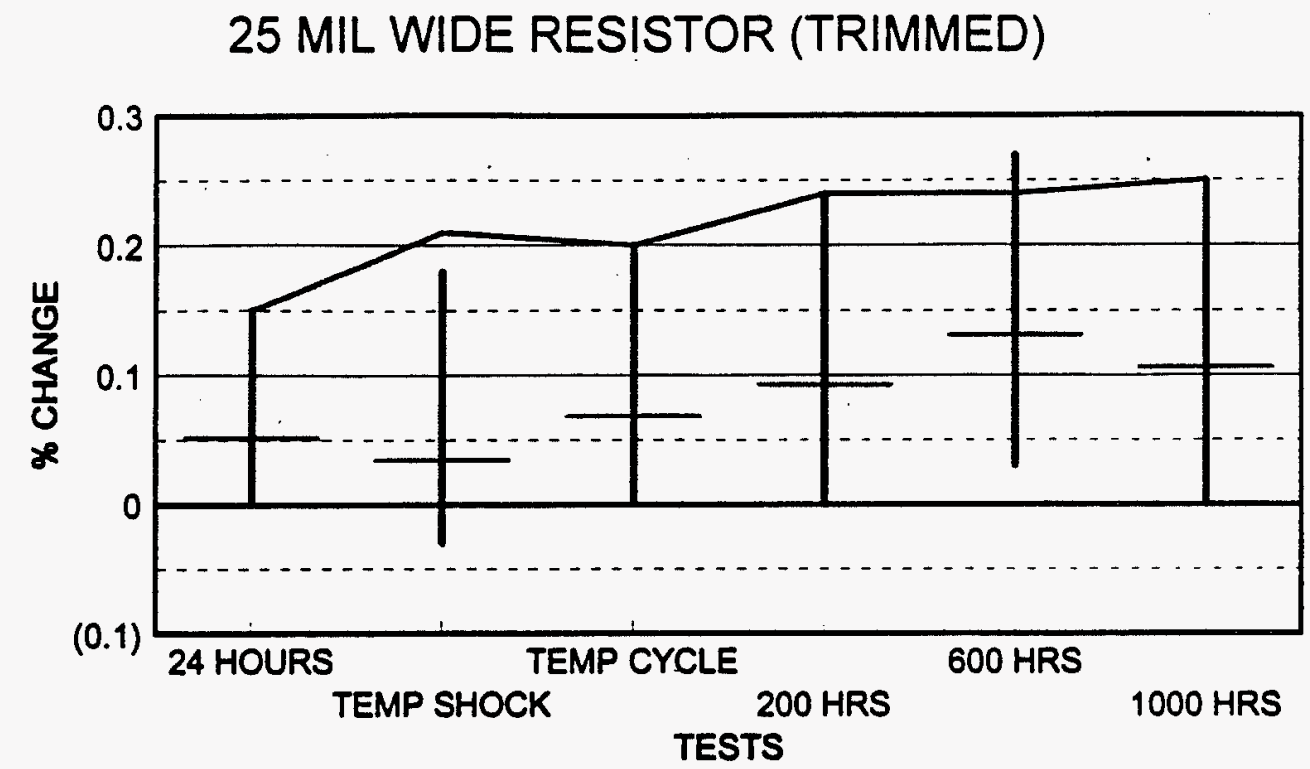

Figure 58

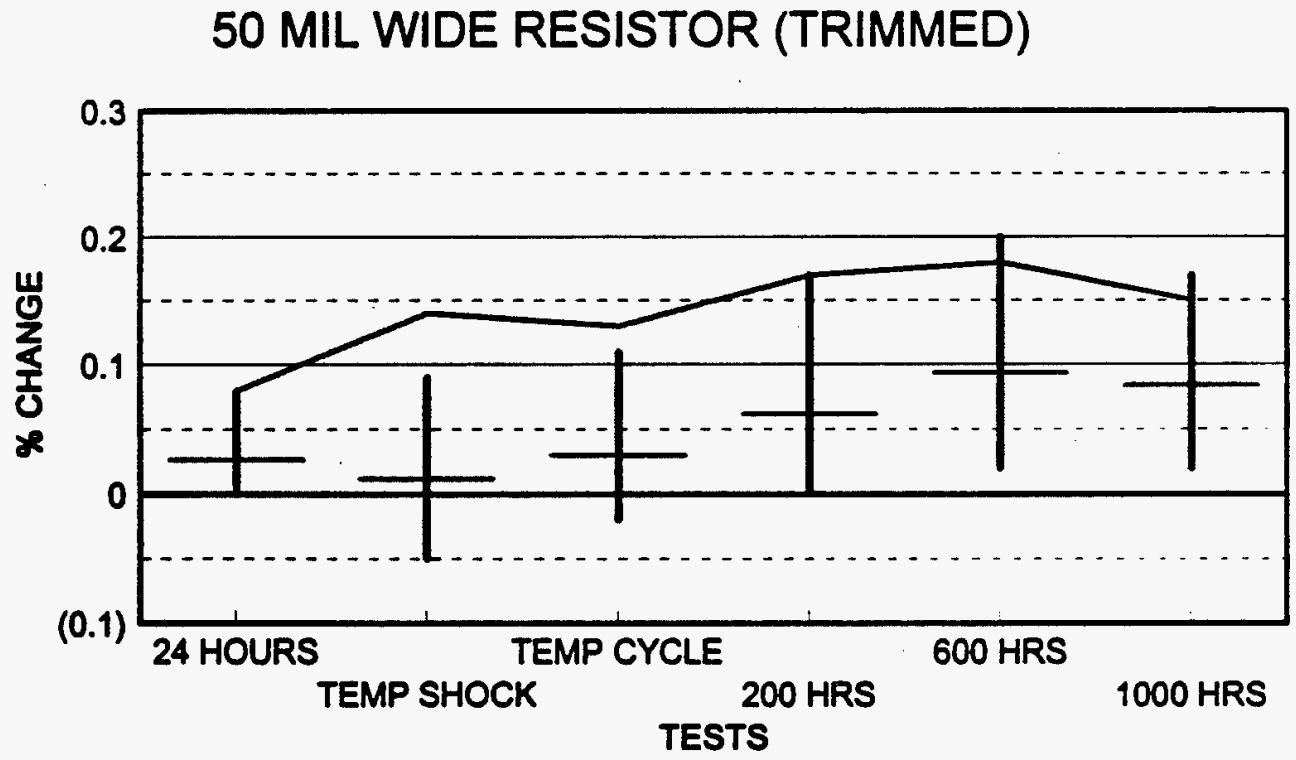

Figure 59 


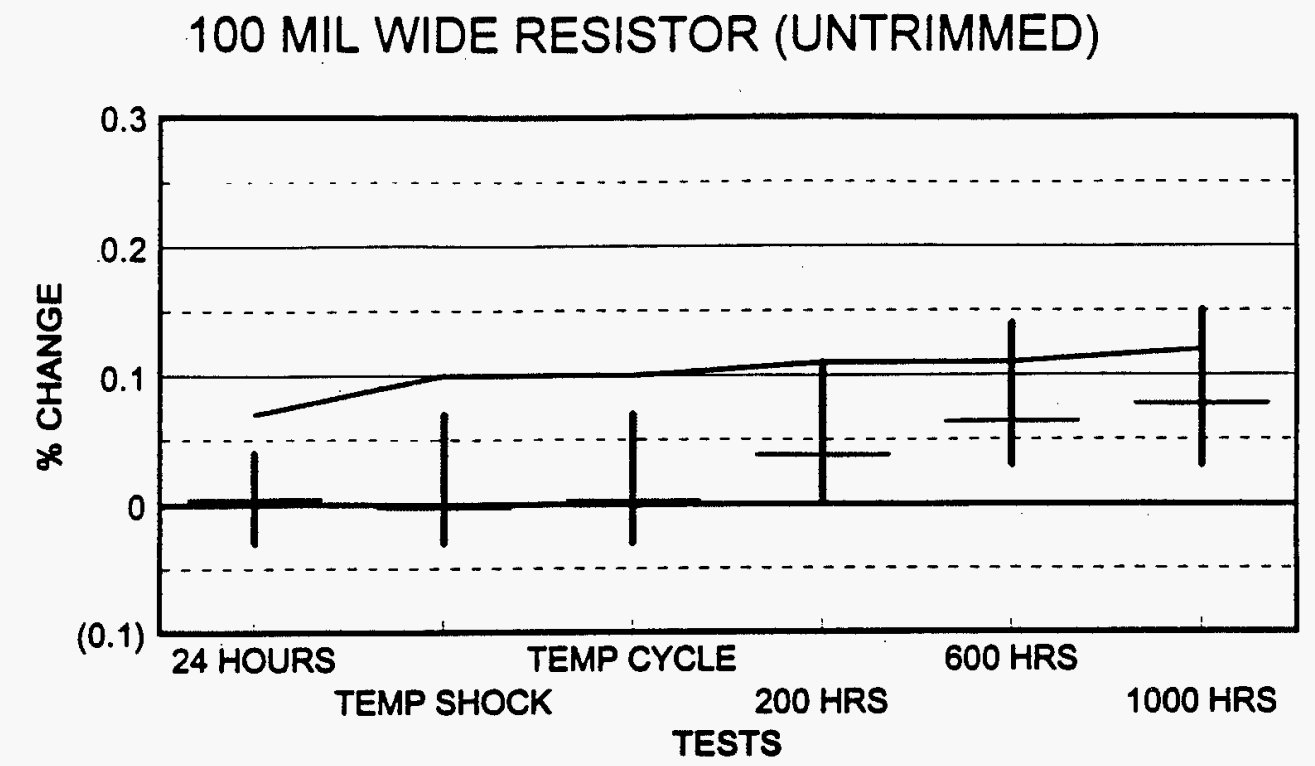

Figure 60

Stability For Resistors Trimmed At The Operating Point - Glazed

25 MIL WIDE RESISTOR (TRIMMED)

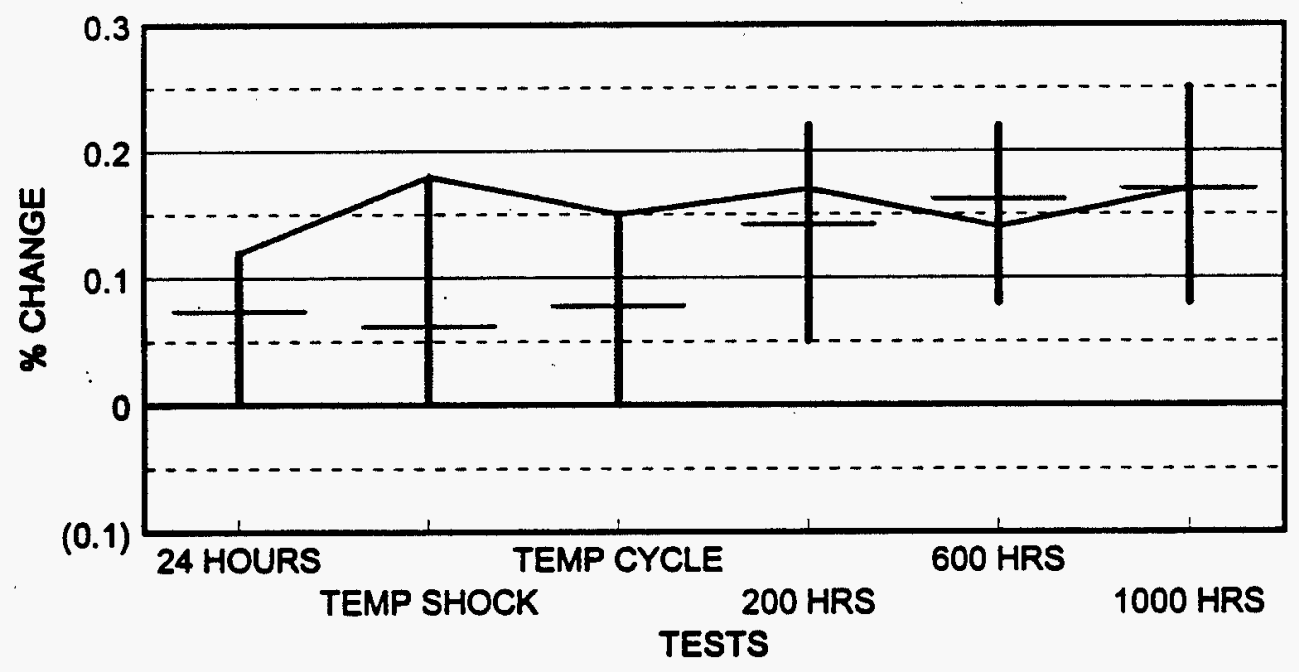

Figure 61 
50 MIL WIDE RESISTOR (TRIMMED)

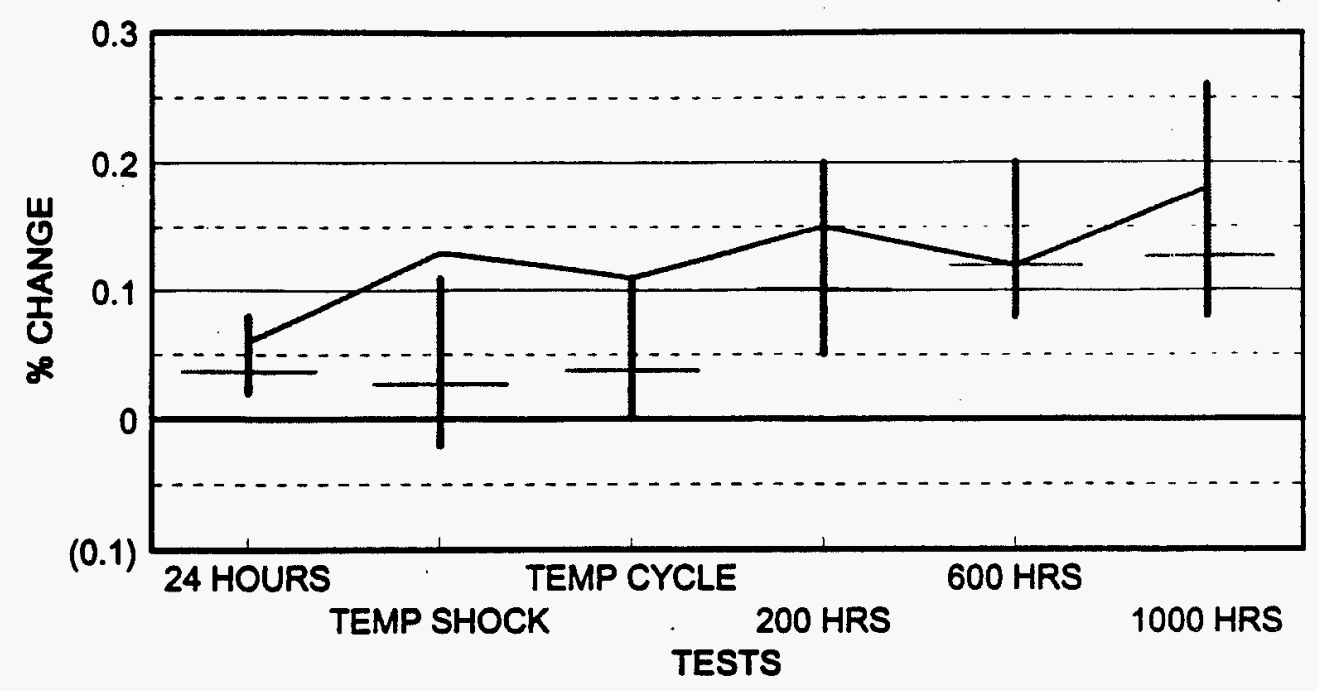

Figure 62

100 MIL WIDE RESISTOR (UNTRIMMED)

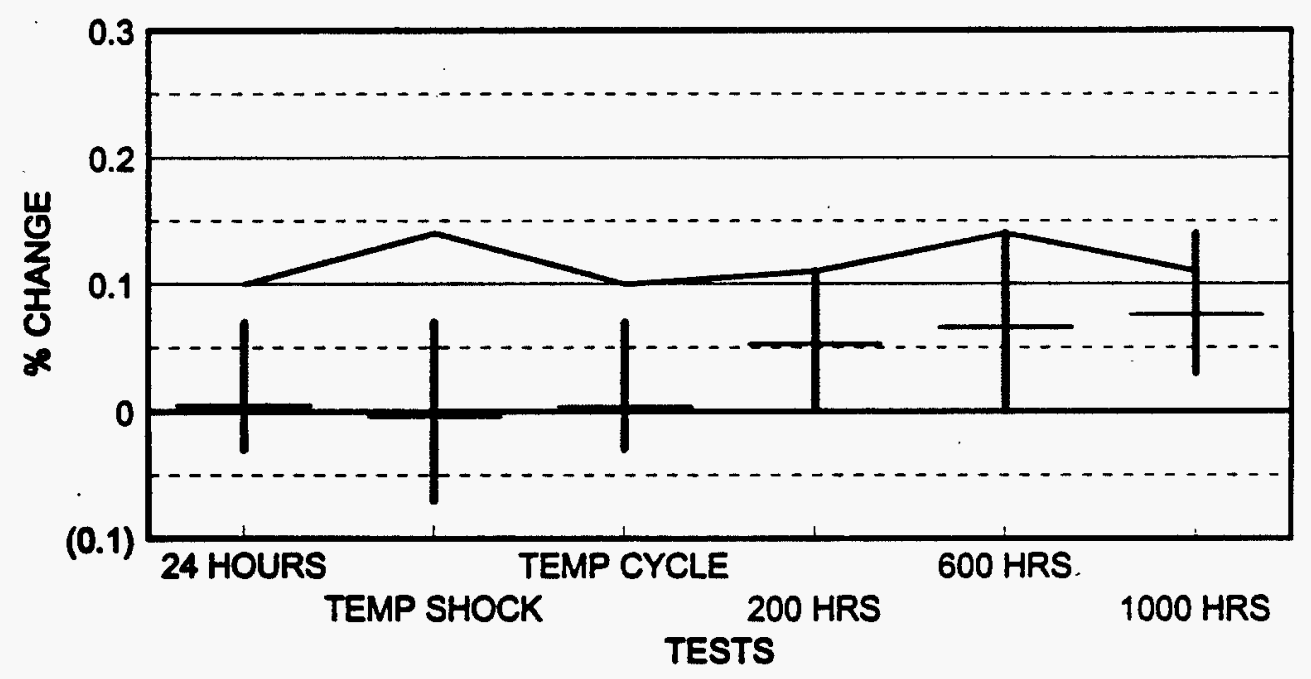

Figure 63 
Analysis Of Resistor Tolerance and Yield Based on Samples Trimmed At The Operating Point - Unglazed

\section{MIL WIDE RESISTOR}

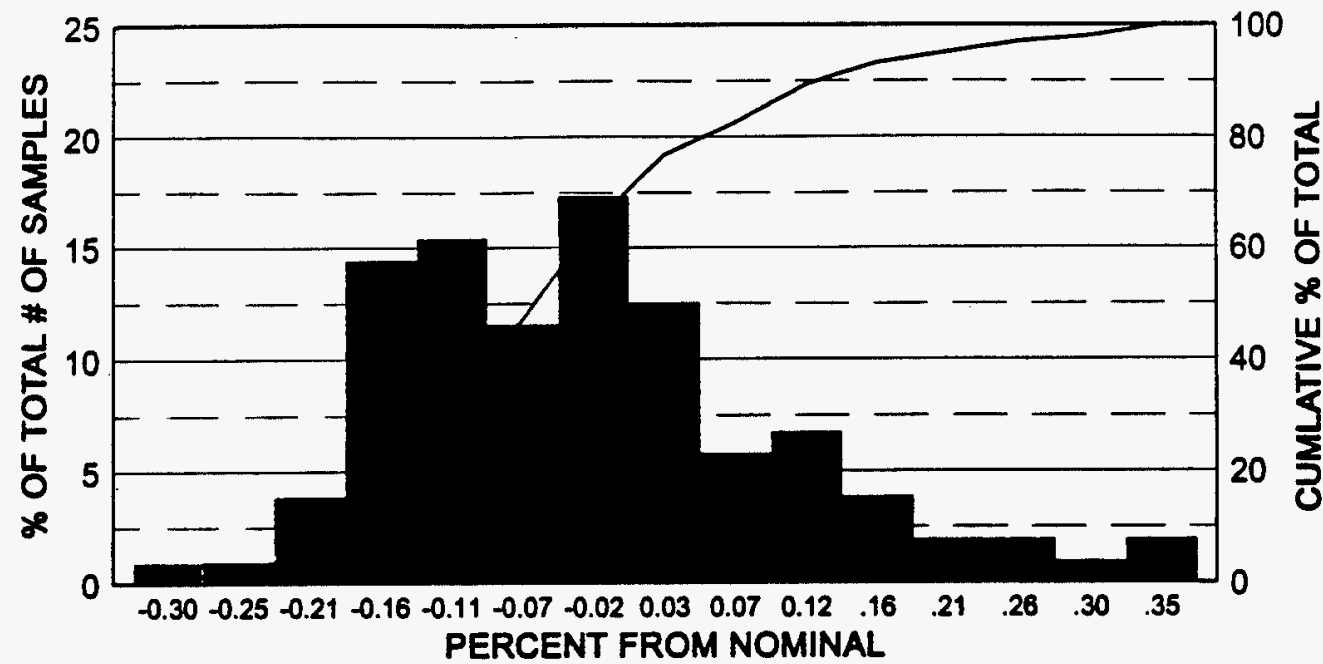

Figure 64

\section{MIL WIDE RESISTOR}

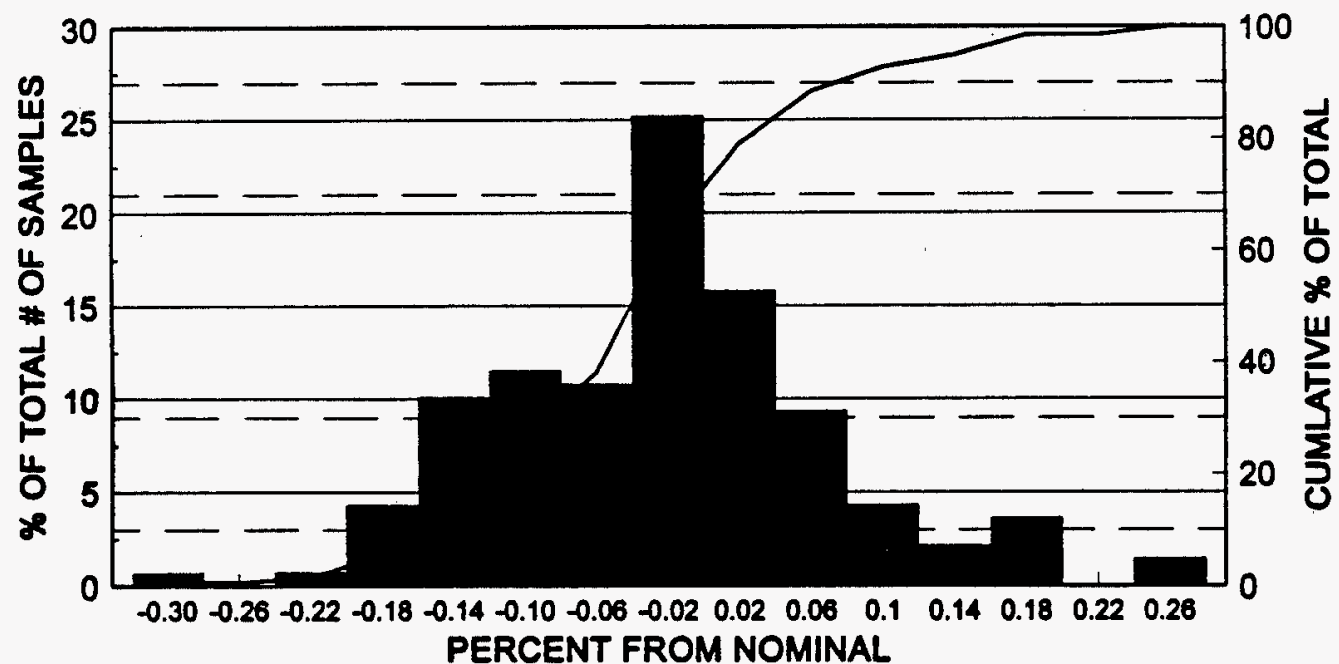

Figure 65 
Analysis Of Resistor Tolerance and Yield Based on Samples Trimmed At The Operating Point - Glazed

\section{MIL WIDE RESISTOR}

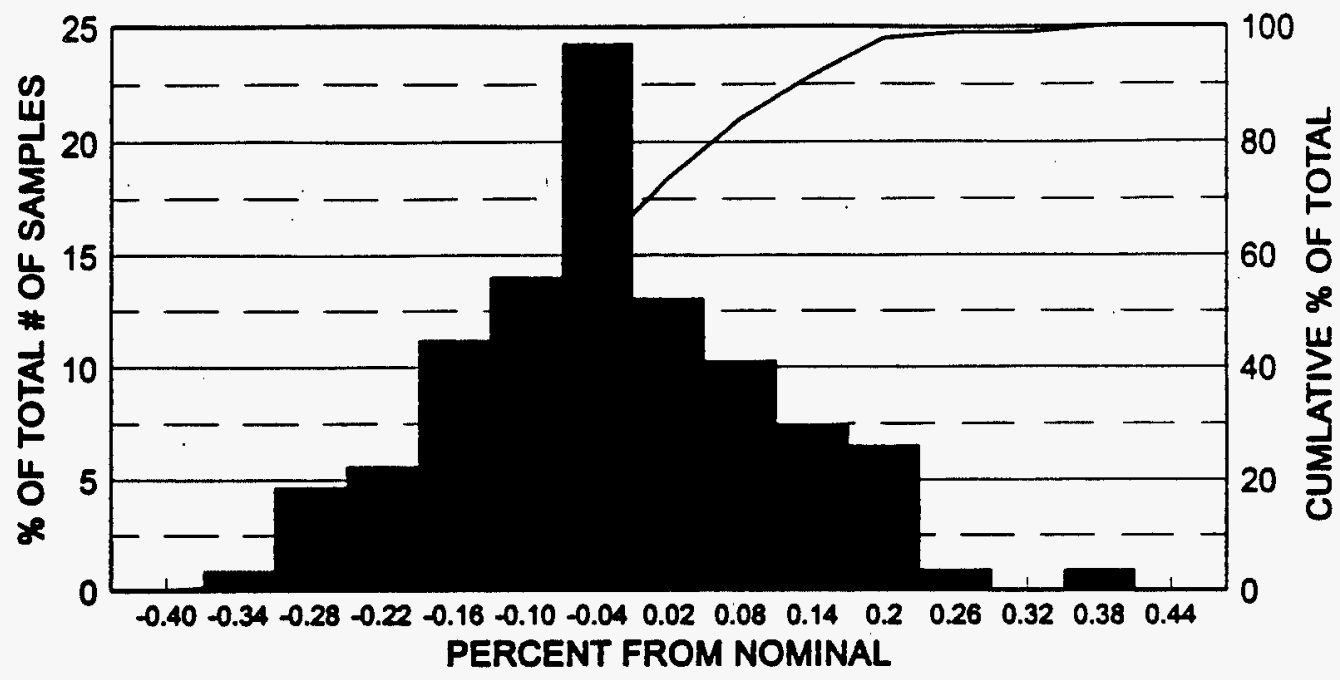

Figure 66

\section{MIL WIDE RESISTOR}

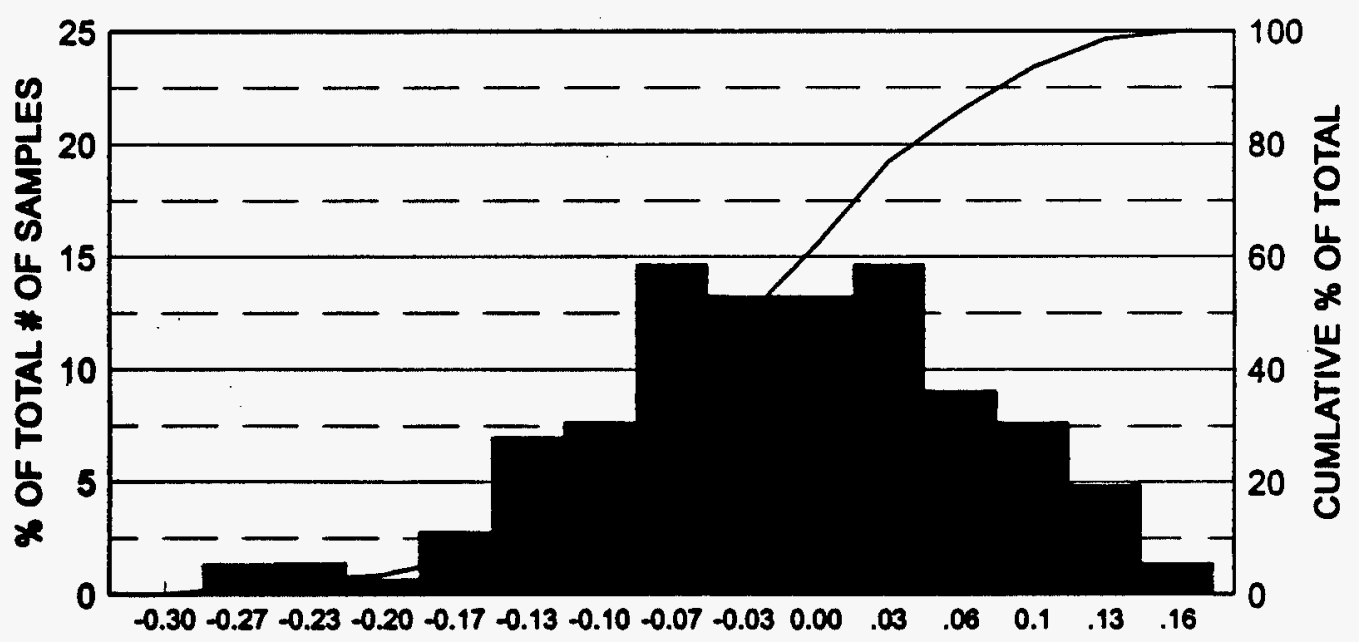

PERCENT FROM NOMINAL

Figure 67 


\section{APPENDIX E}

\section{Test Results For The 1949 Paste}

\section{Pre Trim Distribution}

$825^{\circ} \mathrm{C} / 30$ Minute Profile
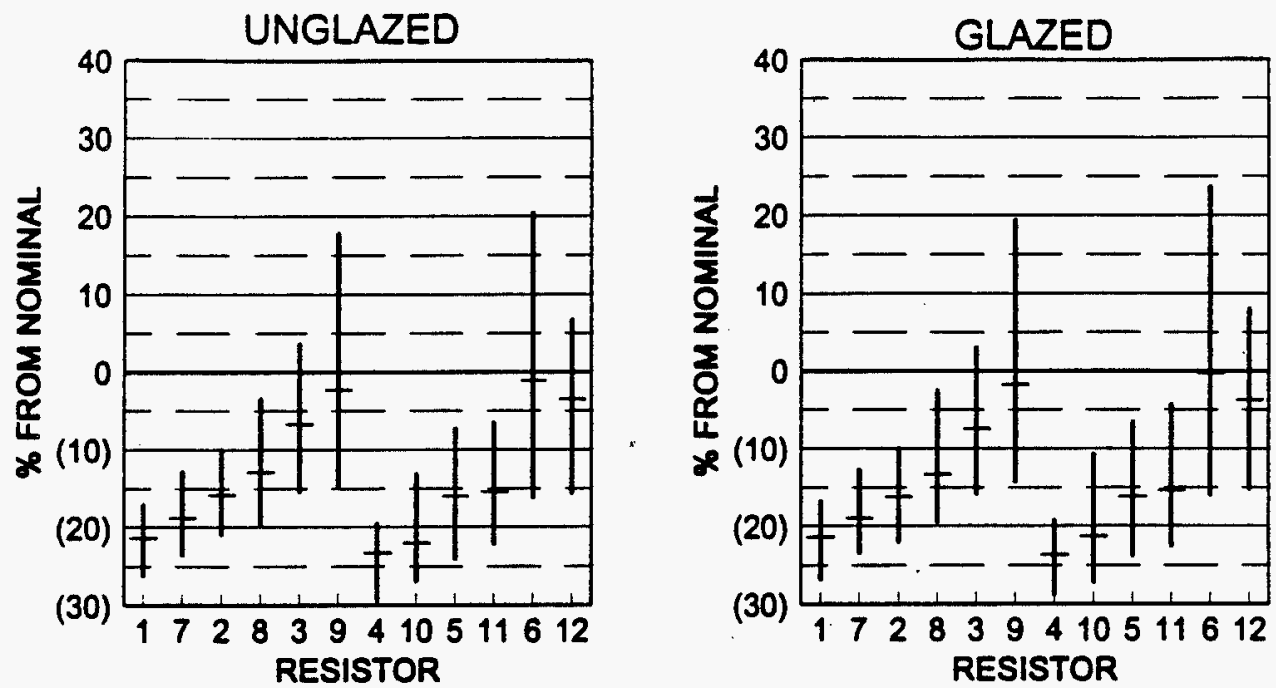

Figure 68
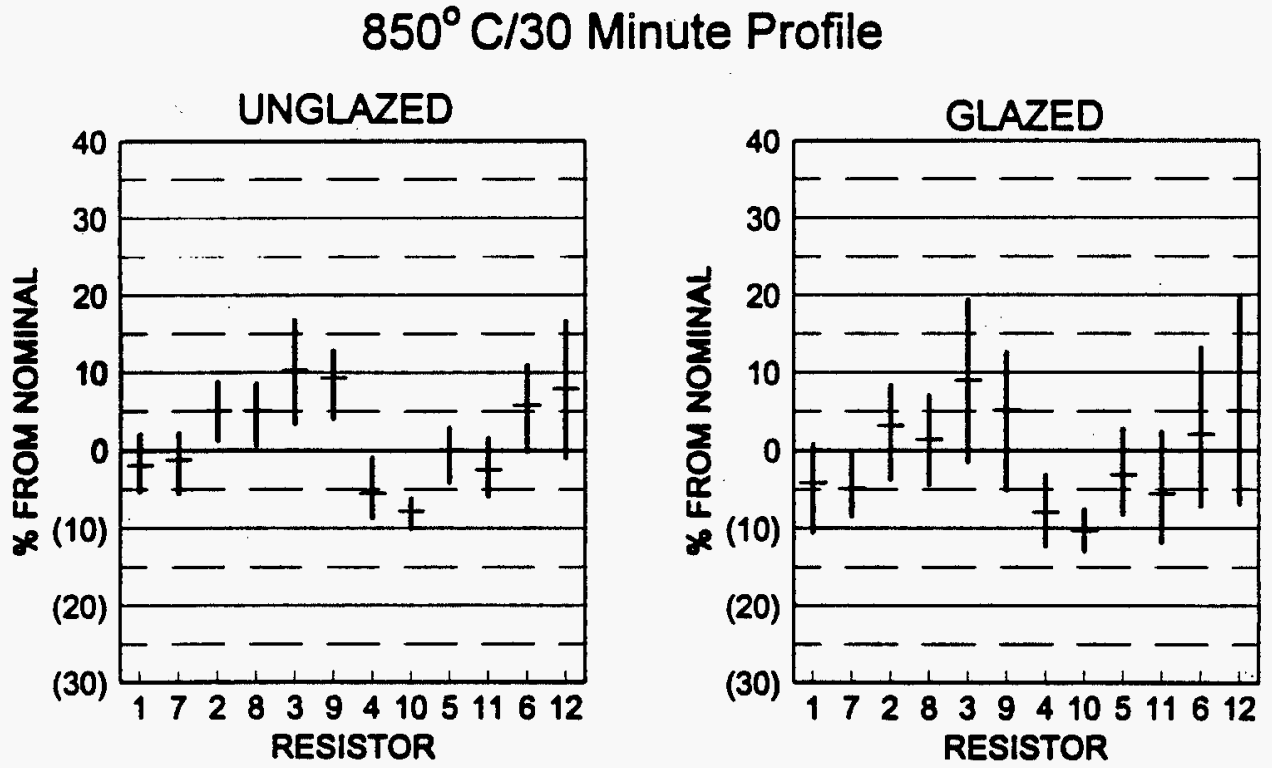

Figure 69 

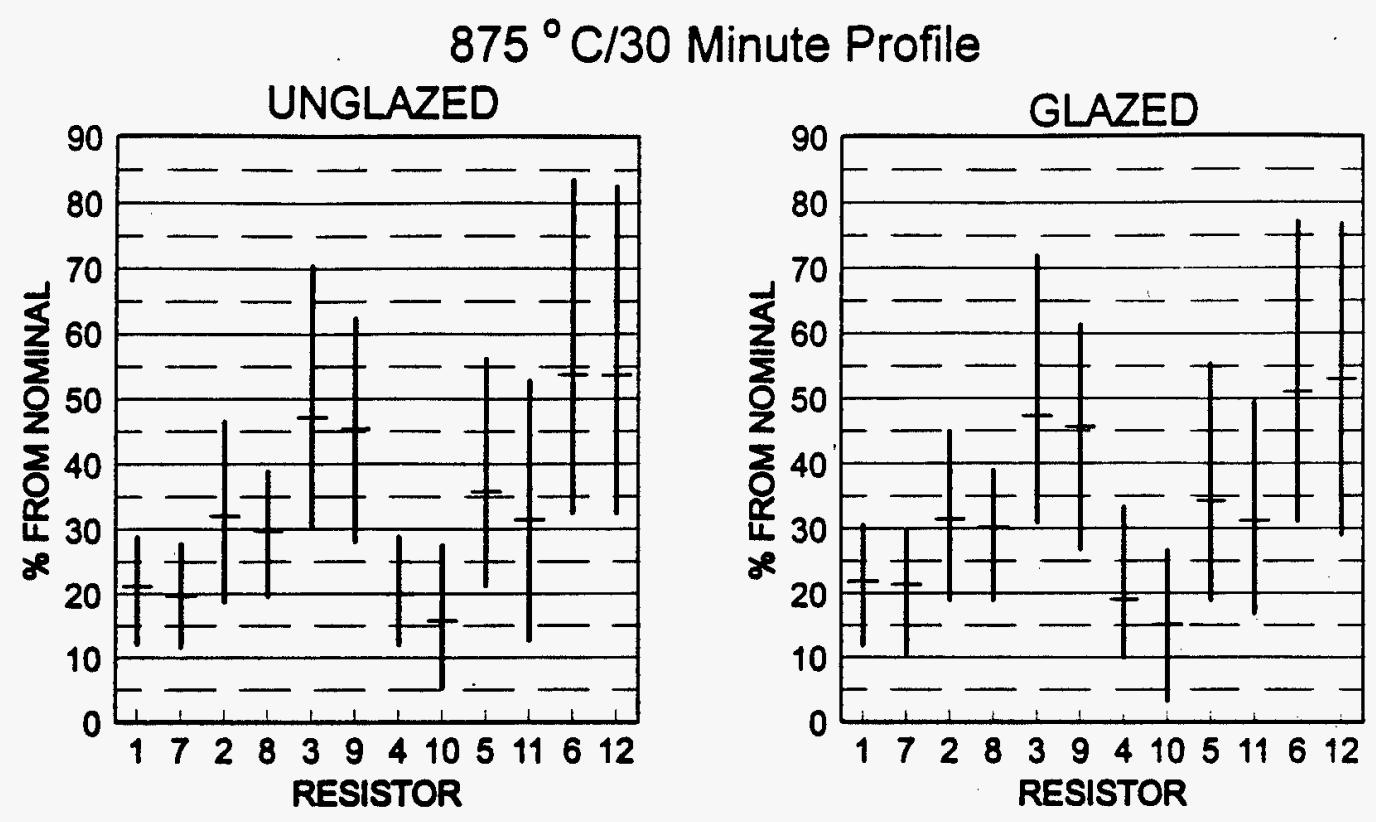

Figure 70
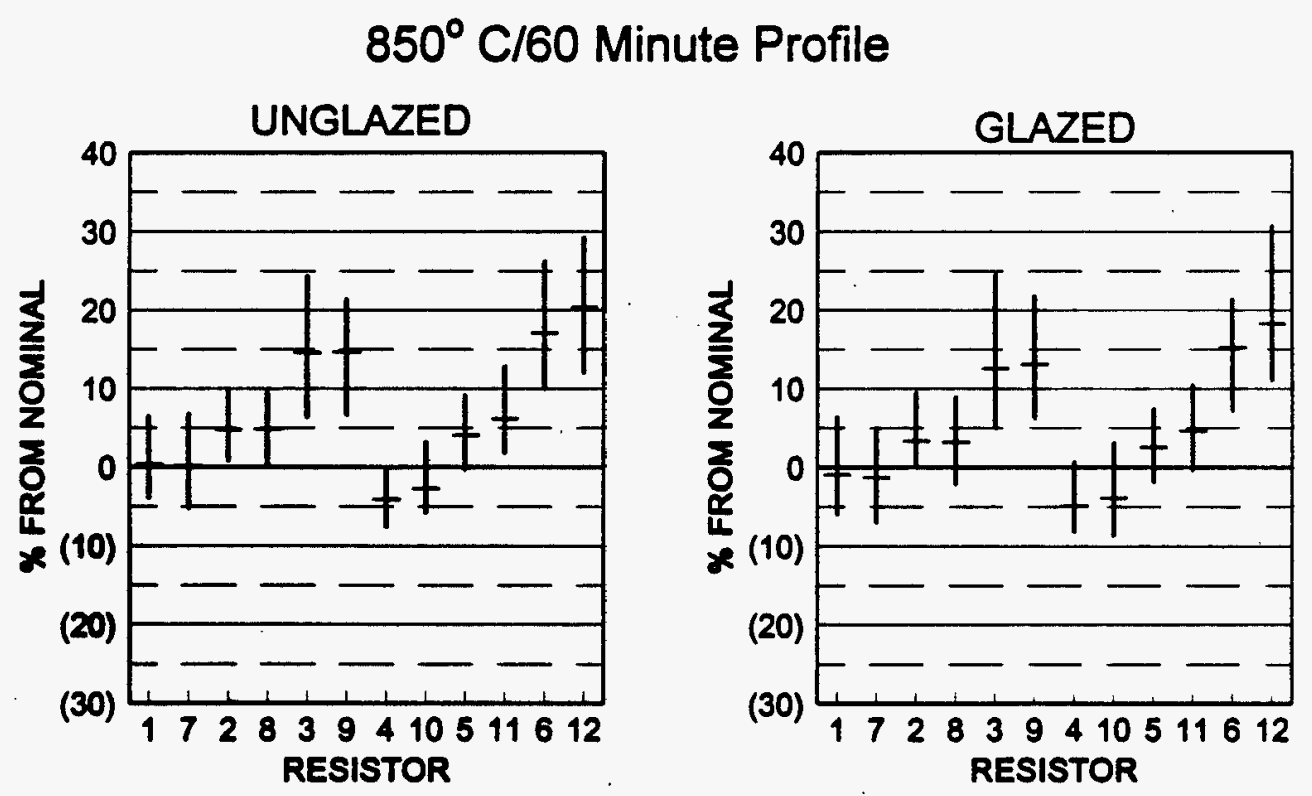

Figuro 71 
Operating Envelope

No Glaze on Resistors

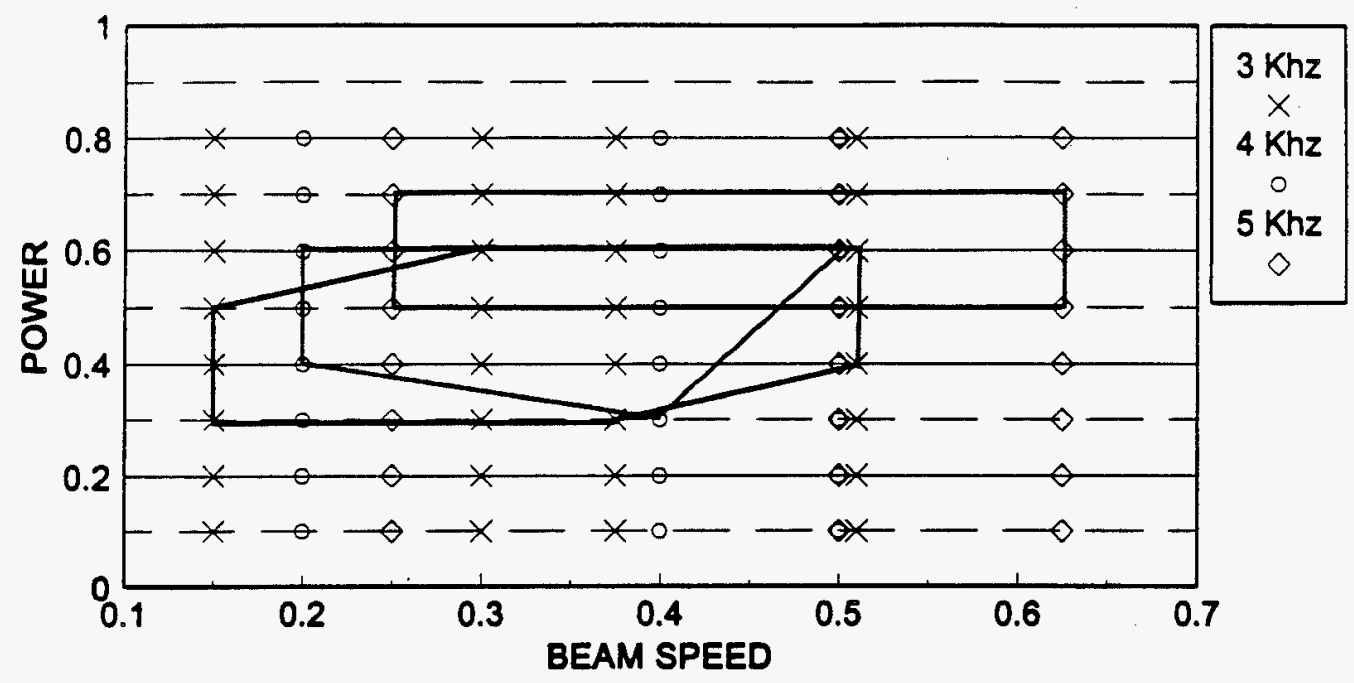

Figure 72

\section{Glaze Over-coated Resistors}

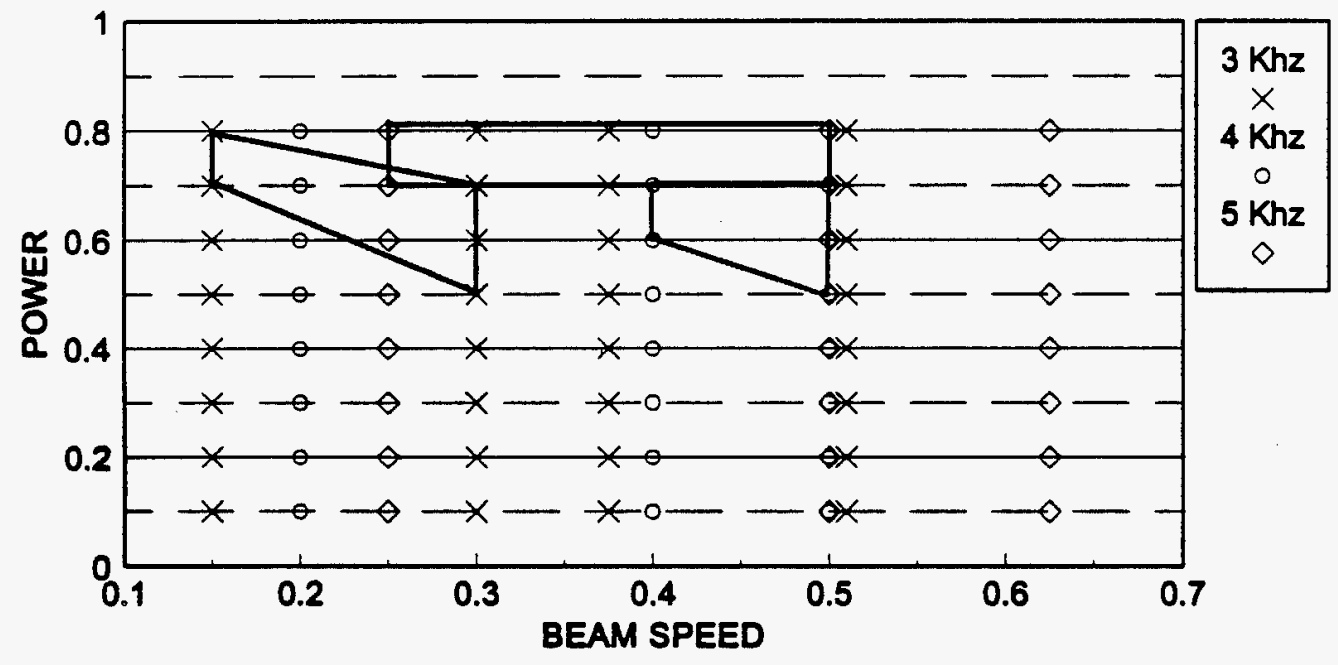

Figure 73 
Stability For Resistors Trimmed Within The Operating Envelope - Unglazed

50 MIL WIDE RESISTOR (TRIMMED)

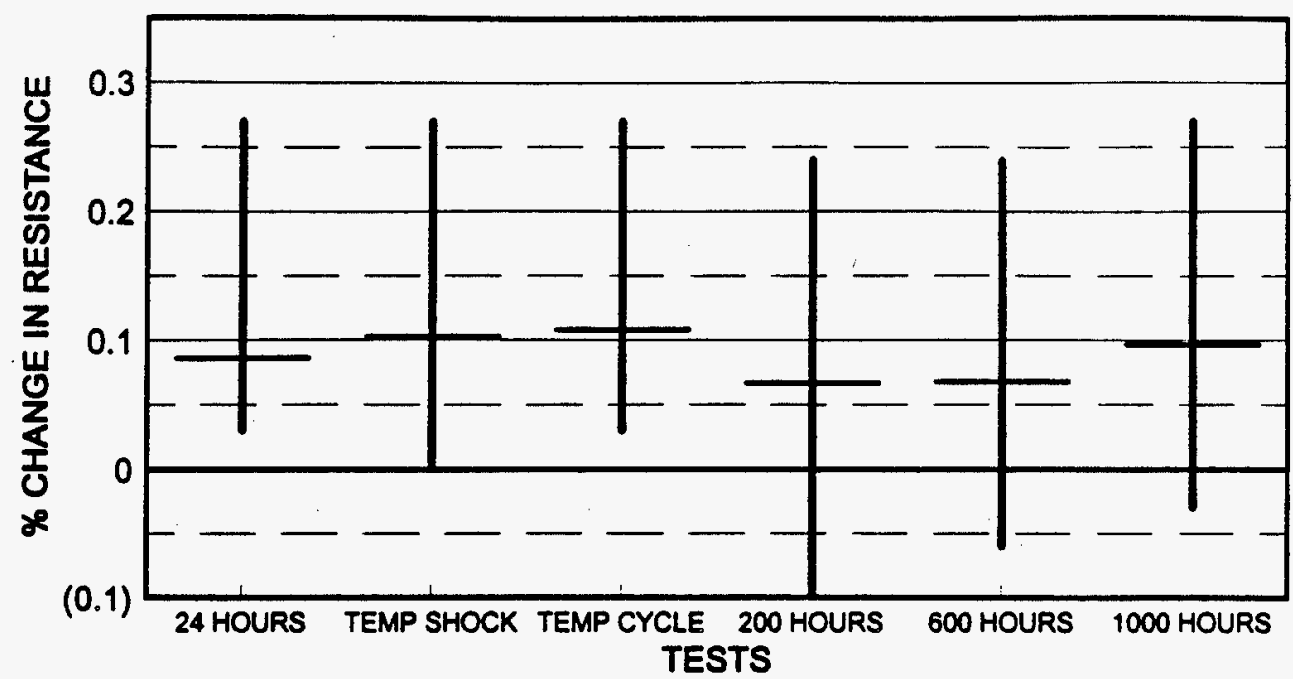

Figure 74

100 MIL WIDE RESISTOR (UNTRIMMED)

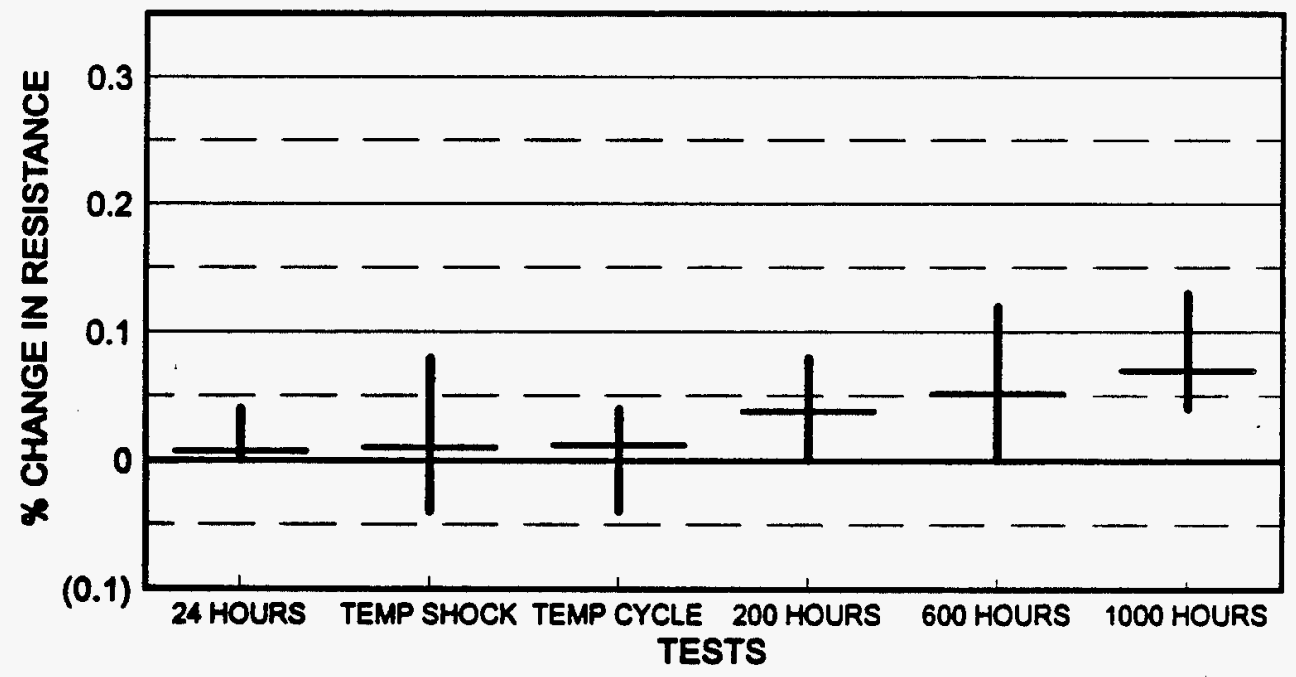

Figure 75 
50 MIL WIDE RESISTOR (TRIMMED)

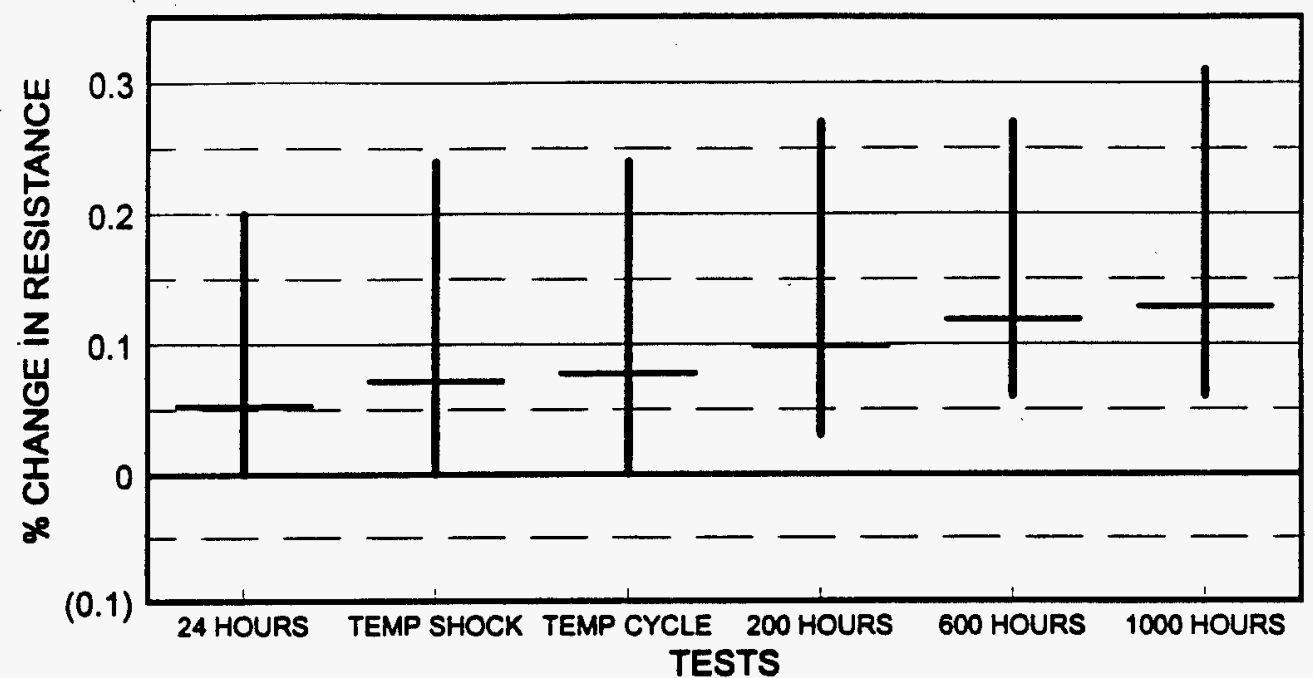

Figure 76

100 MIL WIDE RESISTORS (UNTRIMMED)

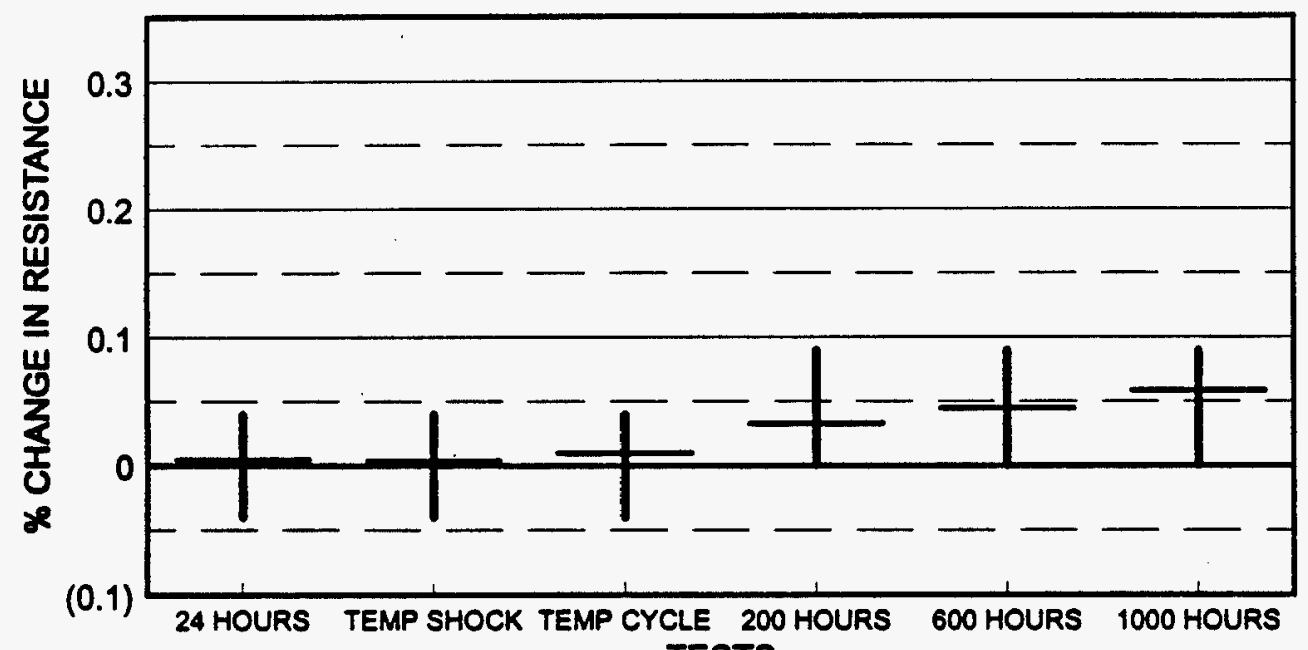

TESTS

Figure 77 
Stability For Resistors Trimmed At The Operating Point - Unglazed

25 MIL WIDE RESISTOR (TRIMMED)

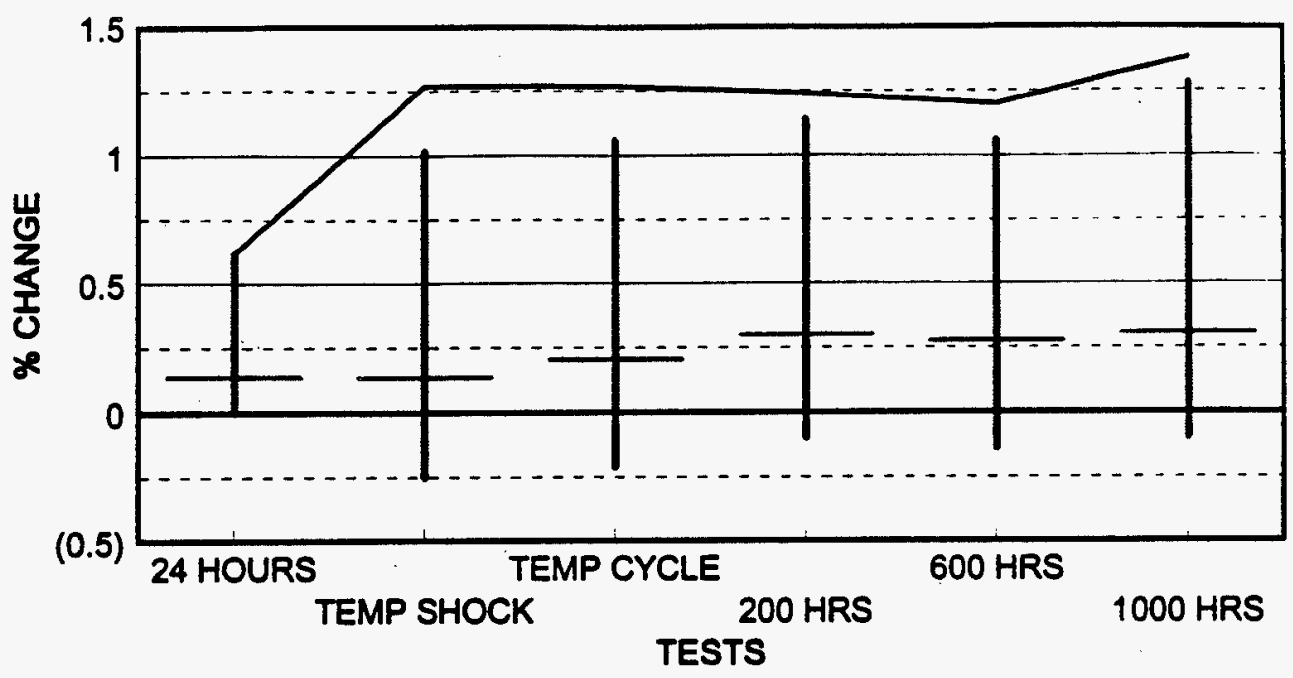

Figure 78

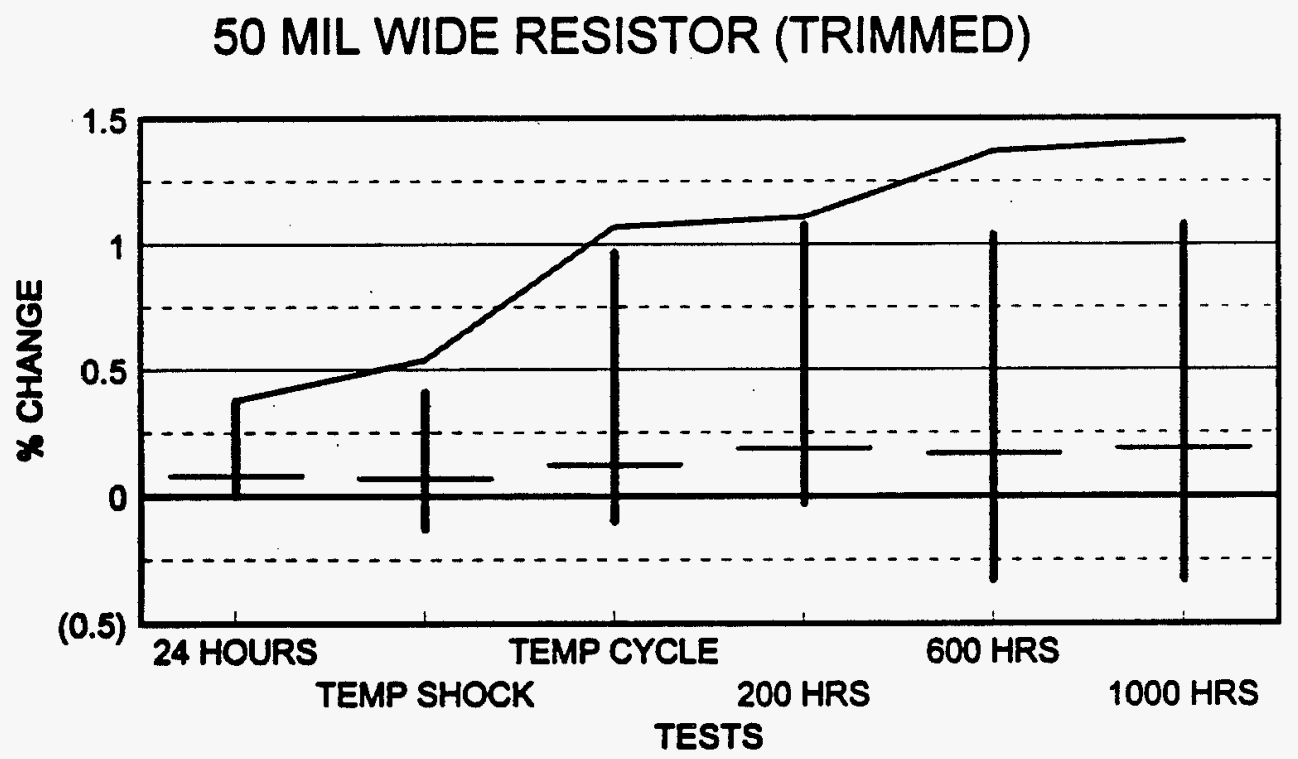

Figure 79 
100 MIL WIDE RESISTOR (UNTRIMMED)

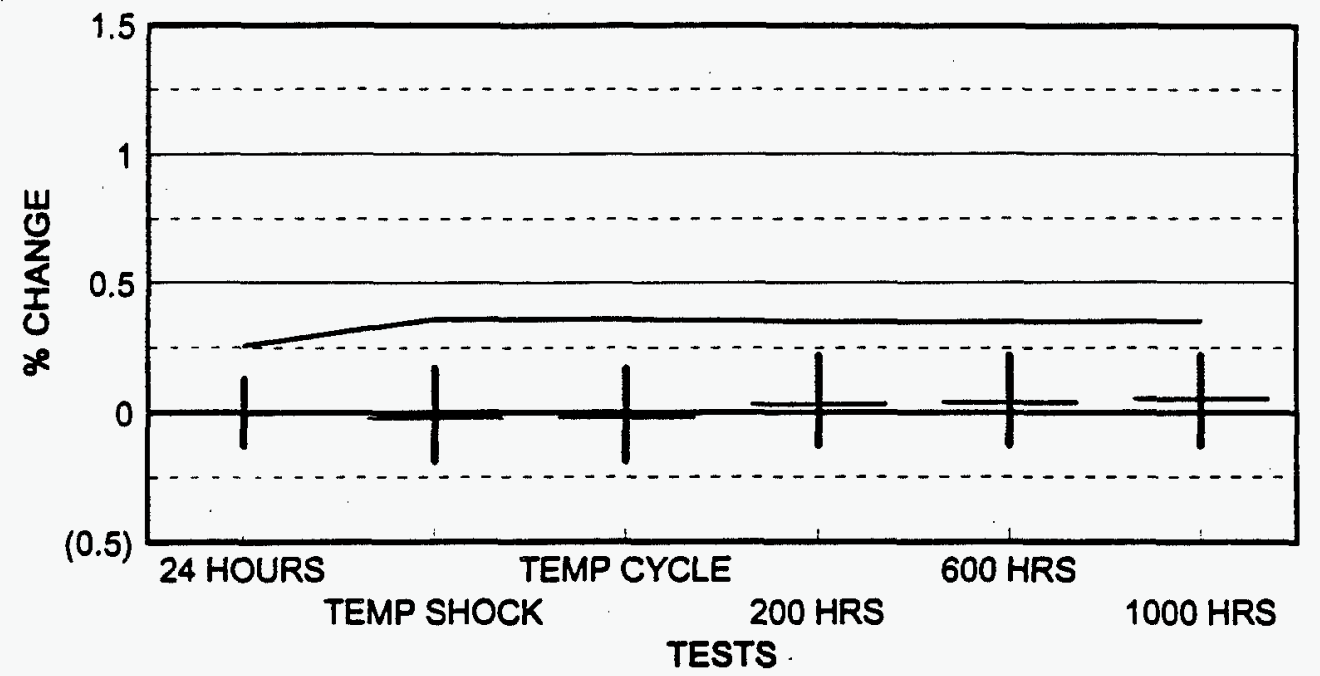

Figure 80

Stability For Resistors Trimmed At The Operating Point - Glazed

\section{MIL WIDE RESISTOR (TRIMMED)}

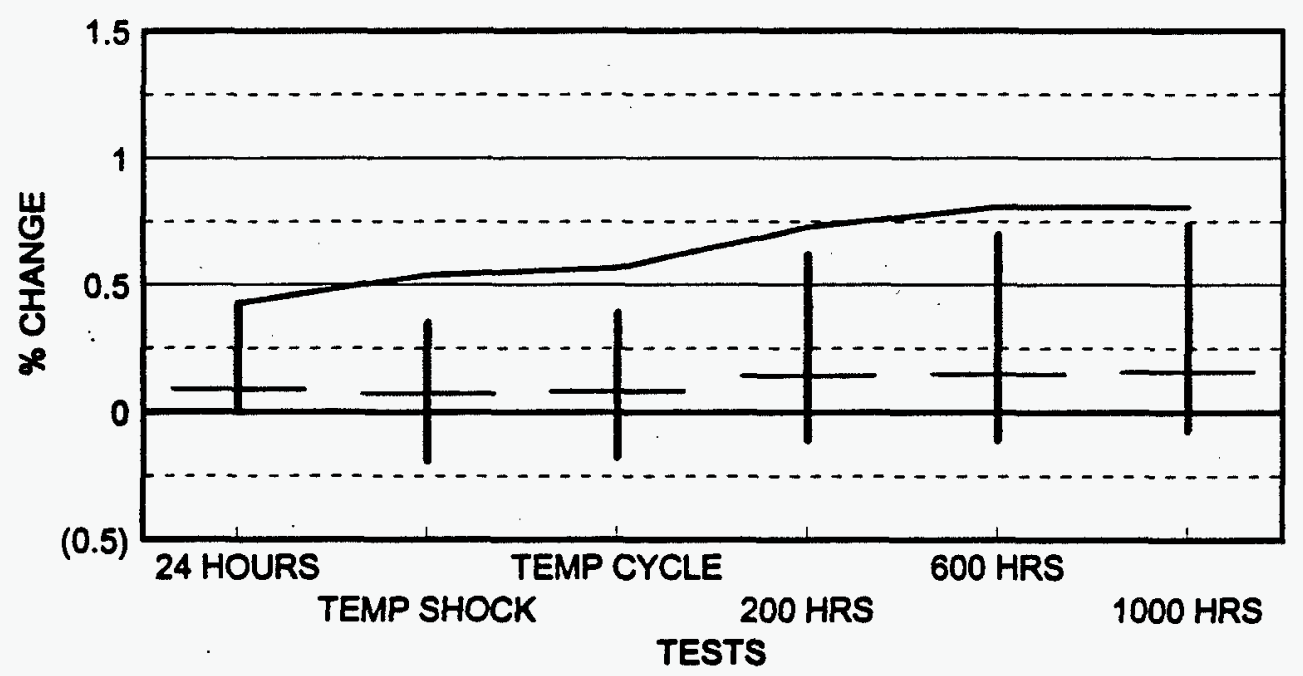

Figure 81 


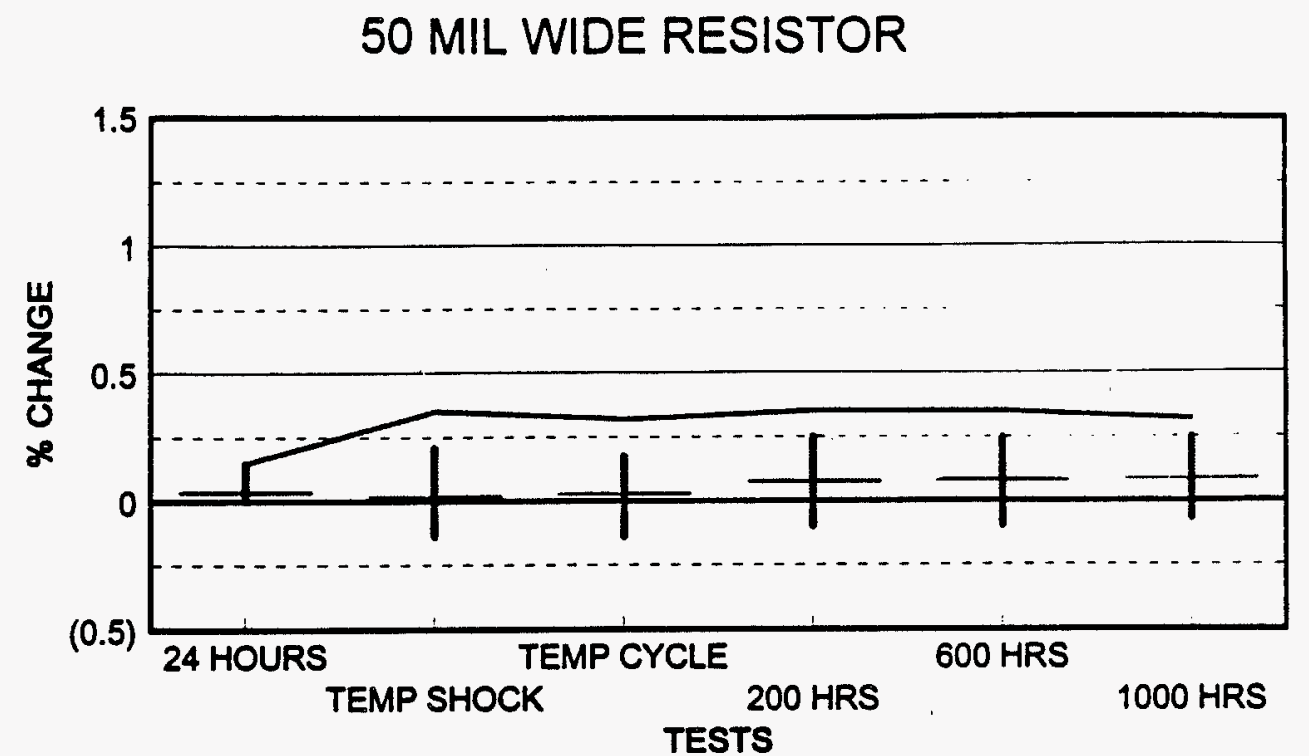

Figure 82

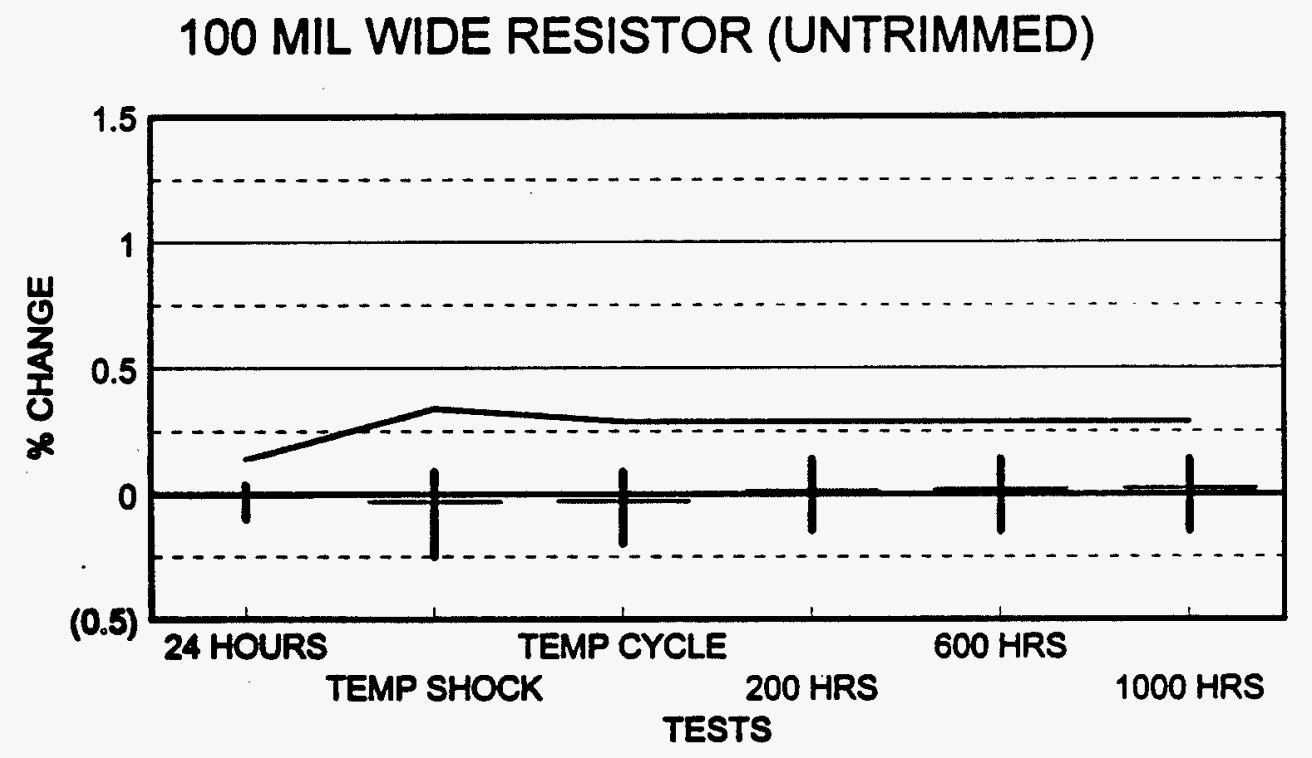

Figure 83 
Analysis Of Resistor Tolerance and Yield Based on Samples Trimmed At The Operating Point - Unglazed

\section{MIL WIDE RESISTOR}

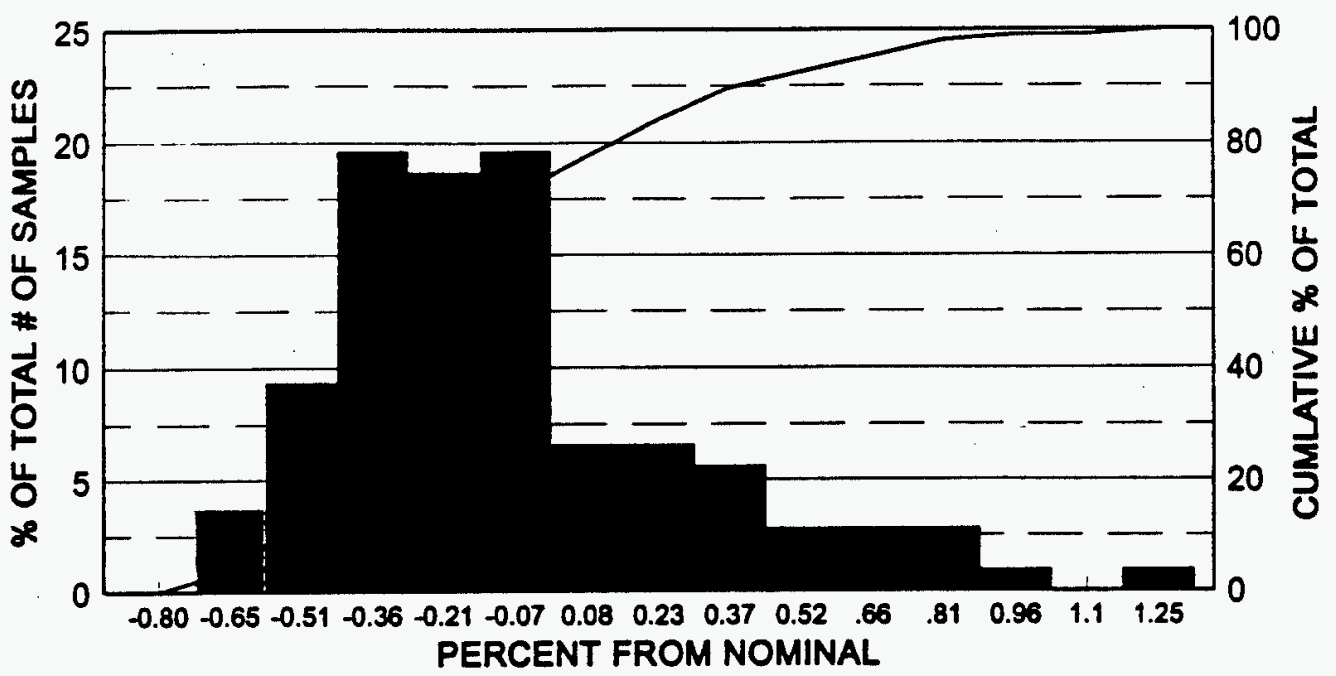

Figure 84

50 MIL WIDE RESISTOR

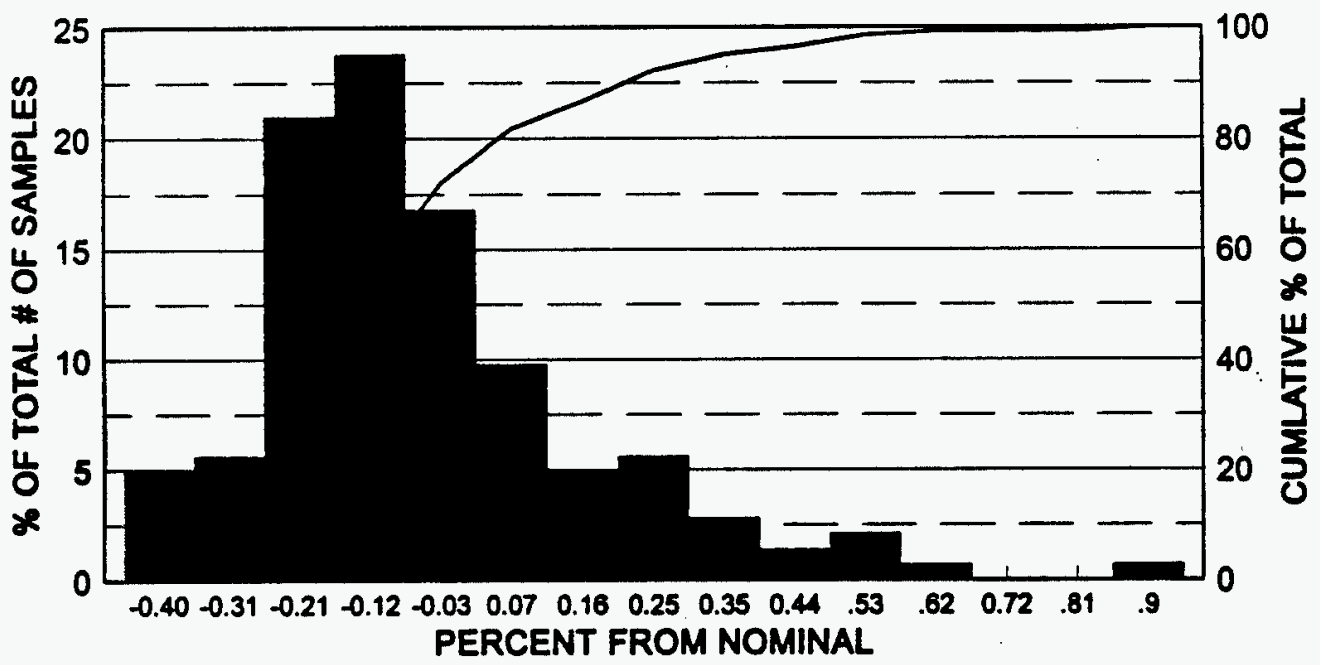

Figure 85 
Analysis Of Resistor Tolerance and Yield Based on Samples Trimmed At The Operating Point - Glazed

\section{MIL WIDE RESISTOR}

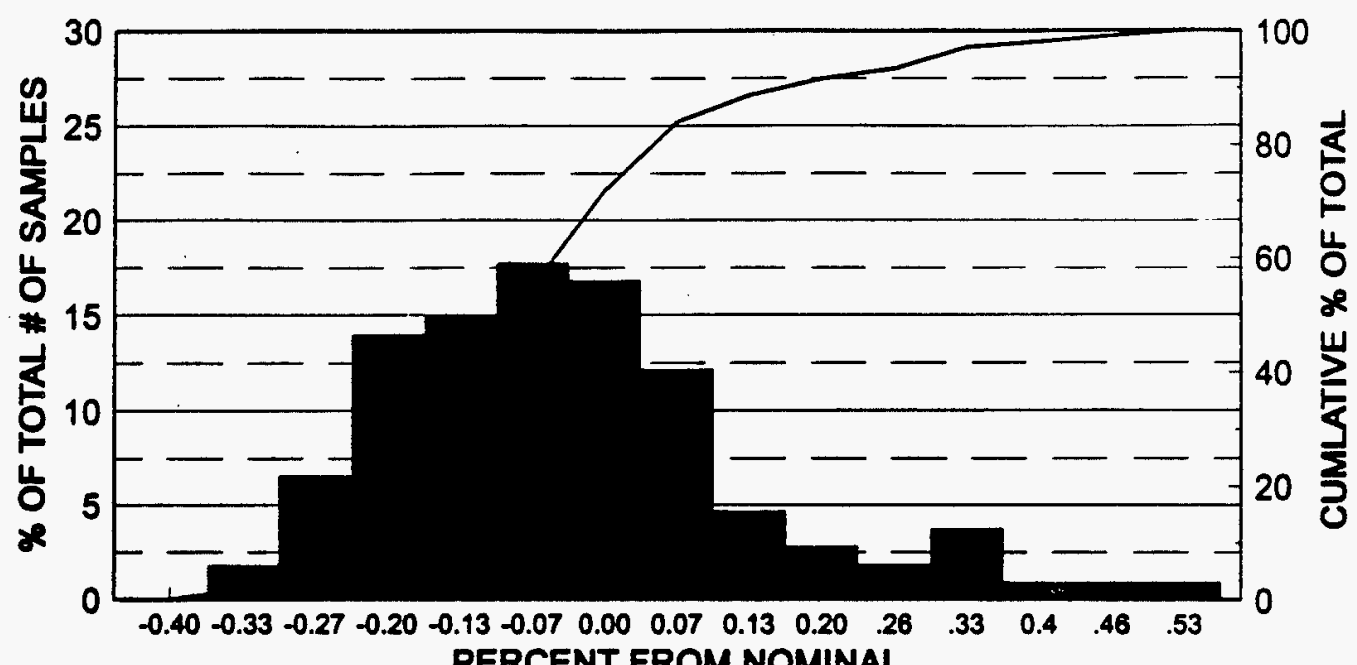

PERCENT FROM NOMINAL

Figure 86

50 MIL WIDE RESISTOR

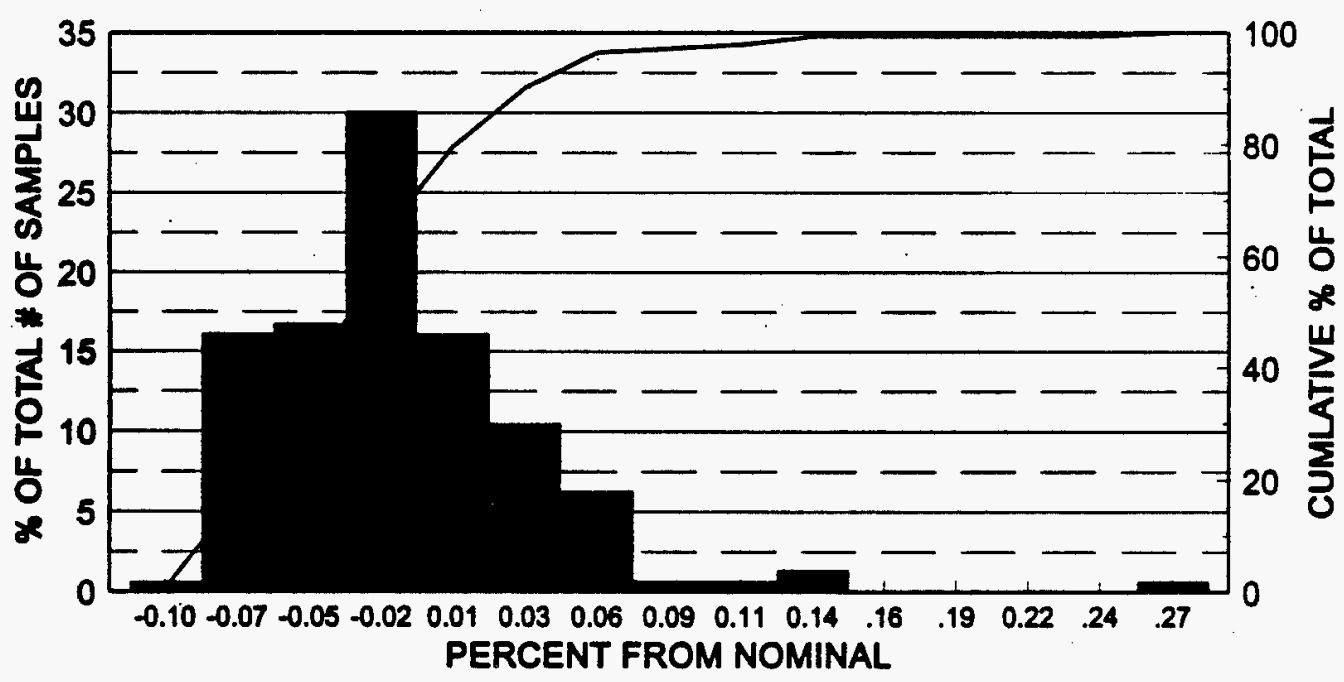

Figure 87 


\section{APPENDIX F}

\section{Test Results For The 1959 Paste}

Pre Trim Distribution

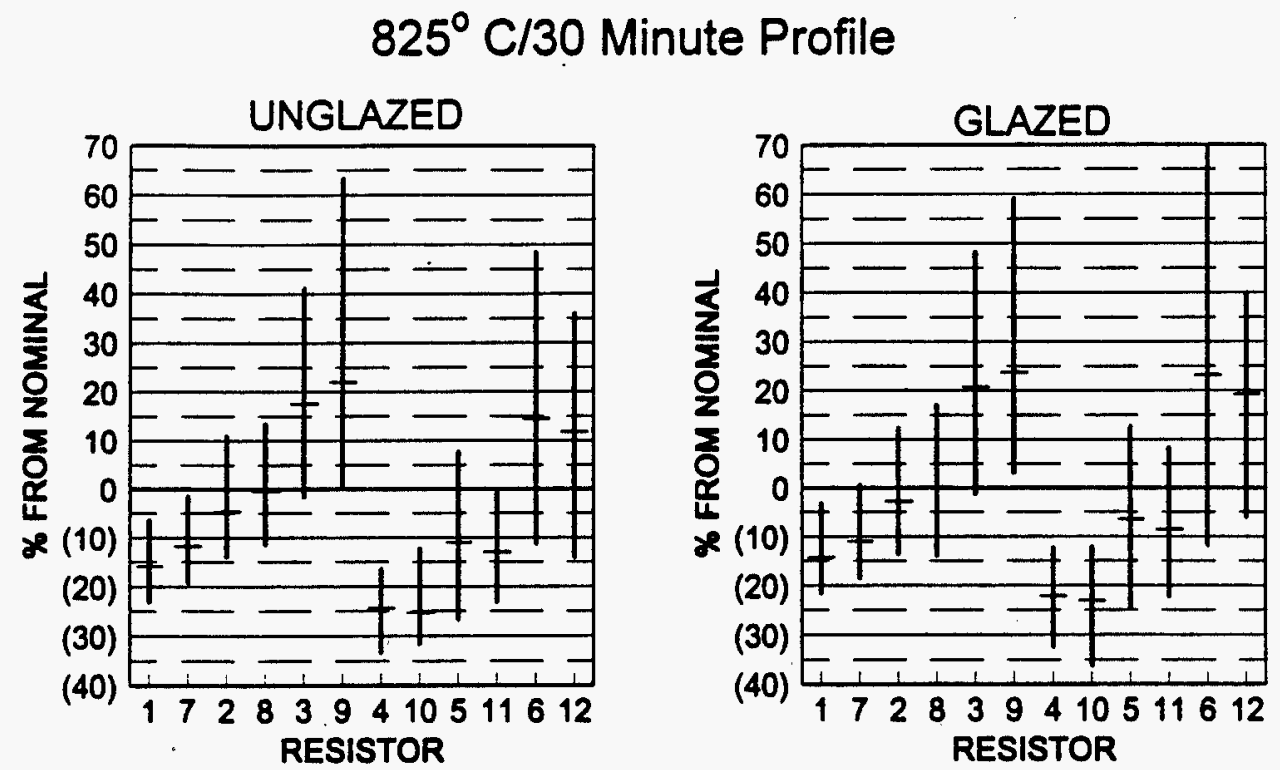

Figure 88
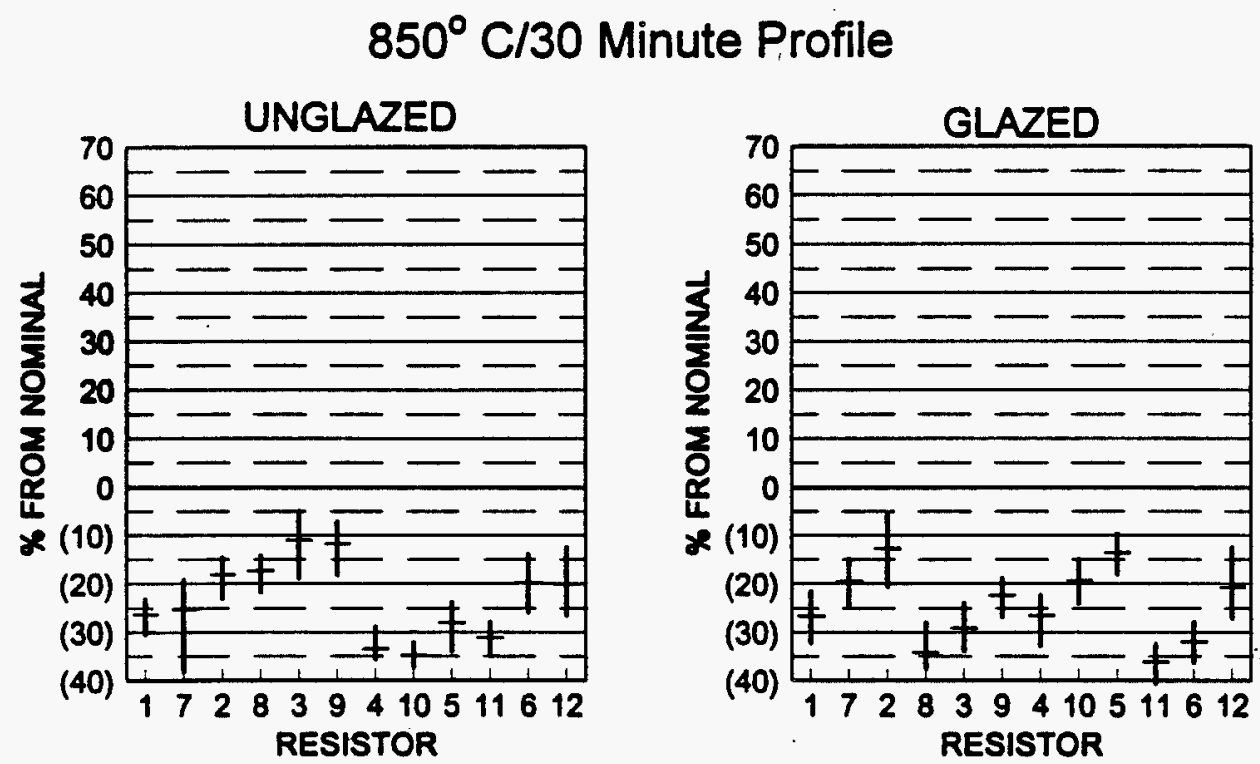

Figure 89 


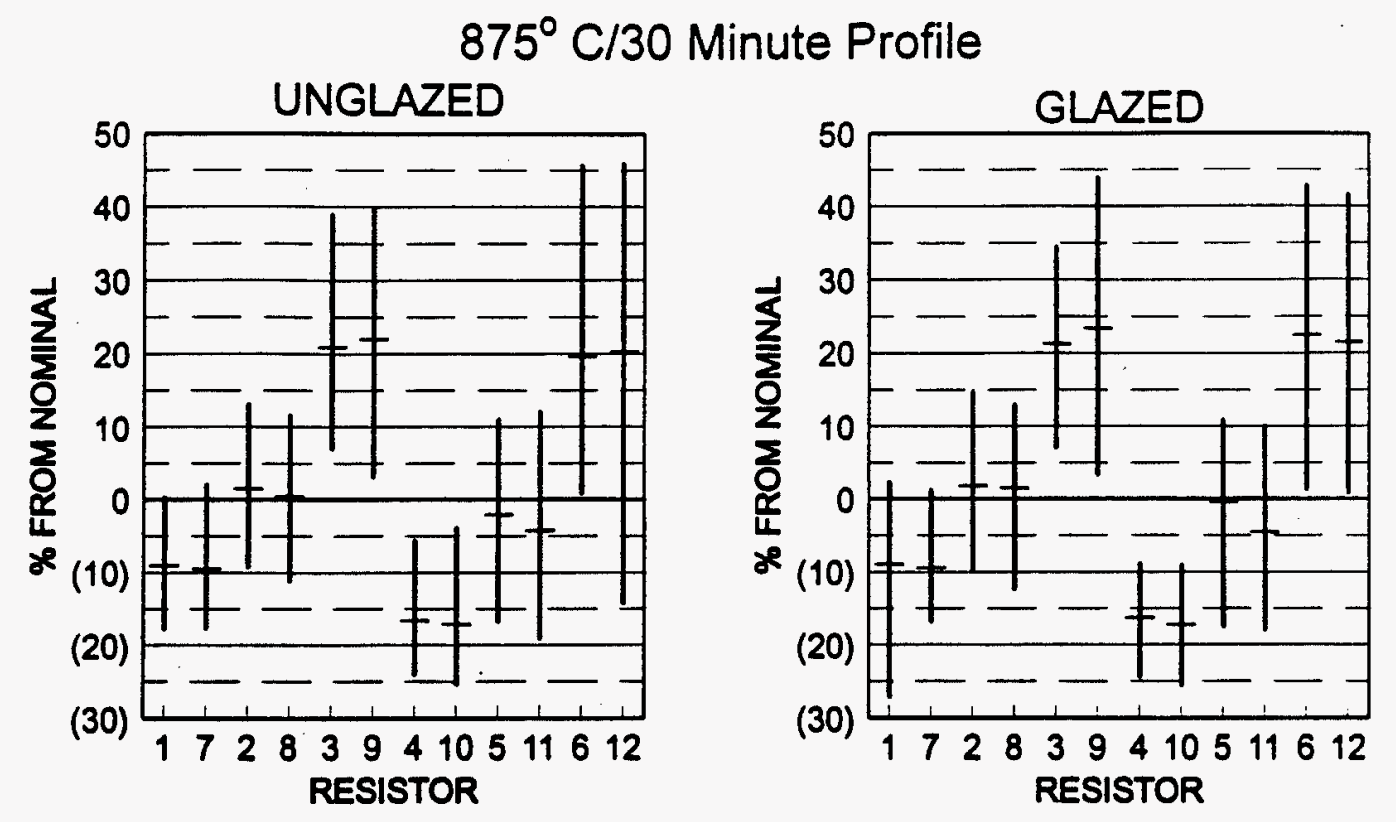

Figure 90
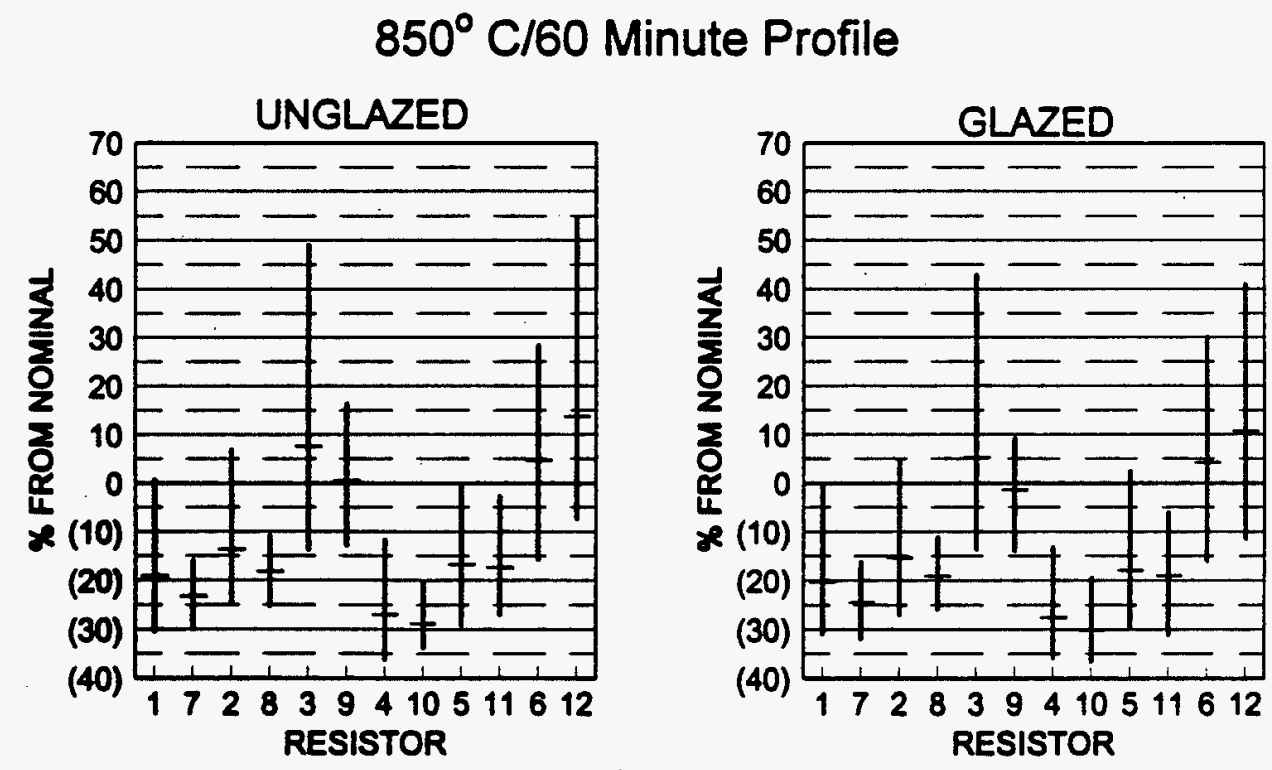

Figure 91 
No Glaze on Resistors

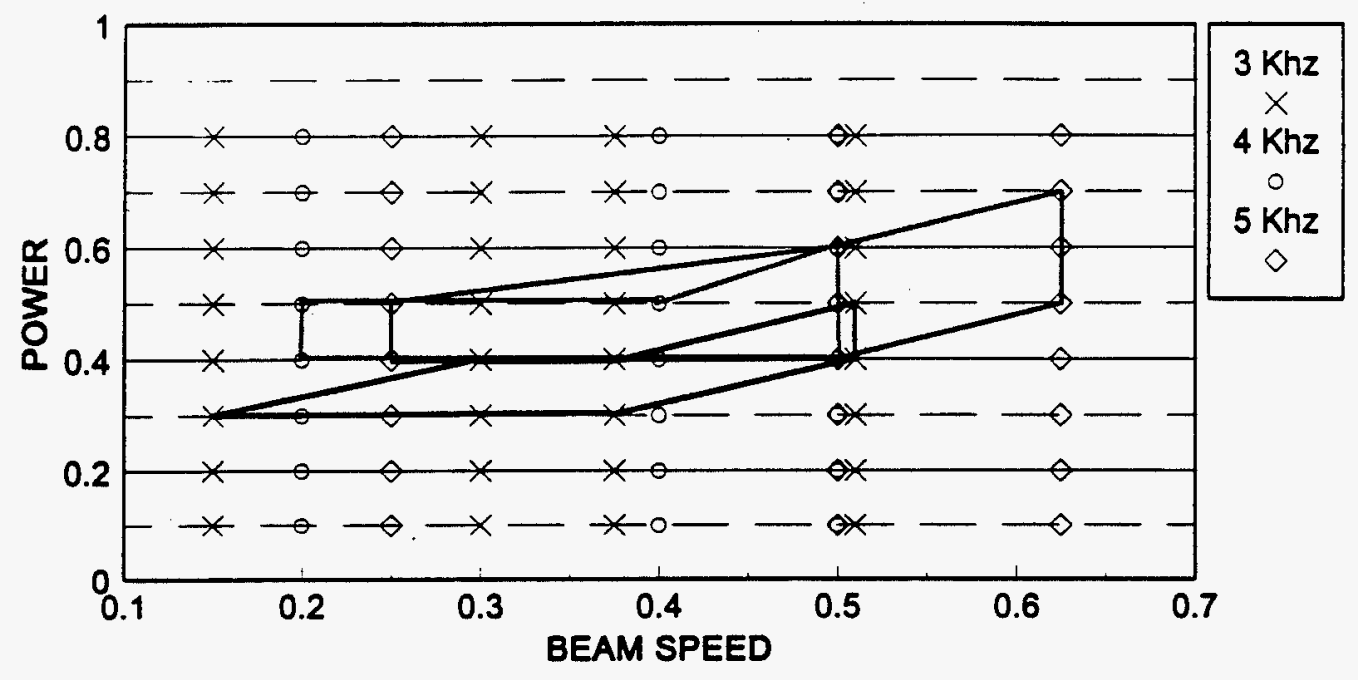

Figure 92

\section{Glaze Over-coated Resistors}

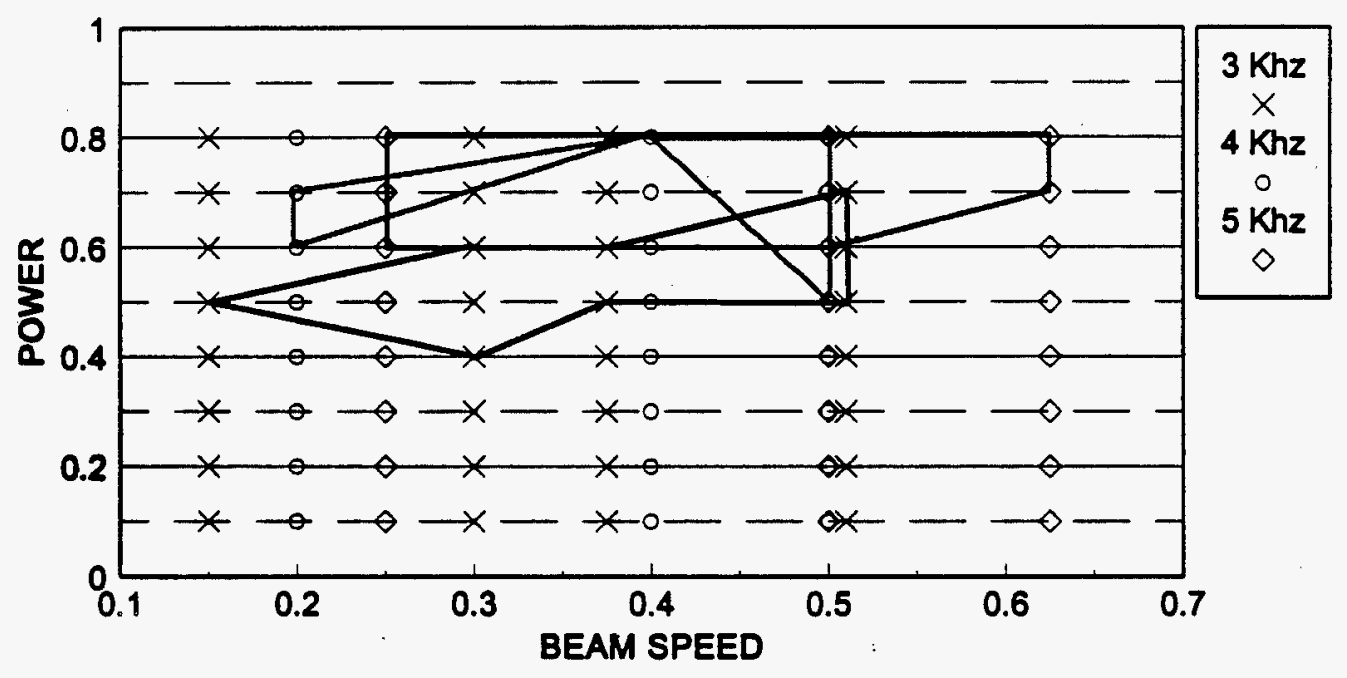

Figure 93 
50 MIL WIDE RESISTOR (TRIMMED)

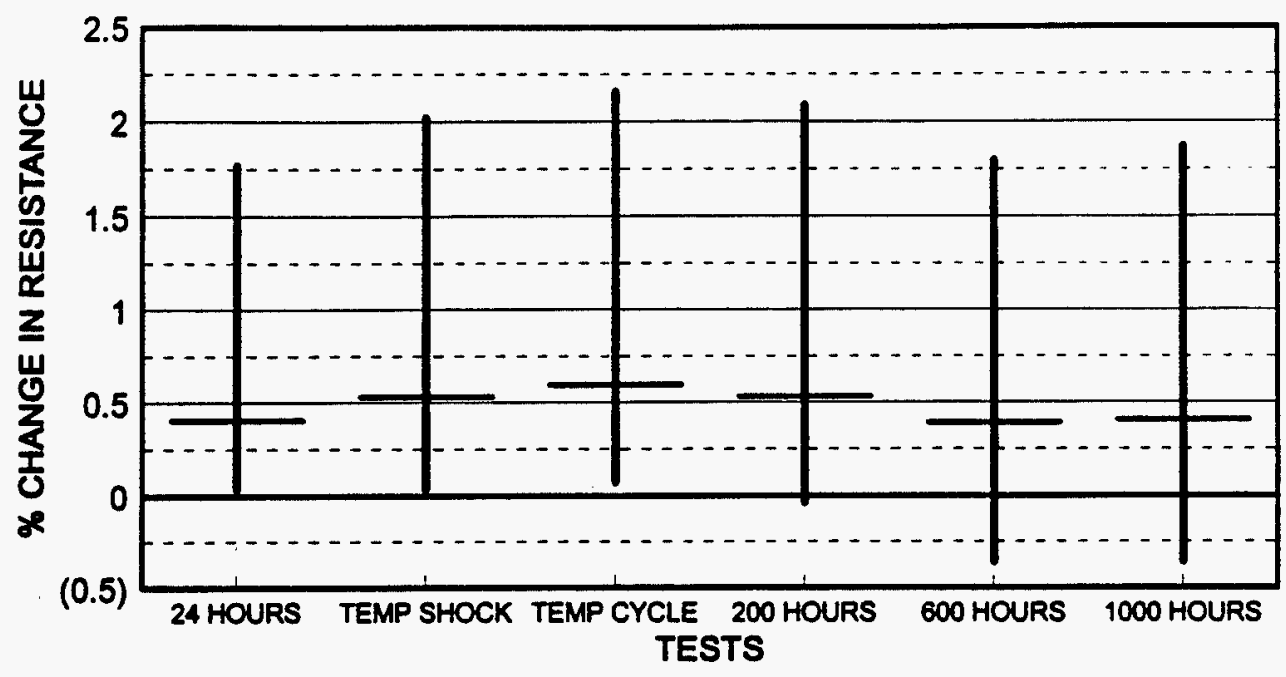

Figure 94

\section{MIL WIDE RESISTOR (UNTRIMMED)}

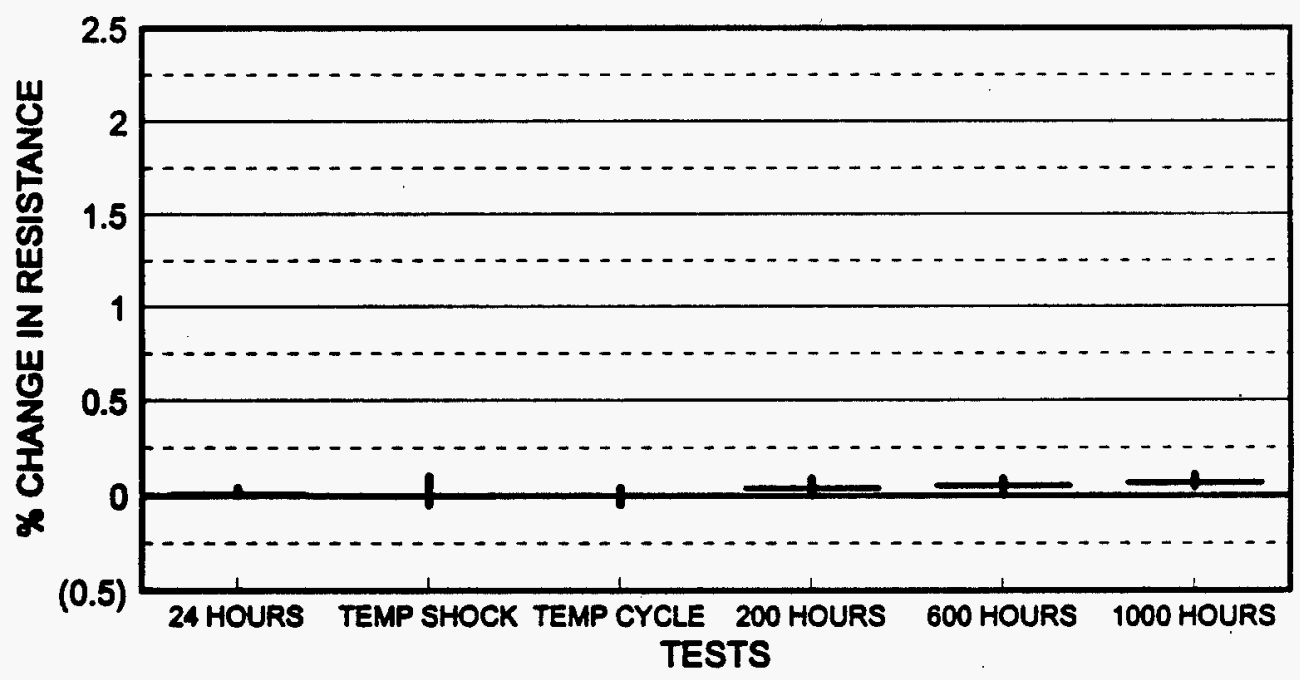

Figure 95 
Stability For Resistors Trimmed Within The Operating Envelope - Glazed

50 MIL WIDE RESISTOR (TRIMMED)

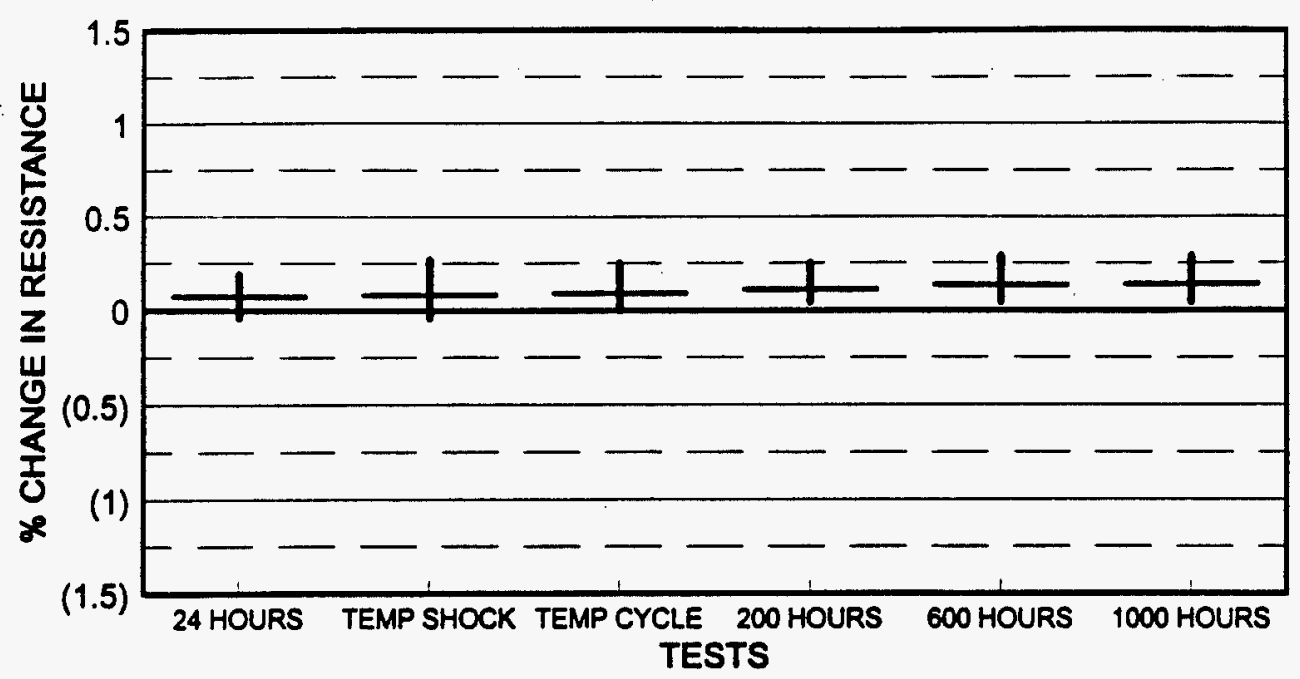

Figure 96

100 MIL WIDE RESISTOR (UNTRIMMED)

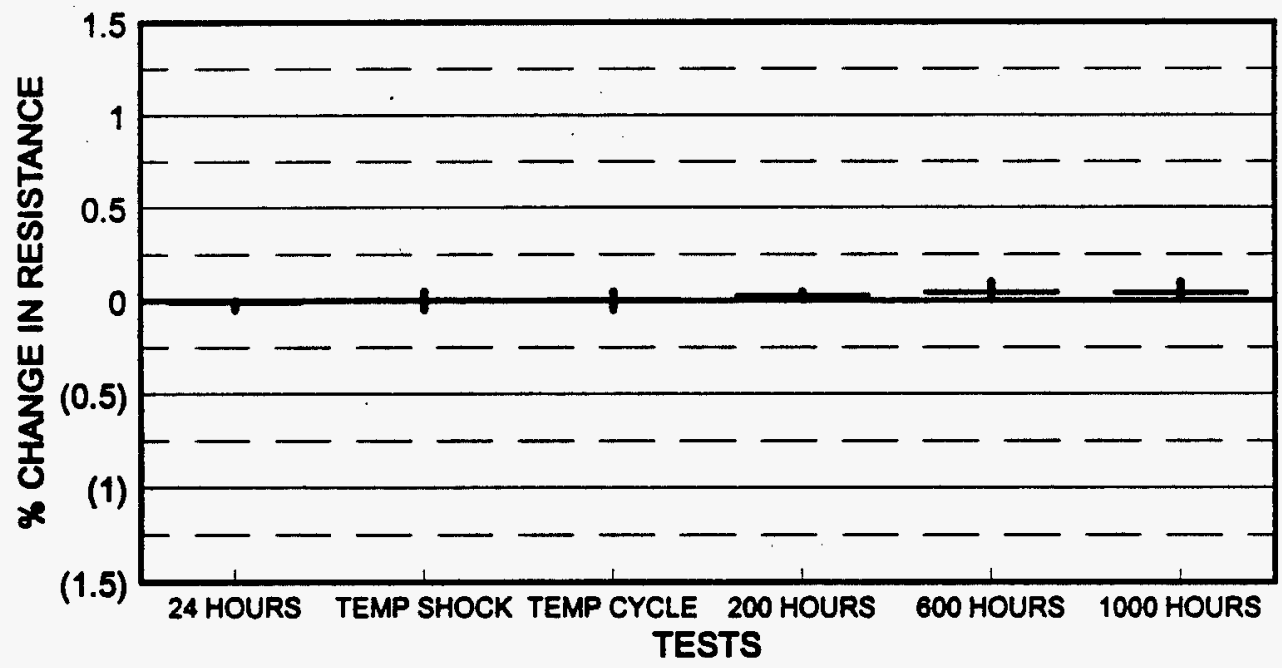

Figure 97 
Stability For Resistors Trimmed At The Operating Point - Unglazed

25 MIL WIDE RESISTOR (TRIMMED)

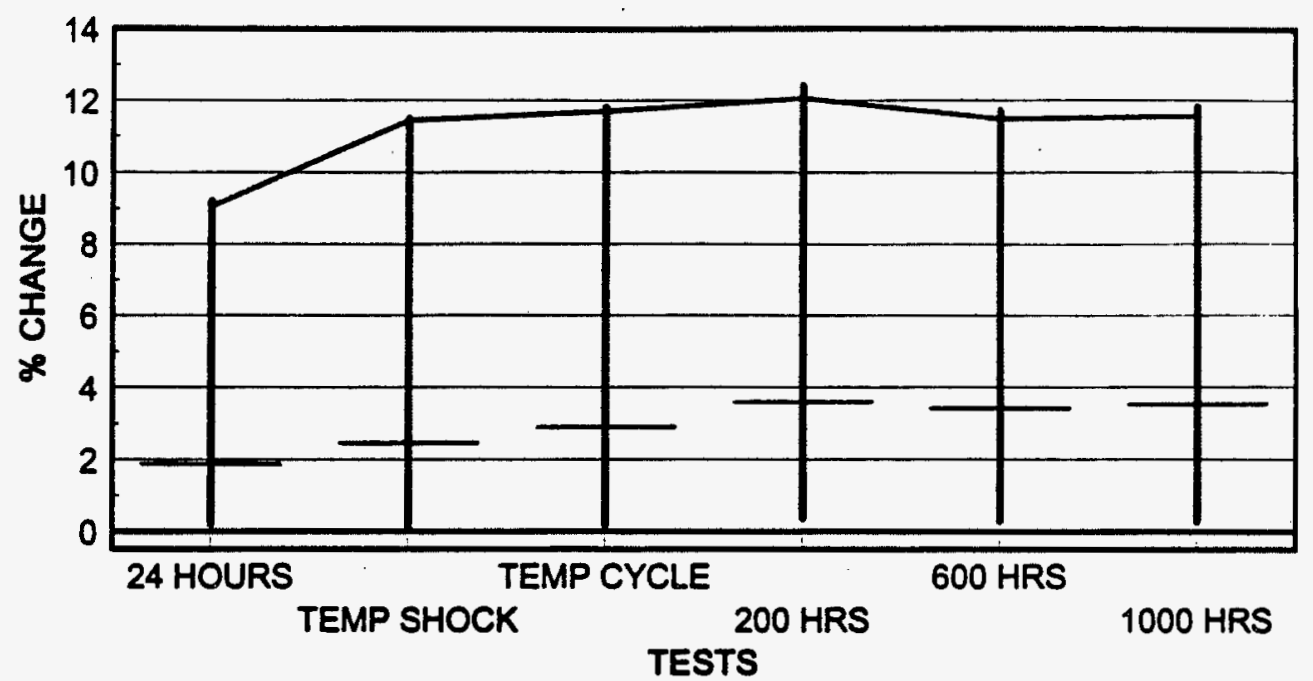

Figure 98

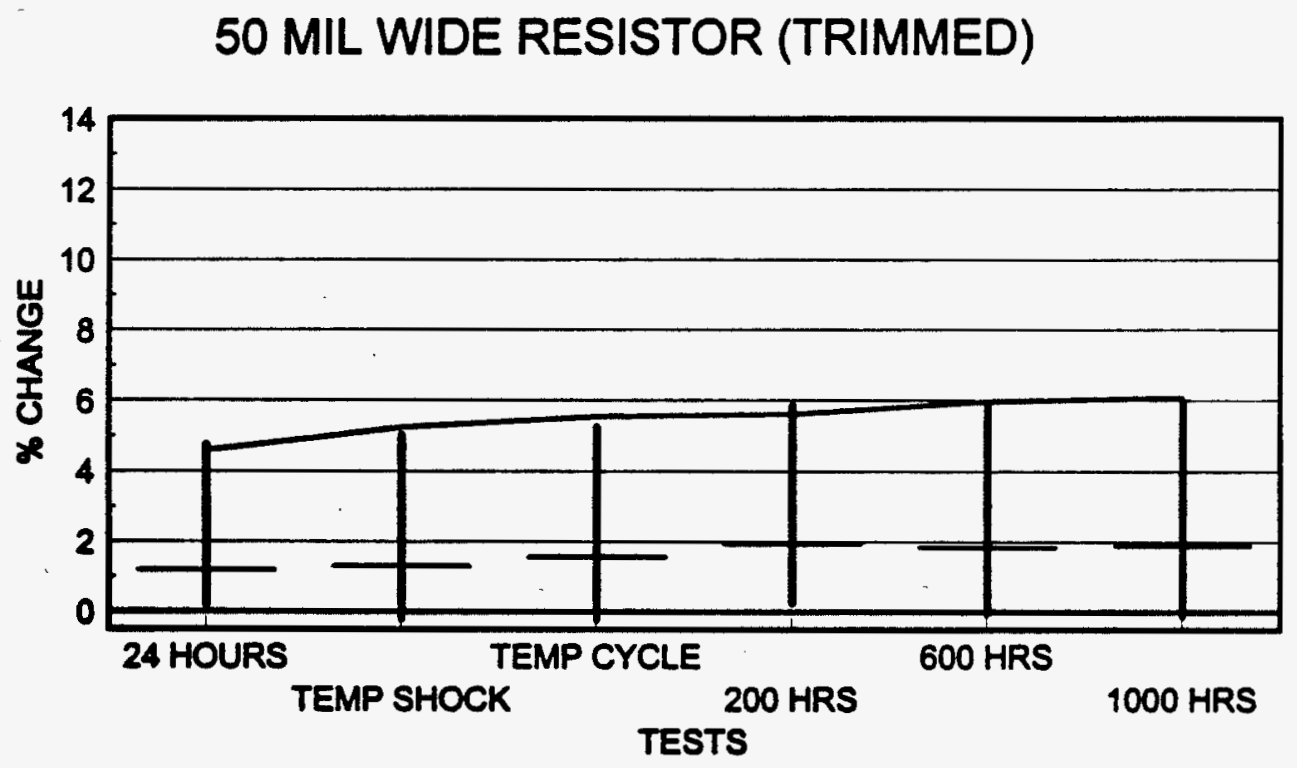

Figure 99 
100 MIL WIDE RESISTOR (UNTRIMMED)

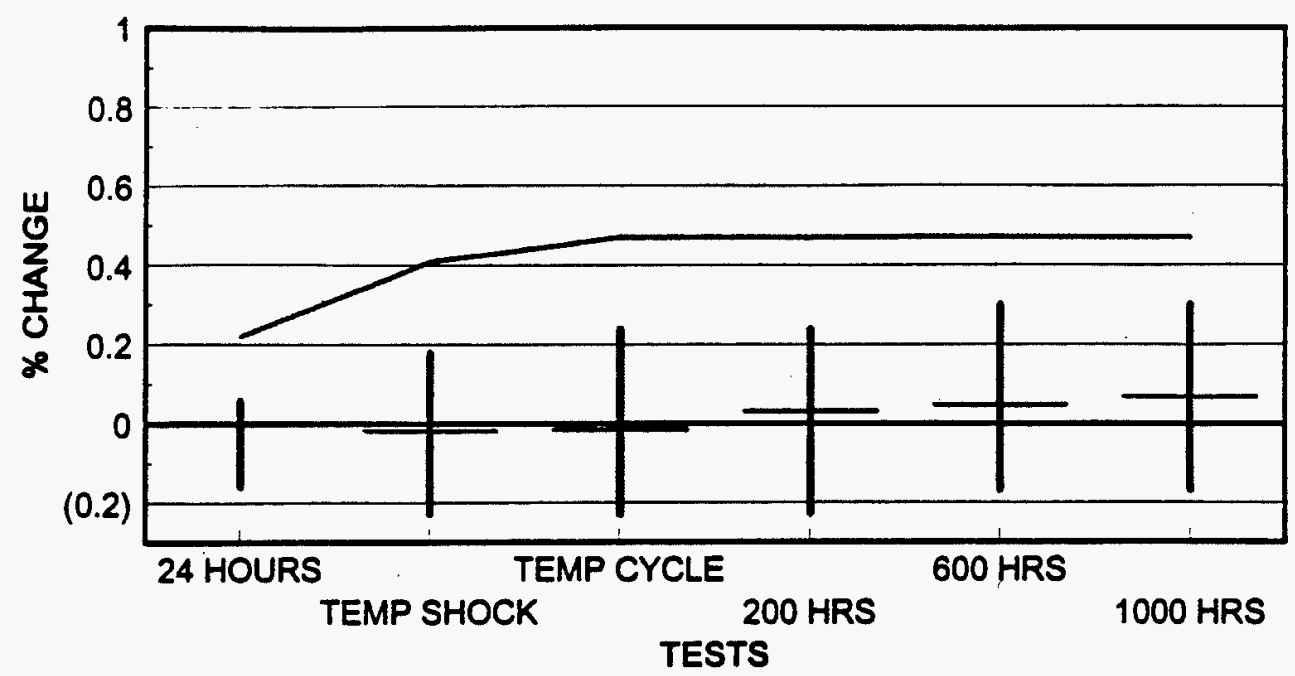

Figure 100

Stability For Resistors Trimmed At The Operating Point - Glazed

25 MIL WIDE RESISTOR (TRIMMED)

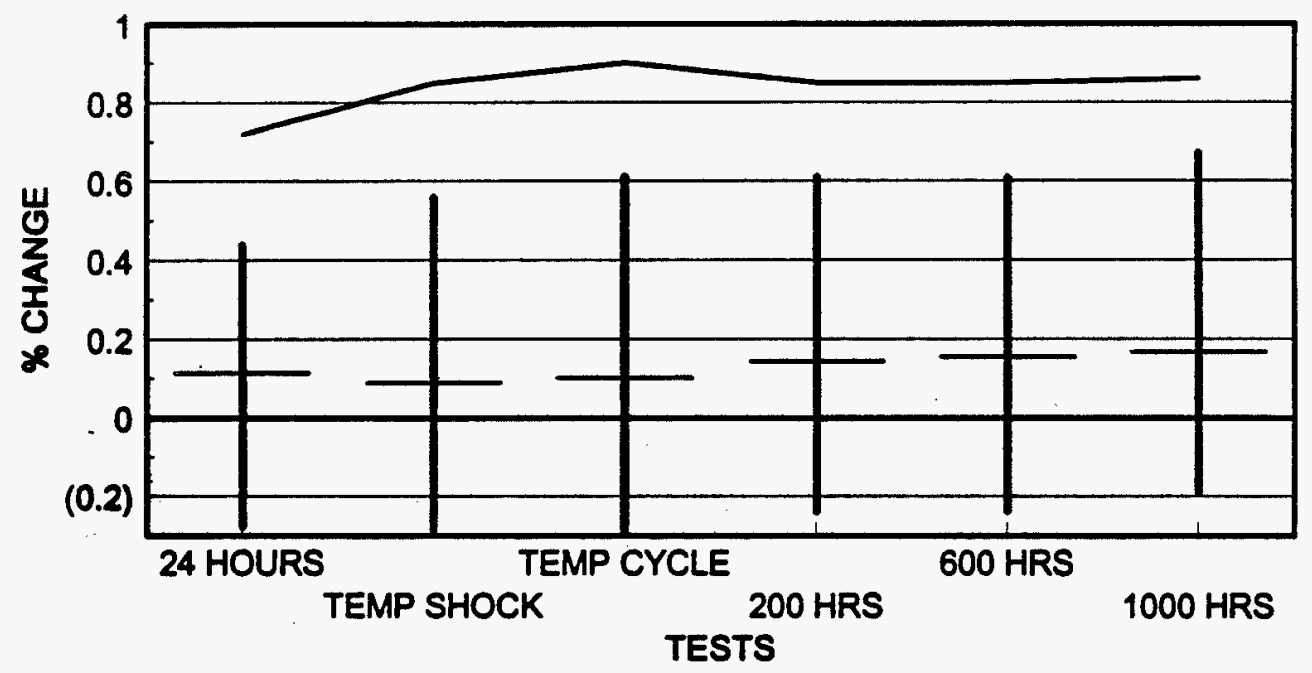

Figure 101 
50 MIL WIDE RESISTOR (TRIMMED)

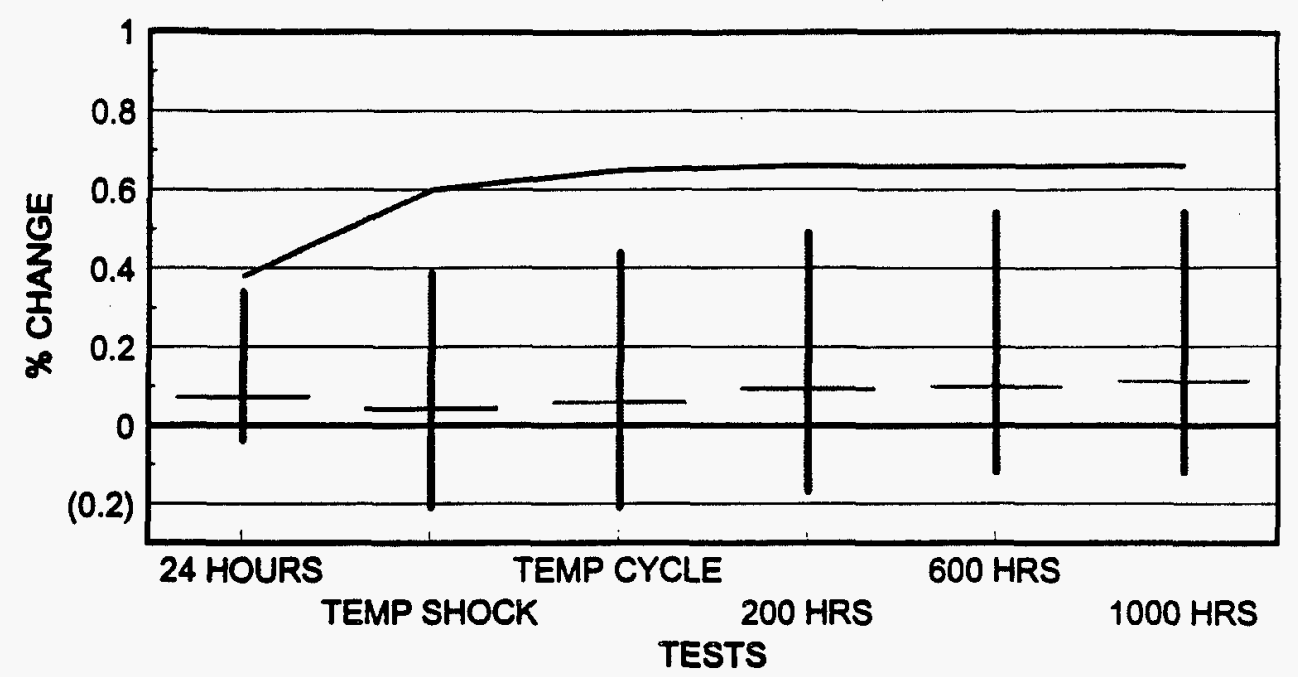

Figure 102

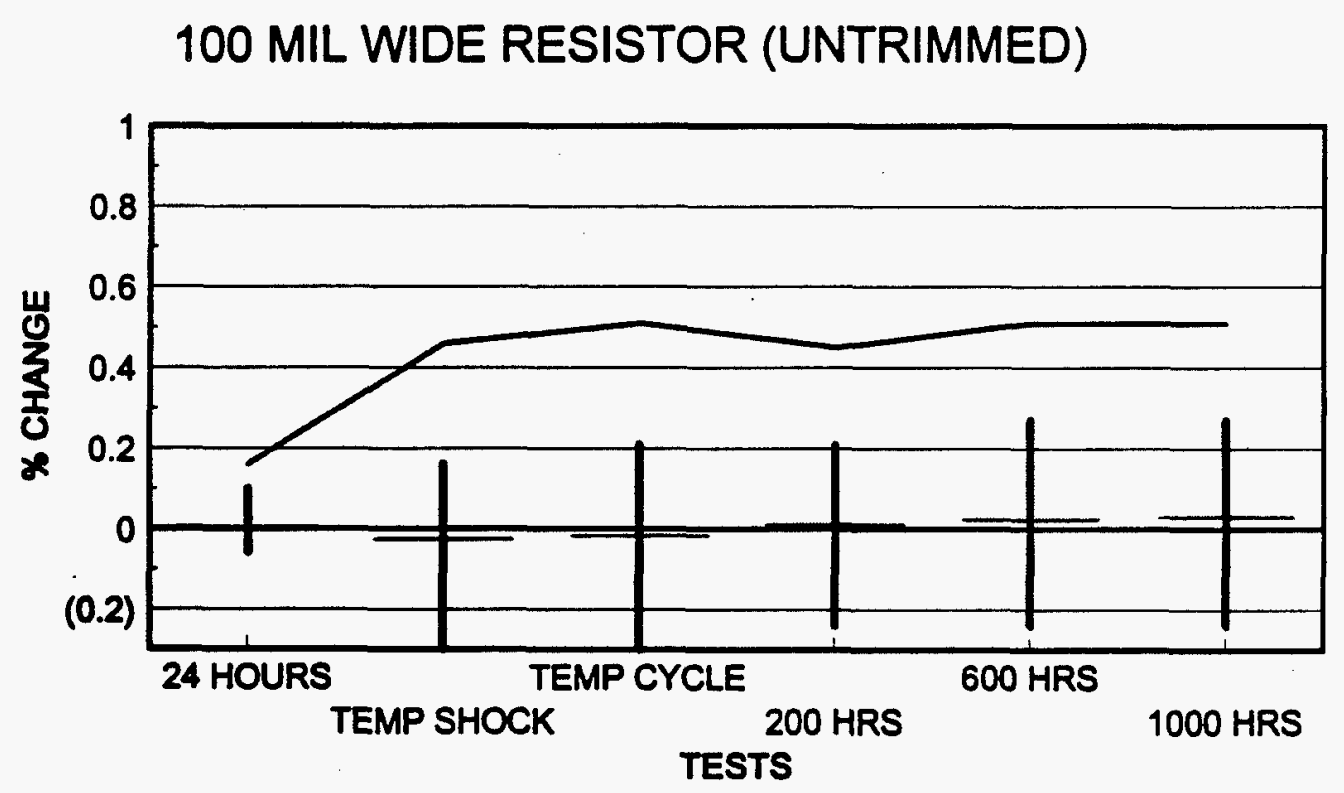

Figure 103 
Analysis Of Resistor Tolerance and Yield Based on Samples Trimmed At The Operating Point - Unglazed

25 MIL WIDE RESISTOR

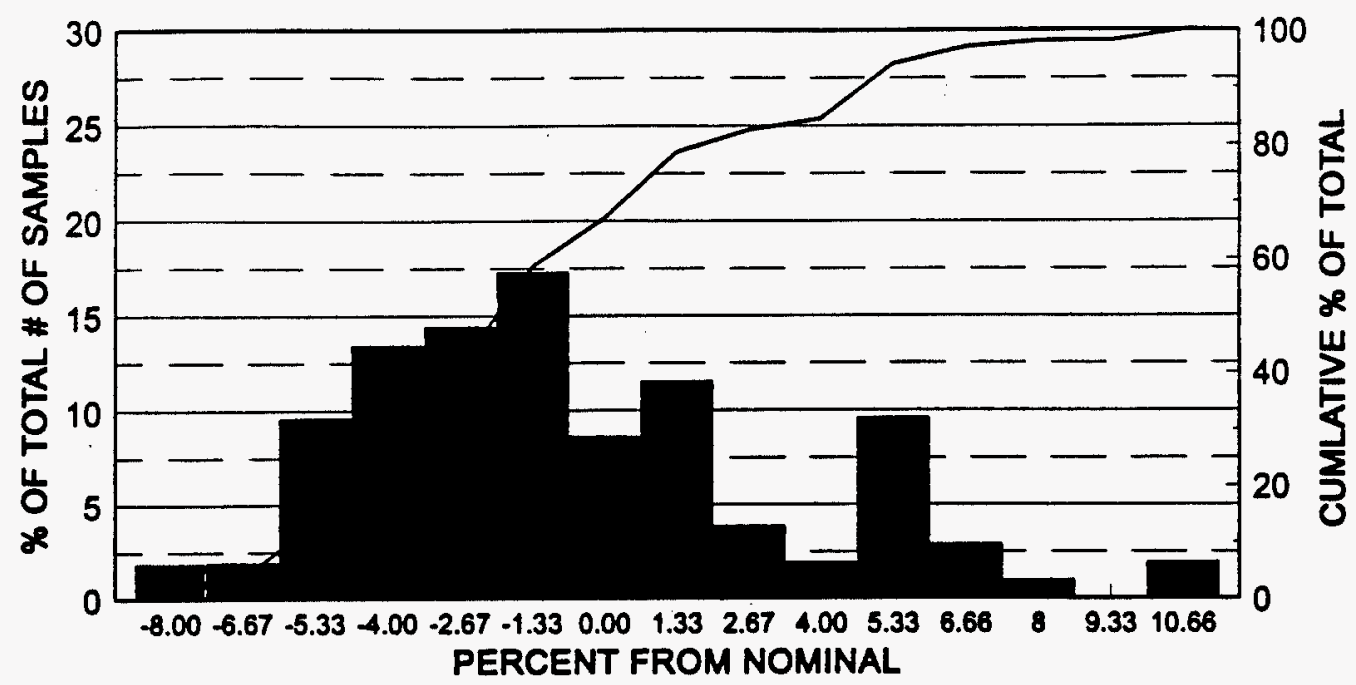

Figure 104

50 MIL WIDE RESISTOR

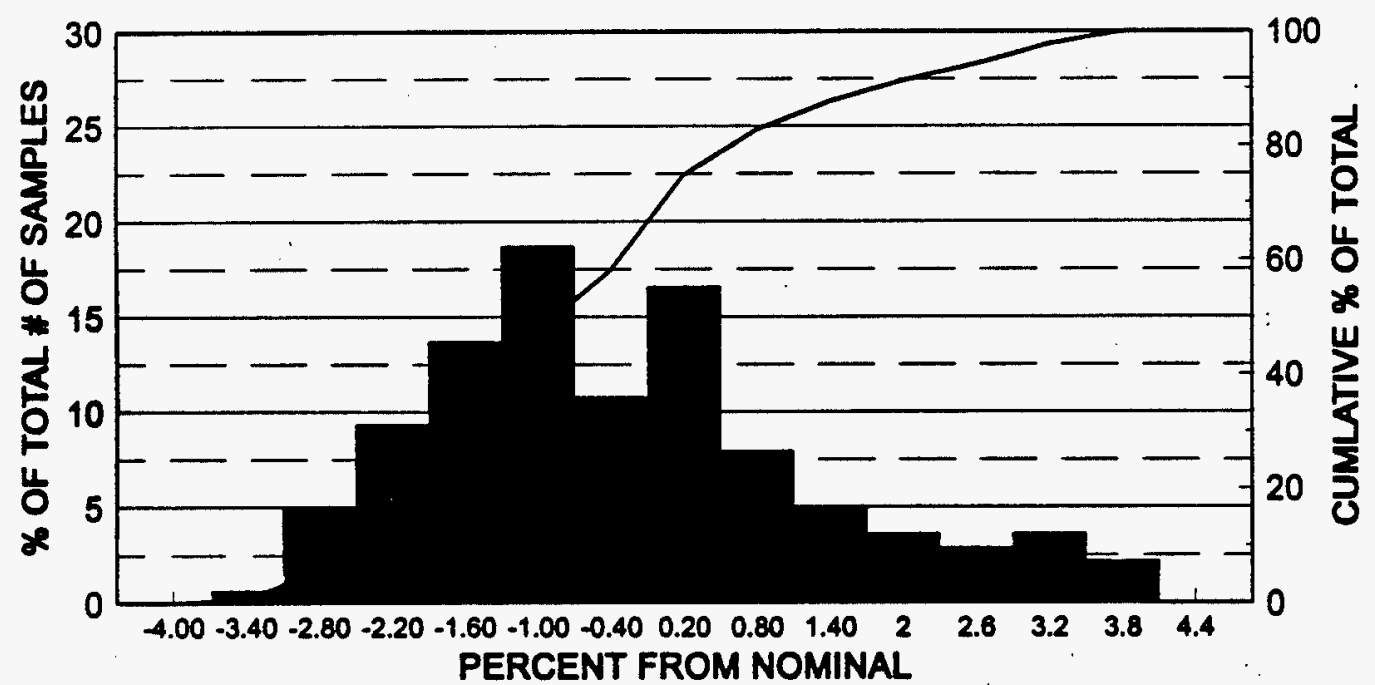

Figure 105 
Analysis Of Resistor Tolerance and Yield Based on Samples Trimmed At The Operating Point - Unglazed

\section{MIL WIDE RESISTOR}

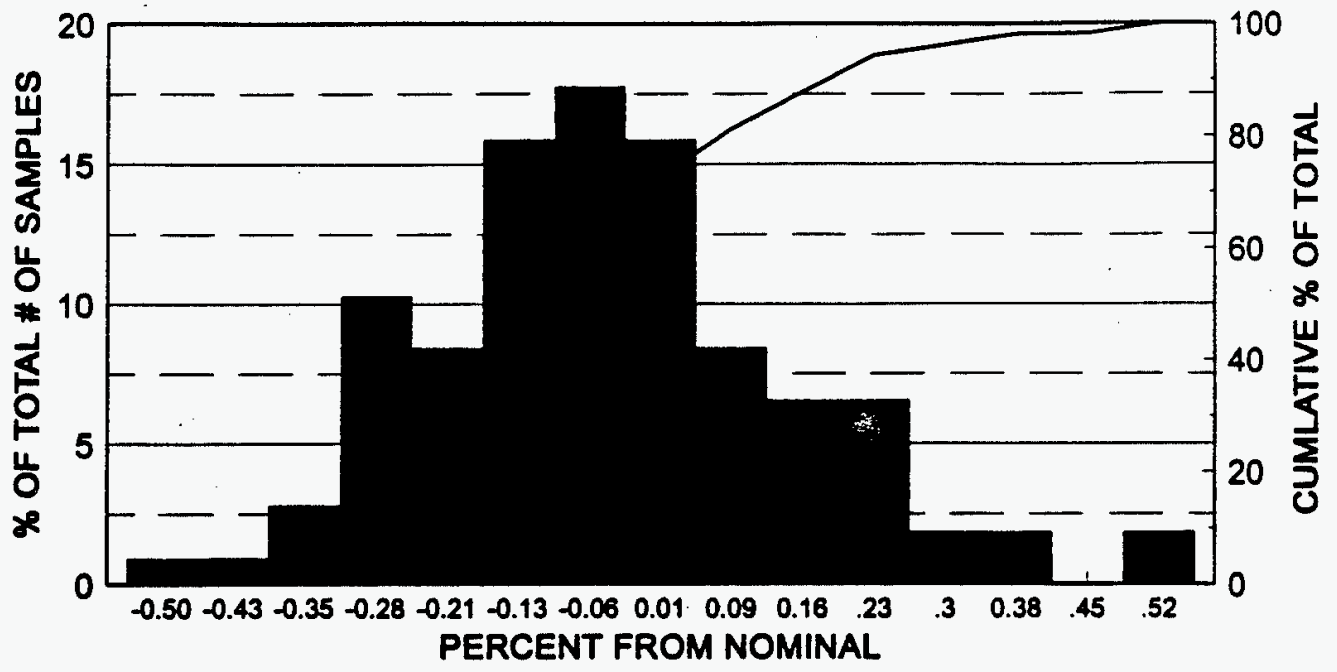

Figure 106

50 MIL WIDE RESISTOR

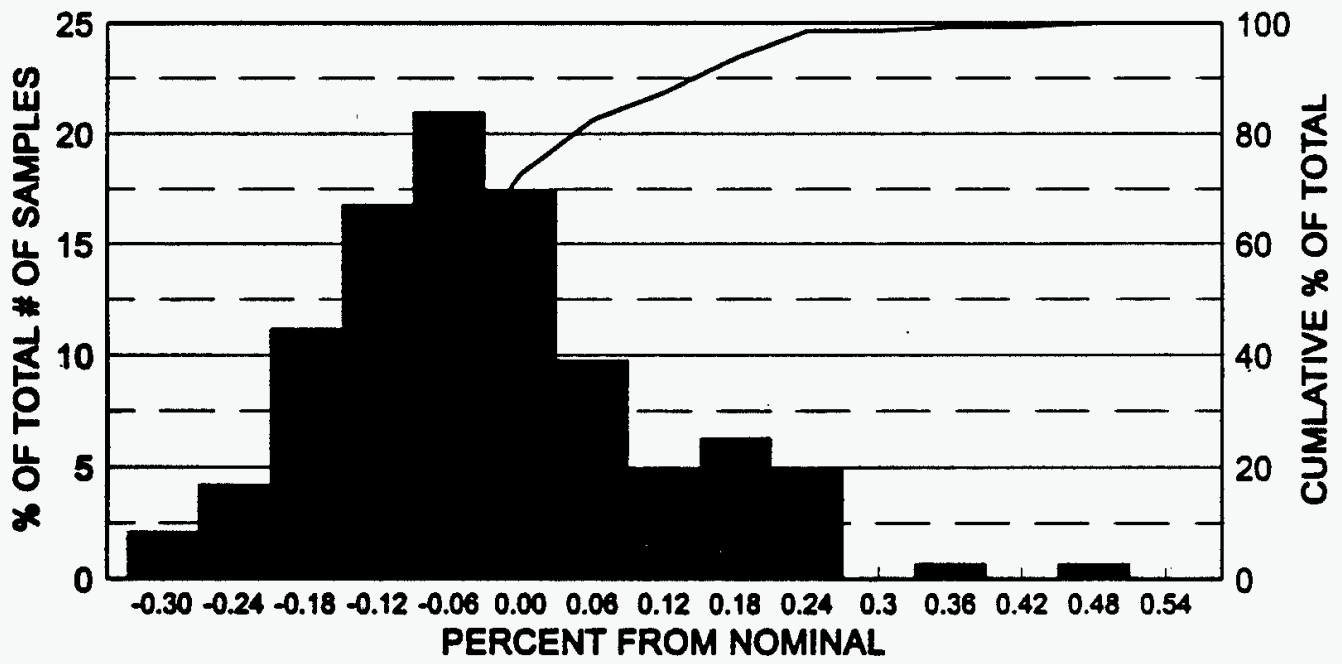

Figure 107 
APPENDIX G

\section{Miscellaneous Data}

\section{TCR For 1900 Series Pasto- No Glaze}

\begin{tabular}{|c|c|c|c|c|c|c|c|c|c|c|c|}
\hline \multicolumn{12}{|c|}{ TCR - NO GLAZE } \\
\hline HOT & PASTE & R Q 25 TIME 1 & R Q25 TIME 2 & R Q 25 TIME 3.* & R Q 125 TIME 1 & R Q125 TIME 2 & R Q125 TIME 3*" & TCR @ 125 & TCR @ 125 & TCR (125 & AVERAGE \\
\hline trimmed & 1921 & 185.859000 & 185.859000 & 185.859000 & 186.720000 & 186.719000 & 186.724000 & 46.325 & 46.272 & 46.541 & 46.379 \\
\hline untrimmed & 1921 & 149.382000 & 149.382000 & 149.382000 & 150.073000 & 150.068000 & 150.074000 & 46.257 & 45.923 & 46.324 & 46.168 \\
\hline trimmed & 1931 & 2.048030 & 2.048030 & 2.048030 & 2.066700 & 2.066670 & 2.066700 & 91.161 & 991.014 & 91.161 & $\overline{91.112}$ \\
\hline untrimmed & 1931 & 1.982100 & 1.982100 & 1.982100 & 1.999630 & 1.999540 & 1.999620 & 88.442 & 87.987 & 88.391 & 88.273 \\
\hline trimmed & 1939 & 32.676000 & 32.676000 & 32.676000 & 32.784000 & 32.785000 & 32.785000 & 33.052 & 33.358 & 33.358 & 33.256 \\
\hline untrimmed & 1939 & 25.521800 & 25.521900 & 25.521900 & 25.639200 & 25.638800 & 25.638800 & 45.961 & 45.804 & 45.804 & 45.856 \\
\hline trimmed & 1949 & 267.693000 & 267.693000 & 267.693000 & 267.977000 & 268.003000 & 268.005000 & 10.609 & 11.580 & 11.655 & 11.282 \\
\hline untrimmed & 1949 & 210.281000 & 210.281000 & 210.281000 & 211.212000 & 211.216000 & 211.218000 & 44.274 & 44.464 & 44.559 & 44.433 \\
\hline trimmed & 1959 & 2.088020 & 2.088020 & 2.088020 & 2.070770 & 2.071030 & 2.071200 & -82.614 & -81.369 & -80.555 & -81.513 \\
\hline untrimmed & 1959 & 1.617900 & 1.617900 & 1.617900 & 1.622920 & 1.622970 & 1.622970 & 31.028 & 31.337 & 31.337 & 31.234 \\
\hline COLD & & R Q25 TIME 1* & R Q25 TIME 2*- & R Q25 TIME 3*- & -55 TIME 1"*- & R Q-55 TIME $2^{* *}$ & R Q Q-55 TIME 3*- & TCR \& -55 & CR (Q)-55 & TCR (1).55 & \\
\hline trimmed & 1921 & 185.859000 & 185.859000 & 185.859000 & 185.994000 & 186.001000 & 185.989000 & -9.079 & -9.550 & -8.743 & -9.124 \\
\hline untrimmed & 1921 & 149.382000 & 149.382000 & 149.382000 & 149.561000 & 149.558000 & 149.547000 & -14.978 & -14.727 & -13.807 & -14.504 \\
\hline trimmed & 1931 & 2.048030 & 2.048030 & 2.048030 & 2.044150 & 2.044160 & 2.044260 & 23.681 & 23.620 & 23.010 & 23.437 \\
\hline untrimmed & 1931 & 1.982100 & 1.982100 & 1.982100 & 1.981640 & 1.981760 & 1.981730 & 2.901 & 2.144 & 2.333 & 2.460 \\
\hline trimmed & 1939 & 32.676000 & 32.676000 & 32.676000 & 32.819000 & 32.820000 & 32.821000 & -54.704 & -55.086 & -55.469 & -55.086 \\
\hline untrimmed & 1939 & 25.521900 & 25.521900 & 25.521900 & 25.605900 & 25.607000 & 25.609200 & -41.141 & -41.680 & -42.757 & -41.859 \\
\hline trimmed & 1949 & 267.693000 & 267.693000 & 267.693000 & 269.355000 & 269.353000 & 269.415000 & -77.608 & -77.514 & -80.409 & -78.510 \\
\hline untrimmed & 1949 & 210.281000 & 210.281000 & 210.281000 & 211.127000 & 211.106000 & 211.125000 & -50.290 & -49.042 & -50.171 & -49.834 \\
\hline trimmed & 1959 & 2.088020 & 2.088020 & 2.088020 & 2.115990 & 2.116490 & 2.117230 & -167.443 & -170.437 & -174.867 & -170.916 \\
\hline untrimmed & 1959 & 1.617900 & 1.617900 & 1.617900 & 1.629170 & 1.629250 & 1.629250 & -87.073 & -87.691 & -87.691 & -87.485 \\
\hline & 478A. & & & & & & & & & & \\
\hline
\end{tabular}

Table 1 
TCR For 1900 Series Paste - Glaze

\section{TCR - GLAZE}

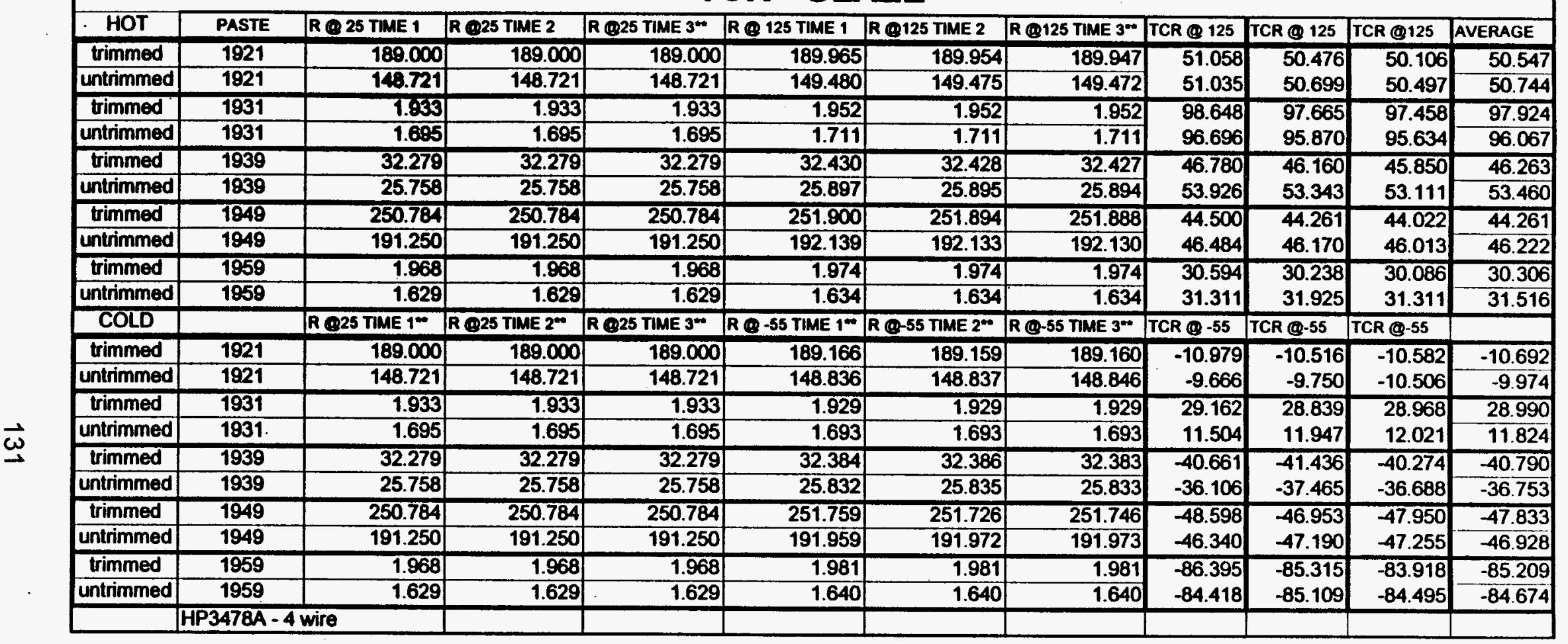

Table 2 


\section{REFERENCE}

${ }^{1}$ Schmidt, Helen E., and Allington, Trevor R. "Laser Trimming Resistors Over Dielectric." Hybrid Circuit Technology October, 1985, pp. 35-43. 


\section{M97053647}

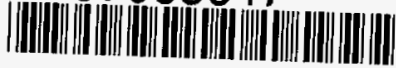

Report Number (14) KC P--

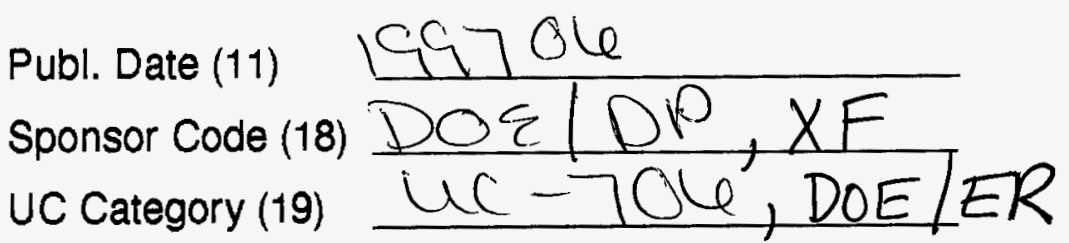

